Universidade de São Paulo

Instituto de Astronomia, Geofísica e Ciências Atmosféricas

Departamento de Astronomia

Raúl E. Puebla

\title{
Síntese Espectral Detalhada de Discos de Acresção com Vento
}

São Paulo 

Raúl E. Puebla

\section{Síntese Espectral Detalhada de Discos de Acresção com Vento}

Tese apresentada ao Departamento de Astronomia do Instituto de Astronomia, Geofísica e Ciências Atmosféricas da Universidade de São Paulo como parte dos requisitos para a obtenção do título de Doutor em Ciências.

Área de Concentração: Astronomia

Orientador(a): Prof. Dr. Marcos Perez Diaz

São Paulo 

A Sandra

No estamos solos en el centro de este mundo impersonal, nos tenemos el uno al otro... 


\section{Agradecimentos}

\section{Equador}

A Dios. A mis padres por su amor y apoyo. A mis hermanos Xavier y Elizabeth por el amor y por mis hermosos sobrinos José Ignacio y Martín.

A Sandra, estos dos años juntos han sido la columna vertebral de este trabajo. Por muchas veces salvarme de mi mismo. Te amo.

Brasil

A Deus. Ao professor Dr. Marcos Perez Diaz, pela paciência em todos estes anos, a guia, a ajuda e os conselhos e a orientação em todos estes anos de doutorado. Aos amigos Juan, Gustavo, Sergio, Gleidson, Adrian, Fernanda e Tatiana e toda a galera do IAG pela companhia e amizade. A todos os professores do IAG. A todo o pessoal da secretaria do departamento, de meneira especial à Marina, ao pessoal da informatica e da CPG. À FAPESP pelo suporte financeiro para este trabalho a través do processo 05/04128-5. Ao Brasil.

\section{EE UU}

To God. To Prof. D. John Hillier, for the invaluable help, answers and collaboration to this work with codes and physics lessons. I will improve my English, I promise.

Esta tese foi escrita em LATEX com a classe IAGTESE, para teses e dissertações do IAG. 
" A vida é uma dádiva, a vida é uma felicidade, cada minuto poderia ser uma eternidade de felicidade"

Fiódor Dostioévski 


\section{Resumo}

Neste trabalho foi desenvolvido um novo método de síntese espectral para modelar o disco de acresção de variáveis cataclísmicas (VC's) não magnéticas. O principal objetivo deste trabalho é analisar a emissão do contínuo e das linhas em uma ampla faixa espectral no ultravioleta (UV). O disco é separado em anéis concêntricos e, para cada anel uma atmosfera de disco com vento é calculada. Na base, as atmosferas são calculadas consistemente com o vento, tendo a distribuição de densidade dos modelos de atmosferas de disco de Wade e Hubeny. A estrutura é calculada no sistema co-móvel com um perfil de velocidade vertical obtido da solução da equação de Euler para um disco de acresção. O comportamento das linhas e do contínuo como função da inclinação orbital é consistente com as observações. Também foi verificado que a taxa de acresção influi sobre a temperatura do vento levando às mudanças correspondentes nas intensidades relativas das linhas. Foi encontrado que a massa da primária tem uma forte influência na profundidade dos perfis de absorção. Também, encontramos que a os perfis de linha são fortemente sensíveis ao incremento da taxa de perda de massa, aumentado a intensidade das linhas de emissão. Foram escolhidos dados espectroscópicos no UV de duas VC's "Nova-like" (NL) de baixa inclinação, RW Sex e V3885 Sgr e dois sistemas de alta inclinação, RW Tri e V347 Pup. Uma concordância dos perfis em emissão dos modelos foi encontrada quando confrontados com os dados no caso de sistemas de alta inclinação. Uma falta de fluxo nas linhas de alta ionização C IV $\lambda \lambda 1548,1551$ and N v $\lambda \lambda 1238,1242$, pode ser o sinal da influência da boundary layer (BL) ou da influência da irradiação das regiões externas do vento pelo disco interno. Estas influências seriam cruciais no caso de sistemas baixa inclinação, mas são menores no caso de sistemas de alta inclinação. 


\section{Abstract}

We have developed a new spectral synthesis method for modeling the accretion disk of non-magnetic cataclysmic variables (CV's). The aim of this work is to analyze the continuum and line emission of disks in a wide ultraviolet (UV) spectral range. The disk is separated in concentric rings, and for each ring a wind plus disk atmosphere are calculated. The wind atmospheres are calculated consistently with a density given by Wade and Hubeny disk-atmosphere models at their base. The structure is calculated in the co-moving frame with a vertical velocity profile defined by the Euler's equation solution for the disk wind. We found that the resulting line and continuum behavior as a function of the orbital inclination is consistent with the observations. We also verify that the accretion rate changes the wind temperature, leading to corresponding trends in the intensity of lines. We found that the primary mass has a strong effect on the absorption profiles depth. It was verified that the lines profiles are strongly sensitive to the wind temperature structure and a rise of mass loss rate increases the line intensity. Selected UV data for two high orbital inclination nova-like (NL) CV's, RW Tri and V347 Pup, were confronted with synthetic spectra. The line widths and profiles are reasonably well reproduced by the models. A lack of flux in some high ionization lines (C IV $\lambda \lambda 1548,1551$ and $\mathrm{NV} \lambda \lambda 1238,1242)$ may be the signature of the boundary layer (BL) effect and/or the irradiation of outer wind by inner disk. We also found that for high inclination systems the vertical wind structure is less important than for low inclination system models. 


\section{Lista de Figuras}

1.1 Superfícies equipotenciais de Roche para um sistema binário com massas $\mathrm{M}_{1}$ e $\mathrm{M}_{2}$. São mostrados os principais pontos de Lagrange instáveis $\left(\mathrm{L}_{1}, \mathrm{~L}_{2}\right.$ e $\left.\mathrm{L}_{3}\right)$ e estáveis $\left(\mathrm{L}_{4}, \mathrm{~L}_{5}\right)($ Frank et al., 2002). . . . . . . . . . . . 3

1.2 Espectros observados no UV para três VC's não magnéticas, as NL's V3885 Sgr e RW Sex observadas pelo HST com o STIS e o GHRS respectivamente, e a DN em erupção Z Cam observada pelo HUT (Astro-2). . . . . . . . . .

1.3 Perfis da linha resonante C IV(1550) para as VC's com disco RZ Gru (IUE), V3885 Sgr (STIS) and RW Sex (GHRS) comparadas com o a observada pelo IUE na estrela tipo $\mathrm{O}, \zeta$ Pup. . . . . . . . . . . . . . . .

1.4 Variação do perfil da linha resonante C IV $\lambda \lambda 1548,1551$ para vários sistemas com alta taxa de acresção e com diferentes inclinações orbitais. . . . . . . . 17

1.5 Esquema de emissão do vento do modelo SV93 . . . . . . . . . . . . . . . . 22

1.6 Perfis de linha calculados com o modelo SV93. Painel da esquerda corresponde a um sistema com $i=27^{\circ}$, e o da direita a um sistema com $i=10^{\circ}$. Os paneis superiores estão ordenados ascendentemente em $\dot{\mathrm{M}}_{a c c}\left(10^{-9}-10^{-7} \mathrm{M}_{\odot}\right.$ $\left.\mathrm{yr}^{-1}\right)$ e os inferiores em $\dot{\mathrm{M}}_{w}\left(10^{-10}-3 \times 10^{-9} \mathrm{M}_{\odot} \mathrm{yr}^{-1}\right) \ldots \ldots . \ldots . . \ldots 23$

1.7 Geometria do vento no modelo KWD95 . . . . . . . . . . . . . . . . . . . . 24

1.8 Espectros sintéticos calculados por LK02, com $\dot{\mathrm{M}}_{a c c}=10^{-8} \mathrm{M}_{\odot} \mathrm{yr}^{-1}$ e $\dot{\mathrm{M}}_{w}=10^{-9} \mathrm{M}_{\odot} \mathrm{yr}^{-1} 25$

1.9 Distribuição de densidade e campo de velocidades no modelo de Pereyra

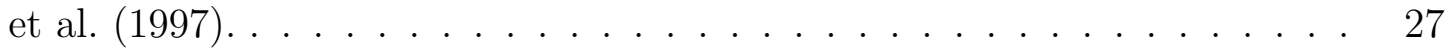

1.10 Distribuição de densidade e campo de velociades no modeo de Pereyra et al.

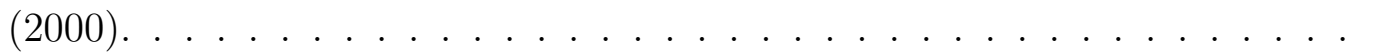


2.1 Funções $\zeta_{1}, \zeta_{2}(\mathrm{I})$ e $\zeta_{2}(\mathrm{O})$ utilizados para mimetizar a comportamento da radiação sobre o disco de acresção. Aqui, $\zeta_{1}$ é calculada usando um valor de

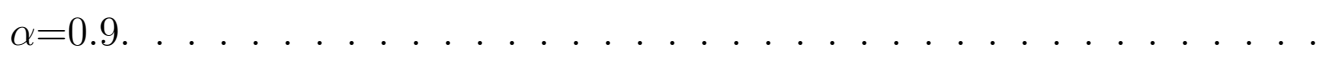

2.2 Soluções da equação de movimento no plano $(v, x)$. São mostradas as diferentes regiões onde a equação tem 1, 2 ou nenhuma solução. Aqui P é o ponto de Parker como definido no texto. Gráfico tirado de Feldmeier et al. (2002)

2.3 Soluções da equação de movimento para um modelos com $M_{1}=0.8 M_{\odot}$, $\dot{\mathrm{M}}_{a}=10^{-8} \mathrm{M}_{\odot} \mathrm{ano}^{-1}$, com $\alpha=0.9$ e $k=0.4$. Os paineis estão ordenados verticalmente segundo a função $\zeta$ utilizada de cima para abaixo $\left(\zeta_{1}, \zeta_{2}\right.$ (I) e $\left.\zeta_{2}(\mathrm{O})\right)$. No painel esquerdo são mostradas as funções $n$ e $\beta \dot{m}$ que são utilizadas para encontrar o ponto crítico (vide texto). No painel direito os perfis de velocidades são mostrados para as diferentes funções $\zeta$ 's, para os dois ramos dentro da região II. As velocidades terminais para os dois ramos também são dadas. . . . . . . . . . . . . . . . . . . . . .

2.4 Soluções da equação de movimento para um modelos com $\mathrm{M}_{1}=0.8 \mathrm{M}_{\odot}$, $\dot{\mathrm{M}}_{a}=10^{-8} \mathrm{M}_{\odot}$ ano $^{-1}$ e a função $\zeta_{3}$ para a distribuição vertical da radiação. Os paineis estão ordenados verticalmente segundo o parâmetro de aceleração radiativa $\alpha=0.5,0.7$ e 0.9 de cima para abaixo, respectivamente. No painel esquerdo são mostradas as funções $n$ e $\beta \dot{m}$ que são utilizadas para encontrar o ponto crítico (vide texto). No painel direito os perfis de velocidades são mostrados para as diferentes $\alpha$ 's, para os dois ramos dentro da região II. As velocidades terminais para os dois ramos também são dadas. . . . . . . . .

2.5 Soluções da equação de Euler para um disco com $\mathrm{M}_{1}=1 \mathrm{M}_{\odot}$ and $\dot{\mathrm{M}}_{a c c}=10^{-8}$ $\mathrm{M}_{\odot} \mathrm{yr}^{-1}$. O painel superior mostra o perfil radial de temperatura efetiva do disco. O painel do meio mostra as velocidades terminais para o ramo superior de soluções para três valores de $\alpha$ comparados com a velocidade de escape. O painel inferior mostra os fluxos de perda de massa que resultam de calcular as soluções críticas da equação de movimento. . . . . . . . . . . 
2.6 Perfil radial de fluxo de perda de matéria calculado levando em conta o maior fluxo local possível para a existência de uma solução estacionária da equação do movimento. Valores para um sistema com $\mathrm{M}_{1}=\mathrm{M}_{\odot}$ e $\dot{\mathrm{M}}_{a c}=10^{-9}$

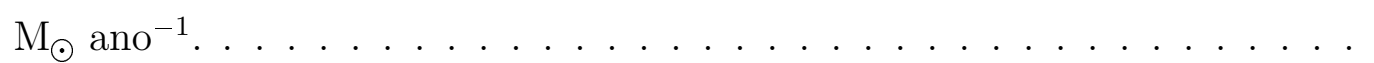

2.7 Esquema da grade de parâmetros de impacto usada para calcular a transferência radiativa. O circulo mais escuro representa o disco. O círculo mais interno a região do disco de onde o vento escapa e os semi-cones representam o vento.

2.8 Mesmo esquema da figura 2.7, mas com o observador agora no plano da folha. Os raios provenientes das diferentes regiões do plano de parâmetros de impacto são mostrados. . . . . . . . . . . . . . . . . . . . . . .

2.9 Distribuição espacial da função fonte para os modelos calculados na região de fronteira entre a fotosfera e o vento para dois modelo como $\mathrm{M}_{1}=\mathrm{M}_{\odot}$ na região de $1110 \AA$. No painel da esquerda é mostrado um modelo com $\dot{\mathrm{M}}_{a}=10^{-9} \mathrm{M}_{\odot} \mathrm{ano}^{-1}$ e $\dot{\mathrm{M}}_{w}=10^{-12} \mathrm{M}_{\odot}$ ano $^{-1}$. No painel da direita um modelos com $\dot{\mathrm{M}}_{a}=10^{-8} \mathrm{M}_{\odot}$ ano $^{-1}$ e $\dot{\mathrm{M}}_{w}=10^{-11} \mathrm{M}_{\odot} \mathrm{ano}^{-1} \ldots \ldots$. . . . . .

2.10 Logaritmo da intensidade especifica média de uma região do espectro $\log \left[1 /\left(\nu_{f}-\right.\right.$ $\left.\left.\nu_{o}\right) \int_{\nu_{o}}^{\nu_{f}} I_{\nu} d \nu\right]$. Nesse caso é mostrado a região de emissão do C IV (1550) para um modelo com $\mathrm{M}_{1}=0.8 \mathrm{M}_{\odot}, \dot{\mathrm{M}}_{a}=10^{-8} \mathrm{M}_{\odot} \mathrm{ano}^{-1}$ e $\dot{\mathrm{M}}_{w}=9.3 \times 10^{-11} \mathrm{M}_{\odot}$

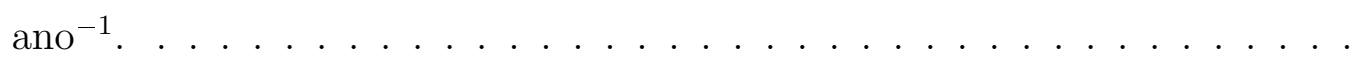

2.11 No painel esquerdo são mostradas as contribuições ao fluxo de cada região do sistema relacionada com um parâmetro de impacto de índice NP. No painel da direita são mostradas as contribuições das diferentes regiões integradas de acordo com a figura 2.8 (linhas vermelha, azul e verde) e o espectro sintético total (linha preta). . . . . . . . . . . . . . . .

3.1 No painel esquerdo é mostrada a geometria do sistema para a síntese espectral. No painel direito é mostrado o esquema que descreve o significado de cada parâmetro geométrico. . . . . . . . . . . . . . . .

3.2 Perfis verticais de temperatura das atmosferas com vento para o modelo "e" na região de transição fotosfera-vento. . . . . . . . . . . . . . . . . . 
3.3 Perfis verticais de temperatura das atmosferas com vento para o modelo "e" na região vertical extensa do vento. . . . . . . . . . . . . . . . . . . . . 74

3.4 Perfil vertical da temperatura (lina preta) e densidade eletrônica (linha vermelha tracilhada) para o quinto anel do modelo. O eixo horizontal superior é profundidade óptica de Rossland $\left(\tau_{R}\right)$ e tem uma escala fortemente não linear. A linha vertical mostra onde a opacidade $\tau_{R}=1$ e a linha horizantal mostra a tepmeratura efetiva $\mathrm{T}=38600 \mathrm{~K} \ldots \ldots \ldots$

3.5 Perfil da aceleração vertical do vento $\log [d \ln v / d \ln z]$ no modelo da figura 3.4 junto com o perfil vertical de temperatura. No painel direito temos uma ampliação da região de máxima aceleração e temperatura mínima. . . . . . .

3.6 Perfil de temperatura em função da profundidade óptica para o modelos plano paralelo do anel 5 do modelo " $e$ " com temperatura efetiva de $38600 \mathrm{~K}$ (linha preta) junto com o perfil de temperatura calculado para uma estrela tipo O com temperatura efetiva de $40000 \mathrm{~K}$ (linha vermelha). . . . . . . .

3.7 Estrutura de ionização do carbono para os anéis 1, 2 e 3 do modelo e. Nos painéis esquerdos a região de transição fotosfera vendo é mostrada. Nos painéis da direita é mostrada a região extensa do vento para cada modelo de atmosfera. . . . . . . . . . . . . . . . . . . . .

3.8 Estrutura de ionização do carbono para os anéis 4,5 e 6 do modelo $e$. Nos painéis esquerdos a região de transição fotosfera vendo é mostrada. Nos painéis da direita é mostrada a região extensa do vento para cada modelo de atmosfera. . . . . . . . . . . . . . . . . .

3.9 Estrutura de ionização do carbono para os anéis 7, 8 e 9 do modelo $e$. Nos painéis esquerdos a região de transição fotosfera vendo é mostrada. Nos painéis da direita é mostrada a região extensa do vento para cada modelo de atmosfera. . . . . . . . . . . . . . . . .

3.10 Estrutura de ionização do carbono para o anel 10 do modelo e. No painel esquerdo a região de transição fotosfera vendo é mostrada. Nos painel da direita a região extensa do vento é mostrada. . . . . . . . . . . . . .

3.11 Estrutura de ionização do hélio para os anéis 1, 2, 3 e 4 do modelo e na região de transição fotosfera-vento é mostrada. . . . . . . . . . . . . . . . . 
3.12 Estrutura de ionização do hélio para os anéis 5, 6, 7, 8, 9 e 10 do modelo $e$ na região de transição fotosfera-vento é mostrada. . . . . . . . . . . . . . . 85

3.13 Estrutura de ionização do oxigeno para o anel 5 do modelo $e\left(\mathrm{~T}_{e f}(\mathrm{R})=38600\right.$ K). No painel esquerdo a região de transição fotosfera vendo é mostrada. Nos painel da direita a região extensa do vento é mostrada. . . . . . . . . .

3.14 Coeficientes de desvio do LTE das populações nos níveis que formam as linhas do C III $(1175,1908)$. No painel esquerdo mostra-se a região de transição fotosfera-vento e no painel direito a região extensa do vento. A linha vermelha mostra o perfil vertical de temperatura nessa região da atmosfera

3.15 Coeficientes de desvio do LTE das populações nos níveis que formam a linha do He II (1640). No painel esquerdo mostra-se a região de transição fotosferavento e no painel direito a região extensa do vento. A linha vermelha mostra o perfil vertical de temperatura nessa região da atmosfera. . . . . . . . . .

3.16 Coeficientes de desvio do LTE das populações nos níveis que formam as linhas do C IV (1550.7, 1548.2). No painel esquerdo mostra-se a região de transição fotosfera-vento e no painel direito a região extensa do vento. A linha vermelha mostra o perfil vertical de temperatura nessa região da atmosfera. . . . . . . . . . . . . . . . . .

3.17 Coeficientes de desvio do LTE das populações nos níveis que formam as linhas do Nv $(1242.8,1238.8)$. No painel esquerdo mostra-se a região de transição fotosfera-vento e no painel direito a região extensa do vento. A linha vermelha mostra o perfil vertical de temperatura nessa região da atmosfera

3.18 Coeficientes de desvio do LTE das populações nos níveis que formam as linhas do Si III (1206.5, 1301.1, 1298.8). No painel esquerdo mostra-se a região de transição fotosfera-vento e no painel direito a região extensa do vento. A linha vermelha mostra o perfil vertical de temperatura nessa região da atmosfera. 
3.19 Coeficientes de desvio do LTE das populações nos níveis que formam as linhas do Si IV $(1402,1393)$. No painel esquerdo mostra-se a região de transição fotosfera-vento e no painel direito a região extensa do vento. A linha vermelha mostra o perfil vertical de temperatura nessa região da atmosfera. . . . . . . . . . . . . . . . . .

3.20 Coeficientes de desvio do LTE das populações nos níveis que formam as linhas do H I $(1216,1025)$. No painel esquerdo mostra-se a região de transição fotosfera-vento e no painel direito a região extensa do vento. A linha vermelha mostra o perfil vertical de temperatura nessa região da atmosfera.

4.1 Espectros sintéticos UV para os modelos $a, b, c$ e $d$ com inclinação orbital $i=30^{\circ}$. No painel superior mostra-se os fluxos absolutos escalonados para uma distância arbitrária. No painel inferior mostra-se os fluxos normalizados pelo contínuo de cada modelo. A Identificação das diferentes linhas espectrais também é mostrada. . . . . . . . . . . . . . . . . . . .

4.2 Perfís de linha normalizados pelo contínuo para as linhas do Si IV, C III, Si III e Nv. Os modelos $a, b, c$ e $d$ correspondem a diferentes taxas de acresção $\dot{\mathrm{M}}_{a}$, de $1.0 \times 10^{-8} \mathrm{M}_{\odot} \mathrm{ano}^{-1}, 5.0 \times 10^{-9} \mathrm{M}_{\odot} \mathrm{ano}^{-1}, 1.0 \times 10^{-9} \mathrm{M}_{\odot} \mathrm{ano}^{-1} \mathrm{e}$ $5.0 \times 10^{-10} \mathrm{M}_{\odot}$ ano $^{-1}$ respectivamente. Em todos os casos foi usada uma inclinação orbital de $i=30^{\circ}$.

4.3 Perfís de linha normalizados pelo contínuo para as linhas do Si III, Si IV, C IV e He II. Os modelos $a, b, c$ e $d$ correspondem a diferentes taxas de acresção $\dot{\mathrm{M}}_{a}$, de $1.0 \times 10^{-8} \mathrm{M}_{\odot}$ ano $^{-1}, 5.0 \times 10^{-9} \mathrm{M}_{\odot} \mathrm{ano}^{-1}, 1.0 \times 10^{-9} \mathrm{M}_{\odot}$ ano $^{-1} \mathrm{e}$ $5.0 \times 10^{-10} \mathrm{M}_{\odot}$ ano $^{-1}$ respectivamente. Em todos os casos foi usada uma

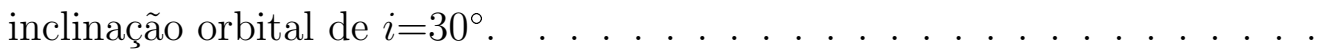

4.4 Espectros sintéticos UV para os modelos $a, b, c$ e $d$ com inclinação orbital $i=70^{\circ}$. No painel superior mostra-se os fluxos absolutos escalonados a uma distância arbitrária. No no painel inferior mostra-se os fluxos normalizados ao contínuo de cada modelo. A ubicação das diferentes linhas espectrais também é mostrada. 
4.5 Perfís de linha normalizados pelo contínuo para as linhas do Si IV, C III, Si III e N v. Os modelos $a, b, c$ e $d$ correspondem a diferentes taxas de acresção $\dot{\mathrm{M}}_{a}$, de $1.0 \times 10^{-8} \mathrm{M}_{\odot}$ ano $^{-1}, 5.0 \times 10^{-9} \mathrm{M}_{\odot}$ ano $^{-1}, 1.0 \times 10^{-9} \mathrm{M}_{\odot}$ ano $^{-1} \mathrm{e}$ $5.0 \times 10^{-10} \mathrm{M}_{\odot}$ ano $^{-1}$ respectivamente. Em todos os casos foi usada uma inclinação orbital de $i=70^{\circ}$. . . . . . . . . . . . . . . . . . . . . . . 104

4.6 Perfís de linha normalizados pelo contínuo para as linhas do Si III, Si IV, C IV e He II. Os modelos $a, b, c$ e $d$ correspondem a diferentes taxas de acresção $\dot{\mathrm{M}}_{a}$, de $1.0 \times 10^{-8} \mathrm{M}_{\odot}$ ano $^{-1}, 5.0 \times 10^{-9} \mathrm{M}_{\odot}$ ano $^{-1}, 1.0 \times 10^{-9} \mathrm{M}_{\odot}$ ano $^{-1} \mathrm{e}$ $5.0 \times 10^{-10} \mathrm{M}_{\odot}$ ano $^{-1}$ respectivamente. Em todos os casos foi usada uma inclinação orbital de $i=70^{\circ}$

4.7 Espectros sintéticos UV para os modelos $c$ e $h$ com inclinação orbital $i=30^{\circ}$. No painel superior mostra-se os fluxos absolutos escalonados a uma distância arbitrária. No painel inferior mostra-se os fluxos normalizados pelo contínuo de cada modelo. A diferença principal entre estes modelos é a massa da primária $\mathrm{M}_{1}$, de $1.0 \mathrm{M}_{\odot}$ para o modelo $c$ e de $0.6 \mathrm{M}_{\odot}$ para o modelo $h$. . .

4.8 Emissão do dupleto do C III $\lambda 1175$ para os modelos $c$ e $h$. No painel direito é mostrado o logarítmo da intensidade específica média entre as freqüências correspondentes ao intervalo de $1172 \AA$ a $1178 \AA$. No painel direito mostrase os perfis de linha integrados normalizados pelo contínuo centrada na componente vermelha. . . . . . . . . . . . . . . . .

4.9 Emissão do dupleto do Si IV $\lambda \lambda 1393,1402$ para os modelos $c$ e $h$. No painel direito mostra-se o logaritmo da intensidade específica média entre as frequecias correspondentes entre o intervalo espectral entre os comprimentos de onda $1390 \AA$ e $1410 \AA$ A. No painel direito mostra-se os perfis de linha do dupleto no espaço de velocidades normalizados pelo contínuo e centralizado na componente vermelha do dupleto. . . . . . . . . . . . . . . . . . . 109 
4.10 Emissão do dupleto do C IV $\lambda \lambda 1548,1551$ para os modelos $c$ e $h$. No painel direito mostra-se o logaritmo da intensidade específica média entre as frequecias correspondentes entre o intervalo espectral entre os comprimentos de onda $1530 \AA$ e $1560 \AA$. No painel direito mostra-se os perfis de linha do dupleto no espaço de velocidades normalizados pelo contínuo e centralizado na componente vermelha do dupleto. . . . . . . . . . . . . . . . . . . 11

4.11 Emissão do dupleto do C IV $\lambda \lambda 1548,1551$ para os modelos $c$ e $h$. No painel direito mostra-se o logaritmo da intensidade específica média entre as frequecias correspondentes entre o intervalo espectral entre os comprimentos de onda $1530 \AA$ e $1560 \AA$. No painel direito mostra-se os perfis de linha do dupleto no espácio de velocidades normalizados pelo contínuo e centralizado na componente vermelha do dupleto. . . . . . . . . . . . . . . . . . 111

4.12 Espectros sintéticos UV para o modelo $h$ com inclinação orbital $i=30^{\circ}$. No painel superior mostra-se os fluxos absolutos escalonados a uma distância arbitrária. No painel inferior mostra-se os fluxos normalizados pelo contínuo de cada modelo. A diferença entre os modelos é taxa de perda total de massa no vento $\dot{\mathrm{M}}_{w}$. Um modelo com $\dot{\mathrm{M}}_{w}=4 \times 10^{-11} \mathrm{M}_{\odot}$ ano ${ }^{-1}$ (linha preta) e com $\dot{\mathrm{M}}_{w}=2 \times 10^{-10} \mathrm{M}_{\odot}$ ano $^{-1}$ (linha vermelha) são mostrados. . . . . . . . . . .

4.13 Perfís de linha normalizados pelo contínuo para as linhas do O vi, N II, Si IV e C II. Os modelos correspondem a diferentes taxas de perda de massa no vento $\dot{\mathrm{M}}_{w}$, de $\dot{\mathrm{M}}_{w}=4 \times 10^{-11} \mathrm{M}_{\odot}$ ano ${ }^{-1}$ (linha preta) e com $\dot{\mathrm{M}}_{w}=2 \times 10^{-10}$ $\mathrm{M}_{\odot}$ ano $^{-1}$ (linha pontilhada). Em todos os casos foi usada uma inclinação orbital de $i=30^{\circ}$. . . . . . . . . . . . . . . . . . . . . . . . . 11

4.14 Perfís de linha normalizados pelo contínuo para as linhas do Si III, C II, Si IV e C IV. Os modelos correspondem a diferentes taxas de perda de massa no vento $\dot{\mathrm{M}}_{w}$, de $\dot{\mathrm{M}}_{w}=4 \times 10^{-11} \mathrm{M}_{\odot}$ ano ${ }^{-1}$ (linha preta) e com $\dot{\mathrm{M}}_{w}=2 \times 10^{-10}$ $\mathrm{M}_{\odot}$ ano $^{-1}$ (linha pontilhada). Em todos os casos foi usada uma inclinação orbital de $i=30^{\circ}$. 
4.15 Espectros sintéticos UV para o modelo $h$ com inclinação orbital $i=70^{\circ}$. No painel superior mostra-se os fluxos absolutos escalonados a uma distância arbitrária. No painel inferior mostra-se os fluxos normalizados pelo contínuo de cada modelo. A diferença entre os modelos é taxa de perda total de massa no vento $\dot{\mathrm{M}}_{w}$. Um modelo com $\dot{\mathrm{M}}_{w}=4 \times 10^{-11} \mathrm{M}_{\odot}$ ano ${ }^{-1}$ (linha preta) e com $\dot{\mathrm{M}}_{w}=2 \times 10^{-10} \mathrm{M}_{\odot}$ ano $^{-1}$ (linha vermelha) são mostrados. . . . . . . . . . . . .

4.16 Espectros sintéticos UV para o modelo e com inclinação orbital $i=30^{\circ}$. No painel superior mostra-se os fluxos absolutos escalonados a uma distância arbitrária. No painel inferior mostra-se os fluxos normalizados pelo contínuo de cada modelo. A diferença entre os modelos é taxa de perda total de massa no vento $\dot{\mathrm{M}}_{w}$. Um modelo com $\dot{\mathrm{M}}_{w}=9 \times 10^{-11} \mathrm{M}_{\odot}$ ano ${ }^{-1}$ (linha preta) e com $\dot{\mathrm{M}}_{w}=4.6 \times 10^{-9} \mathrm{M}_{\odot}$ ano $^{-1}$ (linha vermelha) são mostrados. . . . . . . . . . . .

4.17 Espectros sintéticos calculados para o modelo "c" e para diferentes inclinações orbitais $i=30^{\circ}, 40^{\circ}, 50^{\circ}$ e $60^{\circ}, 70^{\circ}$ e $80^{\circ}$. No painel esquerdo o fluxo é escalonado a 400 pcs e no painel direito é mostrado o fluxo normalizado pelo contínuo, descolado por uma constante para maior clareza. . . .

4.18 Espectros sintéticos calculados para o modelos " $d$ " e para diferentes inclinações orbitais $i=10^{\circ}, 20^{\circ}, 30^{\circ}$ e $40^{\circ}$ nos painéis esquerdos e $i=50^{\circ}, 60^{\circ}$, $70^{\circ}$ e $80^{\circ}$ nos painéis direitos. Os painéis superiores o fluxo é escalonado a 400 pcs e nos painéis inferiores é mostrado o fluxo normalizado pelo contínuo.121

4.19 Emissão do dupleto do Si IV $\lambda \lambda 1393,1402$ para os modelos $c$ e $d$ para os ângulos $i=30^{\circ}$ (painel superior) e $50^{\circ}$ (painel inferior). Os painéis esquerdo mostram o logaritmo da intensidade específica média entre 1390 Å 1407 A. Os painéis direitos mostram os perfis de linha no espaço de velocidades normalizados pelo contínuo. . . . . . . . . . . . . . .

4.20 Emissão do dupleto do Si IV $\lambda \lambda 1393,1402$ para os modelos $c$ e $d$ para os ângulos $i=70^{\circ}$ (painel superior) e $80^{\circ}$ (painel inferior). Os painéis esquerdo mostram o logaritmo da intensidade específica média entre $1390 \AA$ e 1407 A. Os painéis direitos mostram os perfis de linha no espaço de velocidades normalizados pelo contínuo. 
4.21 Perfis de linha normalizados pelo contínuo para as linhas do C III, Si III, N v, Si IV e C IV. Estes perfis correspondem ao modelo $b$ com inclinação orbital $i=30^{\circ}$. O efeito dos ângulos de abertura são mostrados em cada caso para valores de $\theta_{1}=5^{\circ}, 15^{\circ}$ e $\theta_{2}=0^{\circ}$ e $45^{\circ} \ldots \ldots \ldots \ldots$

4.22 Efeito de colocar uma atmosfera fria com vento na região externa do modelo original $b$. A linha preta é o espectro sintético onde a atmosfera mais externa tem uma temperatura de $\sim 16900 \mathrm{~K}$. A linha vermelha representa o espectro sintético onde a atmosfera mais externa tem uma temperatura de 12700 K. 129

4.23 Efeito de colocar uma atmosfera fria com vento na região externa do modelo original $c$. A linha preta é o espectro sintético onde a atmosfera mais externa tem uma temperatura de $\sim 15000 \mathrm{~K}$. A linha vermelha representa o espectro sintético onde a atmosfera mais externa tem uma temperatura de $\sim 11300$ K. 130

4.24 Efeito de colocar uma atmosfera fria com vento na região externa do modelo original $d$. A linha preta é o espectro sintético onde a atmosfera mais externa tem uma temperatura de $\sim 16500 \mathrm{~K}$. A linha vermelha representa o espectro sintético onde a atmosfera mais externa tem uma temperatura de 12500 K. 131

4.25 Efeito de uma região de alta densidade através do disco sobre os perfis de linha é mostrado para o modelo e. Cada cor corresponde a cada modelo onde um conjunto de atmosferas com vento de alto fluxo de perda de massa foi calculado em diferentes regiões do vento de acordo com o descrito na tabela 4.2. Para comparação também é plotado o modelo e (linha preta). . 135

4.26 Razão da intensidade específica média na linha e no contínuo na região azul da dupleto C IV $\lambda \lambda 1548,1551$ para cada modelo da tabela 4.2. Somente as componentes em absorção $\left(I_{l} / I_{c} \leqslant 1\right)$ são mostradas.

4.27 Estrutura vertical da temperatura para o anel 6 do modelo $e$. No painel esquerdo a região de transição fotosfera vendo é mostrada. Nos painel da direita a região extensa do vento é mostrada. Aqui são comparadas as temperaturas eletrônicas para o modelo calculado usando a geometria plano paralela (linha preta) e a estrutura considerando uma diluição esférica da radiação que provém do anel correspondente (linha pontilhada). . . . . . . 138 
4.28 Estrutura de ionização do carbono para o anel 6 do modelo e. No painel esquerdo a região de transição fotosfera vendo é mostrada. Nos painel da direita a região extensa do vento é mostrada. Nos painéis superiores a estrutura calculada usando a geometria plano paralela é mostrada, e nos painéis inferiores a estrutura usando uma diluição esférica da radiação que provém do anel correspondente. . . . . . . . . . . . . . .

4.29 Distribuição espacial da função fonte para a linha C IV $\lambda 1551$ de dos modelos calculados usando os parâmetros físicos do modelo e. O painel esquerdo mostra a função fonte quando modelos plano paralelos são usados e no painel direito é mostrada quando é usada uma geometria esférica para a diluição da radiação de acordo com a equação $(4.2)$. . . . . . . . . . . . . .

4.30 Efeito da diluição geométrica da radiação de acordo com a equação (4.2) sobre o modelo $e$. A linha preta corresponde ao modelo original sem diluição da radiação. A linha vermelha corresponde ao modelos onde cada modelo de atmosfera é calculado com uma diluição geométrica de tipo estelar. . . .

4.31 Efeito da diluição geométrica da radiação de acordo com a equação (4.2) sobre o modelo $e$. A linha preta corresponde ao modelo original sem diluição da radiação. A linha vermelha corresponde ao modelos onde cada modelo de atmosfera é calculado com uma diluição geométrica de tipo estelar. Os modelos foram calculados usando uma inclinhação orbital $i=70^{\circ}$. . . . . .

5.1 Comparação de diferentes espectros sintéticos com os dados observados pelo HST (linha preta) para RW Sex. A linha cinza representa um modelo de atmosfera de disco sem vento. As linhas vermelha e azul representam modelos de atmosfera de disco com vento usando um campo de velocidades tipo estelar no sentido vertical $v(z)$, a diferença entre eles é o parâmetro geométrico $\mathrm{R}_{C}$. No painel superior mostra-se os modelos em fluxo. No painel inferior mostra-se os modelos e os dados normalizados pelo contínuo. . . . . . . . .

5.2 Comparação do modelo " $e$ " (linha azul com $\theta_{2}=45^{\circ}$ e linha vermelha com $\theta_{2}=10^{\circ}$ ) com os dados observados pelo HST (linha preta) para RW Sex. No painel superior mostra-se os modelos em fluxo. No painel inferior mostra-se os modelo e os dados normalizados pelo contínuo. . . . . . . . . . . . . . . 147 
5.3 Perfis de linha normalizados pelo contínuo para as linhas do C III, N v, Si IV e C IV para o modelo " $e$ " com diferentes regiões de alta densidade e os dados observados (linha preta). Os modelos têm uma inclinação orbital $i=30^{\circ} \ldots 148$

5.4 Comparação do modelo " $e$ " (linha azul com $\theta_{2}=45^{\circ}$ e linha vermelha com $\theta_{2}=10^{\circ}$ ) com os dados observados pelo HST (linha preta) para V3885 Sgr. No painel superior mostram-se os modelos em fluxo. No painel inferior mostram-se os modelos e os dados normalizados pelo contínuo. . . . . . .

5.5 Comparação do modelo " $b$ " (linha vermelha) com os dados observados pelo HST (linha preta) para RW Tri. No painel superior mostra-se os modelos em fluxo, o modelo foi escalonado a uma distância de 640 pc e foi calculado com uma inclinação orbital de $i=70^{\circ}$. No painel inferior mostra-se os modelo e os dados normalizados pelo contínuo. . . . . . . . . . . .

5.6 Comparação do modelo " $b$ " (linha vermelha) com os dados observados pelo HST (linha preta) para RW Tri. No painel superior mostra-se os modelos em fluxo. Neste caso o raio $R_{C}$ foi considerado igual $2.7 \times 10^{-2} R_{\odot}$. No painel inferior mostra-se os modelo e os dados normalizados pelo contínuo.

5.7 Comparação do modelo " $b$ " (linha vermelha) com os dados observados pelo HST (linha preta) para RW Tri. No painel superior mostra-se os modelos em fluxo. Neste caso foi considerado um ângulo de $\theta_{2}=5^{\circ}$. No painel inferior mostra-se o modelo e os dados normalizados pelo contínuo. . . . . . . . . . 156

5.8 Comparação do modelo " $h$ " (linha vermelha com $\mathrm{R}_{f}=0.14 \mathrm{R}_{\odot}$ e linha laranja com $\mathrm{R}_{f}=0.2 \mathrm{R}_{\odot}$.) com os dados observados pelo HST (linha preta) para RW Tri. No painel superior mostra-se os modelos em fluxo. No painel inferior mostra-se o modelo e os dados normalizados pelo contínuo.

5.9 Comparação do modelo " $h$ " (linha vermelha com uma região densa entre os anéis 2 e3 e a linha azul com a região densa entre os anéis 1 e 4) com os dados observados pelo HST (linha preta) para RW Tri. No painel inferior mostra-se o modelo e os dados normalizados pelo contínuo. . . . . . . . . . 158

5.10 Perfis de linha normalizados pelo contínuo para as linhas do C III, N v, Si IV e C IV para vários dos modelos descritos no texto e os dados observados. O modelo tem uma inclinação orbital $i=70^{\circ}$. 
5.11 Comparação do modelo " $b$ " (linha vermelha) com inclinação orbital $i=70^{\circ}$ com os dados observados pelo HST (linha preta) para V347 Pup. No painel superior mostra-se os modelos em fluxo. O modelo é o mesmo mostrado na figura 5.6. No painel inferior mostra-se o modelo e os dados normalizados pelo contínuo. . . . . . . . . . . . . . . . . . . . . . 162

5.12 Comparação do modelo " $b$ " (linha vermelha) com os dados observados pelo HST (linha preta) para V347 Pup. No painel superior mostra-se os modelos em fluxo. O modelo é o mesmo mostrado na figura 5.11, mas com uma inclinação orbital de $i=80^{\circ}$. No painel inferior mostra-se o modelo e os dados normalizados pelo contínuo. . . . . . . . . . . . . . . . 163

5.13 Comparação do modelo " $h$ " (linha vermelha) com os dados observados pelo HST (linha preta) para V347 Pup. No painel superior mostra-se os modelos em fluxo. O modelo tem como parâmetros: $\mathrm{M}_{1}=0.6 \mathrm{M}_{\odot}, \dot{\mathrm{M}}_{a}=5 \times 10^{-9} \mathrm{M}_{\odot}$ $\mathrm{ano}^{-1}$ e $_{w}=4.0 \times 10^{-11} \mathrm{M}_{\odot}$ ano $^{-1}$, com $i=80^{\circ}$. No painel inferior mostra-se o modelo e os dados normalizados pelo contínuo. . . . . . . . . . . . . . . . 164 


\section{Lista de Tabelas}

1.1 Linhas usualmente identificadas nos espectros UV de VC's com seus comprimentos de onda de repouso. . . . . . . . . . . . . . . . . 11

1.2 Parâmetros da aceleração por linhas para estrelas OB . . . . . . . . . . . . 19

3.1 Parâmetros Físicos . . . . . . . . . . . . . . . . 66

3.2 Parâmetros Geométricos . . . . . . . . . . . . . . . . . . . . 68

3.3 Caraterísticas físicas de cada anel que conformam o modelo e. O raio de cada anel, a fluxo de perda de massa, a velocidade terminal e a temperatura efetiva de cada um deles é mostrado. Também são mostradas as características físicas dos parâmetros estelares utilizados nos modelos de vento. Os parâmetros físicos do sistema são: $\mathrm{M}_{1}=0.8 \mathrm{M}_{\odot}, \dot{\mathrm{M}}_{a}=10^{-8} \mathrm{M}_{\odot} \mathrm{ano}^{-1} \mathrm{e}$ $\dot{\mathrm{M}}_{w}=9.3 \times 10^{-11} \mathrm{M}_{\odot} \mathrm{ano}^{-1} \ldots \ldots \ldots \ldots$. . . . . . . . . . . . 70

3.4 Ions utilizados para calcular a estrutura de atmosferas de vento em cada anel do disco, com o número de níveis usados para cada ion. . . . . . . . . 71

4.1 Comparação das temperaturas das atmosferas mais externas . . . . . . . . 128

4.2 Modelos com regiões densas . . . . . . . . . . . . . . . . 133 


\section{Sumário}

1. Introdução . . . . . . . . . . . . . . . . . . . . . . . . . . . 1

1.1 Variáveis Cataclísmicas . . . . . . . . . . . . . . . . . . 1

1.1 .1 Geometria . . . . . . . . . . . . . . . . 1

1.1.2 Classificação e Propriedades Estelares . . . . . . . . . . . . . . . . . 3

1.2 Disco de Acresção . . . . . . . . . . . . . . . . . . . . . . . . . 5

1.3 Espectroscopia UV de Variáveis Cataclísmicas . . . . . . . . . . . . . . 9

1.3.1 Linhas . . . . . . . . . . . . . . . . . . . 10

1.4 Ventos em Estrelas Quentes . . . . . . . . . . . . . . . . . . 18

1.5 Ventos em discos de acresção . . . . . . . . . . . . . . . . . . . 20

1.5.1 Modelos Cinemáticos . . . . . . . . . . . . . . . . . 21

1.5.2 Modelos Hidrodinânicos . . . . . . . . . . . . . . . . . 25

1.6 Objetivo e descrição deste trabalho . . . . . . . . . . . . . . . . . . 28

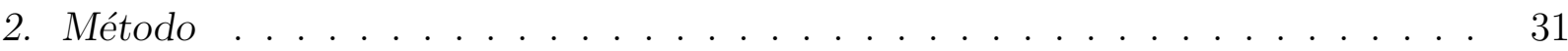

2.1 Atmosferas de Disco com Vento . . . . . . . . . . . . . . . . . . 32

2.1.1 Cálculo da Estrutura . . . . . . . . . . . . . . . . . . . . 33

2.2 Campo Vertical de Velocidades - A lei de aceleração em discos . . . . . . . 40

2.2.1 Existência das soluções e ponto crítico . . . . . . . . . . . . . . . 42

2.2.2 Cálculo do ponto crítico, $\dot{m}$ e da velocidade terminal $\mathrm{v}_{\infty} \ldots \ldots$. . . . . 47

2.2.3 Simulações . . . . . . . . . . . . . . . . . . . . . . . . . 48 48

2.2.4 Cálculo de taxa de perda massa total $\dot{M}_{w}$ no vento. . . . . . . . . . 52

2.3 Síntese Espectral . . . . . . . . . . . . . . . . . . . . 54 
2.3.1 Interpolação 2D das atmosferas do vento e campo 3D de velocidades 55

2.3.2 Trasporte radiativo através do vento . . . . . . . . . . 57

3. Análise das Estruturas . . . . . . . . . . . . . . . . . . . . . . . 65

3.1 Análise das Estruturas de Atmosfera com Vento . . . . . . . . . . . . . . 69

3.1.1 Densidade e Temperatura . . . . . . . . . . . . . . 72

3.1 .2 Estrutura de ionização . . . . . . . . . . . . . . . . 78

3.1.3 Populações de níveis . . . . . . . . . . . . . . . . . 87

4. Análise da Síntese Espectral . . . . . . . . . . . . . . . . . . . . . 95

4.1 Influência da taxa de acresção $\dot{\mathrm{M}}_{a} \ldots \ldots \ldots$. . . . . . . . . . . . . . 95

4.2 Efeito da massa da primária $\mathrm{M}_{1} \ldots \ldots \ldots \ldots$. . . . . . . . . . . 105

4.3 Efeito da taxa de perda de massa. . . . . . . . . . . . . . . 112

4.4 Efeito da inclinação orbital . . . . . . . . . . . . . . . . . 119

4.5 Efeito da geometria do vento - Os ângulos de abertura . . . . . . . . . . 125

4.6 Efeito da inclusão de uma atmosfera externa fria . . . . . . . . . . . . . . 127

4.7 Espectros de ventos heterogêneos . . . . . . . . . . . . . . . 132

4.8 Efeito da diluição na radiação na estrutura do vento . . . . . . . . . . . . 137

5. Comparação com as Observações . . . . . . . . . . . . . . . . . . . 143

5.1 Sistemas de baixa inclinação . . . . . . . . . . . . . . . . . . . 143

$5.1 .1 \quad$ RW $\operatorname{Sex} \ldots \ldots \ldots \ldots \ldots \ldots \ldots$

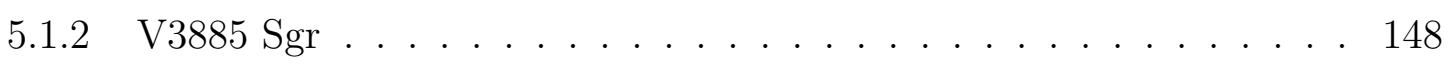

5.2 Sistemas de alta inclinação . . . . . . . . . . . . . . . . . . 152

$5.2 .1 \quad$ RW Tri . . . . . . . . . . . . . . . . . . . . 152

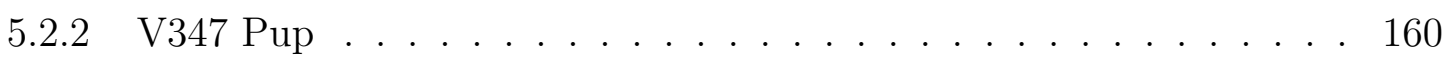

5.3 Discussão . . . . . . . . . . . . . . . . . . . . . 165

6. Conclusões e Perspectivas . . . . . . . . . . . . . . . . . 167

6.1 Conclusões . . . . . . . . . . . . . . . . . . . 167

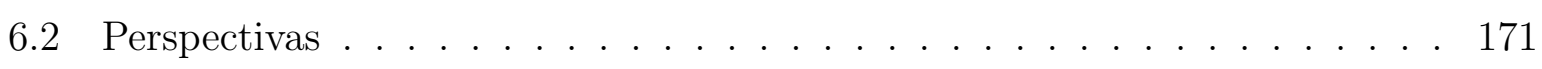

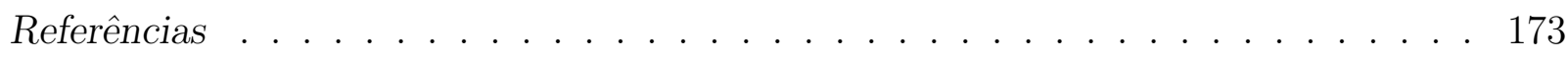


A. Estudo Estatístico do Modelo de Síntese Espectral de Discos de Acrasção em Variáveis

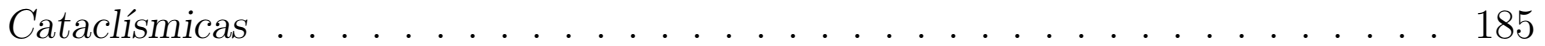


XXX 
Capítulo 1

\section{Introdução}

Neste trabalho nós propomos um novo método de síntese espectral visando melhorar o entendimento da física evolvida na emissão da radiação e produção de ventos em discos de acresção. Como será mostrado posteriormente, o disco de acresção em Variáveis Cataclísmicas (VC's) emite principalmente no ultravioleta (UV), pelo qual o estudo dos espectros UV é vital para entender o seu comportamento. Foi demonstrado que os métodos de síntese espectral desenvolvidos até o momento não conseguem ainda explicar as características observadas no UV, mesmo considerando o grande avanço que tem sido feito nos últimos vinte anos. Um dos principais problemas que os métodos de síntese espectral têm enfrentado é o de reproduzir as linhas em emissão observadas tanto no UV como no óptico. No caso do óptico, especialmente a série de Balmer assim como linhas de He II e He I. No UV fortes linhas de espécies altamente ionizadas como C III $(1175 \AA)$, N V $(1238,1240 \AA)$, Si IV $(1493,1402 \AA)$, C IV $(1548,1551 \AA$ ), e He II (1640 ̊) entre outras. Estas linhas mostram fortes características morfológicas que levam a pensar que têm sua origem em um vento que provém da superfície do disco. Neste trabalho estudamos a influência deste vento sobre a emissão de linhas assim como no contínuo do espectro. Para isso são calculadas atmosferas de disco com vento descritas detalhadamente no capítulo 2. Estes modelos são então confrontados com observações e as propriedades destes ventos são inferidas.

\subsection{Variáveis Cataclísmicas}

\subsubsection{Geometria}

As Variáveis Cataclísmicas são estrelas binárias de período curto $\left(0.28 \lesssim \mathrm{P}_{\text {orb }} \lesssim 18\right.$ horas, (Ritter e Kolb, 2003)). São sistemas onde a secundária apresenta rotação sincrônica 
e as órbitas são circulares devido ás fortes forças de maré que atuam durante a sua evolução. Nestes sistemas uma estrela de baixa massa na seqüência principal (secundária) preenche o lóbulo equipotencial de Roche e transfere matéria para a companheira, uma anã branca (primária). Esta transferência ocorre inicialmente ao longo de uma trajetória balística. No caso de sistemas não magnéticos, devido à conservação do momento angular e à presença de viscosidade, um disco de acresção é formado em torno da primária. Este disco é aquecido por dissipação viscosa de maneira que a energia gravitacional é perdida radiativamente. As características básicas desta radiação podem ser encontradas da geometria do sistema e dos parâmetros físicos de suas componentes. Assim, dentro da aproximação de Roche o sistema binário está composto por duas massas puntuais que geram o potencial mostrado na figura 1.1. A secundária transfere matéria através do ponto instável de Lagrange $\mathrm{L}_{1}$. A matéria que escapa da secundária orbita ao redor da primária até que o fluxo colide consigo mesmo perdendo energia, formando assim um anel circular que minimiza a energia com o mesmo momento angular. Este anel acumula matéria até que devido ao incremento na viscosidade forma um disco de acresção. Assim, a maior parte da matéria cai espiralando até a primária. Da terceira lei de Kepler:

$$
P_{o r b}^{2}=\frac{4 \pi^{2} a^{3}}{G\left[M_{1}+M_{2}\right]},
$$

onde $\mathrm{M}_{1}$ e $\mathrm{M}_{2}$ são as massas da primária e secundária respectivamente, é possível obter a ordem de magnitude de $a$, a separação entre os centros de massa das componentes do sistema. Para VC's, com os períodos orbitais observados, a é da ordem do raio solar $\left(\mathrm{R}_{\odot}\right)$. É possível também da geometria do sistema encontrar as propriedades físicas principais da secundária, já que esta preenche o seu lóbulo de Roche, a sua geometria depende principalmente da dinâmica do sistema. Esta geometria depende inteiramente de $a$ e da razão de massas $q=\mathrm{M}_{2} / \mathrm{M}_{1}$. Assim, os raios das esferas que contêm o mesmo volume do lóbulo de Roche da secundária $\mathrm{R}_{L}(2)$ e da primária $\mathrm{R}_{L}(1)$ dentro da aproximação calculada por Eggleton (1983) são:

$$
\begin{aligned}
\frac{R_{L}(2)}{a} & =\frac{0.49 q^{2 / 3}}{0.6 q^{2 / 3}+\ln \left(1+q^{1 / 3}\right)} \\
\frac{R_{L}(1)}{a} & =0.396 q^{-1 / 6} .
\end{aligned}
$$




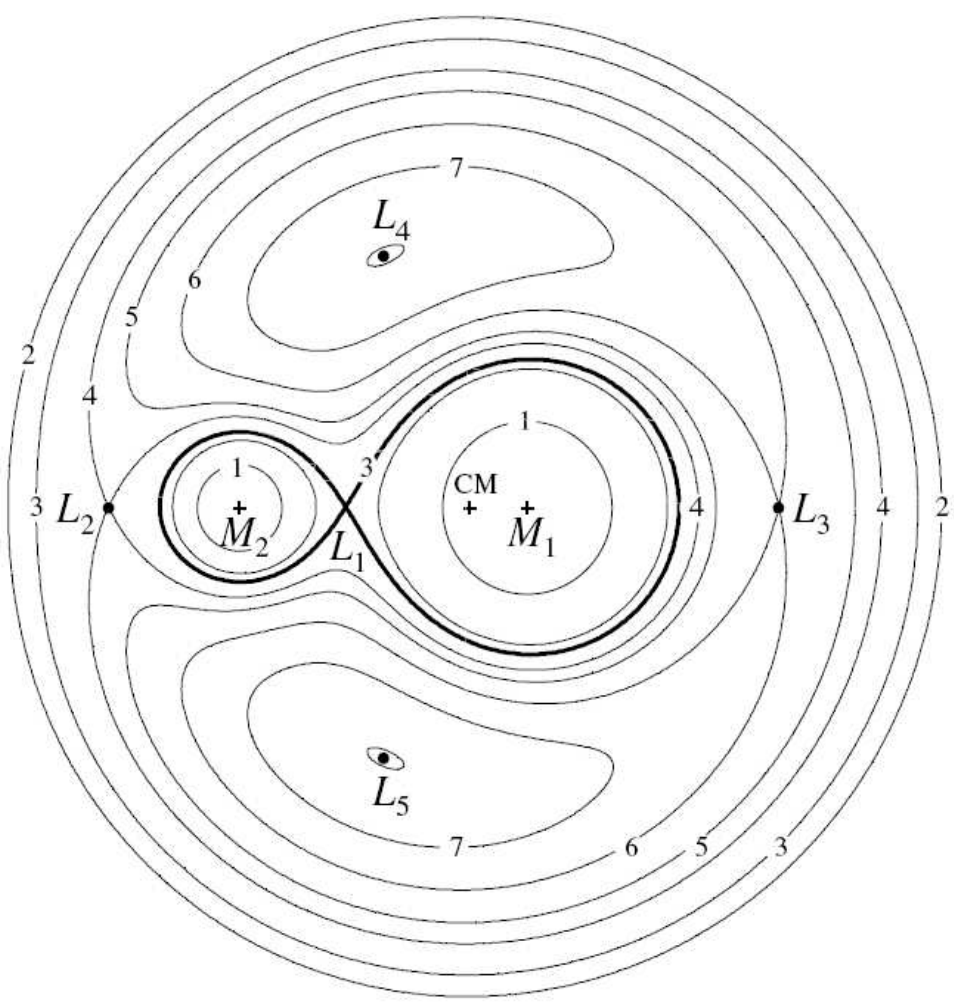

Figura 1.1: Superfícies equipotenciais de Roche para um sistema binário com massas $\mathrm{M}_{1} \mathrm{e}$ $\mathrm{M}_{2}$. São mostrados os principais pontos de Lagrange instáveis $\left(\mathrm{L}_{1}, \mathrm{~L}_{2}\right.$ e $\left.\mathrm{L}_{3}\right)$ e estáveis $\left(\mathrm{L}_{4}\right.$, $\mathrm{L}_{5}$ )(Frank et al., 2002).

Para um sistema com parâmetros típicos para VC's: $q=0.5, \mathrm{M}_{1}=0.8 \mathrm{M}_{\odot}$ e período orbital de 0.3 dias ( $\sim 7$ horas) temos que $a=2 \mathrm{R}_{\odot}, \mathrm{R}_{L}(1)=0.88 \mathrm{R}_{\odot}$ e $\mathrm{R}_{L}(2)=0.64 \mathrm{R}_{\odot}$. Usando a equação 1.1 pode-se calcular a densidade média da secundária, que depende principalmente do período orbital (Warner, 1995):

$$
\bar{\rho}(2)=107 P_{\text {orb }}^{-2}(h) \mathrm{g} \mathrm{cm}^{-3}
$$

que para valores típicos temos uma densidade de $\sim 5 \mathrm{~g} \mathrm{~cm}^{-3}$.

\subsubsection{Classificação e Propriedades Estelares}

Existem dois grandes grupos de Variáveis Cataclísmicas. As cataclísmicas magnéticas e as não magnéticas. Estas se diferenciam principalmente pelo mecanismo com que a 
matéria é acretada sobre a anã branca. No primeiro caso o sistema apresenta uma anã branca fortemente magnetizada e a acresção é feita através de uma ou duas colunas nos pólos magnéticos. Existem dois sub-classes de VC's magnéticas: Polares e Polares Intermediárias. Nas primeiras o campo magnético é tão intenso que impede a formação do disco. No segundo caso o campo magnético é fraco de forma que o disco se forma mas é truncado no raio de Alfven. Outra forma de classificar as VC's aparace da análise de seu comportamento eruptivo, dividindo-se em: Novas Clássicas (NC), Novas Recurrentes (NR), Novas Anãs (DN) e "Nova-like" (NL). As NC e NR apresentam erupções devido a explosões termonucleares que incrementam o seu brilho em 6 até 19 magnitudes. As NR apresentaram esta erupção mais de uma vez. As DN apresentam erupções devido ao repentino incremento da transferência de matéria através do disco, o que leva a um incremento no brilho de 2 a 5 magnitudes e com uma escala de recorrências de dias até anos. A duração de cada erupção é da ordem de dias a dezenas de dias. As NL são sistemas que não apresentam erupções ou também são catalogadas como em permanente erupção, já que as suas propriedades lembram muito as das DN quando se encontram em erupção. Neste trabalho nos concentraremos mais neste tipo de VC's. Dentro das NL também são classificados quatro sub-grupos: RW Tri, UX Uma, SW Sex e VY Scl. No caso das três primeiras a diferença entre elas é simplesmente espectroscópica. Já as VY Scl (alguns autores as colocam em um grupo separado) apresentam eventuais quedas na sua luminosidade, mas sem nenhuma periodicidade, devida muito provavelmente a uma queda na taxa de transferência de matéria. É importante lembrar que os diferentes tipos de VC's não são mutuamente exclusivos. Mas podem corresponder a diferentes estágios evolutivos (Patterson, 1984; Warner, 1995).

As propriedades físicas das VC's dependem muito das propriedades originais de cada sistema binário, por exemplo das massas iniciais, do campo magnético das componentes e do momento angular inicial. Em geral as primárias tem massas ligeiramente superiores às observadas em anãs brancas de campo devido à acresção. Assim, tem-se estimado uma média para $\mathrm{M}_{1}$ de $\sim 0.77 \mathrm{M}_{\odot}$ (Webbink, 1990), quando as anãs brancas de campo apresentam uma média de $0.59 \mathrm{M}_{\odot}$ (p.e. Schmidt et al., 1992). Considerando a estabilidade na transferência de massa, para períodos orbitais maiores a massa média da primária tende a ser maior $\left(0.86 \mathrm{M}_{\odot}\right.$ para $\mathrm{P}_{\text {orb }}>2.4 \mathrm{~h}$ e $0.6 \mathrm{M}_{\odot}$ para $\left.\mathrm{P}_{\text {orb }}<2.4 \mathrm{~h}\right)$. A temperatura da 
primária é também superior às temperaturas medidas em anãs brancas de campo. Esta temperatura depende também do tipo de VC. Assim, para NL's temos uma temperatura média de 50000 K, para DN’s 19000 K e 13000 K para magnéticas (Warner, 1995). Também são observadas temperaturas maiores para sistemas com períodos orbitais longos, o que levaria a pensar em uma certa relação com a acresção. No caso das secundárias, da equação 1.4 é fácil obter uma ideia da ordem da suas massas se contamos com uma relação massa-raio confiável para esse tipo de estrela. É comumente aceito que as secundárias são estrelas de baixa massa da seqüência principal, com uma relação massa-raio conhecida. Mesmo assim, existem controvérsias nesse aspecto (Knigge, 2006). Levando em conta essa relação estima-se que a massa média da secundária estaria próxima de $\sim 0.4 \mathrm{M}_{\odot}$ para todo o intervalo de períodos. A temperatura delas, sendo de um tipo espectral entre $\mathrm{M}$ e $\mathrm{K}$ estaria entre 2000 e $5000 \mathrm{~K}$ emitindo principalmente no óptico e no infravermelho.

\subsection{Disco de Acresção}

O disco de acresção é formado quando a matéria que escapa da secundária cai na direção da primária dentro do seu lóbulo de Roche. Devido a que esta matéria tem momento angular proveniente da órbita da binária, ela forma um anel em volta da anã branca a um distância conhecida pelo nome de raio de circularização, que é aproximadamente a metade da distância ao ponto interno de Lagrange. Dentro deste anel os processos de dissipação viscosa começam a atuar causando a perda de energia e a trasportar o momento angular para fora. Como conseqüência a matéria cai dentro do potencial gravitacional da primária. Mas para que isto ocorra ela deve também perder momento angular. Comumente a escala de tempo de redistribuição do momento angular é muito maior que a escala de tempo de resfriamento e também maior que o tempo dinâmico, o que leva a formar órbitas circulares de matéria em queda na direção da primária. Como não existem torques externos, uma parte da matéria precisa ser drenada para as regiões mais externas levando consigo o momento angular perdido pelas regiões internas. Forma-se assim um disco de acresção cuja velocidade angular pode ser aproximada à kepleriana:

$$
\Omega_{K}=\left(\frac{G M_{1}}{R^{3}}\right)^{1 / 2}
$$


É possível calcular a luminosidade da radiação emitida pelo disco devido à perda de energia gravitacional. Supondo que o gás vem de distâncias muito grandes comparadas com o raio da primária, a luminosidade do disco é dada por:

$$
L_{\text {disco }}=\frac{G M_{1} \dot{M}_{a}}{2 R_{1}}=\frac{1}{2} L_{a c},
$$

onde $\dot{\mathrm{M}}_{a}$ é a taxa de acresção no disco e $\mathrm{L}_{a c}$ é a luminosidade de acresção. Para valores típicos em VC's com taxas de acresção de $10^{-10}-10^{-8} \mathrm{M}_{\odot}$ ano ${ }^{-1}$ temos que a luminosidade é da ordem de 1-100 luminosidades solares $\left(\mathrm{L}_{\odot}\right)$.

Um dos principais problemas na teoria de discos de acresção é o mecanismo pelo qual a energia gravitacional é dissipada no disco para depois ser irradiada, assim como o mecanismo pelo qual o momento angular é trasportado das regiões interiores para as mais externas. O mecanismo responsável por estes dois fenômenos é associado a um atrito de natureza viscosa que existe entre duas regiões do disco com diferentes velocidades de rotação. O torque total sobre uma seção do disco devido a este atrito viscoso será dado por:

$$
G(R)=2 \pi R \nu \Sigma R^{2} d \Omega / d R
$$

este atrito também gera dissipação de energia, cujo fluxo é dado por:

$$
D(R)=\frac{1}{2} \nu \Sigma(R d \Omega / d R)^{2}
$$

onde $\Sigma$ é a densidade superficial do disco e $\nu$ é a viscosidade cinemática. Se a velocidade angular tem a forma kepleriana (eq. 1.5) até a superfície da anã branca em condições estacionarias, a distribuição radial do fluxo de energia dissipada é dada por:

$$
D(R)=\frac{3 G M_{1} \dot{M}_{a}}{8 \pi R^{3}}\left[1-\left(\frac{R_{1}}{R}\right)^{1 / 2}\right],
$$

portanto o fluxo de energia, neste modelo de disco, não depende do valor da viscosidade cinemática. Dentro deste contexto não seria possível estudar as características da viscosidade usando apenas a emissão de sistemas com discos estacionários. Mas esta independência da 
viscosidade provém da condição de contorno de uma lei de velocidades kepleriana até uma distância muito próxima da anã branca. Na realidade existe um ponto onde a velocidade deve atingir um valor máximo antes da superfície da anã branca, já que esta gira com uma velocidade menor. Esta região de desaceleração é conhecida como boundary layer (BL). Se esta região não é pequena comparada com o raio da anã branca, a condição que leva a equação 1.9 não seria mais satisfeita e a lei de dissipação não seria independente da viscosidade cinemática.

O valor da viscosidade cinemática pode ser estimada por:

$$
\nu=\lambda \tilde{v}
$$

onde $\lambda$ é o caminho livre das partículas, moléculas ou elementos do fluido turbulento e $\tilde{v}$ é a velocidade média dos movimentos caóticos ou a velocidade média dos maiores redemoinhos. É possível parametrizar o valor de $\nu$ através no número de Reynolds, $\Re_{e}$, que é definido como a relação entre a força devida à viscosidade e os efeitos inerciais (Lynden-Bell e Pringle, 1974):

$$
\Re_{e} \approx \frac{G M_{1} R}{\nu}
$$

para condições típicas em variáveis cataclísmicas $\Re_{e} \sim 10^{3}-10^{4}$ (Pringle, 1981). É possível colocar limites para $\lambda$ e $\tilde{v}$ : o primeiro seria a espessura do disco $\mathrm{H}$ e o segundo a velocidade do som $\mathrm{c}_{s}$, já que os redemoinhos turbulentos supersônicos seriam rapidamente termalizados devido às ondas de choque. Daqui temos que a viscosidade cinemática poderia ser expressa por:

$$
\nu=\alpha c_{s} H
$$

Esta parametrização para a viscosidade foi proposta por Shakura e Sunyaev (1973), onde o parâmetro $\alpha$ esconde o mecanismo que produz o atrito viscoso. Observações de sistemas não estacionários mostram que $\alpha \sim 0.01-1$ (Verbunt, 1982). Valores negativos de $\alpha$ levariam à fragmentação do disco (veja Frank et al., 2002, e suas referências). Atualmente o mecanismo mais aceito para conduzir as forças viscosas é o chamado de turbulência magneto-hidrodinâmica, causadas por instabilidades de um campo magnético vertical fraco para um gradiente negativo de velocidades, mas estes modelos dependem muito do estado de ionização do gás que propicia o seu acoplamento ao campo (Balbus e Hawley, 1991). 
Dentro do contexto deste modelo, é fácil deduzir uma dependência aproximada da espessura do disco $H$ com o raio. Esta vem dada pela condição de equilíbrio hidrostático dentro do disco. Desprezando a gravidade própria do disco, temos que:

$$
H \approx c_{s}\left(\frac{R}{G M_{1}}\right)^{1 / 2} R,
$$

daqui se deriva que um disco geometricamente fino deve ter uma velocidade de rotação do gás supersônica $\left(v_{\phi} \gg c_{s}\right)$.

Da equação de Euler é fácil deduzir uma expressão para a velocidade radial:

$$
v_{R}=-\frac{3 \nu}{2 R}\left[1-\left(\frac{R_{1}}{R}\right)^{1 / 2}\right]
$$

Destas expressões acima e, levando em conta que $\alpha \sim 0.1$, podemos ter ideia da ordem de magnitude das propriedades físicas do disco. Assim, da equação 1.13 podemos deduzir que $H$ é da ordem do $1 \%$ do $\mathrm{R}_{\text {disco }}$, ou seja $\sim 0.005 \mathrm{R}_{\odot}$. Isto nos leva também a uma velocidade radial de arraste da ordem de $10^{-3} \mathrm{c}_{s}$, ou seja $\sim 0.01 \mathrm{~km} \mathrm{~s}^{-1}$. Ou seja, o tempo de queda desde a borda do disco até atingir a anã branca é da ordem de 100 dias.

A partir do modelo padrão podemos deduzir qual é a região do espectro na qual emite o disco de acresção de VC's. Na aproximação de um disco opticamente espesso, a temperatura efetiva do disco pode ser calculada da equação 1.9:

$$
T(R)=\left(\frac{3 G M_{1} \dot{M}_{a}}{8 \pi \sigma R_{1}^{3}}\right)^{1 / 4}\left(\frac{R_{1}}{R}\right)^{3 / 4}\left[1-\left(\frac{R_{1}}{R}\right)^{1 / 2}\right]^{1 / 4}
$$

se chamamos $\mathrm{T}_{*}=\left(3 G M_{1} \dot{M}_{a} / 8 \pi \sigma R_{1}^{3}\right)^{1 / 4}$, o máximo da temperatura efetiva do disco vem dado por: $\mathrm{T}_{\max }=0.488 \mathrm{~T}_{*}$. Assim, para parâmetros físicos medidos em CV's temos que as temperaturas dos discos acresção então entre 50000 K e 10000 K aproximadamente. Por tanto o espectro do disco é emitido principalmente no ultravioleta, entre $500 \AA$ e 3000 A. Daqui vemos a importância da espectroscopia UV para estudar os processos físicos em discos de acresção. 


\subsection{Espectroscopia UV de Variáveis Cataclísmicas}

A radiação ultravioleta na região de maior interesse é absorvida pela atmosfera terrestre, portanto, a espectroscopia UV de VC's tem que ser feita através de telescópios espacias. Isto não foi possível até 1970 quando o satélite OAO-2 detetou algumas CV's no UV. Historicamente, o satélite que mais contribuiu ao estudo de VC's no UV, pela quantidade e qualidade dos dados, foi o International Ultraviolet Explorer (IUE). O IUE foi lançado em 1978 e mantido numa órbita geo-sincrônica entre 26000 e 42000 km de altitude, até que foi desligado em 1996. Outros satélites têm contribuído através dos anos para o entendimento da física de VC's. Temos por exemplo o HUT, Voyaguers 1 e 2, ASTRO, ROSAT e EUVE. Mais recentemente têm sido muito importantes as contribuições do Hubble Space Telescope (HST) com seus espectrógrafos STIS e GHRS, assim como também o FUSE para o

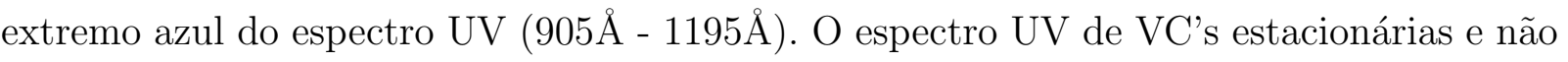
magnéticas (também das DN perto do máximo da erupção) é composto principalmente pela contribuição do disco de acresção, mas também contribui a emissão da anã branca e da BL. Estes sistemas apresentam altas taxas de acresção, pelo qual o seu disco é opticamente espesso. Para sistemas com baixa taxa de acresção (DN em quiescência, sistemas magnéticos e VY no estado baixo), a radiação UV provem principalmente da anã branca.

Muitos esforços têm sido realizados para entender o comportamento do contínuo e das linhas observadas nos espectros UV de VC's. Para discos opticamente espessos e estacionários têm sido desenvolvidos muitos métodos de síntese espectral visando entender o comportamento do contínuo com os parâmetros físicos. Entre os primeiros esforços se estudaram modelos que usam uma superposição de emissão de corpos negros em anéis que acompanham a distribuição radial de temperatura do modelos de disco padrão (equação 1.15) (p.e. Lynden-Bell, 1969; Lynden-Bell e Pringle, 1974; Pringle, 1981). Algum tempo depois foram desenvolvidos modelos mais realistas, usando atmosferas estelares clássicas, com o correspondente valor da gravidade e temperatura efetiva para cada região do disco (Wade, 1984; La Dous, 1989), levando em conta as opacidades nas linhas e descontinuidades do contínuo. Foi estudada a influência da taxa de acresção, da rotação, a massa da primária e a geometria do disco sobre profundidade e forma do perfil das linhas de absorção, o nível do fluxo, assim como sobre a descontinuidade de Balmer. Estes modelos foram confrontados com as observações de alguns sistemas por Wade (1988) que encontrou o que 
atualmente é conhecida como a dicotomia cor-magnitude. Esta dicotomia refere-se a que os modelos calculados não reproduzem ao mesmo tempo o nível de fluxo e a cor dos espectros observados. Mais tarde foram calculados modelos que levam em conta a dissipação interna de energia no cálculo da estrutura da atmosfera (Kriz e Hubeny, 1986; Shaviv e Wehrse, 1986; Hubeny, 1990; Wade e Hubeny, 1998). Todos estes modelos conseguem reproduzir com relativo sucesso algumas características importantes dos espectros observados no UV, tais como a forte cobertura de linhas (line blanketing), especialmente para $\lambda<1400 \AA$, o alargamento Doppler e o forte escurecimento de bordo (Diaz et al., 1996). Posteriormente também foram inclusos os efeitos da presença da anã branca, da borda do disco, assim como o efeito do eclipse (Linnell e Hubeny, 1996; Linnell et al., 2007). Estes modelos têm sido confrontados amplamente com as observações feitas com diferentes satélites no UV para sistemas individuais (Long et al., 1994; Diaz e Hubeny, 1999; Nadalin e Sion, 2001; Engle e Sion, 2005; Linnell et al., 2008) e para uma amostra estatisticamente significativa de NL's (Puebla et al., 2007), mas problemas ainda persistem nestes modelos mais sofisticados, como por exemplo a dicotomia cor-magnitude, o perfil de fortes linhas de absorção (muitas delas deslocada para o azul) e a presença de fortes linhas de emissão no UV e no ótico que nenhum desses modelos pôde reproduzir até o momento.

\subsubsection{Linhas}

Uma característica importante dos espectros observados em VC's é o comportamento do perfil das linhas tanto de emissão como de absorção. Seja no óptico ou no ultravioleta, este tem sido um problema desafiante por décadas. A diversidade de especies iônicas presentes leva a pensar em um perfil de ionização fortemente estruturado e à ideia de que a emissão de diferentes linhas provém de diferentes regiões do sistema. As linhas principais comumente observadas no UV são mostradas na tabela 1.1 com o íon correspondente e o comprimento de onda no sistema de repouso.

Em geral, das observações são vistas algumas características das linhas que são dependentes dos parâmetros do sistema. Também muitas características espectrais estão fortemente associadas ao tipo de VC. Especificamente no caso de sistemas não magnéticos, estas características espectrais mudam conspicuamente se o disco é ou não opticamente espesso. No caso de DN's em quiescência o disco é opticamente fino devido à baixa taxa 
Tabela 1.1 - Linhas usualmente identificadas nos espectros UV de VC's com seus comprimentos de onda de repouso.

\begin{tabular}{|c|c|c|c|}
\hline Ion & $\lambda(\AA)$ & Ion & $\lambda(\AA)$ \\
\hline $\mathrm{Ly}_{\beta}$ & 1025.18 & C II & 1335.3 \\
\hline O IV & 1031.6 & O IV & 1338.6 \\
\hline Si IV & 1062.6 & P III & 1341.6 \\
\hline Si IV & 1073.6 & $\mathrm{Ov}$ & 1371 \\
\hline P IV & 1117.8 & Si IV & $1393.8,1402.7$ \\
\hline $\mathrm{P}_{\mathrm{V}}$ & 1128.01 & $\mathrm{Ni}$ IV] & 1486 \\
\hline C III & 1175 & Si II & $1526.7,1533.4$ \\
\hline Si III & 1201.3 & C IV & $1548.2,1550,7$ \\
\hline Si III & 1206.5 & $\mathrm{Mg} \mathrm{V}$ & 1575.2 \\
\hline $\operatorname{Ly}_{\alpha}$ & 1215.67 & Fe II & 1608 \\
\hline $\mathrm{N} \mathrm{V}$ & $1238.40,1242.78$ & He II & 1640.4 \\
\hline Si II & 1251 & N IV & 1718.5 \\
\hline Si II & 1260,1264 & Si II & 1815 \\
\hline Si III & $1298.9,1304.3$ & $\mathrm{Al}$ III & 1860 \\
\hline$[\mathrm{Mg} \mathrm{V}]$ & 1324 & Si III] & 1896 \\
\hline C II & 1323.9 & C III] & 1909 \\
\hline
\end{tabular}


de acresção. Estes sistemas apresentam fortes linhas de emissão no ótico especialmente na série de Balmer. Já no UV não aparecem correlações claras entre a intensidade das linhas, a profundidade óptica no contínuo e a inclinação orbital. As observações mostram que a maioria das DN's em quiescência apresentem linhas em emissão, mas existem casos nos quais o espectro mostra-se basicamente em absorção (Warner, 1995). Também tem-se observado que a intensidade das linhas decresce com o aumento da inclinação, mas esta correlação não se apresenta muito forte. Também não é observada uma correlação entre a intensidade das linhas e a taxa de acresção.

No caso de sistemas com discos com alta taxa de acresção como as NL's, NC's velhas e DN's em erupção, as características espectrais no UV apresentam comportamentos mais definidos. Os perfis de linha são fortemente dependentes da inclinação. Especialmente, a intensidade das linhas de emissão tende a crescer com a inclinação do sistema (La Dous, 1991). A taxa de acresção também parece estar correlacionada com a força das linhas, mesmo que esta correlação não é muito clara, sistemas com baixas taxas de acresção não apresentam linhas muito fortes (Puebla, 2005). A figura 1.2 mostra três espectros UV para sistemas não magnéticos, as NL's V3885 Sgr e RW Sex, e a DN Z Cam em erupção. É evidente a similitude das características espectrais nestes sistemas, a presença de profundas linhas de absorção no lado azul do espectro e um perfil P-Cyg na linha C IV (1550). Estes sistemas têm inclinações orbitais intermediárias $\left(<50^{\circ}, 35^{\circ}\right.$ e $60^{\circ}$ respectivamente).

Desde os primeiros esforços para reproduzir as linhas de emissão em DN em quiescência, mediante um disco opticamente fino no contínuo mas opticamente espesso na linha (p.e. Williams, 1980; Tylenda, 1981; Williams e Ferguson, 1982; Williams e Shipman, 1988). têm-se postulado muitos cenários físicos para explicar a força e o comportamento com a fase orbital das linhas. Um desses cenários é criar uma inversão de temperatura na superfície do disco através da irradiação do mesmo pela emissão em raios-X moles e ultravioleta extremo (EUV) das anã branca e BL, o que provocaria emissão cromosférica devido ao balanço de fotoionização e recombinação radiativa. Este mecanismo para a formação das

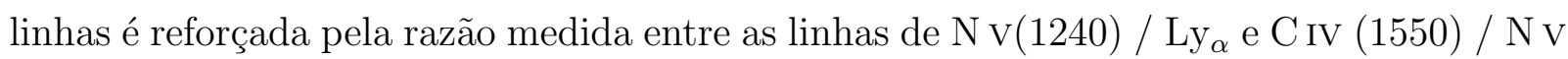
(1240), que são incompatíveis com a teoria de excitação colisional (Jameson et al., 1980). 


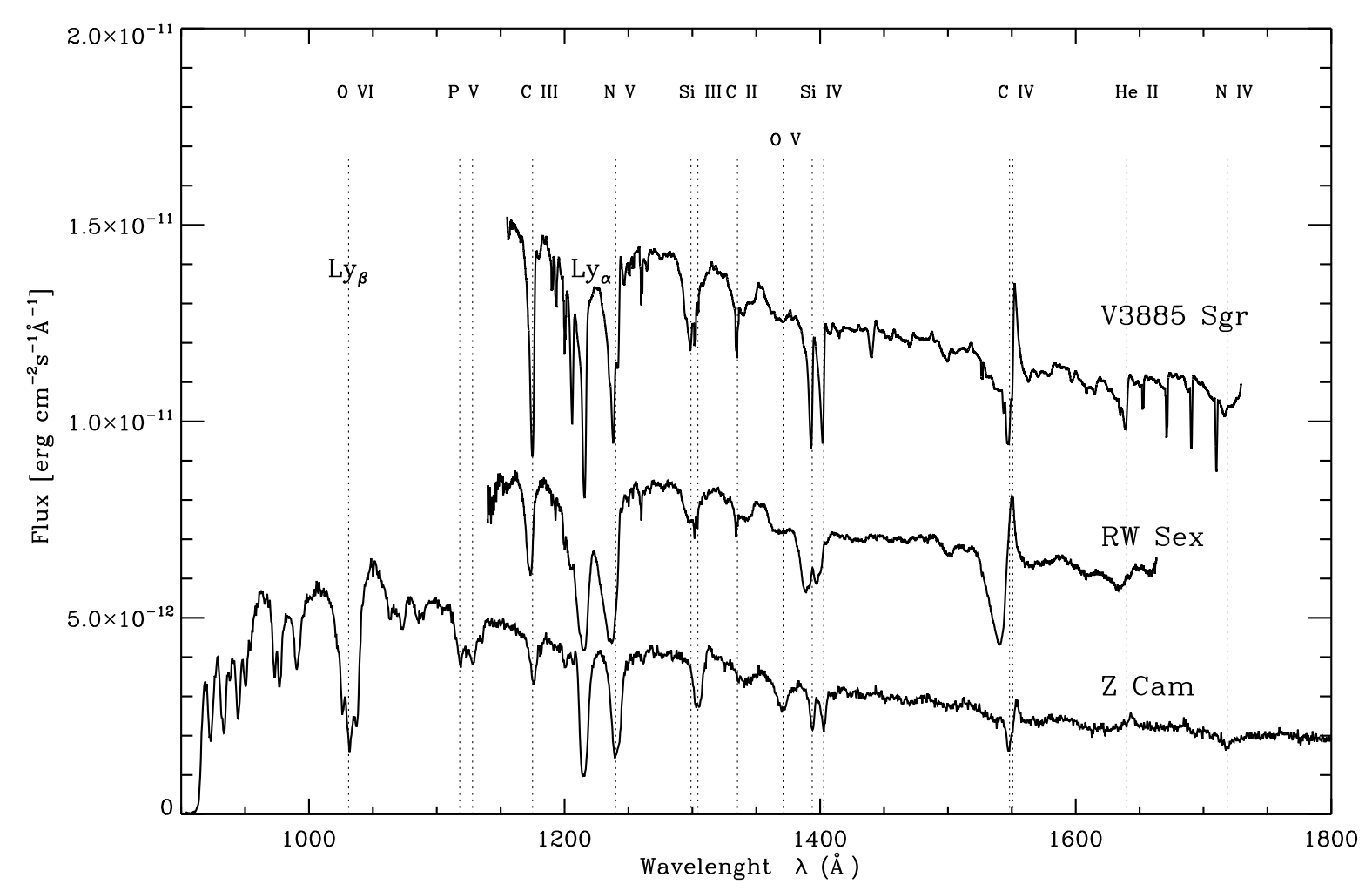

Figura 1.2: Espectros observados no UV para três VC's não magnéticas, as NL's V3885 Sgr e RW Sex observadas pelo HST com o STIS e o GHRS respectivamente, e a DN em erupção Z Cam observada pelo HUT (Astro-2). 
Patterson e Raymond (1985b) encontraram uma correlação entre a intensidade das linhas de emissão de Balmer com o fluxo em raio-X, o que sugere a importância desta irradiação. Estes mesmos autores também encontraram uma forte correlação entre a taxa de acresção e a luminosidade das linhas do He II $(4684,1640)$, mas para esta última a falta de uma base de dados completa impede uma conclusão mais definitiva (Patterson e Raymond, 1985a). Ko et al. (1996) elaboraram um modelo para DN em quiescência, de um disco iluminado por raios-X moles e EUV por um fluxo proporcional à taxa de acresção e à massa da primária. Estes autores mostraram que a intensidade das linhas no UV seria explicada por tal iluminação, mas a luminosidade em raio-X deve ser muito maior do que aquela observada nesses sistemas. Também concluem que a iluminação das regiões externas deve ser muito forte para produzir a intensidade das linhas observadas.

No caso específico de sistemas com discos opticamente espessos com alta taxa de acresção, como os mostrados na figura 1.2, o comportamento das linhas observadas no UV apontam que neles existe perda de massa através de um vento. Isto pode ser inferido dos perfis P-Cyg que são observados em sistemas de inclinação baixa e intermediária, como mostrados na figura 1.2 e que também são observados nas linhas ressonantes do Si IV e N v. A asa azul da componente em absorção destes perfis mostra uma velocidade terminal que pode chegar a 3000-5000 $\mathrm{km} \mathrm{s}^{-1}$, e a asa vermelha da componente em emissão mostra velocidades de até $1000 \mathrm{~km} \mathrm{~s}^{-1}$. Estes perfis lembram os observados em estrelas quentes $\mathrm{O}$ e B o que leva a pensar que estes ventos também seriam acelerados por radiação em linhas (Cordova e Mason, 1982, 1985). Contudo, certas características destes perfis medidas em VC's, são diferentes daquelas observadas em estrelas quentes. Como é mostrado na figura 1.3, o mínimo em fluxo da componente em absorção está mais perto do comprimento de onda em repouso da linha, quando para estrelas quentes este mínimo encontra-se perto da velocidade terminal do vento (Shlosman e Vitello, 1993; Prinja e Rosen, 1995). Existem também correlações entre a forma do perfil observado e a luminosidade do disco, ou a taxa de acresção que evidenciam a presença de um vento. Dessa forma, em sistemas com baixa taxa de acresção (p.e. DN em quiescência), a componente em absorção está ausente ou indistinguível em um perfil de emissão assimétrico. Por outro lado, para sistemas com taxa de acresção alta uma profunda componente azulada de absorção é comumente observada. 


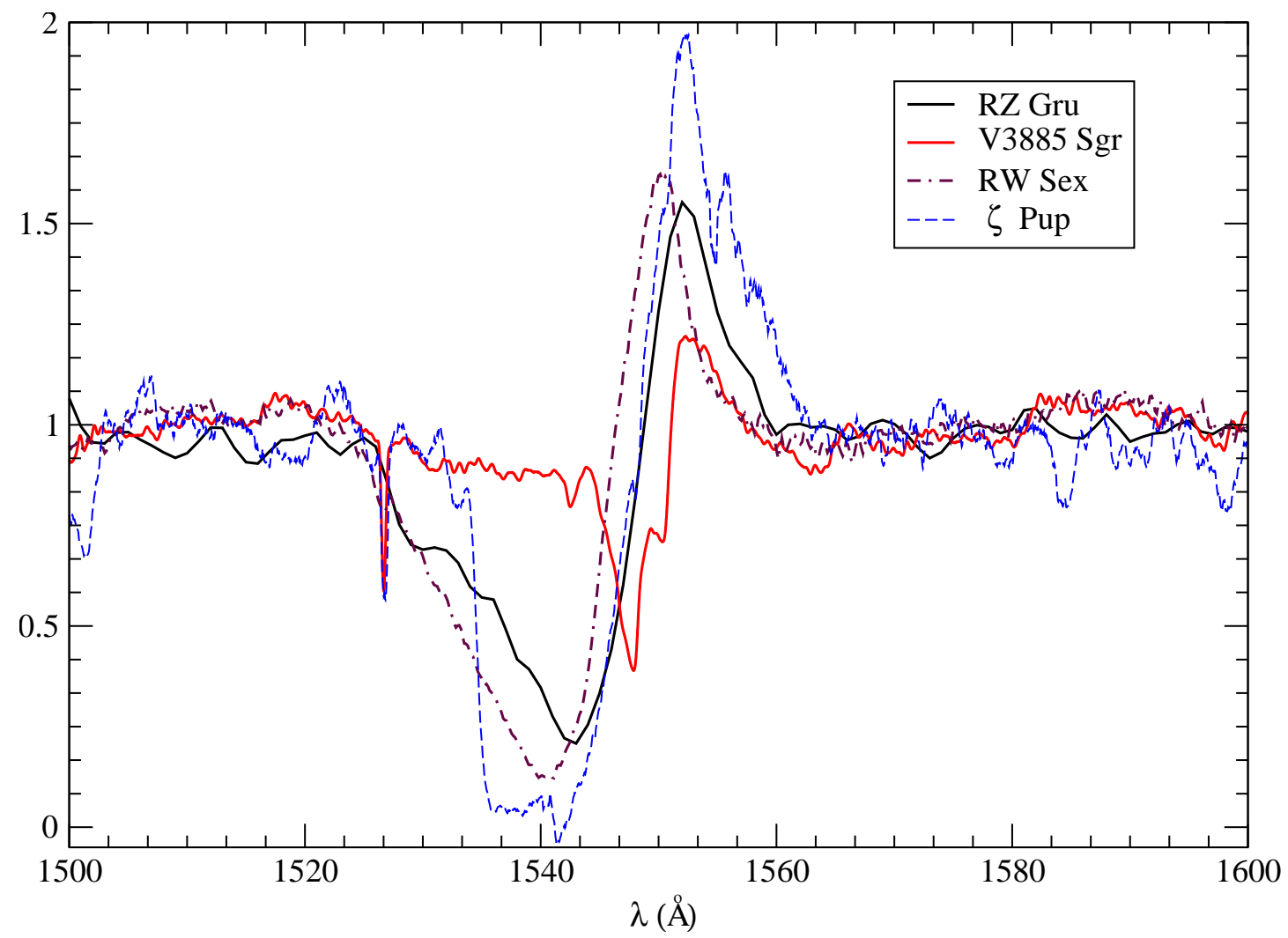

Figura 1.3: Perfis da linha resonante C IV(1550) para as VC's com disco RZ Gru (IUE), V3885 Sgr (STIS) and RW Sex (GHRS) comparadas com o a observada pelo IUE na estrela tipo O, $\zeta$ Pup. 
Também é observada uma forte correlação entre a inclinação orbital e a forma do perfil de linha. A componente azulada em absorção é gradualmente debilitada quando a inclinação aumenta (figura 1.4). Assim, para sistemas com alta inclinação orbital o espectro é dominado por linhas de emissão quase-simétricas. Este fato sugere um vento axi-simétrico, ao contrário de um vento esférico como o presente em estrelas quentes.

Alguns estudos feitos em sistemas eclipsantes mostram regiões de emissão fortemente estruturadas. Mason et al. (1995) usando observações do GHRS da NL UX UMa mostrou variações do perfil de linha e da intensidade ao longo de diferentes fases do eclipse, especialmente para C IV e He II. Estes autores também encontraram que a componente em absorção do C IV praticamente desapareceu durante o eclipse, e verificaram que diferentes regiões espectrais da linha se comportam de forma diferente através do eclipse. Outra conclusão à que chegaram foi que as linhas eram menos eclipsadas que o contínuo. A esta mesma conclusão também chegaram Cordova e Mason (1985) usando dados do IUE para as VC's eclipsantes RW Tri e DQ Her estudando las linhas dos íons Nv, C IV, Si IV e He II. Observações mais recentes no ultravioleta longínquo (FUV) e estudos na variação temporal das linhas no UV e FUV têm sido feitas com o HST e o FUSE. Fortes absorções azuladas são observadas no espectro FUV, entre elas do C III, N III e O vi (Froning et al., 2003). Variabilidade nas linhas não relacionada com o movimento orbital também tem sido observada. Prinja et al. (2000) mostrou que a nova-like BZ Cam tem rápida variabilidade na linha em escalas de tempo da ordem de minutos. Este efeito é evidente na componente azulada em absorção do C II, CiII, Si III, Si IV, Civ e Nv, sugerindo a existência de perturbações que podem viajar através do vento nessas escalas de tempo. Outros sistemas mostram também variabilidades na linha em diferentes escalas de tempo, por exemplo V603 Aql (Prinja et al., 2000) and RW Sex (Prinja et al., 2003). Por outro lado, Hartley et al. (2002), usando dados com alta resolução temporal do STIS (HST) no UV, não encontraram nenhuma variabilidade em sistemas de alta taxa de acresção IX Vel e V3885 Sgr.

Destas observações podemos concluir que a região de formação das linhas deve ser simétrica com respeito ao plano do disco para reproduzir a forte dependência dos perfis com a inclinação. Considerando que o campo de radiação do disco é bipolar, Drew (1987) demostrou que uma bipolaridade do vento também é requerida pelas observações. Podemos 
deduzir das observações que as regiões de formação de C IV, Nv e Si IV são extensas. Também se conclui que as regiões de formação das linhas não são muito distantes uma da outra e que estas são muito próximas da anã branca (Woods et al., 1992). Mas há casos como o de IX Vel, onde a região de formação de Si IV tem uma velocidade média de 400 $\mathrm{km} \mathrm{s}^{-1}$ que é muito mais baixa que a da linha de C IV $\left(\sim 2000-3000 \mathrm{~km} \mathrm{~s}^{-1}\right)$ (Mauche, 1991). Como a curva de velocidade radial do Si IV praticamente acompanha o movimento da primária, deduz-se que a produção desta linha está concentrada perto da anã branca, enquanto que a linha de C IV forma-se numa região mais extensa.

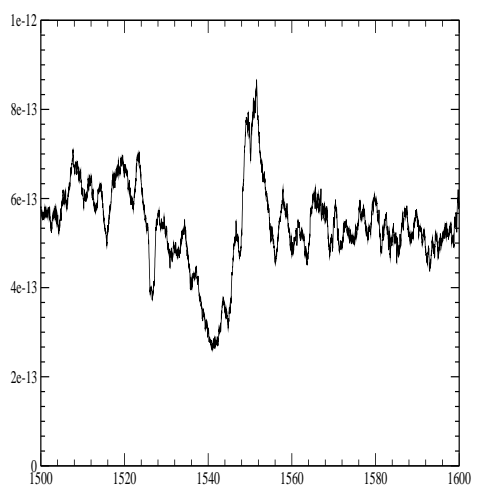

(a) DI Lac, $\mathrm{i}=18^{\circ}$

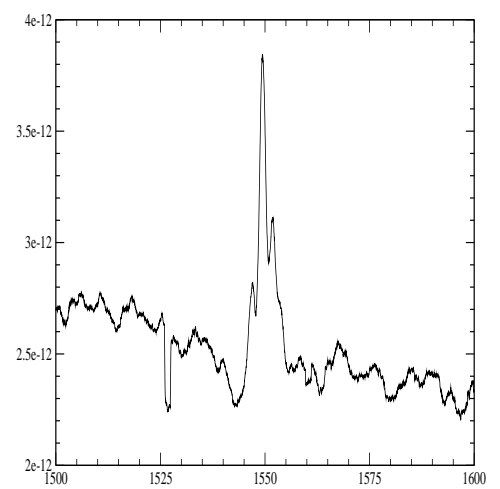

(d) QU Car, $\mathrm{i}=60^{\circ}$

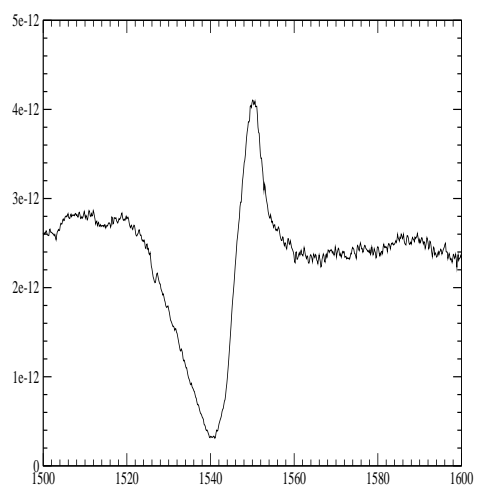

(b) RW Sex, $i=34^{\circ}$

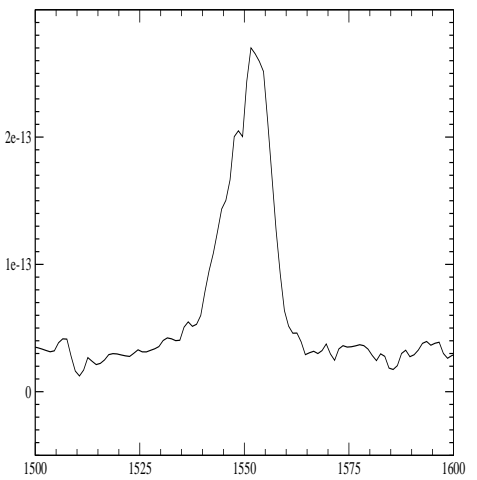

(e) SW Sex, $\mathrm{i}=75^{\circ}$

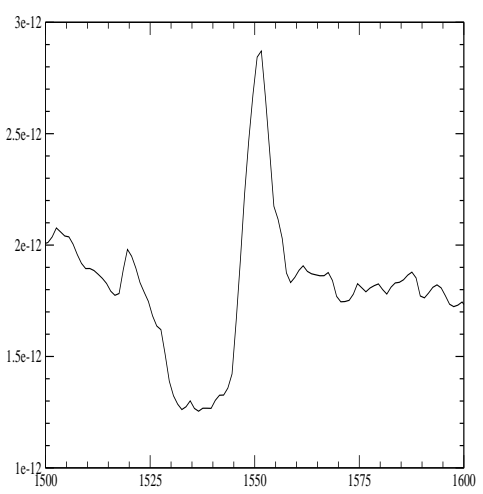

(c) HR Del, $\mathrm{i}=40^{\circ}$

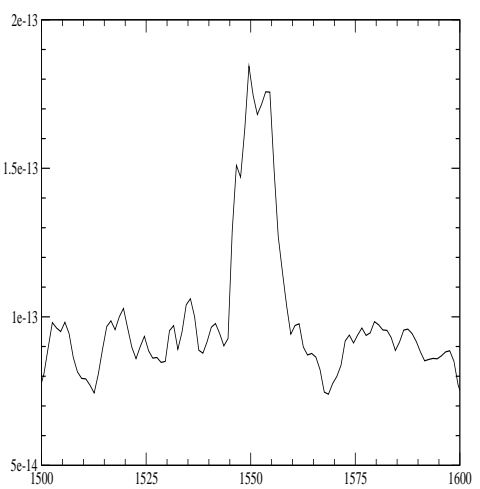

(f) $\mathrm{CM}$ Del, $\mathrm{i}=82^{\circ}$

Figura 1.4: Variação do perfil da linha resonante C IV $\lambda \lambda 1548,1551$ para vários sistemas com alta taxa de acresção e com diferentes inclinações orbitais.

O estado de ionização do gás depende muito da radiação emitida nas regiões internas do disco e da BL. Modelos têm sido elaborados para reproduzir a intensidade das linhas 
usando temperaturas típicas esperadas para a BL ( 10 $0^{5-6}$ K) (Hoare e Drew, 1991, 1993; Mauche e Raymond, 1987). Usando linhas de He II no UV e no visível como diagnóstico para o fluxo da BL, chega-se à conclusão de que a luminosidade da BL é muito menor do que a do disco, sendo obtidos fluxos de He II (1640) em acordo com as observações.

\subsection{Ventos em Estrelas Quentes}

É conhecido que as atmosferas de estrelas early-type OB são dinamicamente instáveis devido ao efeito de blanketing das linhas atmosféricas no UV. Isto causa a aceleração de um vento cuja velocidade terminal é da ordem de umas vezes a velocidade de escape na superfície da estrela. Modelos de ventos em estrelas tem sido desenvolvidos ao longo de muitos anos e suas características e propriedades estão sendo ainda estudadas usando modelos cada vez mais sofisticados. Um dos primeiros trabalhos com o objetivo de calcular as propriedades de ventos conduzidos por linhas foi realizado por Castor et al. (1975)(CAK75). Eles parametrizaram a aceleração do vento devido às linhas mediante uma lei de potência, como se mostra na equação 1.16. As constantes $\alpha$ e $k$ não são independentes e dependem da distribuição da força com a opacidade das linhas e do número de linhas que são levadas em conta no modelo. A aceleração do vento devido às linhas também vai depender da luminosidade da estrela $\left(L_{*}\right)$, da densidade do vento e do gradiente de velocidade de acordo com a equação 1.16:

$$
g_{\text {lines }}(r)=\frac{2 \pi}{c} \sum_{\text {lines }} \kappa_{l} \int I_{\nu_{l}} \frac{1-e^{\tau_{\nu_{l}}}}{\tau_{\nu_{l}}} \mu d \mu \sim \frac{\sigma_{e}^{r e f} L_{*}}{4 \pi r^{2} c} k\left(\frac{1}{\sigma_{e}^{r e f} v_{\text {th }} \rho}\right)^{\alpha}\left(\frac{d v}{d r}\right)^{\alpha},
$$

onde $\sigma_{e}^{r e f}$ é um valor referencial para a opacidade de espalhamento eletrônico que CAK75 usou como $\sigma_{e}^{r e f}=0.325 \mathrm{~cm}^{2} \mathrm{~g}^{-1}, \tau_{\nu_{l}}$ é a profundidade óptica na linha, $\mathrm{L}_{*}$ é a luminosidade da estrela e $\rho$ a densidade do vento. Os valores para $\alpha$ e $k$, alem do número de linhas, dependem muito das condições físicas do vento como a temperatura, o estado de ionização e a densidade (Abbott, 1982; Shimada et al., 1994). Existem mais dois fatores que influenciam no valor da aceleração causada por linhas. Estes termos dependem da densidade eletrônica e o fator de diluição, assim temos que (Kudritzki et al., 1989): 


$$
\begin{array}{r}
g_{\text {grad }}^{\text {line }} \sim k \frac{L_{*}}{r^{2}}\left(\rho^{-1} \frac{d v}{d r}\right)^{\alpha}\left(\frac{N_{e}}{W}\right)^{\delta} C, \text { onde } \\
C=\frac{1}{\alpha+1} \frac{x}{1-h}\left[1-\left(1-\frac{1+h}{x^{2}}\right)^{\alpha+1}\right] \\
h=\frac{d \ln v}{d \ln x} ; \quad x=\frac{r}{R_{*}} \\
W=0.5\left(1-\sqrt{1-\left(R_{*} / r\right)^{2}}\right)
\end{array}
$$

sendo $\mathrm{W}$ o fator que leva em conta o efeito do tamanho finito do disco da estrela, $\mathrm{N}_{e}$ a densidade eletrônica e $\delta$ o exponente que avalia como o estado de ionização do gás influi sobre a força de aceleração nas linhas. É importante dizer que esta aproximação exige que se cumpram duas condições; que o campo de velocidades seja monotônico e que seja válida a aproximação de Sobolev. Isto quer dizer que as mudanças na densidade de partículas e no gradiente de velocidade dentro de um comprimento de Sobolev, $\mathcal{L}_{S}$, têm que ser desprezíveis. Os valores das constantes $k, \alpha$ e $\delta$ tem sido calculados usando 520000 linhas atômicas para estrelas OB super-gigantes com temperaturas entre 10000 e 50000 K. Os mesmos estão resumidos na tabela 1.2 (Shimada et al., 1994).

Tabela 1.2 - Parâmetros da aceleração por linhas para estrelas OB

\begin{tabular}{cccccccc}
\hline \hline & \multicolumn{4}{c}{ Shimada et al. (1994) } & \multicolumn{3}{c}{ Abbott (1982) } \\
\hline Teff & $\log \mathrm{g}$ & $k$ & $\alpha$ & $\delta$ & $k$ & $\alpha$ & $\delta$ \\
\hline 50000 & 4.5 & 0.917 & 0.510 & 0.040 & 0.240 & 0.561 & 0.083 \\
40000 & 4.0 & 0.483 & 0.526 & 0.061 & 0.205 & 0.578 & 0.098 \\
30000 & 3.5 & 0.375 & 0.522 & 0.099 & 0.222 & 0.561 & 0.107 \\
20000 & 2.5 & 0.709 & 0.470 & 0.089 & 0.429 & 0.510 & 0.084 \\
15000 & 2.0 & 0.922 & 0.446 & 0.134 & 0.524 & 0.489 & 0.126 \\
10000 & 1.5 & 0.866 & 0.454 & 0.058 & 0.494 & 0.490 & 0.047 \\
\hline
\end{tabular}

Com estes valores calculados, muitos modelos aproximados foram desenvolvidos para ventos em estrelas quentes. Entretanto, um modelo completo teria que levar em conta o forte acoplamento entre as equações de equilíbrio estatístico que nos dão a população dos diferentes níveis, a equação de transferência e equilíbrio radiativo, e as equações hidro- 
dinâmicas do meio. Este sistema de equações não linear exige um enorme esforço computacional, desse modo, escolheu-se sacrificar alguma das partes do modelo para tornar o cálculo viável. Usando estas aproximações, seja tomando uma expressão parametrizada para a aceleração das linhas, ou seja impondo uma estrutura para o vento evitando resolver as equações hidrodinâmicas é possível resolver as equações de equilíbrio estatístico e de transferência radiativa exatamente, gerando assim um espectro sintético que pode ser comparado com os dados observacionais.

Devido à presença do vento é necessário resolver as equações de transferência radiativa para meios em movimento (Sen, 1998). Existem vários métodos para resolver este sistema de equações, como o método da probabilidade escape de Sobolev (1957) e a generalização desse método para 3D (Rybicki e Hummer, 1978). É possível também resolver o sistema desde o ponto de vista de um observador co-móvel com o meio. Estes métodos são os chamados CMF (comoving frame). Um dos pioneiros nestes métodos e atualmente mais utilizado é o de Mihalas et al. (1975, 1976a,b).

Existem códigos específicos desenvolvidos para resolver este sistema de equações exatamente, levando em conta uma grande quantidade de linhas atômicas. Estes códigos resolvem as equações de estrutura e transferência radiativa em uma simetria esférica em meios em movimento seguindo uma lei estabelecida de velocidades e uma taxa de perda de massa. Devido a esta imposição da lei de velocidades as equações não são resolvidas auto-consistentemente. As equações de transferência e equilíbrio estatístico são resolvidas levando em conta os efeitos de superposição de linhas e o efeito das linhas sobre o contínuo (Blanqueting). A principal aplicação destes códigos são as estrelas quentes tipo O, W-R e LBVs (p.e. Hillier e Miller, 1999).

\subsection{Ventos em discos de acresção}

Modelos de ventos em discos de acresção seja em sistemas binários ou em AGN têm sido desenvolvidos desde a década de oitenta. Três são os principais mecanismos de propulsão do vento postulados nesses trabalhos: ventos esquentados por efeito Compton (Comptonheated winds) (Begelman et al., 1983), ventos hidromagnéticos (Pudritz, 1985) e ventos conduzidos por linhas (Shlosman et al., 1985). Deles só os últimos dois são possíveis dentro da ordem de temperaturas dos discos de VC's. Neste trabalho nós nos concentraremos no 
último tipo de vento, os conduzidos por linhas (LDW) pelas siglas em inglês de line-driven winds.

O cálculo de modelos de ventos em discos de acresção pode se dividir em duas correntes. Os modelos cinemáticos e os modelos hidrodinâmicos. Os primeiros impõem uma geometria ao vento do disco e são utilizados principalmente para sintetizar linhas espectrais, que são comparadas com observações principalmente no UV. Os modelos hidrodinâmicos tentam resolver as equações hidrodinâmicas do meio, aplicando, na maioria dos casos uma parametrização para a aceleração do vento pela radiação. Nesta seção estudamos os modelos mais utilizados dos dois tipos mencionados.

\subsubsection{Modelos Cinemáticos}

Existem principalmente três modelos cinemáticos de LDW em discos desenvolvidos até o presente:

- Modelos de Shlosman e Vitello (1993) (SV93)

- Modelos de Knigge et al. (1995) (KWD95)

- Modelos de Long e Knigge (2002) (LK02)

O modelo SV93 simula o vento emitido pelo disco limitando a perda de massa a uma região localizada entre dois raios definidos dentro do disco, como mostra a figura 1.5. Os valores destes limites são impostos por dois valores de temperatura $\left(\mathrm{T}_{\min }, \mathrm{T}_{\max }\right)$ dentro dos quais se supõe a emissão do vento, sendo esta nula fora destes limites de temperatura.

Este modelo impõe que dentro desta região a temperatura superficial do disco acompanha a lei de distribuição radial de temperatura de um disco padrão. O estado de ionização é calculado primeiro e depois a transferência radiativa é calculada usando a aproximação de Sobolev. A componente poloidal da velocidade segue uma lei de distribuição similar a aquelas calculadas para estrelas quentes OB (eq.1.22).

$$
\begin{gathered}
\theta=\theta+\left(\theta_{\max }-\theta_{\min }\right) x^{\gamma} \\
v_{l}=v_{o}+\left(v_{\infty}-v_{o}\right)\left[\frac{\left(l / R_{v}\right)^{\alpha}}{\left(l / R_{v}\right)^{\alpha}+1}\right] \\
v_{\phi} r=v_{\phi o} r_{o}
\end{gathered}
$$




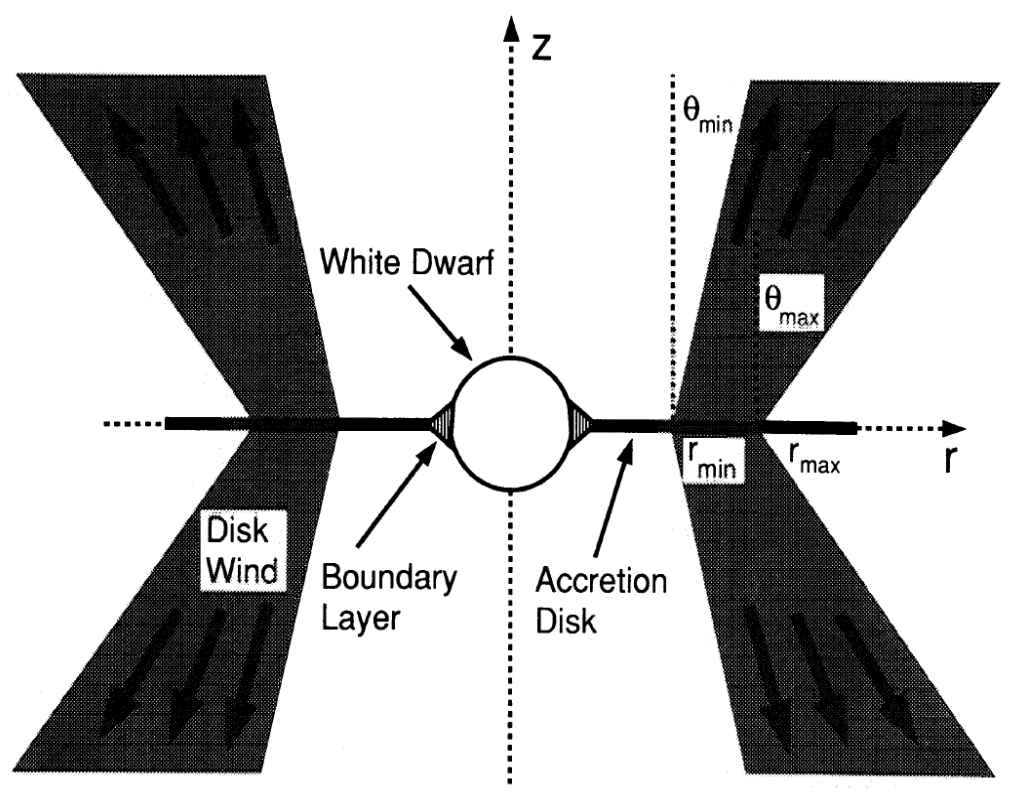

Fig. 1.-Adopted geometry for the disk wind model (not to scale).

Figura 1.5: Esquema de emissão do vento do modelo SV93

$$
l=\sqrt{\left(r-r_{o}\right)^{2}+z^{2}}
$$

aqui, $\theta$ corresponde à distribuição dos ângulos de abertura das linhas de fluxo do vento, estas linhas de fluxo saem do plano do disco a uma distância $\mathrm{r}_{o}$ da anã branca, $l$ é a distância poloidal e $\mathrm{R}_{v}$ e a escala espacial de aceleração através do raio. Na equação 1.21, $x=\left(r_{o}-r_{\max }\right) /\left(r_{\max }-r_{\min }\right)$. Também neste sistema, $v_{l}$ é a velocidade nas linhas de fluxo e $l$ a distância desde a superfície de fluxo desde o pé la linha de fluxo até um ponto do vento. Por último a equação 1.23 avalia a conservação de momento angular específica através do gás que sobe pelas linhas de fluxo.

O fluxo de perda de massa é parametrizada com uma lei de potência:

$$
\dot{m}=\dot{M}_{w} \frac{r_{o}^{\lambda} \cos \theta\left(r_{o}\right)}{\int d A r_{o}^{\lambda} \cos \theta\left(r_{o}\right)}
$$

Na figura 1.6 mostram-se os resultados deste modelo ao sintetizar a linha de C IV(1550 $\AA$ ) para diferentes valores de taxa de acresção $\dot{M}_{a c c}$ (paneis superiores), taxa de perda de massa $\dot{\mathrm{M}}_{w}$ (paneis inferiores) e para duas inclinações diferentes $\left(i=27^{\circ}\right.$ e $\left.10^{\circ}\right)$. Como vemos, para o caso de menor inclinação e no caso de menores valores de taxa de acresção mostra-se uma linha em emissão com uma componente muito estreita em absorção, esta componente aparece porque em baixas inclinações estaríamos observando a base do "cone", que forma 

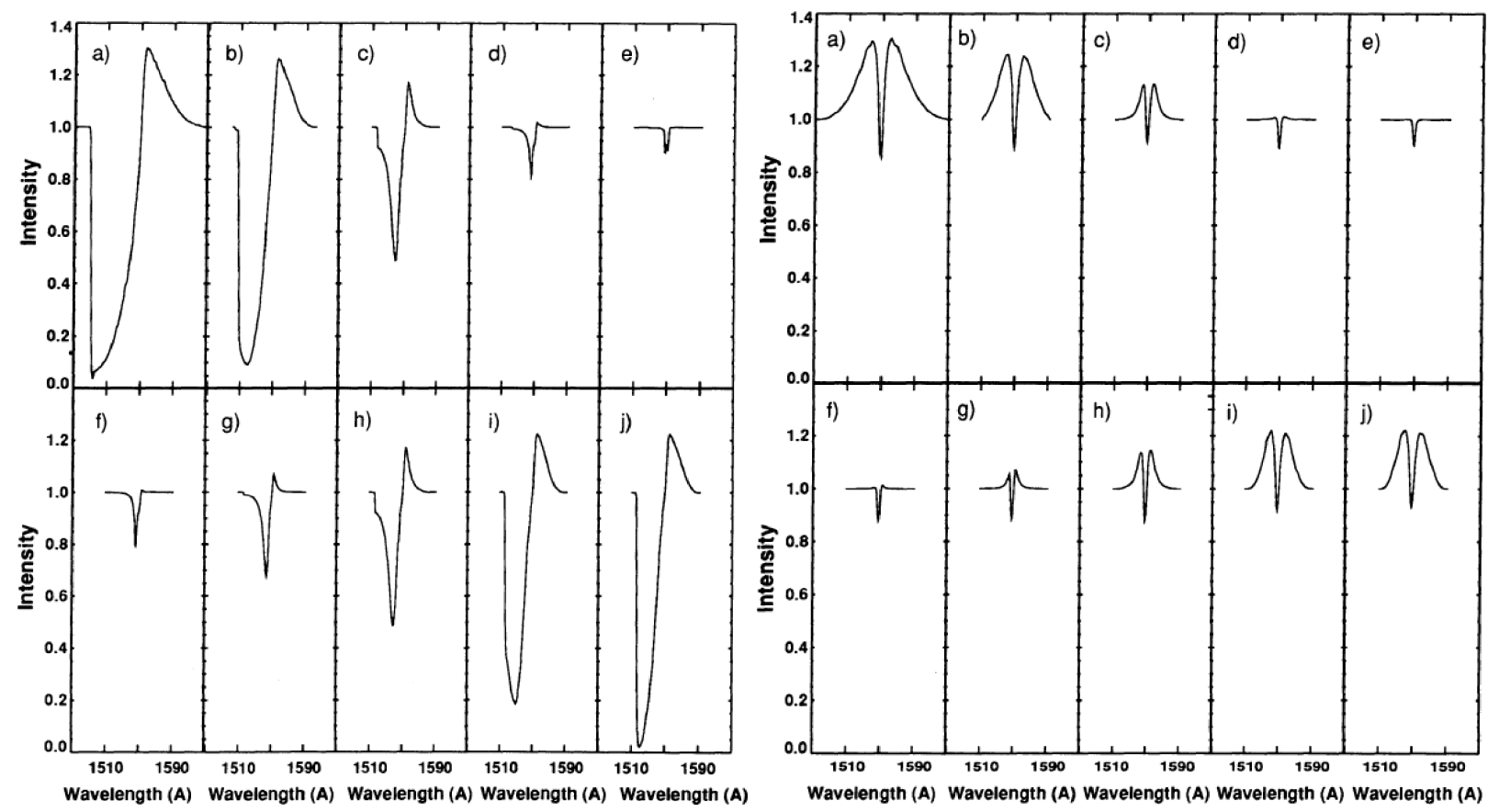

Figura 1.6: Perfis de linha calculados com o modelo SV93. Painel da esquerda corresponde a um sistema com $i=27^{\circ}$, e o da direita a um sistema com $i=10^{\circ}$. Os paneis superiores estão ordenados ascendentemente em $\dot{\mathrm{M}}_{a c c}\left(10^{-9}-10^{-7} \mathrm{M}_{\odot} \mathrm{yr}^{-1}\right)$ e os inferiores em $\dot{\mathrm{M}}_{w}\left(10^{-10}-3 \times 10^{-9} \mathrm{M}_{\odot} \mathrm{yr}^{-1}\right)$.

o vento de uma região opticamente espessa. A forte linha de emissão para baixos valores da taxa de acresção é devida ao fato do vento ser emitido nas regiões mais internas, que segundo esta parametrização têm maior taxa de perda de massa, fazendo o vento mais espesso na linha. O mesmo acontece quando variamos a taxa de perda de massa no vento, que varia a densidade do vento e a profundidade óptica na linha. Para maiores valores da inclinação aparecem os perfis P Cyg que se observam nos espectros UV de VC's. Com diferentes profundidades da componente em absorção, de acordo com a densidade no vento. A dependência deste tipo de perfil com a inclinação é fortemente variável com a colimação do vento que é dada pela lei angular da equação 1.21. Para altos valores de inclinação, o observador se encontra fora do cone do vento e a linha aparece em emissão (figura 10 em SV93).

Os modelos KWD95 e LK02 usam o método Monte Carlo para resolver a equação de transferência radiativa no vento. No primeiro caso esta é resolvida exatamente e no segundo é usada a aproximação de Sobolev. Outra diferença fundamental entre estes modelos é que no segundo caso é calculada primeiro a estrutura de ionização e de temperatura do gás que forma o vento e depois se implementa o transporte radiativo para calcular o espectro. 


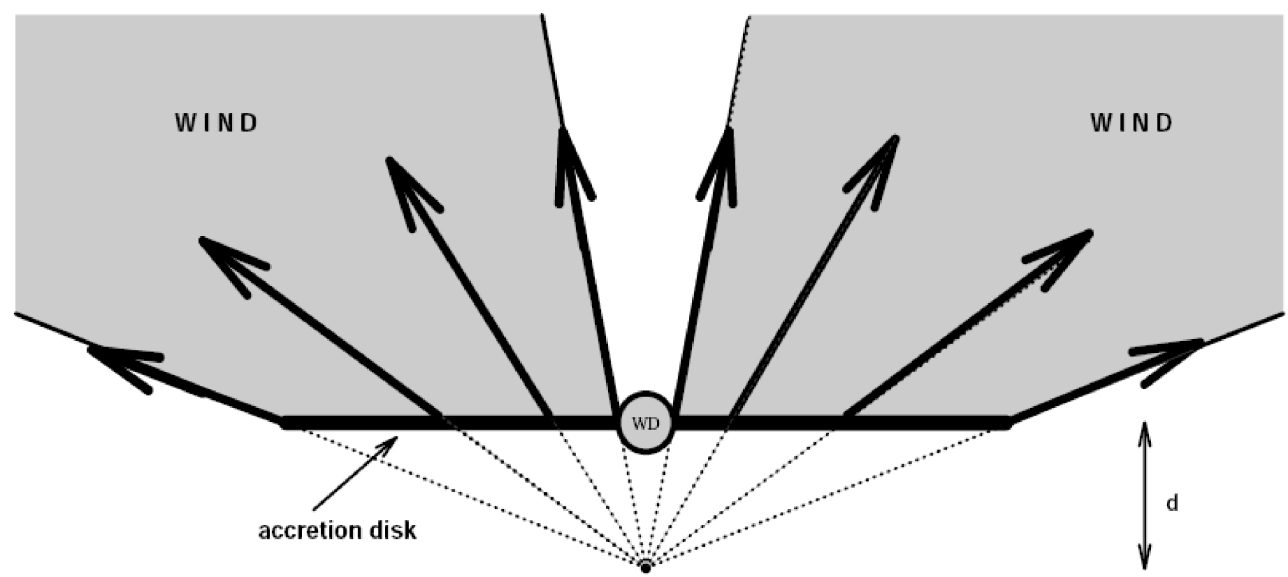

FIG. 8.-The split monopole geometry of our kinematic disk wind model

Figura 1.7: Geometria do vento no modelo KWD95

Por outro lado, KWD95 calcularam o espectro usando uma estrutura fixa de ionização e temperatura onde o íon dominante dentro do gás é o C IV (vide também Knigge et al., 1997). A estrutura de ionização e temperatura em LK02 é calculada iterativamente levando em conta diversos processos radiativos. A fonte de contínuo nesse caso inclui o disco, a anã branca e a BL, os dois primeiros podem ser modelados como atmosferas estelares ou como um corpo negro, já a BL é modelada como um corpo negro (mais detalhes em LK02). KDW95 usam só o disco modelado como uma superposição de corpos negros. Da mesma forma que no caso dos modelos SV93, é usada uma geometria bicônica, mas a colimação do vento vem quantificada pelo parâmetro $d$, como mostra a figura 1.7. A temperatura superficial do disco também segue um disco padrão.

O vento é caracterizado pelas seguintes relações para o campo de velocidades e a taxa de perda de massa. A distribuição radial do fluxo de perda de massa é parametrizado para acompanhar a emissão por dissipação viscosa do disco por uma lei de potência em $\alpha$ (eq. 1.28). A equação 1.27 considera a conservação do momento angular específico no vento considerando que na base do vento o gás tem velocidade kepleriana.

$$
\begin{gathered}
v_{q}=c_{s}\left(r_{o}\right)+\left[f^{\prime} v_{e s c}-c_{s}\left(r_{o}\right)\right]\left(1-\frac{R_{s}}{l+R_{s}}\right)^{\beta} \\
v_{\phi} r_{o}=v_{\phi_{o}} l \\
\dot{m} \propto F\left(r_{o}\right)^{\alpha} \propto T\left(r_{o}\right)^{4 \alpha} \\
c_{s}\left(r_{o}\right) \simeq 10 \sqrt{\frac{T\left(r_{o}\right)}{10^{4} K}}\left(k m s^{-1}\right)
\end{gathered}
$$




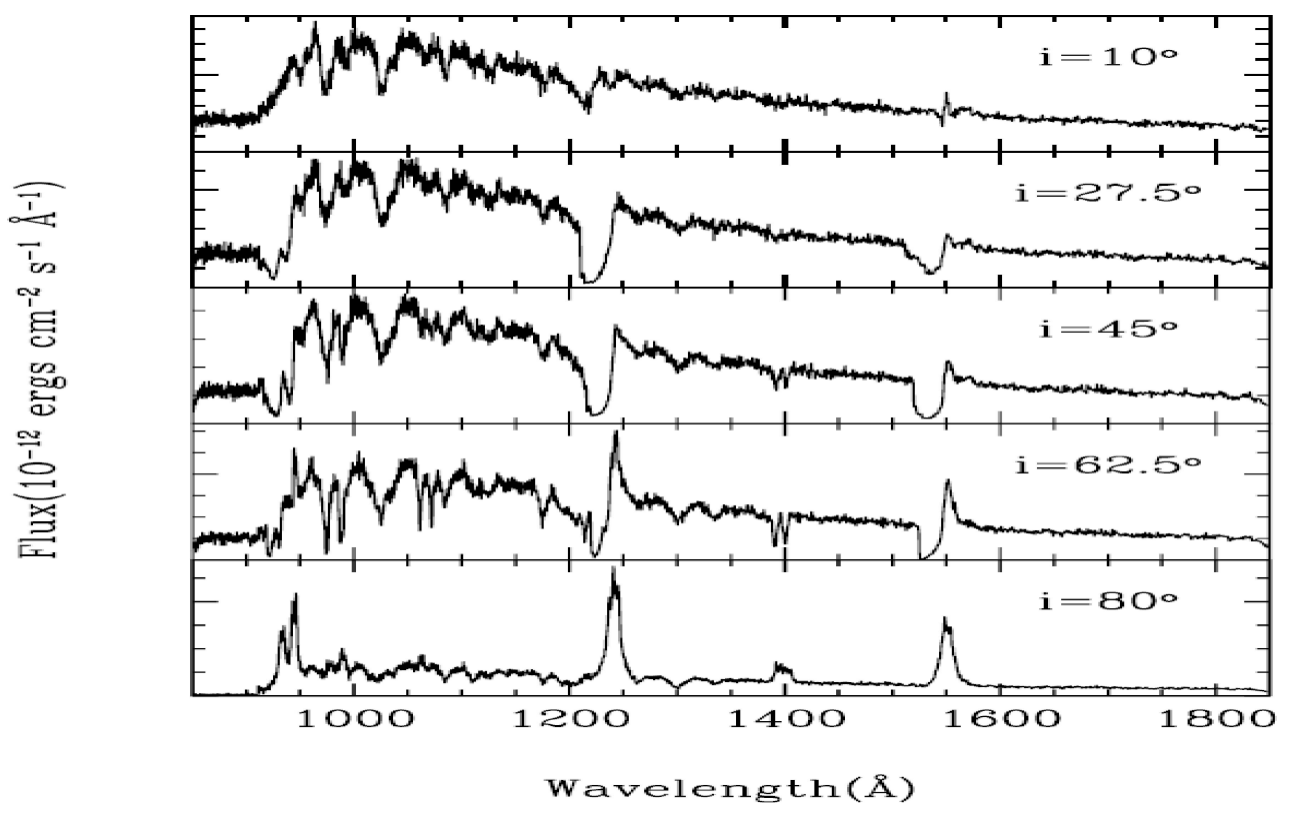

Figura 1.8: Espectros sintéticos calculados por LK02, com $\dot{\mathrm{M}}_{a c c}=10^{-8} \mathrm{M}_{\odot} \mathrm{yr}^{-1}$ e $\dot{\mathrm{M}}_{w}=10^{-9} \mathrm{M}_{\odot} \mathrm{yr}^{-1}$

Estes modelos conseguem reproduzir o comportamento dos perfis de linha com a inclinação, da mesma forma que em SV93. Uma diferença importante é que LK02 consegue sintetizar não só o perfil de uma linha espectral em particular (como é no caso de KDW95 e SV93), mas também uma região do espectro. Além disso, usam como campo de radiação no limite inferior da atmosfera a emissão de uma fotosfera estelar de mesma temperatura efetiva. O comportamento de uma região do espectro UV, calculada por LK02 é mostrada na figura 1.7.

\subsubsection{Modelos Hidrodinânicos}

Modelos hidrodinâmicos para ventos em discos de acresção têm sido desenvolvidos também desde o início da década do oitenta. Os primeiros modelos unidimensionais foram desenvolvidos por Shlosman et al. (1985) e Vitello e Shlosman (1988). Estes autores resolveram as equações hidrodinâmicas de momento e energia no sentido vertical (z) levando em conta, para a aceleração nas linhas, a aproximação de Sobolev. As taxas de resfriamento e aquecimento são calculadas para estimar a distribuição vertical de temperatura. Estes modelos descrevem ventos com velocidades terminais de até de $\sim 3500 \mathrm{~km} \mathrm{~s}^{-1}$, e fluxos de perda de massa da ordem de $\sim 10^{-6} \mathrm{gr}^{-2} \mathrm{~s}^{-1}$.

Uma nova geração de modelos foi desenvolvida por Proga et al. (1998, 1999) estes 
autores calcularam um modelo bidimensional de um vento radial. A força de radiação sobre o vento é dada na aproximação de CAK75, com $k=0.2$ e $\alpha=0.6$. A estrutura do vento calculada por eles apresenta certas instabilidades e condensações. A taxas de perda de massa no vento nos seus modelos é da ordem de $10^{-13} \mathrm{M}_{\odot} \mathrm{yr}^{-1}$, com velocidades terminais de até $7000 \mathrm{~km} \mathrm{~s}^{-1}$.

Recentemente Pereyra et al. (1997, 2000) calcularam uma série de modelos de ventos conduzidos por radiação em discos, resolvendo as equações hidrodinâmicas do vento tanto na aproximação unidimensional como tridimensional, usando uma simetria axial. No primeiro caso impõe-se que o vento só pode fluir verticalmente, já no segundo caso as equações de momento e conservação de massa determinam a geometria do vento de forma auto-consistente. Assim, eles encontraram interessantes características destes ventos dependendo das condições iniciais e da sofisticação do modelo. Nos dois tipos de modelos a força de aceleração nas linhas foi calculada usando a aproximação de CAK75 que, levando em conta a geometria dos discos é dada como:

$$
f_{\text {rad }}=\oint\left[\frac{\sigma \int_{0}^{\infty} I(\hat{n}) d \nu}{c} k\left(\frac{1}{\rho v_{t h} \sigma}\left|\hat{n} \cdot \hat{z} \frac{d v_{z}}{d z}\right|\right)^{\alpha}\right] \hat{n} d \Omega
$$

onde $\sigma$ é a seção eficaz de Thomson por unidade de massa, $v_{t h}$ a velocidade térmica do som, $\hat{n}$ o vetor unitário na direção do raio, $\rho$ a densidade de massa e $c$ a velocidade da luz (Pereyra et al., 1997).

Os primeiros modelos consideraram discos isotérmicos e vento isotérmico, sem levar em conta a força da radiação paralela ao disco, mas somente aquela que impulsa o vento na direção vertical. Como condição de fronteira impuseram que a velocidade na superfície do disco tivesse apenas a componente vertical (z) e a componente azimutal igual à velocidade kepleriana. Foi verificado que tanto a força centrifuga como a de Coriolis fazem com que o gás das regiões mais internas do disco se veja impulsado para fora, chocando assim com os jatos que sobem das vizinhanças, o que provoca uma região de choque onde a densidade do vento se vê fortemente incrementada.

Na figura 1.9 mostra-se tanto os níveis que representam a distribuição de densidade e o campo de velocidades do vento nesta aproximação. Como podemos ver, o vento apresenta uma geometria bicônica como sugerem algumas observações. Ao deixar o vento adiabático, 

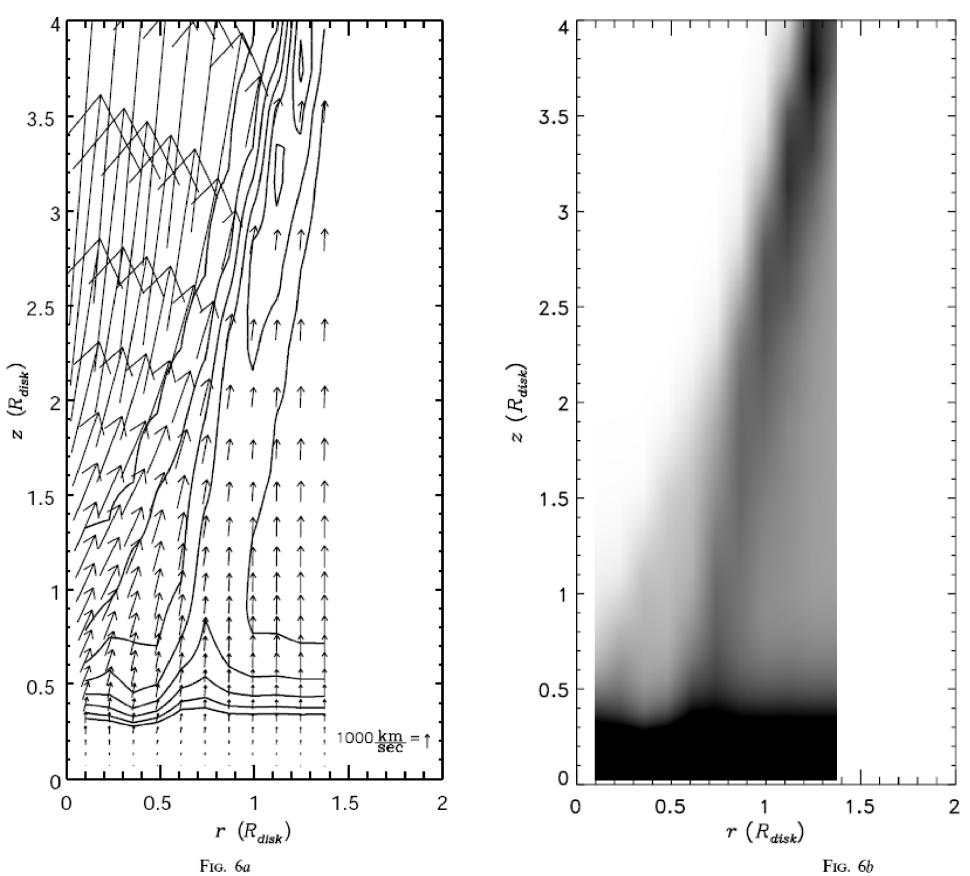

Figura 1.9: Distribuição de densidade e campo de velocidades no modelo de Pereyra et al. (1997).

adotar a distribuição de temperatura do disco padrão e permitir a influência da força paralela ao disco, o campo de velocidades e a distribuição de densidade no vento mudam como é mostrado na figura 1.10.

Vemos que o campo de velocidades do vento é muito complexo, bem como a distribuição de densidades, mas mantém uma geometria bicônica, o que afeta o comportamento das linhas no UV. Estes autores encontraram que o incremento do parâmetro $k$ da força de radiação não afeta o campo de velocidades mas sim a densidade no vento, incrementando a taxa de perda de massa. Isto faz com que os ventos em discos se comportem de maneira muito semelhante aos ventos em estrelas quentes, já que nelas, se incrementada a luminosidade da estrela o campo de velocidades não se vê fortemente afetado, mas a taxa de perda de massa aumenta.

Recentemente Pereyra e Kallman (2003) calcularam modelos de ventos em discos caraterizados principalmente pelo estudo da influência do equilíbrio de ionização sobre as características hidrodinâmicas do vento. Estes autores calcularam os parâmetros que avaliam a força da radiação sobre o vento, $\alpha$ e $k$, de forma auto-consiste com o equilíbrio de ionização local no tempo e no espaço. Para isto é calculado o balanço de ionização através da equação de Saha e as populações dos níveis através da equação de Boltzman e a 

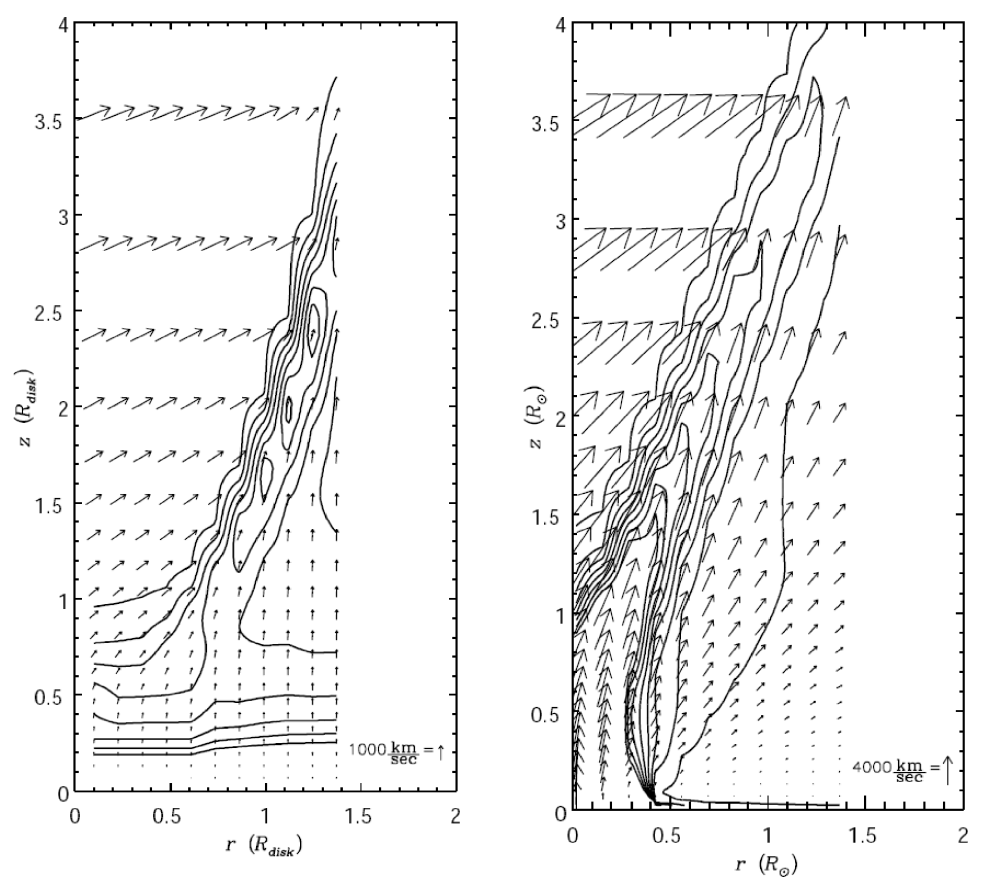

Figura 1.10: Distribuição de densidade e campo de velociades no modeo de Pereyra et al. (2000).

intensidade da radiação através do modelo do disco padrão. Nesse trabalho esses autores encontram que, ao longo do vento, $k$ está entre 0.03 e 0.65 e $\alpha$ entre 0.55 e 0.85 . Assim, os valores para a perda de massa no vento para um disco com a luminosidade do disco $\mathrm{L}_{d}=\mathrm{L}_{\odot}$ e uma anã branca com $0.6 \mathrm{M}_{\odot}$ estão entre $4 \times 10^{-12}$ e $2 \times 10^{-11} \mathrm{M}_{\odot}$ ano $^{-1}$ (mais detalhes em Pereyra e Kallman, 2003).

\subsection{Objetivo e descrição deste trabalho}

Como o descrito neste capítulo os modelos que pretendem reproduzir as características espectrais das Variáveis Cataclísmicas ainda não conseguem resolver o problema de uma forma completa e auto-consistente. Além disso, poucos trabalhos apresentam uma comparação direta com as observações. Os sistemas com discos estacionários e luminosos, brindam-nos a oportunidade de estudar com mais detalhe algumas destas características espectrais devido a sua pouca variabilidade e a sua independência de certos parâmetros, como a viscosidade, que tornariam o trabalho muito mais complexo. É por isso que esse tipo de sistemas foi o escolhido para estudar detalhadamente a emissão UV de VC's. No caso do contínuo tem-se construído modelos realistas que têm obtido um sucesso relativamente bom, mas é evidente que ainda é necessário a inclusão de mais física para conseguir 
modelos totalmente consistentes com as observações. Já no caso da emissão nas linhas, o problema é mais complexo, primeiro devido ao fato que o seu comportamento varia muito de um sistema para outro, o que evidencia características e, seguramente, processos físicos diferentes. Os trabalhos estatísticos e a morfologia dos perfis mostram que, pelo menos no UV, estas características espectrais podem ser causadas por um vento conduzido por radiação como ocorre nos ventos de estrelas quentes. Daqui o objetivo e a motivação deste trabalho. Os modelos descritos neste capítulo usam várias técnicas para descrever e até sintetizar espectros de ventos em discos de VC's. Mas sempre foi usada a hipótese de um disco plano e em nenhum caso foi considerada a interação da fotosfera do disco com o vento. Além disso, mesmo que a estrutura de ionização seja calculada por um método Monte Carlo como em LK02, a estrutura nunca foi calculada exatamente, com a alta sofisticação como atualmente é feito no caso de estrelas quentes. Os modelos hidrodinâmicos, descritos na seção 1.5.2, mostram que o vento deve ter uma geometria bi-cônica e que o campo de velocidades do vento tem sua componente principal no sentido vertical, além de que uma distribuição muito suave da densidade e temperatura no vento não seria possível devido à formação de estruturas de choque.

Um sistema tão complexo como o descrito pelos modelos hidrodinâmicos, acoplado com as equações envolvidas no cálculo da estrutura de ionização, transferência radiativa e equilíbrio radiativo como os descritos nos modelos cinemáticos, escapa às capacidades computacionais atualmente disponíveis. Existe um código do tipo CMF para estudar amplamente a física dos ventos em estrelas quentes que pode calcular a estrutura do vento em detalhe. Recentemente, este código permitiu resgatar também as características fotosféricas destas estrelas. Este código chamado CMFGEN foi desenvolvido nos últimos vinte anos pelo Prof. John Hillier ${ }^{1}$. Para estudar detalhadamente as linhas formadas na região de transição entre o vento e a fotosfera, este código foi modificado pelo autor para tratar com atmosferas com geometria plano-paralela. Esta geometria é utilizada neste trabalho para simular a presença de vento sobre a fotosfera do disco. Uma descrição mais detalhada do método desenvolvido e modificado do código utilizado é feita no capítulo 2. Neste capítulo também é descrito o cálculo do perfil de velocidades vertical, necessário para o calculo das atmosferas com vento, assim como o método aqui desenvolvido para o

\footnotetext{
${ }^{1}$ Department of Physics and Astronomy, University of Pittsburgh.
} 
cálculo do transporte radiativo necessário para a obtenção do espectro sintético.

Na terceira parte deste trabalho é mostrado como os diferentes parâmetros do sistema binário afetam tanto o contínuo como o perfil de emissão das linhas. A forte influência da região de transição é evidente na forma do espectro, especialmente nas fortes linhas de absorção, característica que é observada nos espectros de VC's. Também neste capítulo é mostrada a influência sobre o espectro sintético de parâmetros geométricos tanto de vento como do disco, é mostrado que estes parâmetros influem fortemente no perfil e na intensidade das linhas. A influência sobre as características espectrais de regiões com densidade maior dentro do vento (condensações) também é estudada nesta parte do trabalho e bem como a influência de uma pequena diluição geométrica do tipo estelar sobre a estrutura do vento e sobre os perfis de linha.

Na quarta parte é feita uma análise ao comparar os modelos com espectros observados em alta resolução no UV. Sistemas de baixa e alta inclinação são analisados para obter as características físicas do vento em cada um dos casos. No caso de sistemas com baixa inclinação orbital são estudadas as NL’s RW Sex e V3885 Sgr, já no caso de sistemas com alta inclinação as NL's RW Tri e V347 Pup são estudadas. Na última parte as conclusões deste trabalho são expostas e as perspectivas para continuidade do trabalho.

Um resultado paralelo a este trabalho é mostrado no anexo A. Nesta contribuição mostramos os resultados de uma análise espectral feita sobre um conjunto de VC's quentes em quiescência. Ali foram apontadas as virtudes e deficiências dos modelos atuais de síntese espectral utilizados para analisar o contínuo. Uma analise da estabilidade desses discos foi feita, além de investigar a possível contaminação que uma anã branca poderia introduzir no espectro. Essa análise apontou para introdução de uma atmosfera extensa bem como a presença de ventos nos modelos de discos, como a melhor forma de reproduzir as linhas de emissão observadas. 


\section{Método}

Neste trabalho um novo método foi desenvolvido para entender a emissão de vento em discos luminosos de VC's. Como foi descrito no capítulo anterior os perfis de linha observados no UV em sistemas de inclinação baixa e intermediária lembram aqueles observados em estrelas quentes de alta massa tipo OB. Devido a esta similitude entre as características espectrais, é factível supor que no caso de VC's estas linhas também seriam formadas em um vento expelido no sistema binário. Como também foi mencionado no capítulo anterior, evidências observacionais mostram que este vento deve ser produzido nas regiões internas do disco de acresção.

No modelo proposto neste trabalho é suposto que o vento provém da superfície de disco. Este disco é dividido em um conjunto de anéis concêntricos, onde cada anel está localizado a uma distância $\mathrm{R}$ do centro da anã branca. Os anéis formam uma grade com raios logaritmicamente equidistantes. Para cada anel é calculada a estrutura de uma atmosfera de disco com vento. Estes modelos contêm a estrutura vertical de temperatura, densidade, populações dos níveis atômicos para cada espécie e estado de ionização. Com estes valores são calculadas depois a emissividade e a opacidade no sistema co-móvel (CMF). Estes modelos, como será descrito na seguinte seção, precisam de um campo de velocidades vertical para cada anel do disco. Este campo de velocidades é calculado resolvendo a equação de Euler para um vento vertical que é produzido na superfície sob as condições físicas locais de gravidade, temperatura e radiação encontradas no disco de acresção. O método utilizado para obter estes perfis de velocidades é descrito com detalhe na seção 2.2. Os valores da emissividade e opacidade calculados são então interpolados bi-dimensionalmente numa grade mais fina no espaço $(r, z)$. Estes novos valores são repetidos para diferentes 
ângulos azimutais equidistantes, para formar assim uma grade tri-dimensional cilíndrica. Esta grade é então usada no cálculo da transferência radiativa.

Os modelos de atmosferas de disco são calculados entre dois limites de raios no disco: $\mathrm{R}_{i}$ e $\mathrm{R}_{f}$. O limite interno $\mathrm{R}_{i}$ foi imposto como 1.05 vezes o raio da anã branca $\mathrm{R}_{1}$, o qual é calculado usando a relação massa-raio para anãs brancas de carbono de $0 \mathrm{~K}$ calculada por Hamada e Salpeter (1961). O limite externo $\mathrm{R}_{f}$, é calculado usando um limite de temperatura efetiva e fluxo de perda de massa nessa região, condições que nos permitam a convergência do modelos de atmosferas com vento. Esta temperatura nos modelos calculados está por volta de $\mathrm{T}\left(\mathrm{R}_{f}\right) \sim 14000 \mathrm{~K}$.

Para o cálculo da transferência radiativa através do vento, nós geramos uma grade de parâmetros de impacto no plano do céu centrada na anã branca. De cada ponto formado pela interseção entre esta grade e a grade de ângulos azimutais, temos um raio na direção do observador, a transferência radiativa é feita ao longo desse raio até que escapa para fora do vento. Estes valores da intensidade específica são calculados para cada frequência. Os mesmos são então integrados no ângulo solido subtendido pelo lobo de Roche para obter o fluxo que chega ao observador. Os detalhes de como este cálculo é feito são descritos na seção 2.3 .

\subsection{Atmosferas de Disco com Vento}

Como foi mencionado na seção anterior, uma grade de modelos de atmosferas com vento foi calculada. O código CMFGEN está descrito em Hillier (1987, 1990); Hillier e Miller (1998, 1999) e Busche e Hillier (2005). A vantagem de usar este método é o detalhamento físico que está incluso dentro do código, que até o momento não foi utilizado para estudar a emissão de ventos em discos de acresção. Estes processos físicos incluem a troca de carga, ionização Auer, a emissão de raios X dentro do vento, alem da cobertura por linhas. Outra vantagem é o uso de modelos atômicos completos para cada espécie iônica levando em conta a inclusão de centenas de níveis atômicos e milhares de transições atômicas. Todos estes processos físicos têm uma forte influência na estrutura do vento e conseqüentemente na forma dos perfis de linha e do contínuo, especialmente no UV. Entretanto, várias modificações foram necessárias nesses códigos para a aplicação em discos. 


\subsubsection{Cálculo da Estrutura}

Atmosferas estelares de alta luminosidade no caso de estrelas, ou de alta temperatura em caso de discos, requerem modelos que levem em conta o fato de que a radiação pode superar o limite de Eddington provocando alta perda de massa. Assim, seja no caso estelar ou em discos, o gás deve ser descrito pelo sistema de equações hidrodinâmicas, que para sistemas não magnéticos está formado por trés condições: conservação de massa, de momento e de energia. Este sistema deve incluir todas as forças às quais o gás é submetido, ou seja, gravidade, pressão térmica e pressão por radiação. Neste último caso, a aceleração é devida à interação da radiação com a matéria na forma de transições no contínuo, nas linhas e o espalhamento eletrônico, que provoca uma aceleração da forma:

$$
g_{\text {rad }}=\frac{2 \pi}{c \rho} \int_{0}^{\infty} \int_{-1}^{+1} \chi_{\nu} I_{\nu} \mu d \mu d \nu+\frac{2 \pi^{2} e^{2}}{\rho m_{e} c^{2}} \sum_{i} f_{i j}\left(n_{i}-\frac{g_{i}}{g_{j}} n_{j}\right) \int_{0}^{\infty} \int_{-1}^{+1} I_{\nu} \phi\left(\nu^{\prime}\right) \mu d \mu d \nu
$$

onde $n_{i}$ é a densidade de eléctrons no nível $i$. No primeiro termo $\chi_{\nu}$ é a opacidade devido ao processos de espalhamento no contínuo, livre-livre e ligado-livre, enquanto o segundo termo corresponde às transições ligado-ligado. Esta aceleração deve ser levada em conta na solução das equações hidrodinâmicas do vento em estado estacionário:

$$
\begin{aligned}
\nabla \cdot(\rho \mathbf{v}) & =0 \\
\mathbf{v} \cdot \nabla \mathbf{v} & =-\frac{1}{\rho} \nabla P-g+g_{\text {rad }}
\end{aligned}
$$

onde $g$ é a aceleração da gravidade e $P$ é a pressão do gás. Daqui obtemos que para conhecer o comportamento completo do gás é necessário conhecer os valores das intensidades específicas $I_{\nu}$, para todas as frequências em todos os pontos do gás. Isto só é possível resolvendo também a equação de transferência radiativa:

$$
\frac{d I_{\nu}}{d s}=\eta_{\nu}-\chi_{\nu} I_{\nu}
$$


onde $\chi_{\nu}$ e $\eta_{\nu}$ são a opacidade e a emissividade do gás em cada ponto. Estes valores assim como as populações dos níveis $n_{i}$, dependem fortemente também do valor de $I_{\nu}$, da densidade e temperatura eletrônica já que estão acopladas, em um sistema estacionário, pelas condição de equilíbrio estatístico. Sob esta condição a variação temporal da população média dos níveis atômicos deve ser nula $\left(\partial n_{i} / \partial t=0\right)$. Daqui chega-se a um sistema de equações comumente conhecidas como "Rate Equations" com uma equação para a população de cada nível da forma:

$$
\sum_{j \neq i}\left(n_{j x} P_{j i}^{x}-n_{i x} P_{i j}^{x}\right)-\nabla \cdot\left(n_{i x} \mathbf{v}\right)=0
$$

onde $x$ representa cada espécie iônica, $\mathrm{P}_{j i}^{x}$ é a taxa de transições no nível $j$ ao nível $i$ que leva em conta processos radiativos e colisionais. No caso de uma atmosfera estática a equação 2.5 fica então da forma:

$$
\begin{aligned}
& \sum_{k=i+1}^{\bar{C}} n_{k}\left(A_{k i}+B_{k i} \bar{J}_{i k}+n_{e} C_{k i}\right)+\sum_{j=1}^{i-1} n_{j}\left(B_{j i} \bar{J}_{j i}+n_{e} C_{j i}\right) \\
& =n_{i} \sum_{j=1}^{i-1}\left(A_{i j}+B_{i j} \bar{J}_{j i}+n_{e} C_{i j}\right)+n_{i} \sum_{k=i+1}^{\bar{C}}\left(B_{i k} \bar{J}_{i k}+n_{e} C_{i k}\right)
\end{aligned}
$$

onde $\mathrm{A}_{i j}, \mathrm{~B}_{i j}$ são os coeficientes de Einstein das transições radiativas e $\mathrm{C}_{i j}$ as taxas das transições colisionais (na equação 2.6 os termos devido à recombinação do contínuo e três corpos, assim como os da fotoionização radiativa e colisional foram excluídos, mas estes também devem ser levados em conta (Sen, 1998)).

A estas relações deve-se agregar a equação de conservação da energia, conservação de carga e conservação do número de partículas. Uma solução auto-consistente deste sistema de equações levaria um esforço computacional gigantesco, ainda mais se levamos em conta que a geometria de um disco de acresção obrigaria à utilização de um espaço tridimensional para as soluções, o que nas atuais circunstâncias é impossível de implementar computacionalmente. 
Equação de transferência radiativa no sistema co-móvel (CMF)

Devido ao esforço que levaria a solução auto-consistente do sistema completo de equações descrito no parágrafo anterior, os métodos de estudo de estrelas quentes com vento realizam aproximações que, com a ajuda dos dados observacionais tornam factível a análise física destes objetos. Um dos principais problemas que aparecem ao tentar resolver o sistema de equações é que tanto a opacidade como a emissividade em cada ponto do gás dentro do meio em movimento são anisotrópicas. Isto ocorre devido a sua dependência com a frequência e ao deslocamento Doppler provocado pelos gradientes de velocidade presentes no meio. Devido a isto um dos mais robustos métodos para o cálculo da estrutura destas atmosferas utiliza um sistema de coordenadas co-móvel com o meio (CMF). Neste sistema tanto a emissividade como a opacidade são isotrópicas e o segundo termo das equações de equilíbrio estatístico (eq. 2.5) seria zero.

Neste trabalho, considerando o vento de um disco geometricamente fino, uma geometria plano-paralela foi implementada. A equação de transferência radiativa nesse caso no sistema CMF é:

$$
\mu \frac{d I_{\nu}}{d z}-\left[\left(\frac{\mu \nu}{c}\right) \frac{\partial v}{\partial z}\right] \frac{\partial I_{\nu}}{\partial \nu}=\eta_{\nu}-\chi_{\nu} I_{\nu}
$$

onde $\mu=\cos i, I_{\nu}$ é a intensidade específica, $\nu$ a frequência, $\eta_{\nu}$ a emissividade e $\chi_{\nu}$ a opacidade. Todas estas magnitudes medidas no sistema CMF. Esta equação nos leva ao sistema equações dos momentos angulares da intensidade específica:

$$
\begin{aligned}
& \frac{d H_{\nu}}{d z}-\left[\left(\frac{\nu}{c}\right) \frac{\partial v}{\partial z}\right] \frac{d H_{\nu}}{d \nu}=\eta_{\nu}-\chi_{\nu} J_{\nu} \\
& \frac{d K_{\nu}}{d z}-\left[\left(\frac{\nu}{c}\right) \frac{\partial v}{\partial z}\right] \frac{d K_{\nu}}{d \nu}=-\chi_{\nu} H_{\nu}
\end{aligned}
$$

onde:

$$
\left[J_{\nu}, H_{\nu}, K_{\nu}\right]=\frac{1}{2} \int_{-1}^{+1} I_{\nu}\left[1, \mu, \mu^{2}\right] d \mu
$$

Definindo o fator de Eddington como: 


$$
f_{\nu}=K_{\nu} / J_{\nu}
$$

o qual suponha-se conhecido na primeira iteração, temos que o sistema:

$$
\begin{aligned}
\frac{d H_{\nu}}{d z}-\left[\left(\frac{\nu}{c}\right) \frac{\partial v}{\partial z}\right] \frac{d H_{\nu}}{d \nu} & =\eta_{\nu}-\chi_{\nu} J_{\nu} \\
\frac{d\left(f_{\nu} J_{\nu}\right)}{d z}-\left[\left(\frac{\nu}{c}\right) \frac{\partial v}{\partial z}\right] \frac{d\left(f_{\nu} J_{\nu}\right)}{d \nu} & =-\chi_{\nu} H_{\nu}
\end{aligned}
$$

é formado por duas equações com duas incógnitas $\left(\mathrm{H}_{\nu}\right.$ e $\left.\mathrm{J}_{\nu}\right)$. Resolvendo este sistema, são calculados novos valores para $f_{\nu}$ até que a convergência é atingida (Mihalas, 1978).

Para resolver este sistema de equações através da atmosfera recorre-se ao método de discretização de Mihalas et al. (1975, 1976b). Onde este sistema obtém a forma:

$$
\begin{aligned}
\boldsymbol{T}_{m} \cdot \boldsymbol{J}_{m} & =\boldsymbol{X}_{m}+\boldsymbol{U}_{m} \cdot \boldsymbol{J}_{m-1}+\boldsymbol{V}_{\boldsymbol{m}} \cdot \boldsymbol{H}_{m-1} \\
\boldsymbol{H}_{m} & =\boldsymbol{A}_{m} \cdot \boldsymbol{J}_{m}+\boldsymbol{B}_{m} \cdot \boldsymbol{H}_{m-1}
\end{aligned}
$$

Onde $\mathrm{N}_{D}$ é o numero de pontos da grade espacial, $m$ é o índice da freqüência, $\boldsymbol{J}$ é o vector da intensidade específica média de tamanho $\mathrm{N}_{D}, \boldsymbol{H}$ é o vector fluxo de dimensão $\mathrm{N}_{D^{-}}$, $\boldsymbol{T}$ uma matriz tri-diagonal de dimensões $\mathrm{N}_{D} \times \mathrm{N}_{D}, \boldsymbol{U}$ uma matriz diagonal de dimensões $\mathrm{N}_{D} \times \mathrm{N}_{D}, \boldsymbol{V}$ uma matriz bi-diagonal inferior de dimensões $\mathrm{N}_{D} \times\left(\mathrm{N}_{D^{-}}-1\right), \boldsymbol{A}$ uma matriz bidiagonal superior de dimensões $\left(\mathrm{N}_{D^{-}}-1\right) \times \mathrm{N}_{D}, \boldsymbol{B}$ uma matriz de dimensões $\left(\mathrm{N}_{D^{-}}-1\right) \times\left(\mathrm{N}_{D^{-}}-1\right)$ e $\boldsymbol{X}$ um vector de dimensões $\mathrm{N}_{D}$. Este sistema é resolvido por linearização e nos fornece o valor da intensidade média para cada ponto da grade espacial para cada freqüência.

\section{Equações de equilíbrio estatístico}

O sistema de equações de equilíbrio estatístico é resolvido mediante um método de Newton-Raphson multidimensional análogo ao de completa linearização desenvolvido por Auer e Mihalas (1969c). Usando as populações que provêm de um modelo convergido semelhante ao qual queremos calcular, avaliamos as equações de equilíbrio radiativo. Estas populações serão então inconsistentes com o campo de radiação dentro deste sistema. 
Para encontrar as correções para as populações se procede à linearização do sistema que compreende as equações de equilíbrio estatístico, a conservação de carga, a equação de equilíbrio radiativo e de conservação de partículas, para formar assim um sistema da forma:

$$
\partial \boldsymbol{S}_{d} \cdot \delta \boldsymbol{n}_{d}=\delta \boldsymbol{S}_{d}
$$

onde $\partial \boldsymbol{S}$ é a matriz de linearização do sistema de equações de tamanho $\mathrm{N}_{C} \times \mathrm{N}_{T}$, onde $\mathrm{N}_{T}$ é o número de incógnitas (populações dos níveis, temperatura eletrônica, densidade eletrônica e campo de radiação) em cada ponto da grade espacial, $\mathrm{N}_{C}$ é o número de equações no sistema, $\delta \boldsymbol{S}$ é um vector de tamanho $\mathrm{N}_{C}$ contendo o correspondente erro nas equações quando avaliadas com as populações atuais e $\delta \boldsymbol{n}$ é um vetor da forma:

$$
\left(\delta n_{1 d}, \ldots, \delta n_{N d}, \delta N_{e}, \delta T_{d}, \delta J_{1 d}, \delta J_{2 d}, \ldots, \delta \bar{J}_{1 d}, \delta \bar{J}_{1 d}, \ldots\right)
$$

que contêm as correções a serem aplicadas a todas as incógnitas. As correções para o campo de radiação $\delta J_{m d}$, podem ser eliminadas a partir de $\delta n, \delta T_{e}$ e $\delta N_{e}$ através da equação de trasporte radiativo.

Devido ao grande número de níveis e de freqüências necessárias para o cálculo da estrutura da atmosfera, o esforço computacional ainda é muito grande. Isto leva a um tempo de processamento considerável que cresce com $\mathrm{N}_{C}^{3}$. Existe uma técnica desenvolvida por Anderson (1989, 1991)(veja também Hubeny e Lanz, 1995) que agrupa um número de níveis com similares energias em somente um nível que é comumente conhecido como supernível. Assim, este supernível é utilizado no sistema de equações de equilíbrio, e a sua população avaliada pelo coeficiente do desvio do equilíbrio termodinâmico local $b$, correspondente à este supernível é igualado aos coeficientes de todos os níveis que ele agrupa (Hillier e Miller, 1998). Assim temos que:

$$
\begin{aligned}
\sum_{i} n_{i j} & =S_{n_{j}} \\
\sum_{i} n_{i j}^{*} & =S_{n_{j}^{*}} \\
b_{i j}=n_{i j} / n_{i j}^{*} & =S_{n_{j}} / S_{n_{j}^{*}}
\end{aligned}
$$


onde $n_{i j}$ é a população do nível $i$ que corresponde ao supernível $j, n_{i j}^{*}$ e a população do mesmo nível em LTE e $S_{n_{j}}$ é a população do supernível calculado com o sistema de equações de equilíbrio.

Equação de equilíbrio radiativo

Dentro do sistema de equações de equilíbrio está incluída a de conservação da energia que no nosso caso é avaliada pela equação de equilíbrio radiativo:

$$
\int_{0}^{\infty} \chi_{\nu}\left[J_{\nu}-S_{\nu}\right] d \nu=0
$$

Esta condição, junto com as equações de equilíbrio estatístico é equivalente à condição do balanço de energia de eléctrons livres:

$$
\frac{3}{2} \frac{d\left(k T_{e} N_{e}\right)}{d t}=4 \pi \int_{0}^{\infty} \chi_{\nu}\left[J_{\nu}-S_{\nu}\right] d \nu+\sum_{i} h \nu_{i} \frac{d n_{i}}{d t}
$$

onde o termo da esquerda avalia a variação de energia dos elétrons livres, já o segundo termo avalia a taxa de resfriamento dos elétrons. Se estes dois termos são identicamente iguais a 0, se cumpriria exatamente a condição de balanço de energia. Mas na prática esta condição não é cumprida, mesmo que as outras duas condições sejam satisfeitas separadamente. Esta inconsistência aparece devido ao uso dos superníveis (Hillier e Miller, 1998; Hillier, 2003).

Equações hidrodinâmicas e parâmetros de entrada

Como foi mencionado na seção 2.1.1 a resolução do sistema de equações 2.2 seria muito complexo e computacionalmente inviável nas condições atuais. A primeira aproximação feita neste trabalho foi que as estruturas de atmosfera com vento são calculadas na geometria plano-paralela. Mas ainda nessa aproximação o sistema de equações hidrodinâmicas é fortemente acoplado ao sistema equações de equilíbrio e à equação de transferência, já que a aceleração radiativa é fortemente sensível às mudanças nos níveis atômicos devido à forte não linearidade destes fenômenos. 
Neste trabalho adotamos o método utilizado no código CMFGEN, no qual as propriedades dinâmicas do vento são colocadas a priori, evitando assim resolver a equação de conservação de momento. Estas propriedades são o perfil vertical de velocidades e a taxa de perda de massa, que por sua vez proporcionam o perfil vertical de densidade através da equação de conservação da massa. A dinâmica do gás vem a ser então uma das entradas do método. O CMFGEN, mesmo na geometria plano-paralela, usa como parâmetros de entrada similares àqueles utilizados para o cálculo de ventos com geometria esférica em estrelas. Estes parâmetros são a luminosidade fotosférica $\left(\mathrm{L}_{*}\right)$ e a taxa de perda de massa total $\left(\dot{\mathrm{M}}_{v}\right)$. Estes parâmetros corresponderiam, caso plano paralelo à temperatura efetiva e a um fluxo de perda de massa superficial $(\dot{m})$, que da equação de conservação de massa vem definido como:

$$
\dot{m}=A \rho(z) v(z)
$$

aqui, $\dot{m}$ teria unidades de gr s $\mathrm{s}^{-1} \mathrm{~cm}^{-2}$ e $A$ é um fator geométrico que simula a expansão do gás, por exemplo no caso esférico $A=r^{2} / R_{*}^{2}$ (Vitello e Shlosman, 1988). Daqui temos que para cada modelo os parâmetros físicos encontrados localmente no disco de acresção são associados aos parâmetros de uma estrela levando em conta as seguintes relações:

$$
\begin{aligned}
R_{*} & =10.051 R_{\odot} \\
L_{*} & =4 \pi \sigma R_{*}^{2} T_{e f f}^{4} \\
\dot{M}_{v} & =4 \pi R_{*}^{2} \dot{m}(R)
\end{aligned}
$$

onde $\sigma$ é a constante de Stefan-Boltzmann. Estes parâmetros de entrada são inseridos no código nas seguintes unidades: $\mathrm{R}_{*}$ em $\mathrm{R}_{\odot}, \mathrm{L}_{*}$ em $\mathrm{L}_{\odot}$ e $\dot{\mathrm{M}}_{v}$ em $\mathrm{M}_{\odot}$ ano ${ }^{-1}$. Também como parâmetro de entrada temos a escolha das espécies atômicas que serão incluídas no cálculo da estrutura do vento, os estados de ionização para cada espécie, o número de níveis e superníveis para cada estado de ionização e a abundância de cada espécie atômica que neste trabalho foram assumidas como sendo solares. Também é necessário para o cálculo definir o número de pontos que terá a grade vertical $N_{D}$. 
Uma questão importante é o perfil de velocidades do vento, este perfil pode ser colocado como uma lei $\beta$ usualmente utilizada em estrelas quentes, ou como um perfil pré-calculado qualquer. Neste trabalho, inicialmente foram calculados modelos usando o perfil de velocidades tipo estelar para cada anel do disco. Este perfil vertical de velocidades reproduz a estrutura de densidade da fotosfera do disco até o ponto onde $\tau_{R}=1$ no modelo fotosférico (seção 2.2). Desde esse ponto cada vento obedece a um perfil de velocidades tipo $\beta$ (Knigge et al., 1995):

$$
v(z)=v_{o}+\left(v_{e s c}-v_{o}\right)\left[\frac{\left(\frac{z-z_{o}}{z_{h}}\right)^{\beta}}{\left(\frac{z-z_{o}}{z_{h}}\right)^{\beta}+1}\right],
$$

onde $v_{e s c}=\sqrt{2 G M_{1} / R}$ é velocidade de escape no plano do disco em $R, v_{o}=0, z_{o}$ é ajustado para que a velocidade no ponto de conexão $z_{c}$ coincida com o valor fotosférico naquele ponto, $z_{h}$ é a escala de aceleração do vento e $\beta$ o exponente da lei de aceleração que neste caso foi usado um valor igual a 4 .

A seguir foi derivado um perfil de velocidades resolvendo a equação de Euler para as condições de gravidade e temperatura encontradas localmente no disco em cada raio. O método desenvolvido para calcular estes perfis de velocidade é descrito na seção seguinte. Este trabalho está focado principalmente neste tipo de perfil.

\subsection{Campo Vertical de Velocidades - A lei de aceleração em discos}

Neste trabalho foi desenvolvido um método para calcular o perfil de velocidades do vento no sentido vertical (z) para cada atmosfera calculada. Este método esta baseado em trabalhos preliminares (p.e. Vitello e Shlosman, 1988; Pereyra et al., 1997; Gayley et al., 1999; Feldmeier e Shlosman, 1999; Feldmeier et al., 1999). Nestes trabalhos a equação de momento no sentido vertical é resolvida levando em conta a física local do disco. No caso de Feldmeier e Shlosman (1999) também é analisado o caso de linhas de fluxo inclinadas com relação à vertical. O sistema de equações hidrodinâmicas está formado pela equação de conservação de massa e de momento. Resolvemos este sistema para um fluxo de massa vertical que escapa da superfície do disco submetido à componente vertical da gravidade da anã branca, às forças de pressão e às forças radiativas no contínuo e nas linhas. No 
último caso, esta força é parametrizada da acordo com a aproximação CAK75. Assim, o sistema de equações hidrodinâmicas uni-dimensional seria:

$$
\begin{aligned}
P & =b^{2} \rho \\
\rho v_{z} A & =\dot{m}(R) \\
\rho v_{z} \frac{d v_{z}}{d z} & =-\rho \frac{G M z}{\left(R^{2}+z^{2}\right)^{3 / 2}}+\rho \frac{\sigma_{e}^{r e f} F}{c}\left[1+k\left(\frac{1}{\rho \sigma_{e}^{r e f} c} \frac{d v_{z}}{d z}\right)^{\alpha}\right]-\frac{d P}{d z}
\end{aligned}
$$

aqui $P$ é a pressão do gás, $b$ é velocidade do som, $\rho$ a densidade, $\dot{m}$ é o fluxo de perda de massa local, $\sigma_{e}^{r e f}$ é a opacidade de Thomsom do espalhamento eletrônico (neste trabalho usou-se o valor referencial definido na seção 1.4), G é a constante gravitacional e $c$ a velocidade da luz. Neste sistema, $A$ simula a expansão do gás depois que abandona a superfície do disco. Nestas simulações foram usadas funções que mimetizam uma expansão hiperbólica, ou seja, que na superfície do disco as linhas de fluxo sejam verticais inclinandose assintoticamente até um ângulo de $45^{\circ}$ no infinito. Este tipo de expansão pode ser reproduzida com um fator $A=\left(1+z^{2} / R^{2}\right)$.

Os fatores CAK75, $\alpha$ e $k$, avaliam a força radiativa nas linhas. Estes parâmetros estão fisicamente relacionados com a distribuição das linhas com a opacidade e com a relação entre as linhas opticamente espessas e opticamente finas consideradas para a força radiativa. Assim, para $\alpha=1$ somente são consideradas linhas opticamente espessas e para $\alpha=0$, somente linhas opticamente finas. Estes parâmetros não são independentes um do outro, como foi apontado por Gayley (1995)(vide também Castor et al., 1975). No caso de discos de acresção, o comportamento da gravidade no sentido vertical limita os valores permitidos para $\alpha$. Como é mostrado na equação 2.28, a gravidade tem um comportamento muito diferente ao das estrelas; em discos esta cresce fortemente até atingir um valor máximo para depois decrescer até que a grandes distâncias, recupera a forma estelar. Portanto, para que o vento consiga ser expelido é necessário que a força radiativa nas linhas seja a suficiente para superar esta barreira gravitacional. Essa condição se traduz numa profundidade óptica mínima nas linhas, ou um limite inferior do valor de $\alpha$. Usando um modelo hidrodinâmico uni-dimensional, Pereyra et al. (1997) encontraram $\alpha \gtrsim 0.5$ para que a força radiativa supere a barreira gravitacional. Devido à dependência de $\alpha$ 
com o estado de ionização do gás (Abbott, 1982), é evidente que a estrutura de ionização é crucial para a existência ou não de vento no caso de discos de acresção (Vitello e Shlosman, 1988). Outra característica importante de ventos em discos é que o campo radiação contém contribuições provenientes de regiões diferentes do disco, o que provoca um aumento da radiação com a altura em regiões próximas à fotosfera do disco, o que também contribui para a força radiativa.

Na equação 1.27, $F$ representa o fluxo de radiação que chega a um determinado ponto do vento e que promove a força radiativa, tanto no contínuo como na linha. Como o disco de acresção não é isotérmico, o fluxo em determinado ponto do vento recebe contribuições de regiões de diferentes temperaturas e distâncias. Isto leva a que $F$ não seja constante, mas uma função da altura z. Neste trabalho nos baseamos em funções analíticas que mimetizam o comportamento do fluxo com altura. Foi utilizada a relação proposta por Pereyra et al. (1997) onde é calculada aproximadamente a contribuição do disco completo ao fluxo de radiação num ponto do vento. Também foram estudadas outras formas para o perfil do fluxo, estas funções são as mesmas que Pereyra et al. (2004) usaram na análise da existência de soluções estacionárias de ventos em discos de acreção. Seguindo a mesma nomenclatura destes autores, aqui são definidos os modelos " $I$ " para atmosferas internas e "O" para atmosferas externas. Assim, temos que a o fluxo é parametrizado como:

$$
F_{1}=\sigma T^{4}(R) \frac{1}{1+(z / R)^{2}}\left(\frac{z}{\sqrt{R^{2}+z^{2}}}\right)^{\alpha}
$$

ou:

$$
F_{2}= \begin{cases}\sigma T^{4}(R)\left(\frac{1}{1+(z / 2 R)^{2}}\right) & \text { para modelos } I \\ \sigma T^{4}(R)\left(\frac{1+[(z / R) /(1+z / R)]}{1+(z / R)^{2}}\right) & \text { para modelos } O\end{cases}
$$

onde $T(R)$ corresponde à temperatura fotosférica do disco dada pela equação $1.15, \mathrm{~F}_{1}$ é a distribuição usada por Pereyra et al. (1997) e $\mathrm{F}_{2}$ corresponde aos modelos "I" e "O", respectivamente tais como usados por Pereyra et al. (2004).

\subsubsection{Existência das soluções e ponto crítico}

Substituindo a equação de conservação de massa na equação de momento e se realizarmos as seguintes definições: 


$$
\begin{aligned}
\omega & =\frac{v^{2}}{v_{o}^{2}} \\
x & =\arctan (z / R) \\
a & =\sec ^{2}(x) \\
s & =\frac{b^{2}}{v_{o}^{2}} \\
\dot{m} & =\dot{m}(R) / \dot{m}_{o}, \\
\dot{m}_{o} & =\alpha(1-\alpha)^{(1-\alpha) / \alpha} \gamma_{o}^{1 / \alpha}\left(\frac{2 R}{v_{o}^{2}}\right)^{(1-\alpha) / \alpha} \\
\gamma_{o} & =\frac{\sigma_{e}^{r e f} \sigma T^{4}(R) k}{c}\left(\frac{1}{\sigma_{e}^{r e f} v_{t h}}\right)^{\alpha} \\
f & =\frac{1}{\alpha^{\alpha}(1-\alpha)^{1-\alpha}} \zeta(x) \\
g & =\frac{\sin ^{2}(x)}{\sec ^{2}(x)}-\frac{\sigma_{e}^{r e f} \sigma T^{4}(R) R^{2}}{c G M_{1}} \cos ^{2}(x),
\end{aligned}
$$

verificamos, para o caso de um vento isotérmico, que a à equação do movimento do gás é dada por:

$$
\left(1-\frac{s}{\omega}\right) \frac{d \omega}{d x}=-g a+f a\left(\frac{1}{\dot{m}} \frac{d \omega}{d x}\right)^{\alpha}+\frac{2 s}{a} \frac{d a}{d x}
$$

onde $v_{o}=\sqrt{2 G M_{1} / R}$ é a velocidade de escape no plano do disco, $b=\sqrt{k_{B} T(R) / \mu m_{H}}$ é a velocidade do som através do vento, $\mu=1.28$ é o peso molecular próximo do valor solar, $m_{H}$ é a massa do proton e $k_{B}$ é a constante de Boltzmann. A função $\zeta(x)$ avalia a distribuição da componente vertical da radiação, dada pelas equações:

$$
\begin{aligned}
& \zeta_{1}(x)=\sin ^{\alpha}(x) \cos ^{2}(x) \\
& \zeta_{2}(x)= \begin{cases}\frac{4}{4+\tan ^{2}(x)} & I \text { case } \\
\frac{1+2 \tan (x)}{1+\tan (x)} \cos ^{2}(x) & O \text { case }\end{cases}
\end{aligned}
$$

onde $\zeta_{1}$ e $\zeta_{2}$ são as correspondentes transformações das funções $F_{1}$ e $F_{2}$ normalizadas ao fluxo do disco $\sigma T^{4}(R)$. O comportamento destas funções é mostrado na fig 2.1. 


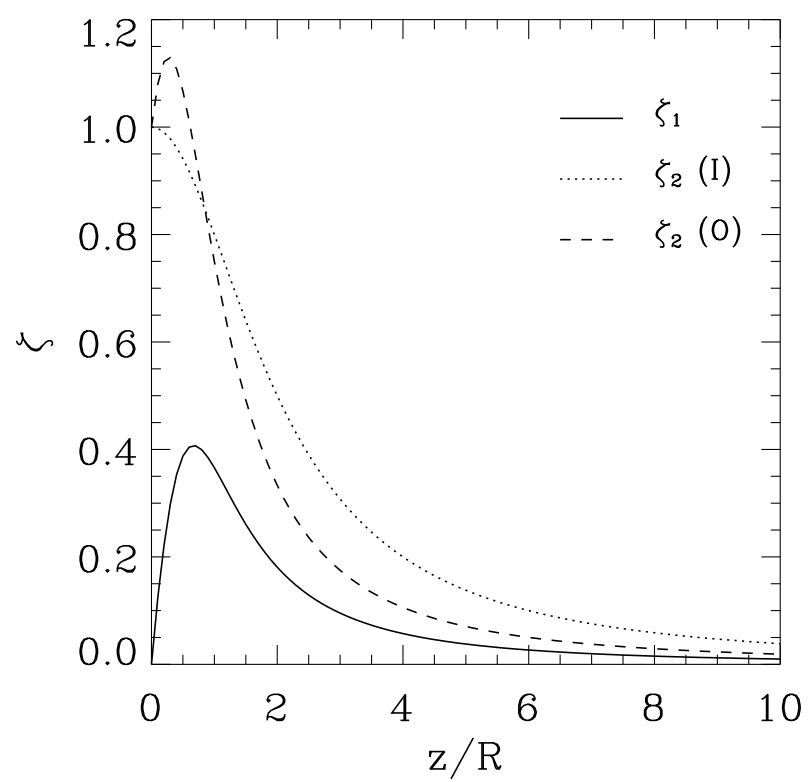

Figura 2.1: Funções $\zeta_{1}, \zeta_{2}(\mathrm{I})$ e $\zeta_{2}(\mathrm{O})$ utilizados para mimetizar a comportamento da radiação sobre o disco de acresção. Aqui, $\zeta_{1}$ é calculada usando um valor de $\alpha=0.9$.

Aqui seguiremos o raciocínio de Pereyra et al. (2004) baseado naquele usado por CAK75 em estrelas. A equação 2.34 é uma equação diferencial não linear em $d \omega / d x$ que pode ser expressa como:

$$
G\left(x, w, w^{\prime}\right)=0
$$

Esta expressão e a equação 2.34 é uma generalização das equações de Euler para ventos em geral como foi apontado por Pereyra et al. (2004) e os critérios de existência são aplicados tanto no caso de discos como no caso de estrelas, tais critérios foram expostos pela primeira vez por Abbott (1980).

A aproximação de um vento isotérmico, não reduz de maneira importante a generalidade do resultado já que Pereyra et al. (2000) demostraram que, para um vento não isotérmico, o perfil de velocidades não muda fortemente se comparado com o caso isotérmico. Assim, definindo:

$$
\begin{aligned}
& h(x)=-g a+\frac{2 s}{a} \frac{d a}{d x}, \\
& \beta(\omega)=1-\frac{s}{\omega},
\end{aligned}
$$


A equação 2.34 fica:

$$
G\left(x, w, w^{\prime}\right)=\beta \frac{d \omega}{d x}-h-f a\left(\frac{1}{\dot{m}} \frac{d \omega}{d x}\right)^{\alpha}=0
$$

Aqui $h(x)$ avalia a diferença entre a força gravitacional (corrigida pelo espalhamento eletrônico) e a força devida à expansão do gás expressa pelo gradiente da pressão. Esta função define o ponto de Parker $\left(\mathrm{R}_{P}\right)$, que é o ponto no qual a força de expansão do gás supera a força de gravidade, ou seja quando $h(x)=0$. No caso estelar, este ponto é comumente atingido antes de alcançar a velocidade terminal. No caso das nossas simulações este ponto nunca é atingido devido à forte gravidade.

Definimos agora a função de gargalo (nozzle function):

$$
n(x)=\alpha(1-\alpha)^{(1-\alpha) / \alpha} \frac{(f a)^{1 / \alpha}}{-h^{(1-\alpha) / \alpha}}
$$

Esta função surge da analogia existente entre o problema de ventos acelerados por linhas e os ventos supersônicos acelerados por pressão. A função gargalo é utilizada para encontrar o "ponto crítico" de conexão contínua entre duas soluções da equação de momento de nossos ventos, no mesmo contexto que o ponto sônico conecta às regiões subsônica da supersônica nos ventos acelerados por pressão (Abbott, 1980; Pereyra et al., 2004).

É possível separar no plano $(w, x)$ diferentes regiões onde a equação de movimento tem solução ou não e estudar ali as características das mesmas (Pereyra, 2005):

Região I: $\omega<s$ e $h(x)<0$ a equação do movimento tem 1 solução.

Região II: $\omega>s, h(x)<0$ e $\beta(\omega) \dot{m}<n(x)$ a equação do movimento tem 2 soluções.

Região III: $\omega>s$ e $h(x)>0$ a equação do movimento tem 1 solução.

Região IV: $\omega>s, h(x)<0$ e $\beta(\omega) \dot{m}>n(x)$ a equação do movimento não tem solução. Região $\mathrm{V}: \omega<s$ e $h(x)>0$ a equação do movimento não tem solução.

A topologia das soluções da equação de movimentos como as diferentes regiões onde estas estão definidas são mostradas na figura 2.2. Daqui podemos ver que para a existência de uma solução que comece na região subsônica e consiga atingir o infinito com velocidade supersônica, é preciso que na região II (onde existem dois ramos de solução) o ramo inferior 
deve encontrar-se continuamente com o ramo superior que por sua vez entrará na região III além do ponto de Parker para o infinito. Existe somente um ponto onde os dois ramos se encontram continuamente na região II, este é o conhecido ponto crítico do sistema, e a solução que passa por esse ponto é conhecida como solução crítica. Esta solução é tangente ao limite entre a região II e IV. Daqui vemos que a taxa de perda de massa é dada pelo ponto crítico $x_{c}$, já que neste ponto deve-se cumprir a condição:

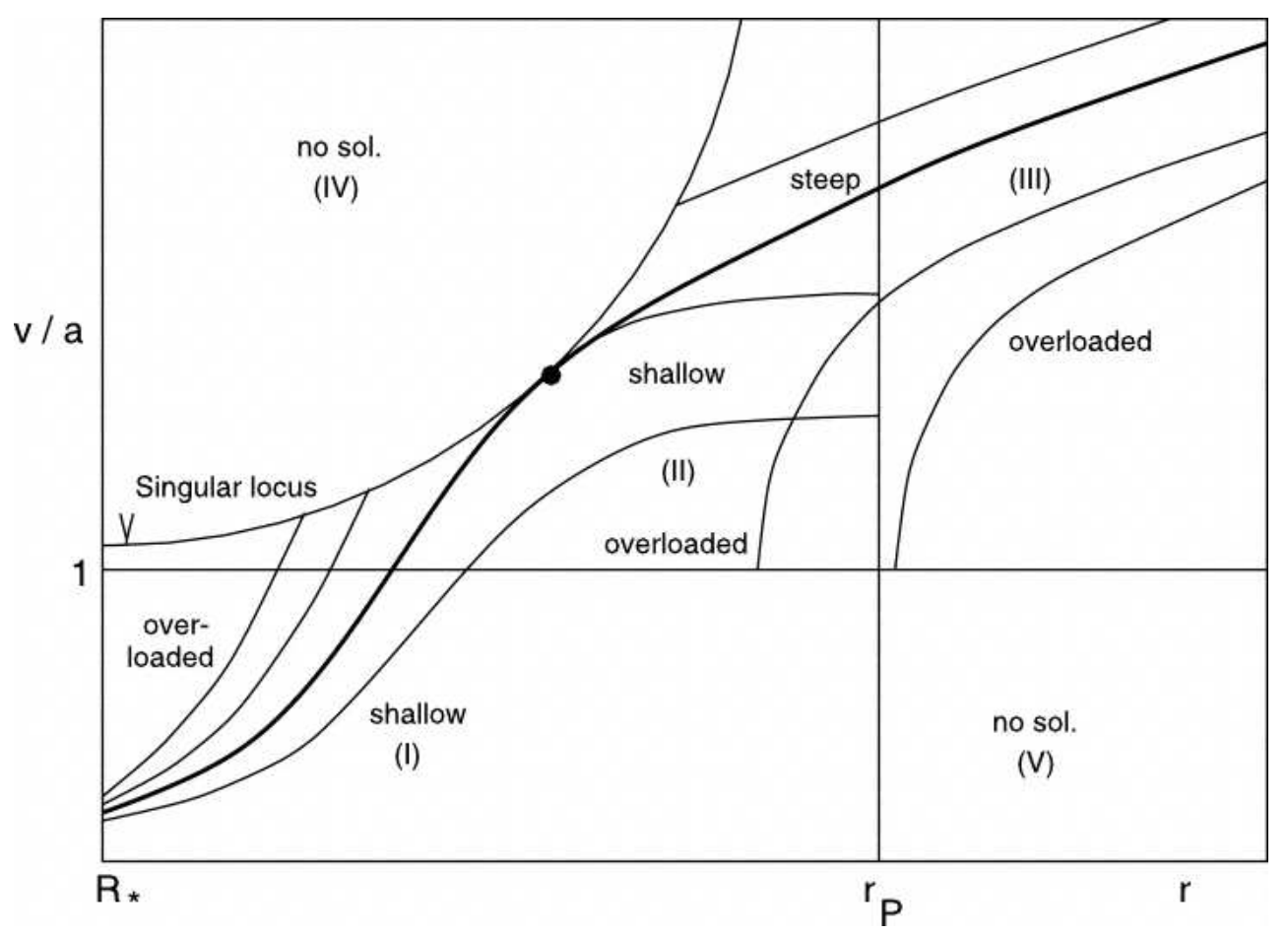

Figura 2.2: Soluções da equação de movimento no plano $(v, x)$. São mostradas as diferentes regiões onde a equação tem 1, 2 ou nenhuma solução. Aqui P é o ponto de Parker como definido no texto. Gráfico tirado de Feldmeier et al. (2002)

$$
\beta\left(\omega_{c}\right) \dot{m}=n\left(x_{c}\right)
$$

Agora, o ponto crítico deve satisfazer algumas condições:

1. Satisfazer a equação de movimento:

$$
G\left(x, w, w^{\prime}\right)=0
$$


2. O ponto crítico deve estar na fronteira entre as regiões II e IV:

$$
\frac{\partial G}{\partial \omega^{\prime}}=0
$$

3. Deve haver continuidade da primeira derivada das soluções $\omega^{\prime}$ :

$$
\frac{\partial G}{\partial x}+\omega^{\prime} \frac{\partial G}{\partial \omega}=0
$$

Além destas condições devem existir soluções nas proximidades envolta do ponto crítico e deve existir uma solução em todo o espaço de integração. Estas duas condições podem ser expressas por (Pereyra, 2005):

$$
\begin{gathered}
h\left(x_{c}\right)<0 \\
\frac{d n}{d x}>0 \\
\beta^{\prime \prime}\left(\omega_{c}\right) \dot{m}\left(\omega_{c}^{\prime}\right)^{2}+\beta^{\prime}\left(\omega_{c}\right) \dot{m} \omega_{c}^{\prime \prime}-n^{\prime \prime}\left(x_{c}\right)<0 \\
\beta(\omega) \dot{m}<n(x)
\end{gathered}
$$

\subsubsection{Cálculo do ponto crítico, $\dot{m}$ e da velocidade terminal $v_{\infty}$.}

Neste trabalho o cálculo do perfil de velocidades vertical foi feito em duas partes. A primeira vai desde o plano do disco até o limite da fotosfera ou $z_{o}=z(\tau=1)$. Nesta região é calculada uma atmosfera de disco plano paralela usando o método de Hubeny (1990) e Wade e Hubeny (1998). A estrutura de densidade destas atmosferas é usada para calcular um perfil de velocidades pela equação de continuidade $v(z)=\dot{m}(R) / \rho(z)$ até $z_{o}$. Também são encontrados os valores da velocidade no ponto $v_{c}=v\left(z_{o}\right)$ e da primeira derivada $v_{c}^{\prime}=\frac{d v}{d z}\left(z_{o}\right)$. A equação de movimento (eq. 2.34) é então resolvida desde $z_{o}$ até uma altura máxima $z_{f}$ impondo como condição de fronteira que $v_{o}=v_{c}$ calculada na fotosfera e que $v_{o}^{\prime}=v_{c}^{\prime}$. O limite $z_{f}$ foi imposto como sendo igual ao raio do disco $R_{\text {disk }}$.

Para cada modelo de atmosfera, o perfil de velocidades é calculado encontrando o ponto crítico e a solução crítica da equação de movimento. Ao encontrar esta solução também encontra-se o valor do fluxo de perda de massa consistente com esta solução. Para encontrar esta solução é usado um método iterativo, tomando um valor inicial fiduciário para $\dot{m}$ a equação 2.34 é resolvida com as condições já expostas. Se a solução entra na região IV, um valor menor para $\dot{m}$ é usado na próxima iteração até encontrar uma solução que não 
entre nessa região. Se a solução não entra na região IV, um valor maior para $\dot{m}$ é usado na próxima iteração até que a solução encontre a região IV. A cada vez que a solução encontra a região IV, o valor de $\dot{m}$ para a próxima iteração toma-se como o valor médio das duas últimas iterações. O critério de convergência utilizado para encontrar a solução crítica foi:

$$
\min \left(\frac{\beta[\omega(x)] \dot{m}}{n(x)}-1\right)<10^{-5}
$$

O ponto crítico $x_{c}$ é a coordenada onde encontra-se este mínimo. Uma vez encontrado este ponto e o valor correspondente de $\dot{m}$, mais um vez é integrada a equação 2.34 forçando que além do ponto crítico sejam calculados os dois ramos de soluções da região II. Esta solução é depois confirmada confrontando-a com as condições de existência descritas anteriormente (equações 2.43 - 2.49). Neste trabalho em nenhum dos casos foi atingido o ponto de Parker em todo o intervalo de integração $\left[z_{o}, z_{f}\right]$. Por tanto as duas soluções existem nesse espaço. A cada iteração um Runge-Kutta de ordem 4 foi utilizado para resolver a equação de movimento. Este método exige que a primeira derivada $\omega^{\prime}$, deve ser expressa isoladamente em função de $\omega$ e $x$. No caso da equação 2.34 é impossível insolar a derivada analiticamente. Devido a isso, em cada passo de solução esta derivada foi isolada numéricamente utilizando o método de Newton-Raphson.

\subsubsection{Simulações}

Neste trabalho foi estudada a influência dos diferentes parâmetros físicos do sistema sobre o perfil de velocidades do vento e suas principais características; a velocidade terminal $\mathrm{v}_{\infty}$ e o fluxo de perda de massa para cada raio $\dot{m}(R)$ no disco. Na figura 2.3 são mostradas as soluções da equação de movimento para um sistema com $\mathrm{M}_{1}=0.8 \mathrm{M}_{\odot}$ e $\dot{\mathrm{M}}_{a}=10^{-8} \mathrm{M}_{\odot}$ $\mathrm{ano}^{-1}$. Os parâmetros do vento utilizados foram $\alpha=0.9$ e $k=0.4$. Verticalmente na figura 2.3 estão distribuídas as soluções de acordo com as diferentes funções $\zeta$ 's, para evidenciar a influência da distribuição de radiação cobre a taxa de perda de massa e a velocidade terminal. Como podemos ver na figura, esta distribuição tem uma forte influência sobre esses fatores; alterando a localização do ponto crítico. Vemos que a função $\zeta_{1}$ (painel superior), cuja principal caraterística é possuir fluxo igual a 0 no plano do disco, traz o ponto crítico para regiões mais internas do vento, isto provoca uma menor taxa de perda 
de massa e também uma menor velocidade de escape no ramo inferior das soluções. Ao contrário, no ramo superior das soluções a velocidade terminal atinge valores extremamente altos que não são observados. Já nos outros casos, quando são utilizadas as outras funções $\zeta_{2}(\mathrm{I})$ e $\zeta_{2}(\mathrm{O})$ (paineis médio e inferior), o ponto crítico encontra-se em uma região mais externa, isso também provoca uma maior perda de massa e também uma maior velocidade terminal no ramo inferior das soluções e velocidades menores, mesmo ainda grandes, no ramo superior.

Na figura 2.4 são mostrados os mesmos perfis mas, neste caso, diferentes valores do parâmetro de aceleração radiativa $\alpha$ são comparados mantendo os mesmos parâmetros físicos. Na comparação também foi fixada a função $\zeta(x)=\zeta_{2}(O)$ para a distribuição vertical da radiação. Vemos que, a exemplo das atmosferas estelares, o parâmetro $\alpha$ também tem uma forte influência sobre o perfil de velocidades e sobre a taxa de perda de massa do disco. Neste caso é claro que o ponto crítico se aprofunda na atmosfera quando $\alpha$ aumenta. Isto leva a um aumento no fluxo de perda de massa. No caso da velocidade terminal, tanto o ramo inferior como o superior acompanham o comportamento de $\alpha$, sendo evidente que quanto maior é este parâmetro, maior é a divergência entre as velocidades terminais dos respectivos ramos. Esta tendência é natural levando em conta que $\alpha$ avalia o número de linhas opticamente espessas que atuam na aceleração radiativa que é $\sim 10^{5}$ vezes maior do que a aceleração por espalhamento eletrônico. Ao aumentar este número de linhas opticamente espessas aumenta tanto a perda de massa como a velocidade terminal do vento. A ordem de magnitude da velocidade terminal varia amplamente como vemos desde uma fração da velocidade de escape até algumas ordens de magnitude vezes maior que a mesma (por exemplo no painel superior direito da figura 2.3). Das observações de espectros no UV, sabe-se que os ventos em VC's apresentam velocidades terminais que vão desde uma fração próxima até umas poucas vezes maior que a velocidade de escape da anã branca, que é da ordem de 3000-6000 $\mathrm{km} \mathrm{s}^{-1}$. Isto limita os valores de $\alpha$ e a função $\zeta$ a serem utilizados para sintetizar os espectros UV de VC's. Assim, vemos que valores de $\alpha$ altos geram valores absurdamente elevados de velocidade terminal no ramo superior das soluções, enquanto que no ramo inferior gera valores razoáveis. Enquanto a função $\zeta_{1}$ provoca velocidades terminais muito altas no ramo superior, no ramo inferior são razoáveis e até menores que a velocidade de escape. No caso das funções $\zeta_{2}(I)$ e $\zeta_{2}(O)$, o fato que suas 


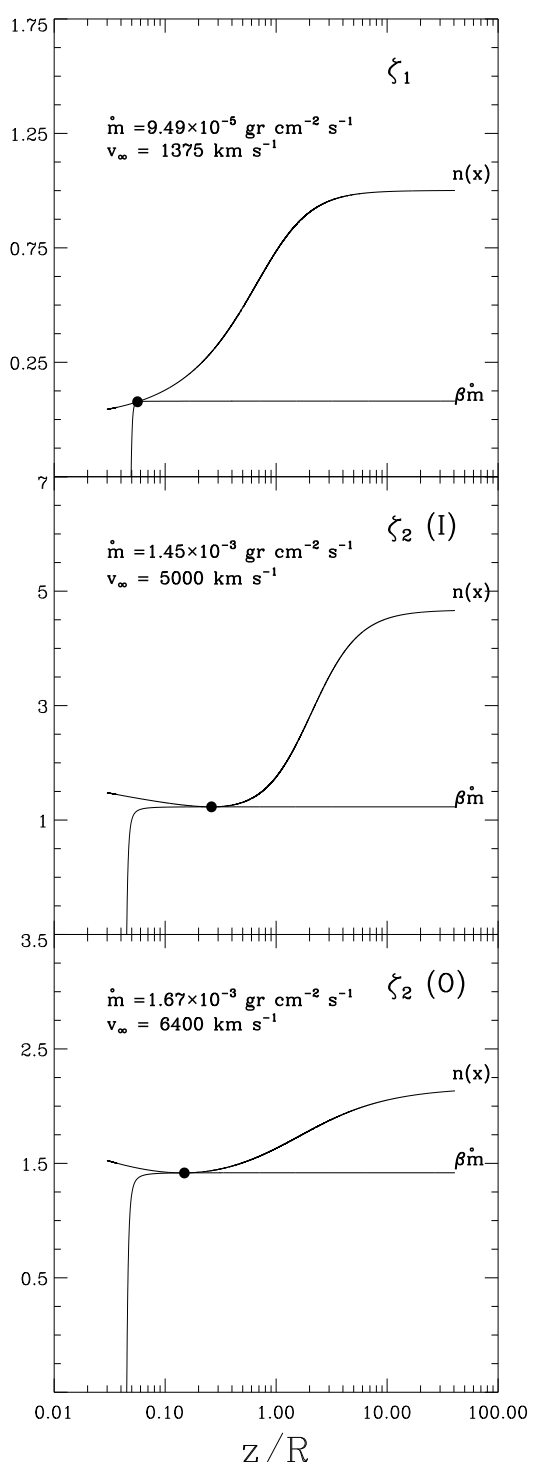

(a) Ponto Crítico

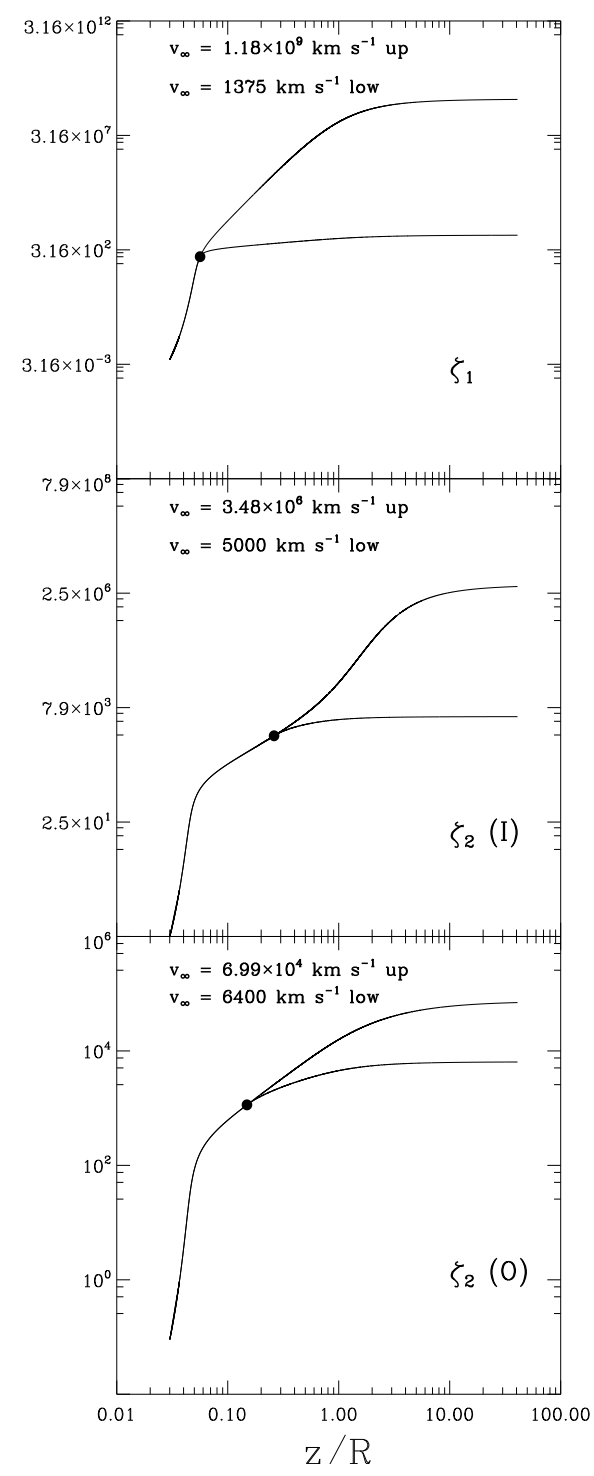

(b) Velocidades $\left(\mathrm{km} \mathrm{s}^{-1}\right)$

Figura 2.3: Soluções da equação de movimento para um modelos com $\mathrm{M}_{1}=0.8 \mathrm{M}_{\odot}, \dot{\mathrm{M}}_{a}=10^{-8} \mathrm{M}_{\odot}$ ano ${ }^{-1}$, com $\alpha=0.9$ e $k=0.4$. Os paineis estão ordenados verticalmente segundo a função $\zeta$ utilizada de cima para abaixo $\left(\zeta_{1}, \zeta_{2}(\mathrm{I})\right.$ e $\left.\zeta_{2}(\mathrm{O})\right)$. No painel esquerdo são mostradas as funções $n$ e $\beta \dot{m}$ que são utilizadas para encontrar o ponto crítico (vide texto). No painel direito os perfis de velocidades são mostrados para as diferentes funções $\zeta$ 's, para os dois ramos dentro da região II. As velocidades terminais para os dois ramos também são dadas.

soluções apresentarem um ponto crítico mais externo faz com que as velocidades terminais do ramo superior sejam menores do que no caso da função $\zeta_{1}$, e as do ramal inferior maiores. Os valores destas velocidades neste caso são da ordem da velocidade de escape no plano do 


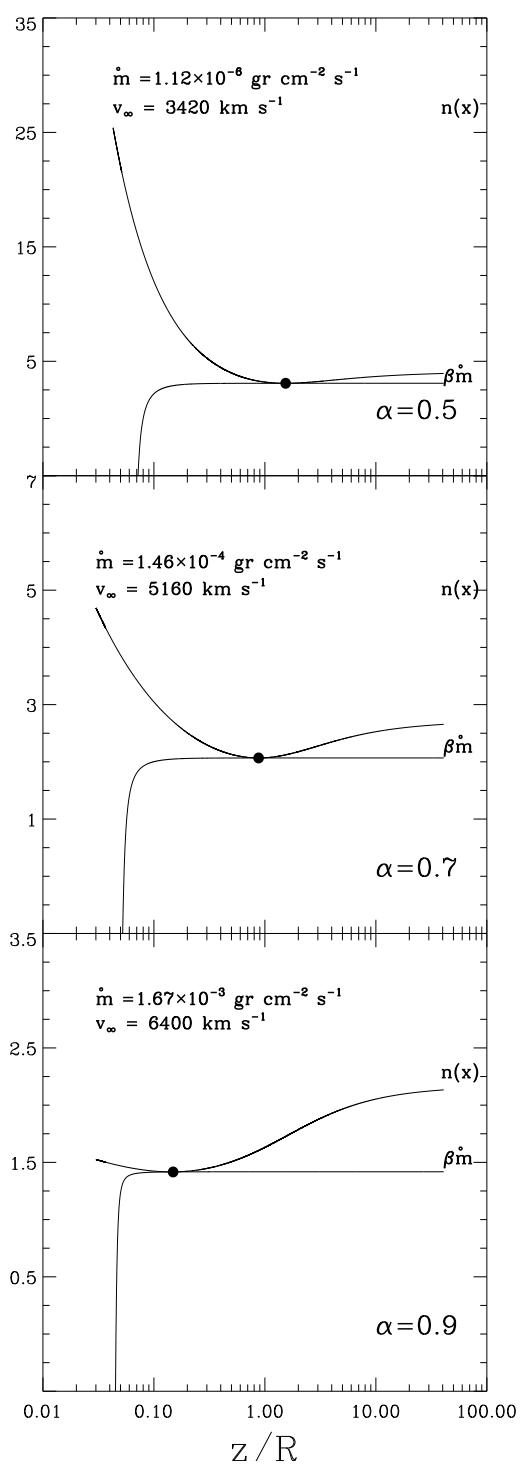

(a) Ponto Crítico

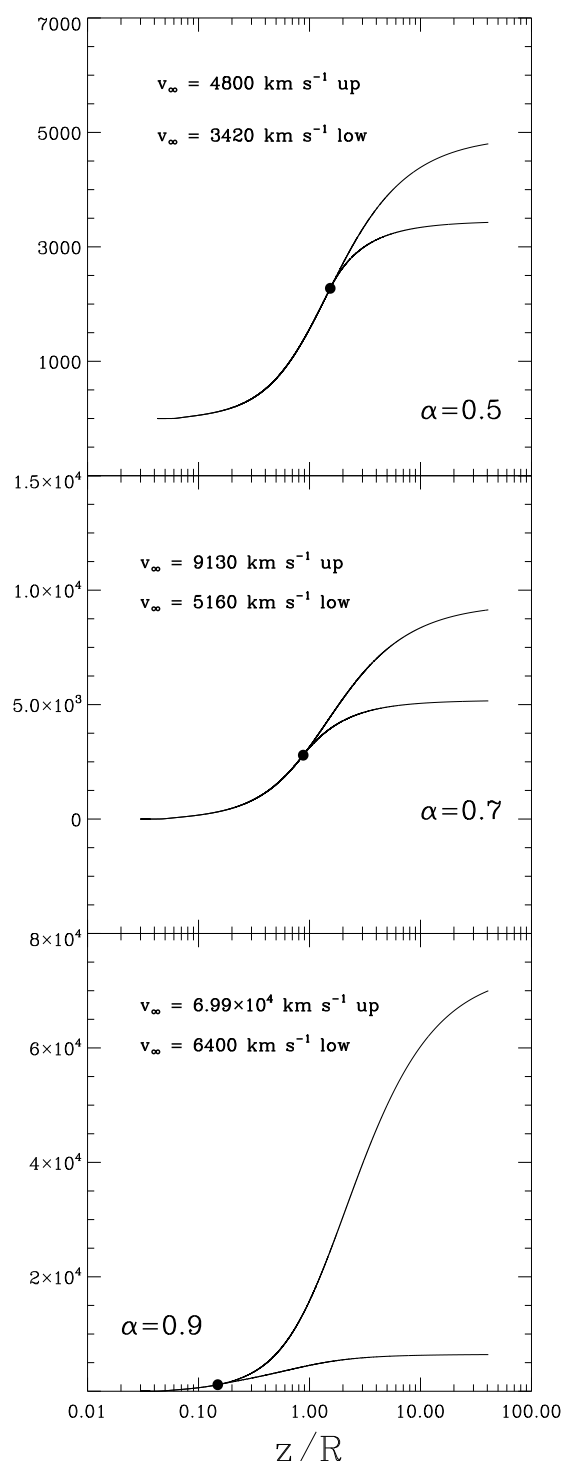

(b) Velocidades $\left(\mathrm{km} \mathrm{s}^{-1}\right)$

Figura 2.4: Soluções da equação de movimento para um modelos com $\mathrm{M}_{1}=0.8 \mathrm{M}_{\odot}, \dot{\mathrm{M}}_{a}=10^{-8} \mathrm{M}_{\odot}$ ano ${ }^{-1}$ e a função $\zeta_{3}$ para a distribuição vertical da radiação. Os paineis estão ordenados verticalmente segundo o parâmetro de aceleração radiativa $\alpha=0.5,0.7$ e 0.9 de cima para abaixo, respectivamente. No painel esquerdo são mostradas as funções $n$ e $\beta \dot{m}$ que são utilizadas para encontrar o ponto crítico (vide texto). No painel direito os perfis de velocidades são mostrados para as diferentes $\alpha$ 's, para os dois ramos dentro da região II. As velocidades terminais para os dois ramos também são dadas.

disco. É claro dos gráficos que estes parâmetros $(\alpha$ e $\zeta$ ) podem ser ajustados de forma tal que o resultado seja consistente com as velocidades observadas nos ventos de VC's. Uma melhor forma de limitar esta extrema degenerescência de parâmetros seria usar funções $\zeta$ 
e valores de $\alpha$ mais realistas para discos, mas como veremos mas adiante, é preciso antes resolver outros problemas que influem mais fortemente na forma dos perfis de linha e do espectro (por exemplo: geometria, estrutura de ionização, transferência radiativa, etc.).

\subsubsection{Cálculo de taxa de perda massa total $\dot{M}_{w}$ no vento.}

Usando o método descrito na seção anterior é possível calcular um valor do fluxo de perda de massa para cada raio do disco. Este fluxo, se integrado da superfície do disco onde o vento é expelido, fornecem a taxa de perda massa total no vento. Isto seria exatamente correto nas proximidades da fotosfera do disco, mas quando o gás abandona esta superfície ele se expande e também é deslocado por causa das forças de Coriolis e centrífuga (vide seção 1.5.2). Assim a estrutura do vento nessas regiões é possivelmente muito mais complexa do que um simples fluxo vertical laminar. Neste trabalho esta forte aproximação foi feita, entretanto, os valores da perda de massa no vento obtidos não discordam muito daqueles calculadas usando modelos hidrodinâmicos complexos (Pereyra et al., 1997, 2000; Pereyra e Kallman, 2003; Proga et al., 1998, 1999).

Como foi apontado na seção anterior o fluxo de perda de massa, assim como a velocidade terminal são fortemente dependentes dos parâmetros utilizados para avaliar a força radiativa nas linhas. Isto é ilustrado da figura 2.5 onde mostra-se o fluxo de perda de massa assim como a velocidade terminal em função do raio do disco. Vemos que a velocidade terminal acompanha o comportamento da velocidade de escape em cada raio, mesmo que com uma inclinação um pouco maior nas regiões mais externas. Também, a dependência com $\alpha$ mostra-se mais evidente nas regiões externas. No caso do fluxo de perda de massa, o seu comportamento acompanha melhor o perfil radial de temperatura efetiva do disco. Este resultado é similar ao encontrado em estrelas onde a taxa de perda de massa é função da luminosidade. Este fato em discos também foi apontado por Pereyra et al. (1997).

Usando esta distribuição radial calculada do fluxo de perda de massa existem duas formas de integrar a taxa de perda de massa total no vento. A primeira seria uma integração numérica da forma:

$$
\dot{M}_{w}=2 \times 2 \pi \int_{R o}^{R f} \dot{m}(R) R d R=4 \pi \sum_{i=1}^{n}\left(\dot{m}\left(R_{i+1}\right) R_{i+1}+\dot{m}\left(R_{i}\right) R_{i}\right)\left(\frac{R_{i+1}-R_{i}}{2}\right)
$$




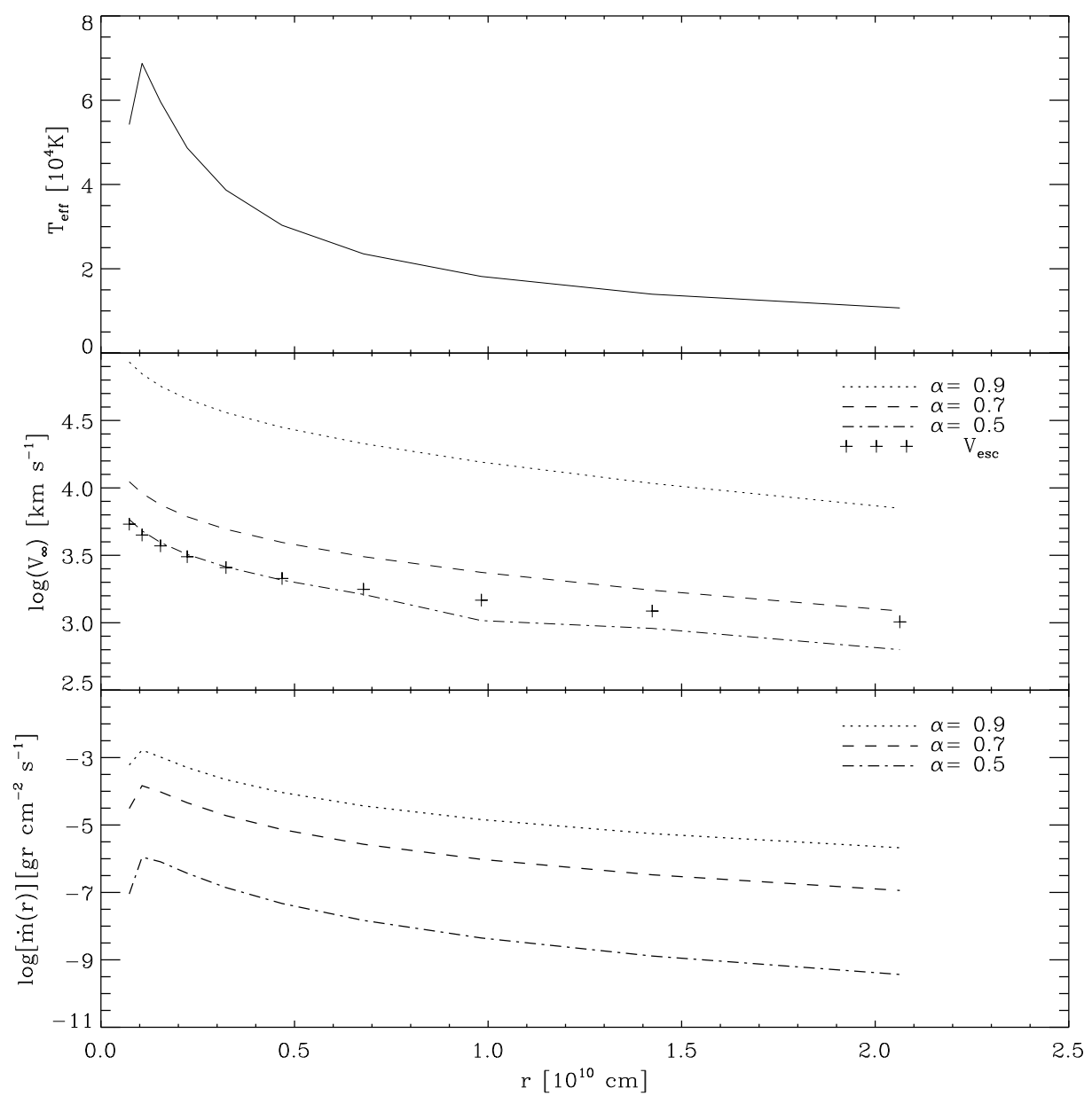

Figura 2.5: Soluções da equação de Euler para um disco com $\mathrm{M}_{1}=1 \mathrm{M}_{\odot}$ and $\dot{\mathrm{M}}_{a c c}=10^{-8}$ $\mathrm{M}_{\odot} \mathrm{yr}^{-1}$. O painel superior mostra o perfil radial de temperatura efetiva do disco. O painel do meio mostra as velocidades terminais para o ramo superior de soluções para três valores de $\alpha$ comparados com a velocidade de escape. O painel inferior mostra os fluxos de perda de massa que resultam de calcular as soluções críticas da equação de movimento.

onde $n$ é o numero de anéis que cobrem a região do disco que expele vento.

A outra forma seria aproximar os valores de $\dot{m}(\mathrm{R})$ por uma lei de potência no raio (eq. 2.52) e integrar diretamente o fluxo entre os raios $\mathrm{R}_{i}$ e $\mathrm{R}_{f}$. Uma ilustração deste método é mostrado da figura 2.6 para um sistema com $\mathrm{M}_{1}=\mathrm{M}_{\odot}, \dot{\mathrm{M}}_{a c}=10^{-9} \mathrm{M}_{\odot} \mathrm{ano}^{-1}$.

$$
\dot{m}(R)=A R^{\lambda}
$$

A aplicação de um ajuste simples de mínimos quadrados de uma lei de potência resulta em uma expressão da forma $\sim r^{-2}$ (eq. 2.53), que resulta ser um perfil muito mais pro- 


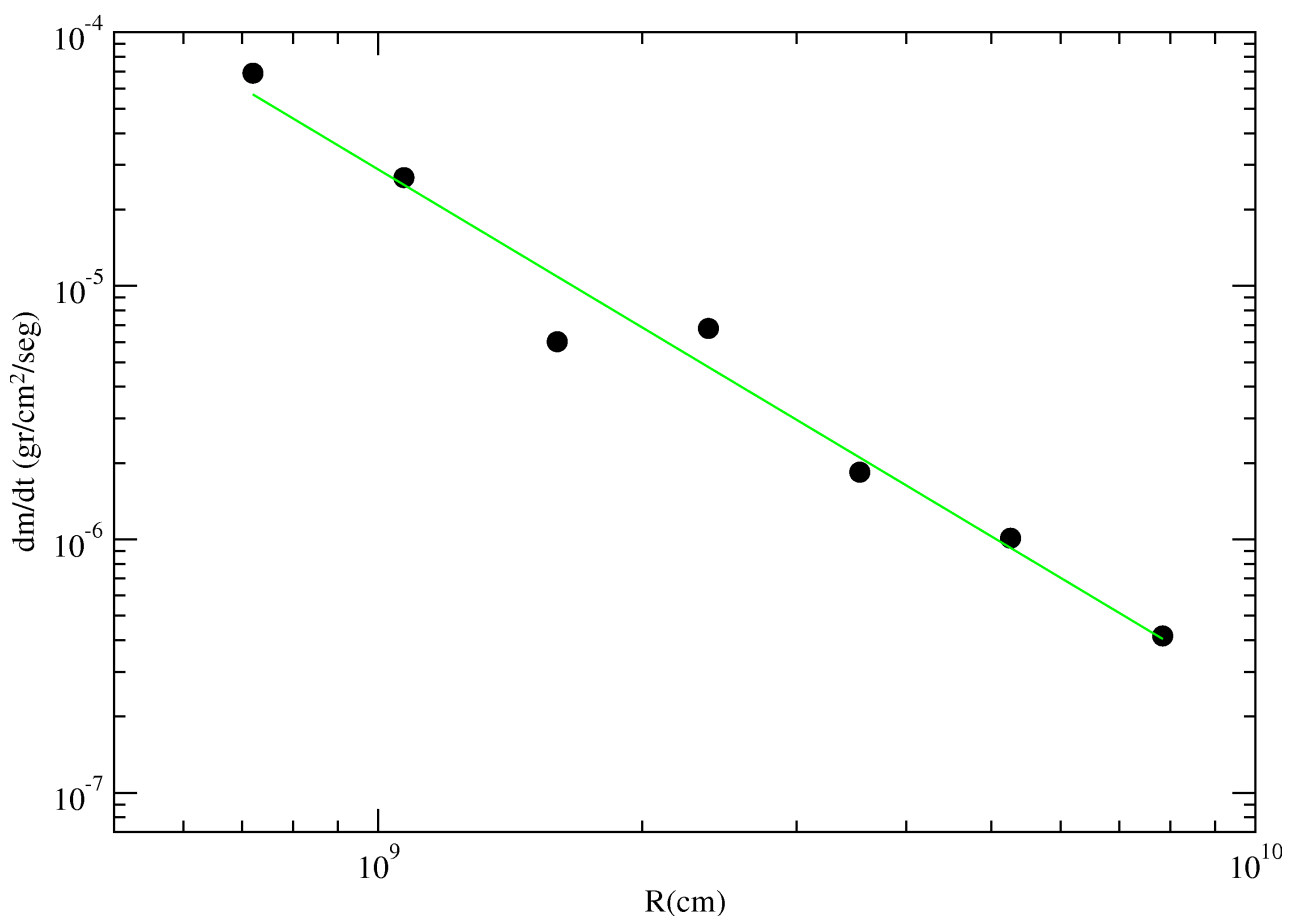

Figura 2.6: Perfil radial de fluxo de perda de matéria calculado levando em conta o maior fluxo local possível para a existência de uma solução estacionária da equação do movimento. Valores para um sistema $\operatorname{com~} \mathrm{M}_{1}=\mathrm{M}_{\odot}$ e $\dot{\mathrm{M}}_{a c}=10^{-9} \mathrm{M}_{\odot}$ ano $^{-1}$.

nunciado do que o perfil de temperatura do disco $\sim r^{-3 / 4}$. Vemos que a maioria da massa expelida no vento provém das regiões mais internas, levando em conta também a forte contribuição das regiões externas devido a que a área é maior. Para este caso particular o valor da taxa de perda total de massa é $\dot{\mathrm{M}}_{w}=5.10 \times 10^{-11} \mathrm{M}_{\odot}$ ano ${ }^{-1}$, ou $\sim 5 \%$ da taxa de acreção no disco. Valor que corresponde àqueles preditos nos modelos hidrodinâmicos tridimensionais de ventos em discos de acresção (Pereyra et al., 1997, 2000; Pereyra e Kallman, 2003; Proga et al., 1998, 1999).

$$
\dot{m}(R)=1.24 \times 10^{14} R^{-2.1}
$$

\subsection{Síntese Espectral}

A idéia inicial deste trabalho consistia em simplesmente adicionar a emissão das correspondentes atmosferas com vento associadas a cada anel. Nossa análise revelou um problema adicional. A transferência radiativa no sentido radial é importante e deve ser levada em consideração. Mas para isso nós precisamos de um tratamento em 3D da região emissora. 
O problema da transferência radiativa em três dimensões em um meio em movimento é bastante complexo. Para obter o espectro sintético desenvolvemos um método que leva em conta a geometria do sistema disco-vento e também a transferência radiativa através do vento. Por tanto foram implementados dois códigos: O primeiro toma as atmosferas de disco com vento calculadas como o descrito na seção 2.1 e interpola tridimensionalmente os valores da emissividade e opacidade dentro de uma grade mais fina. Em continuação um segundo código calcula o transporte radiativo dentro dessa grade levando em conta o campo de velocidades em 3D e a presença das regiões exteriores do disco que não expelem vento.

\subsubsection{Interpolação $2 D$ das atmosferas do vento e campo $3 D$ de velocidades}

Para conseguir a implementação da transferência radiativa dentro do nosso sistema, os modelos de atmosfera calculados entre os raios do disco $\mathrm{R}_{i}$ e $\mathrm{R}_{f}$ foram interpolados numa grade bi-dimensional mais fina. Para isso foi desenvolvido um código que interpola cada atmosfera calculada. As grandezas no sistema co-móvel na direção vertical são o campo de velocidades $v_{z}$, a opacidade $\chi_{C M F}\left(\nu_{C M F}, z\right)$ e a emissividade $\eta_{C M F}\left(\nu_{C M F}, z\right)$ para cada freqüência e a grade de freqüências $\nu_{C M F}$.

Cada uma destas grandezas é armazenada em um vetor ou matriz que depois é interpolado numa grade espacial com o dobro da amostragem dos vetores originais, e sendo a mesma para cada atmosfera. Esta grade acompanha o mesmo comportamento das grades dos modelos originais, ou seja é mais fina quando existem variações fortes na profundidade óptica (no sentido vertical). Esta interpolação é feita logaritmicamente devido ao intervalo de variação na região de transição entre a fotosfera e o vento. Cada um destes vetores é então interpolado numa grade de freqüências que leva em conta os mesmos pontos da grade original dos modelos. Como a grade de freqüências é diferente para cada modelo devido à diferente estrutura de temperatura de cada atmosfera, para formar a grade comum, são usados os pontos espectrais do modelo mais quente, o mais frio e de um modelo de temperatura intermediária. Isto garantirá que sejam levadas em conta todas as características espectrais do sistema como um todo. Devido a que esta grade é extremamente numerosa, já que cobre freqüências desde os raios-X até o infravermelho longínquo, só a região do espectro de interesse é levada em conta na interpolação e os novos vetores terão somente 
componentes espectrais selecionadas.

Uma vez feito isto, é implementada uma interpolação no sentido radial, também logarítmica. Como é conhecido as fotosferas de disco têm altura variável com o raio causada pela forte variação da gravidade, pelo que esta interpolação é feita sobre grandezas que podem variar muito em pequenos intervalos. Todas estas interpolações são feitas levando em conta, para cada ponto da nova grade, quatro pontos vizinhos da grade original.

Uma opção dentro deste código é o de estender esta grade para raios mais externos. Até o momento, a grade é estendida da atmosfera mais externa (a mais fria) até a borda física do disco. Isto foi implementado para produzir emissão de uma região mais extensa correspondendo à região de variação mais lenta de temperatura no disco.

\section{Campo 3D de velocidades}

O vento que é expelido do disco de acresção sofre efeitos externos que modificam o seu comportamento cinemático. Ao escapar da superfície a sua velocidade têm só duas componentes, a componente vertical e a componente rotacional, que neste caso é considerada kepleriana. Ao subir os efeitos de Coriolis e centrifugo fazem com que o vento ganhe também uma componente radial devido à conservação do momento angular específico e às forças radiativas no sentido radial (Pereyra et al., 1997, 2000; Pereyra e Kallman, 2003). Neste trabalho as componentes azimutal e radial da velocidade (num sistema cilíndrico) não são calculadas consistentemente, mas com os argumentos expostos, estas velocidades são parametrizadas para expressar suas propriedades cinemáticas.

A componente vertical da velocidade é calculada de acordo com o exposto na seção 2.2. A componente radial é parametrizada de forma de mimetizar a expansão hiperbólica do vento. Este tipo de expansão faz com que as linhas de fluxo saiam da superfície verticalmente e vão abrindo-se assintoticamente até um certo ângulo de abertura. Nesta parametrização, a velocidade radial é dada por:

$$
V_{r}(r, z)= \begin{cases}\frac{z}{r \tan (\beta)} V_{z}(r, z), & \text { se } z<r \tan (\beta), \\ \frac{1}{\tan ^{2}(\beta)} V_{z}(r, z) & \text { se } z \geqslant r \tan (\beta)\end{cases}
$$

onde $\beta$ é o ângulo de abertura e a segunda linha serve para limitar os valores de $\mathrm{V}_{r}$ a 
grandes alturas.

A componente azimutal da velocidade é calculado levanda em conta a conservação do momento angular específico de um vento com linhas de fluxo divergentes como o exposto, sendo escrita como:

$$
V_{\phi}(r, z)= \begin{cases}\sqrt{\left(1-\frac{z^{2}}{r^{2} \tan ^{2}(\beta)}\right)^{1 / 2} \frac{G M}{r}} & \text { se } z<r \tan (\beta), \\ V_{\phi}(r, h) & \text { se } z \geqslant r \tan (\beta)\end{cases}
$$

onde a segunda linha serve para evitar a descontinuidade alem de $z=r \tan (\beta)$, sendo $h$ o valor de $z$ do ultimo ponto da grade vertical $(z<r \tan (\beta))$ de maneira que $V_{\phi}>0$.

Assim, este código gera todas as grandezas estruturais interpoladas em que serão usadas para o cálculo da transferência radiativa através do vento. Estes valores são: a distribuição bi-dimensional do campo de velocidades $V_{z}(r, z), V_{r}(r, z)$ e $V_{\phi}(r, z)$; a distribuição espacial de densidade eletrônica $N_{e}(r, z)$ e de temperatura eletrônica $T_{e}(r, z)$; as opacidades no sistema co-móvel $\chi_{C M F}\left(r, z, \nu_{C M F}\right)$ e a emissividade no mesmo sistema $\eta_{C M F}\left(r, z, \nu_{C M F}\right)$. Esta estrutura serve de entrada para o cálculo do espectro sintético descrito na seção seguinte.

\subsubsection{Trasporte radiativo através do vento}

Uma vez obtidos estas grades de valores a transferência radiativa é implementada. Para isto um método específico focado para a geometria de discos de acresção foi desenvolvido. Este código lê os arquivos descritos no parágrafo anterior, alem disso gera uma grade de freqüências no sistema de observador $\left(\nu_{\text {obs }}\right)$ no intervalo espectral de interesse. O método começa definindo um espaço de parâmetros de impacto no plano do céu. Para isto uma grade de parâmetros de impacto é gerada. Esta é uma grade anéis concêntricos centrada na anã branca, que estende-se até o raio do ponto mais externo da projeção do sistema no plano do céu. Este raio corresponde à projeção do ponto mais alto e mais afastado do vento e depende da inclinação do sistema. Nesta grade os pontos são separados de forma logaritmicamente uniforme. Assim, a grade parâmetros de impacto P, varia entre os limites: 


$$
1.05 R_{1}<P<R_{d i s k}[1+\tan (i)]
$$

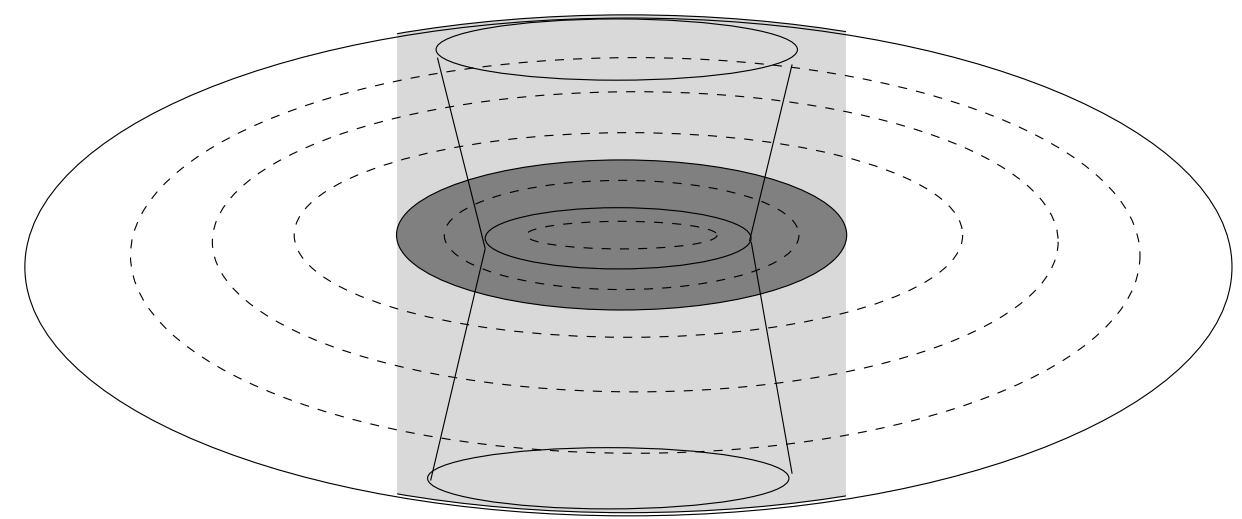

Figura 2.7: Esquema da grade de parâmetros de impacto usada para calcular a transferência radiativa. O circulo mais escuro representa o disco. O círculo mais interno a região do disco de onde o vento escapa e os semi-cones representam o vento.

A figura 2.7 mostra um esquema dos parâmetros de impacto utilizados para sintetizar o espectro. As linhas pontilhadas representam a cobertura no plano do céu de todo o sistema (disco + vento). A região cinza cobre os pontos realmente levados em conta no cálculo. Uma segunda grade de ângulos azimutais também é gerada formando assim a amostragem no espaço de parâmetros de impacto.

O código faz a síntese usando 5 laços. O primeiro laço corresponde ao das bandas espectrais. Como a quantidade de freqüências necessária para uma síntese detalhada do contínuo e das linhas é muito grande o código separa a grade de freqüências observadas em bandas de aproximadamente 1000 freqüências por banda e calcula o transporte radiativo dentro daquele intervalo, banda por banda. O segundo laço, mais interno, corresponde ao dos parâmetros de impacto. Os raios de cada parâmetro de impacto correspondem a uma grade mais fina ainda ( 500 anéis) para garantir a boa amostragem do sistema. O terceiro laço cobre a coordenada azimutal $\phi$, passando por cada ponto da grade. De cada um desses pontos é calculada uma intensidade específica na direção do observador. O quarto laço escolhe pontos no raio que vão ser usados para o calculo da transferência radiativa. 
Cada raio pode ser dividido em dois ou mais partes no caso de um gás com fronteiras irregulares. Aqui são calculadas as coordenadas dos pontos dentro de cada raio usando as projeções dos pontos da grade vertical ao longo do raio. Pontos extras são incluídos nessa grade dentro do raio, calculando a velocidade projetada na direção do observador ao longo do raio:

$$
V_{p}=V_{r} \cos \phi \cos i+V_{\phi} \sin \phi \cos i+V_{z} \sin i
$$

é imposto que a distância em velocidade entre pontos seja no máximo de $0.5 \mathrm{~km} \mathrm{~s}^{-1}$. Usando uma interpolação bi-dimensional logarítmica são calculados então os valores da emissividade e opacidade em cada ponto do raio no sistema CMF e armazenados em dois vetores uni-dimensionais separados $\eta_{C M F}\left(n_{\text {ray }}\right)$ e $\chi_{C M F}\left(n_{\text {ray }}\right)$, onde $n_{\text {ray }}$ é o número de pontos em cada raio.

O quinto laço calcula a transferência radiativa propriamente dita, para cada valor da grade de freqüências no sistema do observador. O cálculo da intensidade específica é feita usando a solução formal da equação de transferência radiativa:

$$
I_{\nu}(0)=I\left(\tau_{\nu}^{\max }\right) e^{-\tau_{\nu}^{\max }}+\int_{\tau_{\nu}^{\max }}^{0} S_{\nu}\left(t_{\nu}\right) e^{\left(t_{\nu}-\tau_{\nu}^{\max }\right)} d t_{\nu},
$$

onde todas as magnitudes devem ser avaliadas no sistema do observador. Para isso a emissividade e a opacidade para cada freqüência no sistema do observador em cada ponto do raio são calculadas. Usando a grade de freqüências no sistema do observador a correspondente freqüência no sistema CMF é encontrada usando o deslocamento Doppler provocado pela velocidade projetada na direção do observador (eq. 2.57):

$$
\nu_{C M F}=\nu_{o b s}\left(1-\frac{V_{p}(r, z, i)}{c}\right)
$$

Posteriormente, dentro da grade de freqüências no sistema CMF, são encontrados os dois elementos entre os quais calcula-se $\nu_{C M F}$. Os valores respectivos da emissividade e opacidade no sistema do observador $\left(\eta_{o b s}\right.$ e $\left.\chi_{\text {obs }}\right)$ são calculados então mediante interpolação 
linear em freqüência usando os respectivos valores dos vetores $\eta_{C M F}\left(n_{\text {ray }}\right)$ e $\chi_{C M F}\left(n_{\text {ray }}\right)$. Com esses valores a função fonte no sistema do observador é calculada:

$$
S_{o b s}\left(r, z, \nu_{o b s}\right)=\frac{\eta_{o b s}\left(r, z, \nu_{o b s}\right)}{\chi_{o b s}\left(r, z, \nu_{o b s}\right)}
$$

A intensidade específica que provém de cada raio é calculada então para cada parâmetro de impacto e para cada valor da grade do ângulo $\phi$ como é ilustrado na figura 2.8.

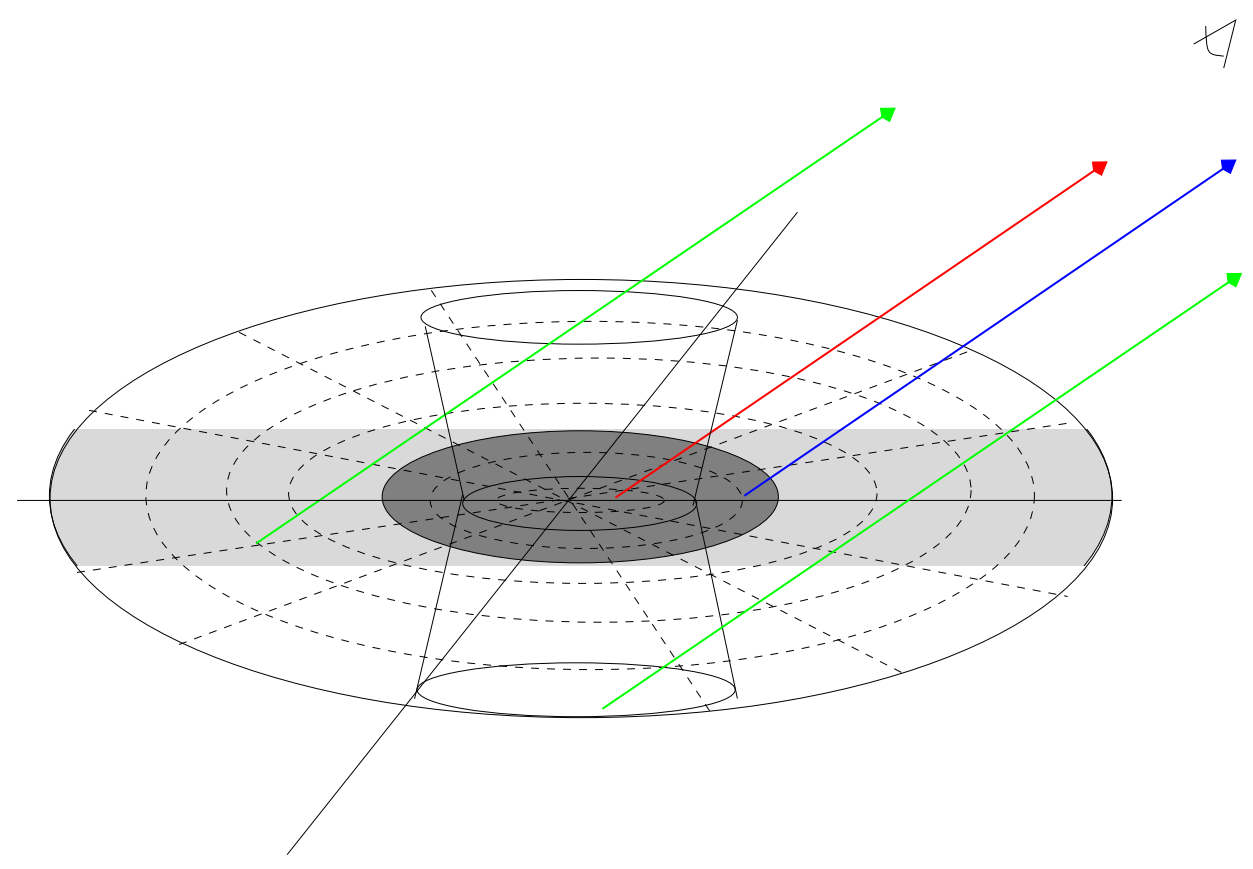

Figura 2.8: Mesmo esquema da figura 2.7, mas com o observador agora no plano da folha. Os raios provenientes das diferentes regiões do plano de parâmetros de impacto são mostrados.

Os valores da intensidade específica são interpolados dentro de uma grade mais fina em $\phi$, para posteriormente serem integradas em todos os ângulos com o respectivo peso dado pelo ângulo sólido de cada elemento. A contribuição de cada parâmetro de impacto é então somada e este fluxo total, escalonada pela distância ao objeto.

Para cada raio e freqüência é calculada também a profundidade óptica para cada ponto ao longo do raio, medido desde o ponto mais próximo ao observador. A equação de transferência radiativa é calculada desde uma profundidade óptica $\tau_{\max }=30$. As condições de fronteira na base de cada raio depende da região da onde ele sai. Se o raio sai da região do disco que expele o vento (raio vermelho na fig. 2.8) $I_{\nu}\left(\tau_{\max }\right)=S_{\nu}\left(\tau_{\max }\right)$. Para 
os raios que saem de regiões do disco que não expelem vento (raio azul na fig. 2.8) então $I_{\nu}=I_{d i s k}\left(r, \phi, \nu_{o b s}\right)$, onde $I_{\nu}=I_{d i s k}\left(r, \phi, \nu_{o b s}\right)$ é a intensidade específica emitida por uma atmosfera de disco calculada com o método desenvolvido por Wade e Hubeny (1998) que leva conta exatamente o escurecimento de bordo do disco (Diaz et al., 1996), com $\nu_{\text {obs }}$ corrigida pela rotação kepleriana do disco em cada ponto. Se o raio de uma região do vento não intercepta o disco (raios verdes na fig. 2.8) então $I_{\nu}=0$.
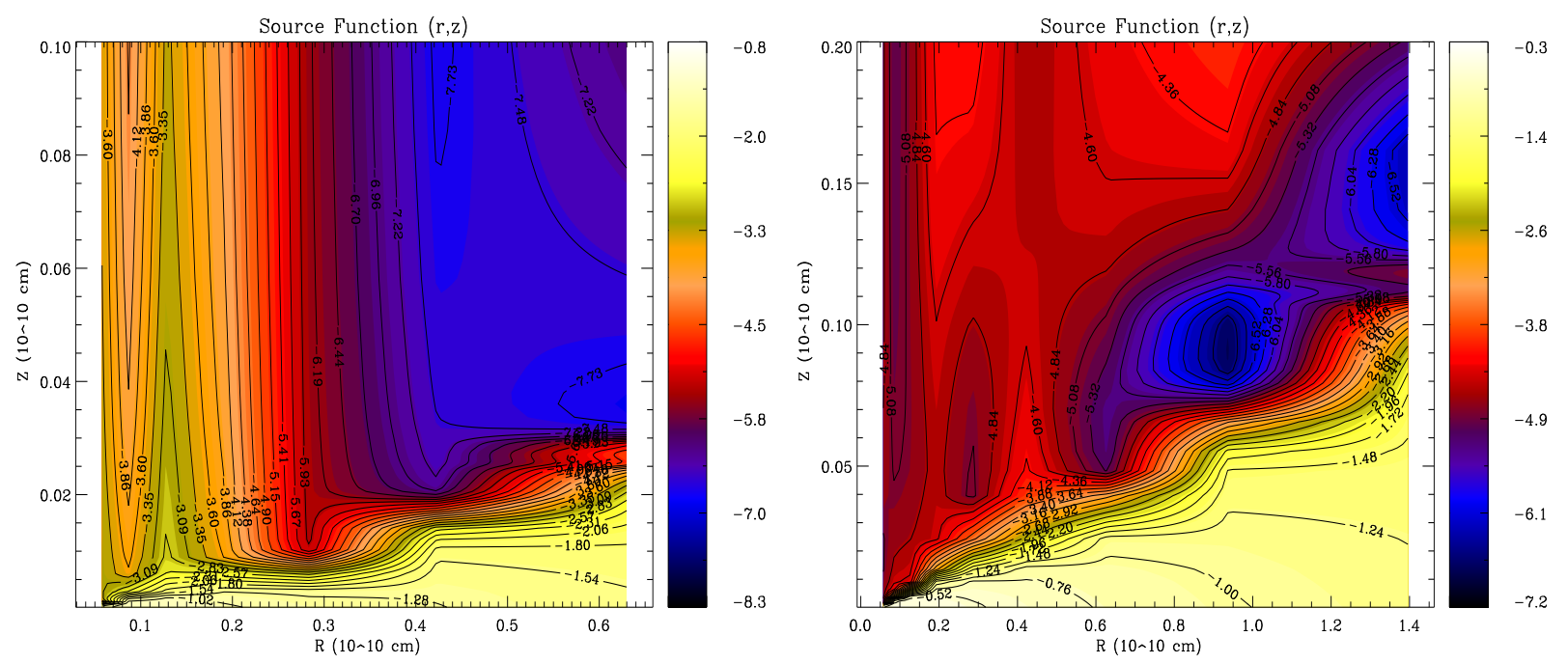

Figura 2.9: Distribuição espacial da função fonte para os modelos calculados na região de fronteira entre a fotosfera e o vento para dois modelo como $\mathrm{M}_{1}=\mathrm{M}_{\odot}$ na região de $1110 \AA$. No painel da esquerda é mostrado um modelo com $\dot{\mathrm{M}}_{a}=10^{-9} \mathrm{M}_{\odot}$ ano ${ }^{-1}$ e $\dot{\mathrm{M}}_{w}=10^{-12} \mathrm{M}_{\odot}$ ano ${ }^{-1}$. No painel da direita um modelos $\operatorname{com} \dot{\mathrm{M}}_{a}=10^{-8} \mathrm{M}_{\odot}$ ano $^{-1}$ e $\dot{\mathrm{M}}_{w}=10^{-11} \mathrm{M}_{\odot}$ ano $^{-1}$

Como exemplo, na figura 2.9 a distribuição espacial da função fonte no sistema co-móvel $\mathrm{S}_{C M F}=\eta_{C M F} / \chi_{C M F}$ na região de $1100 \AA$ é mostrada. Estes modelos correspondem aos calculados com $\dot{\mathrm{M}}_{a}=10^{-9} \mathrm{M}_{\odot}$ ano $^{-1}$ e $\dot{\mathrm{M}}_{w}=10^{-12} \mathrm{M}_{\odot}$ ano ${ }^{-1}$ (painel esquerdo) e $\dot{\mathrm{M}}_{a}=10^{-8}$ $\mathrm{M}_{\odot} \mathrm{ano}^{-1}$ e $\dot{\mathrm{M}}_{w}=10^{-11} \mathrm{M}_{\odot}$ (painel direito). É evidente a região de transição entre a fotosfera do disco e o vento, além da estrutura do interna do vento. Também é possível ver a formação da concavidade do disco, com a variação da altura da fotosfera com o raio.

$\mathrm{Na}$ figura 2.10 é vista a intensidade especifica média de uma região do espectro em escala logarítmica:

$$
\log \left[\frac{1}{\left(\nu_{f}-\nu_{o}\right)} \int_{\nu_{o}}^{\nu_{f}} I_{\nu} d \nu\right]
$$




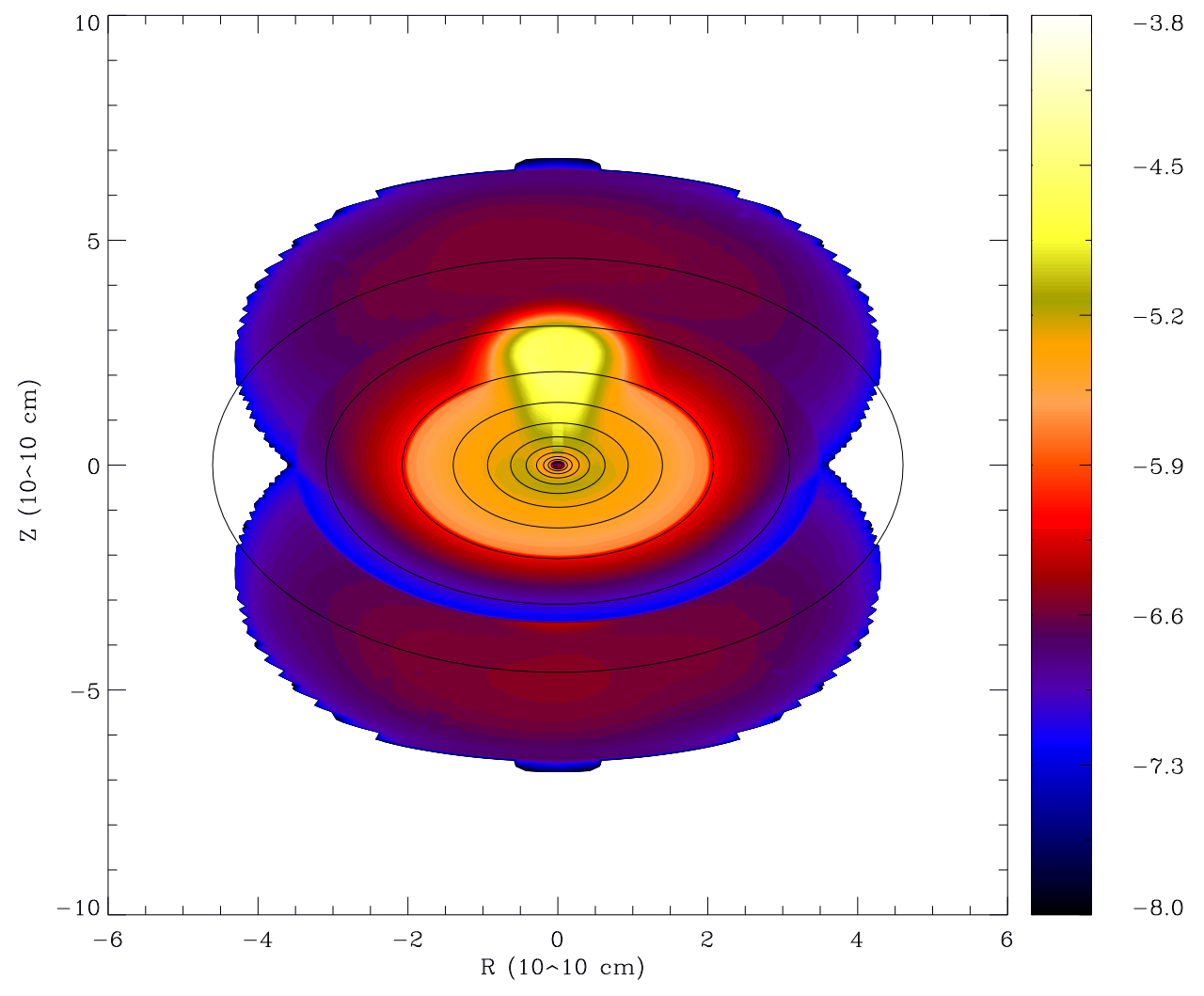

Figura 2.10: Logaritmo da intensidade especifica média de uma região do espectro $\log \left[1 /\left(\nu_{f}-\nu_{o}\right) \int_{\nu_{o}}^{\nu_{f}} I_{\nu} d \nu\right]$. Nesse caso é mostrado a região de emissão do C IV (1550) para um modelo com $\mathrm{M}_{1}=0.8 \mathrm{M}_{\odot}, \dot{\mathrm{M}}_{a}=10^{-8}$ $\mathrm{M}_{\odot} \mathrm{ano}^{-1}$ e $\dot{\mathrm{M}}_{w}=9.3 \times 10^{-11} \mathrm{M}_{\odot} \mathrm{ano}^{-1}$.

Nesse caso é mostrado a região de emissão do C IV (1550) para um modelo com $\mathrm{M}_{1}=$ $0.8 \mathrm{M}_{\odot}, \dot{\mathrm{M}}_{a}=10^{-8} \mathrm{M}_{\odot}$ ano $^{-1}$ e $\dot{\mathrm{M}}_{w}=9.3 \times 10^{-11} \mathrm{M}_{\odot}$ ano $^{-1}$. A figura reproduz a geometria mostrada no esquema da figura 2.7. Este tipo de gráfico é de grande utilidade para a análise das regiões de emissão nas diferentes componentes observadas nas linhas.

Na figura 2.11 no painel esquerdo são mostradas as contribuições ao fluxo de cada região do sistema relacionada com um parâmetro de impacto de índice NP. Os parâmetros do sistema são os mesmos da figura 2.10. É possível notar como as estruturas do contínuo e da linha variam dependendo da região de sua formação. No painel da direita são mostradas as contribuições das diferentes regiões integradas de acordo com a figura 2.8 (linhas 

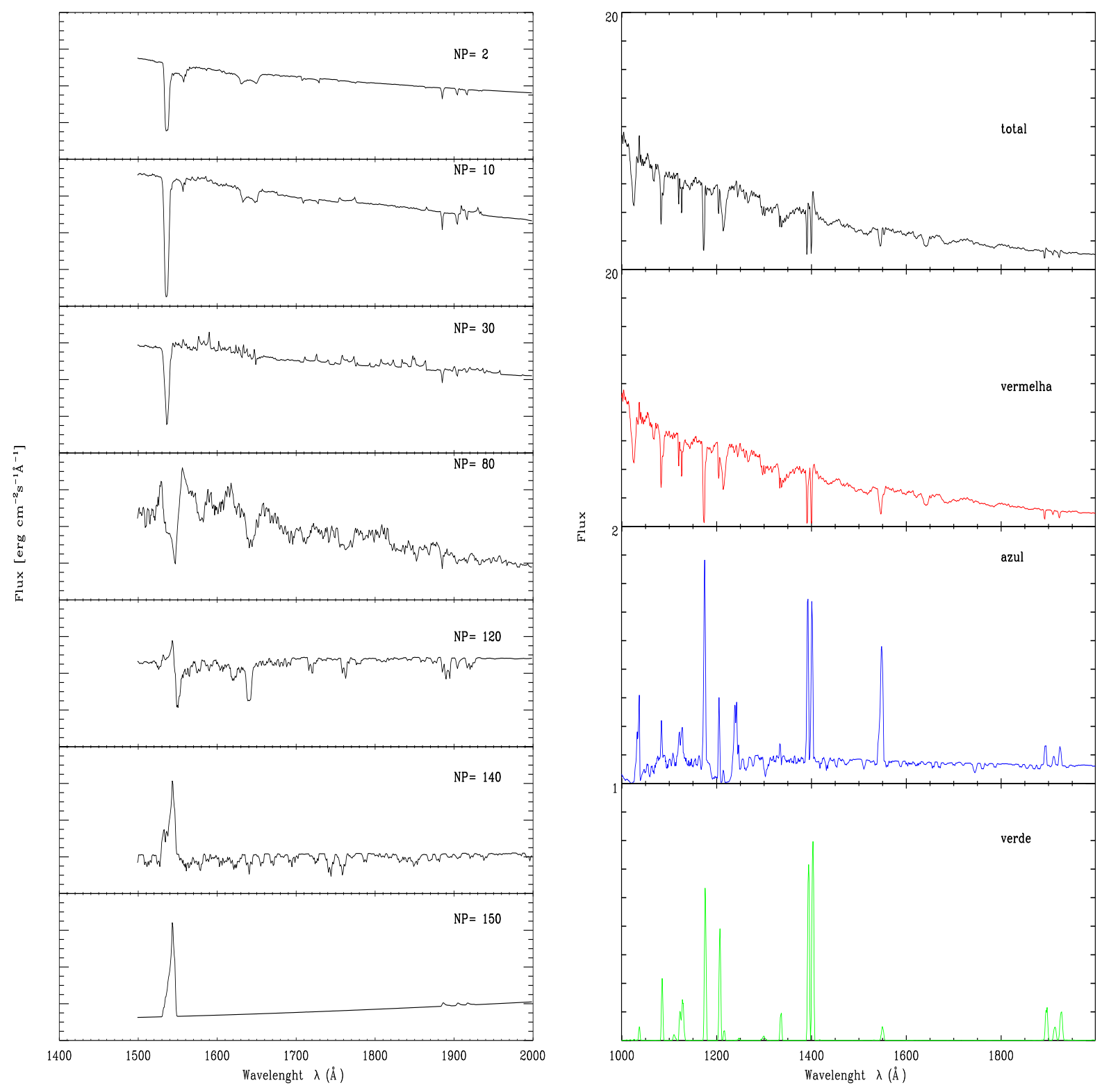

Figura 2.11: No painel esquerdo são mostradas as contribuições ao fluxo de cada região do sistema relacionada com um parâmetro de impacto de índice NP. No painel da direita são mostradas as contribuições das diferentes regiões integradas de acordo com a figura 2.8 (linhas vermelha, azul e verde) e o espectro sintético total (linha preta).

vermelha, azul e verde) e o espectro sintético total (linha preta). O segundo painel mostra a contribuição do espectro de raios provenientes da região do disco que expele vento. Esta região corresponde à mais quente do disco e contribui com a maior quantidade de fluxo para o espectro. Esta região emite um espectro fortemente azulado que é uma característica típica dos espectros observados em discos. Também nesta região são gerados 
fortes perfis de absorção nas linhas, que estão fortemente azuladas devido à presença do vento. Estas fortes absorções provém principalmente na região de transição entre a fotosfera e o vento, onde existe um forte gradiente de temperatura somada à alta aceleração do vento como será descrito com mais detalhe mais adiante. Os raios provenientes da região do disco que não expele vento (terceiro painel) geram um espectro caraterizado por um contínuo praticamente plano, o que evidencia a baixa temperatura das regiões. Também apresenta estruturas em absorção alargadas provenientes da fotosfera do disco, algumas das quais são levemente modificadas por estreitas estruturas em emissão que provém do vento. Mas a principal caraterística são as fortes linhas de emissão geradas no vento que se encontra diante da fotosfera que gera o contínuo. Este vento, que é expelido das regiões mais internas, reflete a temperatura e o estado de ionização dessas regiões, já que o gás do vento, (na aproximação deste trabalho) é iluminado por elas. Isto faz com que a função fonte $S_{\nu}^{l} \approx B\left(T_{R}\right)$ onde $T_{R}$ é a temperatura da radiação que é próxima à temperatura efetiva da região do disco da onde escapa o vento (capítulo 3). Devido a que a radiação que escapa das regiões mais externas da fotosfera do disco tem uma intensidade específica $I_{\nu}^{l} \lesssim B\left(T_{R}\right)$, é que são produzidas as fortes linhas de emissão. A intensidade das linhas depende principalmente do tamanho da região emissora e da grandeza de $S_{\nu}^{l}$. A função fonte das diferentes linhas vai depender por sua vez da temperatura do vento e da sua estrutura de ionização. No painel inferior é mostrada a contribuição ao espectro dos raios que se originam em regiões que não impactam o disco. Estas regiões são pouco densas e não produzem contínuo, mas somente linhas de emissão, correspondendo à temperatura do gás iluminado pelo disco. Assim, a intensidade no contínuo e principalmente nas linhas vai depender fortemente da inclinação orbital do sistema, já que o ângulo sólido emissor depende fortemente dela. Esta separação espacial das diferentes estruturas do espectro são essenciais para a análise feita no capítulo 4 . 
Capítulo 3

\section{Análise das Estruturas}

Neste trabalho foram calculados vários modelos de discos de acresção com vento tentando estudar a influência dos diferentes parâmetros do sistema tanto sobre a estrutura de ionização do vento, como na temperatura e principalmente sobre os perfis de linhas no UV. Devido ao grande esforço computacional requerido para o cálculo de cada modelo, foi impossível cobrir um amplo espaço de parâmetros. Levando em conta que, para cada modelo de disco com vento é necessária a convergência de 6 a 10 atmosferas de disco. Cada um desses modelos requer uma grande quantidade de memória e tempo de processamento, já que são levados em conta, em NLTE, milhares de transições e centenas de níveis atômicos. Mesmo assim, neste trabalho foi possível cobrir uma adequada variedade de parâmetros físicos e geométricos que nos ajudaram a entender melhor a física envolvida no vento em discos e a emissão deste vento no UV.

As tabelas 3.1 e 3.2 mostram os parâmetros físicos e geométricos respectivamente, dos modelos calculados neste trabalho até o momento. Na tabela 3.1 cada modelo é referenciado na primeira coluna com uma letra. Também são mostrados a massa da primária $\mathrm{M}_{1}$ e a taxa de transferência de massa no disco $\dot{\mathrm{M}}_{a}$. Estes parâmetros determinam a magnitude e a distribuição de temperatura efetiva no disco e deste modo a estrutura de ionização do vento, que é fundamental para a síntese espectral. A taxa de total de massa perdida no vento $\dot{\mathrm{M}}_{w}$ calculada de acordo como a seção 2.2.4 é mostrada na quarta coluna da tabela. É importante enfatizar que devido à dependência da $\mathrm{T}_{e f f}(R) \operatorname{com} \mathrm{M}_{1}$ e $\dot{\mathrm{M}}_{a}$ a taxa de perda de massa total $\left(\dot{\mathrm{M}}_{w}\right)$ é afetada por esses dois parâmetros. Pelo qual o estado de ionização, a densidade do vento e a geometria não independentes dentro do quadro deste modelo. As velocidades terminais no sentido vertical do anel mais interno e do mais externo 
são mostradas também para caracterizar a cinemática do vento. Como foi mostrado no capítulo anterior, a velocidade do vento que provem das regiões mais internas apresentam velocidades terminais maiores. O raio mais externo para o qual é calculada a atmosfera de disco com vento $\mathrm{R}_{f}$ também é mostrado em raios solares $\mathrm{R}_{\odot}$. Este raio depende da distribuição de temperatura efetiva no disco e obedece, como já foi mencionado, à condição $\mathrm{T}\left(\mathrm{R}_{f}\right) \sim 1.4 \times 10^{4} \mathrm{~K}$, temperatura na qual os modelos de atmosferas com vento começam a apresentar problemas de convergência.

Tabela 3.1 - Parâmetros Físicos

\begin{tabular}{|c|c|c|c|c|c|c|c|c|c|c|}
\hline Modelo & $\begin{array}{l}\mathrm{M}_{1} \\
\mathrm{M}_{\odot}\end{array}$ & $\begin{array}{c}\dot{\mathrm{M}}_{a} \\
\mathrm{M}_{\odot} \mathrm{yr}^{-1}\end{array}$ & $\begin{array}{c}\dot{\mathrm{M}}_{w} \\
\mathrm{M}_{\odot} \mathrm{yr}\end{array}$ & $\begin{array}{l}\mathrm{T}_{\text {disk }}{ }^{1} \\
10^{4} \mathrm{~K}\end{array}$ & $\begin{array}{c}\mathrm{V}_{\infty}^{2} \\
\mathrm{~km} \mathrm{~s}^{-1}\end{array}$ & $\begin{array}{c}\mathrm{V}_{\infty}{ }^{3} \\
\mathrm{~km} \mathrm{~s}^{-1}\end{array}$ & $\begin{array}{l}\mathrm{R}_{f}^{4} \\
\mathrm{R}_{\odot}\end{array}$ & $\alpha$ & $k$ & $\zeta(x)$ \\
\hline$a$ & 1.0 & $1.0 \times 10^{-8}$ & $1.1 \times 10^{-10}$ & 8.60 & $1540^{5}$ & 491 & 0.2 & 0.9 & 0.6 & $\zeta_{1}$ \\
\hline$b$ & 1.0 & $5.0 \times 10^{-9}$ & $4.0 \times 10^{-11}$ & 7.20 & $1640^{5}$ & 461 & 0.2 & 0.9 & 0.6 & $\zeta_{1}$ \\
\hline$c$ & 1.0 & $1.0 \times 10^{-9}$ & $7.0 \times 10^{-12}$ & 4.80 & $1470^{5}$ & 580 & 0.13 & 0.9 & 0.6 & $\zeta_{1}$ \\
\hline$d$ & 1.0 & $5.0 \times 10^{-10}$ & $5.0 \times 10^{-12}$ & 4.10 & $1110^{5}$ & 570 & 0.06 & 0.9 & 0.6 & $\zeta_{1}$ \\
\hline$e$ & 0.8 & $1.0 \times 10^{-8}$ & $9.3 \times 10^{-11}$ & 6.80 & $6200^{5}$ & 1200 & 0.2 & 0.7 & 0.7 & $\zeta_{2}$ \\
\hline$f$ & 0.8 & $1.0 \times 10^{-8}$ & $4.7 \times 10^{-10}$ & 6.80 & $5800^{6}$ & 908 & 0.2 & 0.5 & 0.9 & $\zeta_{2}$ \\
\hline$g$ & 0.8 & $1.0 \times 10^{-9}$ & $1.7 \times 10^{-12}$ & 3.86 & $1248^{5}$ & 324 & 0.07 & 0.9 & 0.6 & $\zeta_{1}$ \\
\hline$h$ & 0.6 & $5.0 \times 10^{-9}$ & $4.0 \times 10^{-11}$ & 4.63 & $1182^{5}$ & 523 & 0.13 & 0.9 & 0.6 & $\zeta_{1}$ \\
\hline$i$ & 0.6 & $5.0 \times 10^{-9}$ & $6.5 \times 10^{-11}$ & 4.63 & $4500^{6}$ & 1360 & 0.13 & 0.5 & 0.9 & $\zeta_{2}$ \\
\hline
\end{tabular}

${ }^{1}$ Temperatura efetiva do disco, $\mathrm{T}_{\text {disk }}=0.488\left(3 G M_{1} \dot{M}_{a} / 8 \pi \sigma R_{1}^{3}\right)^{1 / 4}$.

${ }^{2}$ Velocidade vertical máxima $\mathrm{V}_{z_{\infty}}$ no primeiro anel.

3 Velocidade vertical máxima $\mathrm{V}_{z_{\infty}}$ no útimo anel $\mathrm{R}_{f}$.

${ }^{4}$ Raio máximo até o qual atmosferas com vento foram calculadas, $\mathrm{T}\left(\mathrm{R}_{f}\right) \sim 14000 \mathrm{~K}$.

${ }^{5}$ Ramo inferior das soluções

${ }^{6}$ Ramo superior das soluções

As seguintes colunas mostram os parâmetros $\alpha$ e $k$ da força radiativa nas linhas usados no cálculo do perfil de velocidades vertical e da taxa de perda de massa. Na maioria dos modelos um valor de $\alpha=0.9$ e a função $\zeta(x)=\zeta_{1}$ foram utilizados, isto devido a que, como 
foi demostrado no capítulo anterior, estes parâmetros nos levam a valores razoáveis da densidade no vento e da velocidade terminal no ramo inferior das soluções. No caso dos modelos " $f$ " e " $i$ " foi usado usado o ramo superior da soluções para um valor de $\alpha=0.5$ e uma distribuição vertical da radiação $\zeta(x)=\zeta_{2}$. Esta combinação de parâmetros também gera valores razoáveis para a velocidade terminal, mas valores muito baixos ( $\sim 4$ ordens de magnitude menor) para a taxa de perda de massa. Devido a isso no caso de $\alpha=0.5$, o termo da força radiativa nas linhas na equação de Euler (eq. 2.34) foi multiplicado por um fator $(\epsilon=27)$ para levar o valor da taxa de perda de massa para valores compatíveis com os modelos hidrodinâmicos e da ordem necessária para gerar linhas intensas no UV. Mesmo apresentando estes problemas, este valor de $\alpha$ foi utilizado visando investigar o comportamento do vento e do espectro ao escolhermos o ramo superior das soluções da equação de movimento. Por último, no caso do modelo " $e$ " valores de $\alpha=0.7$ e $k=0.7$ foram utilizados junto com uma função $\zeta(x)=\zeta_{2}$ e o ramo inferior da soluções. Esta combinação também gera valores razoáveis da velocidade terminal e da taxa de perda de massa no vento. Como foi mencionado anteriormente existem muitas combinações para $\alpha, k$ e $\zeta$ que produziriam valores da velocidade terminal e da taxa de perda de massa compatíveis com os observados e preditos nos modelos hidrodinâmicos complexos. Mas devido ao esforço gigantesco que implicaria cobrir todo um amplo espaço de valores para estes parâmetros, foram escolhidos os valores expostos numa primeira tentativa de entender o comportamento dos modelos físicos e do método desenvolvido neste trabalho.

Durante o estudo das soluções encontramos que seria de muita utilidade flexibilizar em uma certa medida a geometria do vento expelido pelo disco, já que existem poucos vínculos observacionais para a geometria. Assim, dentro do código de transferência radiativa foram incluídos parâmetros geométricos que nós ajudaram a estudar o efeito da forma do vento sobre o espectro. Na figura 3.1 é mostrada a geometria do vento usada neste trabalho, a qual está inspirada na proposta feita por SV93. Na tabela 3.2 são mostrados os parâmetros geométricos escolhidos neste trabalho para estudar a sua influência sobre os espectros sintéticos. O primeiro parâmetro é inclinação orbital $(i)$, fator muito importante na forma dos perfis de linha observados. O segundo fator é o limite interno das atmosferas do disco com vento calculadas. Nestes modelos e em primeira instância, este raio foi fixado a 1.05 $\mathrm{R}_{1}$, mas o nosso código de síntese possibilita variação deste raio permitindo assim o estudo 
Tabela 3.2 - Parâmetros Geométricos

\begin{tabular}{cc}
\hline \hline Parâmetro & Valores \\
\hline$i\left(^{\circ}\right)$ & $30,40,50,60,70,80$ \\
$\mathrm{R}_{\min } / \mathrm{R}_{1}$ & 1.05 \\
$\theta_{1}\left(^{\circ}\right)$ & $0,5,15$ \\
$\theta_{2}\left(^{\circ}\right)$ & $0,15,45$ \\
$\mathrm{Z}_{\max } / \mathrm{R}_{\text {disk }}$ & 1 \\
$\mathrm{R}_{\max } / \mathrm{R}_{\text {disk }}$ & 1.0 \\
\hline
\end{tabular}

do efeito que produziria o excluir emissão de vento provenientes de regiões internas do disco (pe. no caso de polares intermediários).

Originalmente a geometria do vento calculado na estrutura atmosférica é cilíndrica, como ilustram o conjunto de linhas contínuas no painel direito da figura 3.1. No código de transferência radiativa é possível ajustar essa geometria para uma bi-cônica como é mostrada na região cinza da mesma figura. Para isso foram incluídos os parâmetros geométricos $\theta_{1}, \theta_{2}$ e $R_{C}$. Os dois primeiros são os ângulos de abertura interno e externo respectivamente; $\mathrm{R}_{C}$ é o raio até o qual a estrutura dos modelos de atmosfera com vento são levamos em conta completamente desde $z=0$. Além de $\mathrm{R}_{C}$, a estrutura vertical dos modelos de vento é retirada desde a base até uma altura correspondente à interseção com a linha que sai da base do disco no raio $\mathrm{R}_{C}$ com inclinação $\theta_{2}$. Os raios que saem dessas regiões do disco têm uma intensidade $I_{\nu}(0)=I_{d i s k}\left(r, \phi, \nu_{o b s}\right)$ como o descrito no capítulo anterior, a mesma que é trasportada através do vento quando este raio atinge na região cinza. Estruturas de vento são também esvaziadas para alturas além da linha que sai de $\mathrm{R}_{\text {min }}$ com uma inclinação $\theta_{1}$. Para regiões com $\mathrm{R}>\mathrm{R}_{f}$, a estrutura da última atmosfera (a mais fria) é repetida até $\mathrm{R}_{\text {disk }}$, como foi descrito anteriormente. Por último, o parâmetro $\mathrm{R}_{\max }$ avalia o tamanho do disco em relação ao tamanho determinado pelo limite máximo dado pelas forças de maré $\left(\mathrm{R}_{\text {disk }} \sim 0.8 \mathrm{R}_{L_{1}}\right)$. Isto nos ajuda a estudar o efeito do ocultamento do vento de regiões do gás expelido com $z<0$ pelo disco. 
Todos estes parâmetros geométricos influenciam nas estruturas dos perfis de linha, as serão analisadas nas seções seguintes.
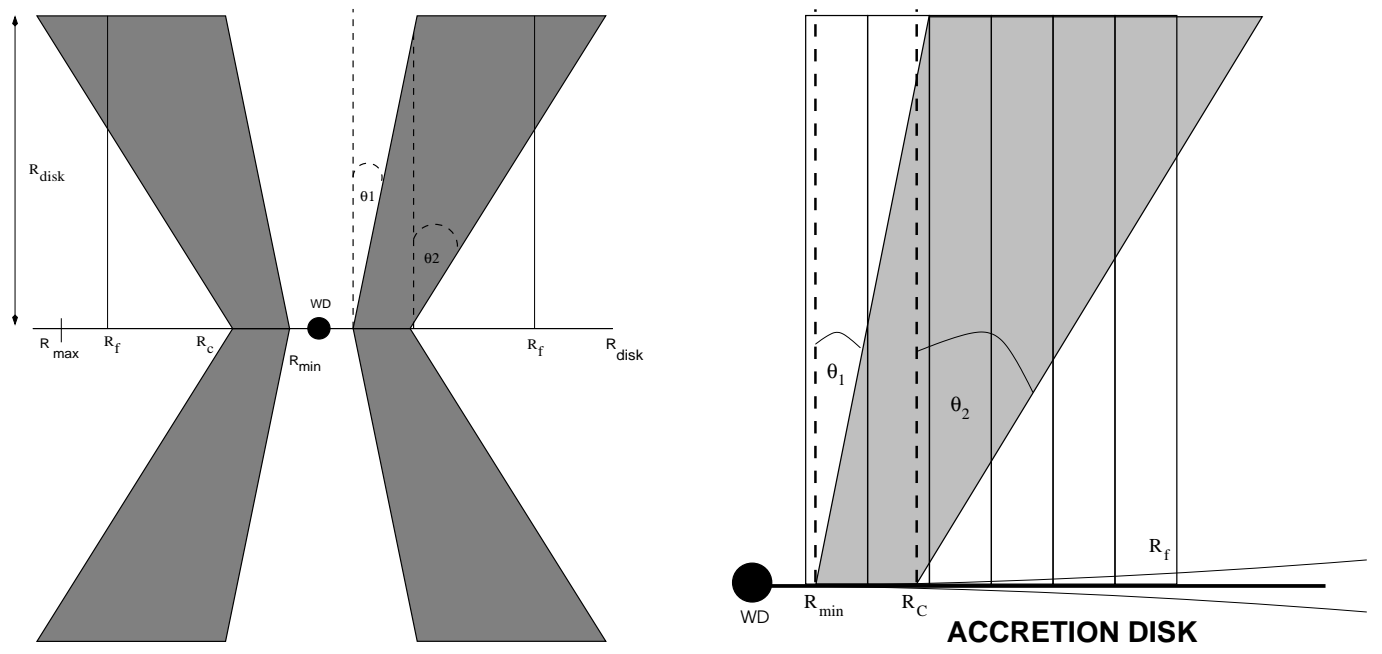

Figura 3.1: No painel esquerdo é mostrada a geometria do sistema para a síntese espectral. No painel direito é mostrado o esquema que descreve o significado de cada parâmetro geométrico.

\subsection{Análise das Estruturas de Atmosfera com Vento}

Nesta seção analisaremos as estruturas de atmosferas de disco com vento calculadas como o descrito no capítulo anterior. Do ponto de vista qualitativo, o comportamento geral da estrutura no sentido vertical destas atmosferas não varia muito de raio para raio. Isto, como veremos mais a adiante, é devido principalmente à própria aproximação planoparalela e também devido a que a interação entre as atmosferas não foi considerada no cálculo da estrutura. Esta iteração é levada em conta unicamente no momento de calcular a transferência radiativa na síntese espectral. Outras influências sobre a estrutura que não são levadas em conta até o momento são a da anã branca e da boundary layer. Esta última teria maior relevância nas regiões internas do vento.

Por estas razões será analisado um dos modelos calculados, e pontualizaremos os casos nos quais a diferenças entre os modelos sejam importantes. Esse modelo está identificado na tabela $3.1 \mathrm{com}$ a letra " $e$ ". As características principais dos modelos de atmosfera que formam parte deste modelo de disco estão descritas detalhadamente na tabela 3.3. Aqui o raio de cada anel é dado em raios da anã branca $R_{W D}$. A taxa de perda de massa, a velocidade terminal e a temperatura efetiva são mostrados como os parâmetros 
Tabela 3.3 - Caraterísticas físicas de cada anel que conformam o modelo e. O raio de cada anel, a fluxo de perda de massa, a velocidade terminal e a temperatura efetiva de cada um deles é mostrado. Também são mostradas as características físicas dos parâmetros estelares utilizados nos modelos de vento. Os parâmetros físicos do sistema são: $\mathrm{M}_{1}=0.8 \mathrm{M}_{\odot}, \dot{\mathrm{M}}_{a}=10^{-8} \mathrm{M}_{\odot}$ ano ${ }^{-1}$ e $\dot{\mathrm{M}}_{w}=9.3 \times 10^{-11} \mathrm{M}_{\odot} \mathrm{ano}^{-1}$.

\begin{tabular}{ccccccccc}
\hline \hline & & & & & & & \\
Anel & $\mathrm{R}$ & $\dot{\mathrm{m}}(\mathrm{R})$ & $\mathrm{V}_{\infty}$ & $\mathrm{T}_{\text {eff }}$ & $\mathrm{R}_{*}$ & $\mathrm{R}_{P}$ & $\mathrm{~L}$ & $\dot{\mathrm{M}}_{v}$ \\
& $\mathrm{R}_{W D}$ & $\mathrm{gr} \mathrm{cm}^{-2} \mathrm{~s}^{-1}$ & $\mathrm{~km} \mathrm{~s}^{-1}$ & $10^{4} \mathrm{~K}$ & $10^{10} \mathrm{~cm}$ & $\mathrm{R}_{*}$ & $\mathrm{~L}_{\odot}$ & $\mathrm{M}_{\odot} \mathrm{ano}^{-1}$ \\
\hline & & & & & & & & \\
1 & 1.05 & $1.2 \times 10^{-5}$ & 4043 & 5.42 & 70.00 & 1.0658 & $7.9 \times 10^{5}$ & $1.2 \times 10^{-6}$ \\
2 & 1.52 & $6.6 \times 10^{-5}$ & 3351 & 6.87 & 70.00 & 1.0658 & $2.0 \times 10^{6}$ & $5.5 \times 10^{-6}$ \\
3 & 2.20 & $3.7 \times 10^{-5}$ & 2770 & 5.96 & 70.00 & 1.0658 & $1.1 \times 10^{6}$ & $3.6 \times 10^{-6}$ \\
4 & 3.19 & $1.8 \times 10^{-5}$ & 2500 & 4.86 & 70.00 & 1.0658 & $5.1 \times 10^{5}$ & $1.7 \times 10^{-6}$ \\
5 & 4.63 & $8.5 \times 10^{-6}$ & 2500 & 3.86 & 70.00 & 1.0658 & $2.0 \times 10^{5}$ & $8.3 \times 10^{-7}$ \\
6 & 6.70 & $3.2 \times 10^{-6}$ & 2400 & 3.03 & 70.00 & 1.0658 & $7.7 \times 10^{4}$ & $3.2 \times 10^{-7}$ \\
7 & 9.72 & $1.2 \times 10^{-6}$ & 1950 & 2.35 & 70.00 & 1.0658 & $2.7 \times 10^{4}$ & $1.2 \times 10^{-7}$ \\
8 & 14.08 & $9.8 \times 10^{-7}$ & 1600 & 1.81 & 70.00 & 1.0658 & $9.9 \times 10^{3}$ & $9.3 \times 10^{-8}$ \\
9 & 20.41 & $1.5 \times 10^{-7}$ & 1260 & 1.39 & 70.00 & 1.0658 & $3.4 \times 10^{3}$ & $1.4 \times 10^{-8}$ \\
10 & 29.58 & $1.2 \times 10^{-7}$ & 980 & 1.06 & 70.00 & 1.0658 & $1.19 \times 10^{3}$ & $1.1 \times 10^{-8}$ \\
11 & 42.80 & - & - & 0.81 & 70.00 & 1.0658 & - & - \\
12 & 62.10 & - & - & 0.62 & 70.00 & 1.0658 & - & - \\
\hline
\end{tabular}

estelares análogos utilizados para o cálculo das atmosferas com vento. Os últimos dois anéis não foram calculados já que devido a sua baixa temperatura e densidade não contribuem fortemente ao contínuo nem às linhas no UV, além disso, nessas condições de densidades e temperaturas o código cai em fortes instabilidades devido a um excesso de radiação quando são levados em conta no cálculo do equilíbrio e transporte radiativo, fótons no extremo UV e raios-X. Estas instabilidades causam grandes problemas de convergência nos modelos.

Neste modelo e também nos outros modelos, a estrutura de atmosfera com vento é calculada em NLTE levando em conta as opacidades do H, He, C, N, O, Ne, Si e Fe. Os estados de ionização destas espécies inclusos em cada modelo são mostrados na tabela 3.4 junto com o número de níveis utilizados para cada íon. Daqui que o número de níveis é de 1200 e o número de transições levadas em conta com estes níveis é de 140000. Existem limitações que impõem compromissos tanto na resoluções espacial em raio como no número 
Tabela 3.4 - Ions utilizados para calcular a estrutura de atmosferas de vento em cada anel do disco, com o número de níveis usados para cada ion.

\begin{tabular}{cccccc}
\hline \hline Espécie & Níveis & Super-níveis & Espécie & Níveis & Super-níveis \\
\hline H I & 20 & 20 & O V & 41 & 41 \\
He I & 40 & 40 & O VI & 13 & 13 \\
He II & 22 & 22 & O VII & 1 & 1 \\
C II & 0 & 14 & Ne II & 0 & 14 \\
C III & 62 & 62 & Ne III & 23 & 13 \\
CIV & 13 & 13 & Ne IV & 17 & 17 \\
N II & 36 & 36 & Si III & 20 & 20 \\
N III & 34 & 34 & Si IV & 22 & 22 \\
N IV & 90 & 90 & Fe II & 135 & 135 \\
N V & 33 & 33 & Fe III & 96 & 96 \\
N VI & 1 & 1 & Fe IV & 100 & 100 \\
O II & 46 & 46 & Fe V & 139 & 139 \\
O III & 92 & 92 & Fe VI & 44 & 44 \\
O IV & 29 & 29 & Fe VII & 29 & 29
\end{tabular}

${ }^{1}$ Íons usados para modelos com $\mathrm{T}_{\text {eff }} \lesssim 20000 \mathrm{~K}$. 
de especies iônicas utilizadas devido principalmente à quantidade de memória necessária e ao tempo de processamento de cada modelo. Se levamos em conta que para cada modelo de disco é preciso a convergência de entre 6 até 10 modelos radiais de atmosferas, o tempo de processamento seria 15 dias no melhor dos casos. Apesar dessas limitações, é importante no futuro incorporar no cálculo um maior número de espécies atômicas e de estados de ionização assim como aumentar a resolução em raio do modelo de disco já que estas podem influenciar as características espectrais.

\subsubsection{Densidade e Temperatura}

Utilizando o modelo descrito na tabela 3.3, estruturas de atmosferas com vento foram calculadas para cada raio. A distribuição vertical de temperatura para cada atmosfera é mostrada na figura 3.2. Nesta figura a região de transição entre a fotosfera e o vento é mostrada. Em todas as atmosferas a temperatura decresce fortemente desde as regiões internas até a fotosfera do disco e atingir um mínimo, para depois crescer de novo em regiões opticamente finas até um valor inferior, mas próximo, da temperatura efetiva correspondente.

Este comportamento é característico de uma atmosfera calculada em NLTE e é provocado pelo efeito indireto das linhas de Lyman e Balmer sobre a taxa de aquecimento do contínuo de Lyman (Auer e Mihalas, 1969a,b,c). Quando a contínuo fica transparente $\left(\tau_{c}=1\right)$ a radiação que provém de regiões mais internas contínua a energizar as regiões exteriores de densidade decrescente. No caso da geometria plano-paralela $J_{\nu}$ mantem-se constante nas regiões opticamente finas já que não existe diluição da radiação e a temperatura dessas regiões continua a refletir as características da radiação mais interna. O mínimo da temperatura é produzido na região mais externa onde o gás ainda está em equilíbrio termodinâmico local, já que nessas regiões a radiação encontra-se ainda acoplada com o gás. Este mínimo de temperatura ao depender da profundidade óptica da atmosfera, tem a sua localização no sentido vertical dependente do raio, já que a espessura da "fotosfera" aumenta com o raio, produzindo o que é conhecido como "flare" do disco.

Na figura 3.3 os perfis de temperatura para as regiões mais externas de cada atmosfera é mostrado. Estes perfis são praticamente planos devido à geometria plano paralela. Somente os anéis mais internos mostram um pequeno resfriamento de $\sim 150 \mathrm{~K}$. A forte diferença 


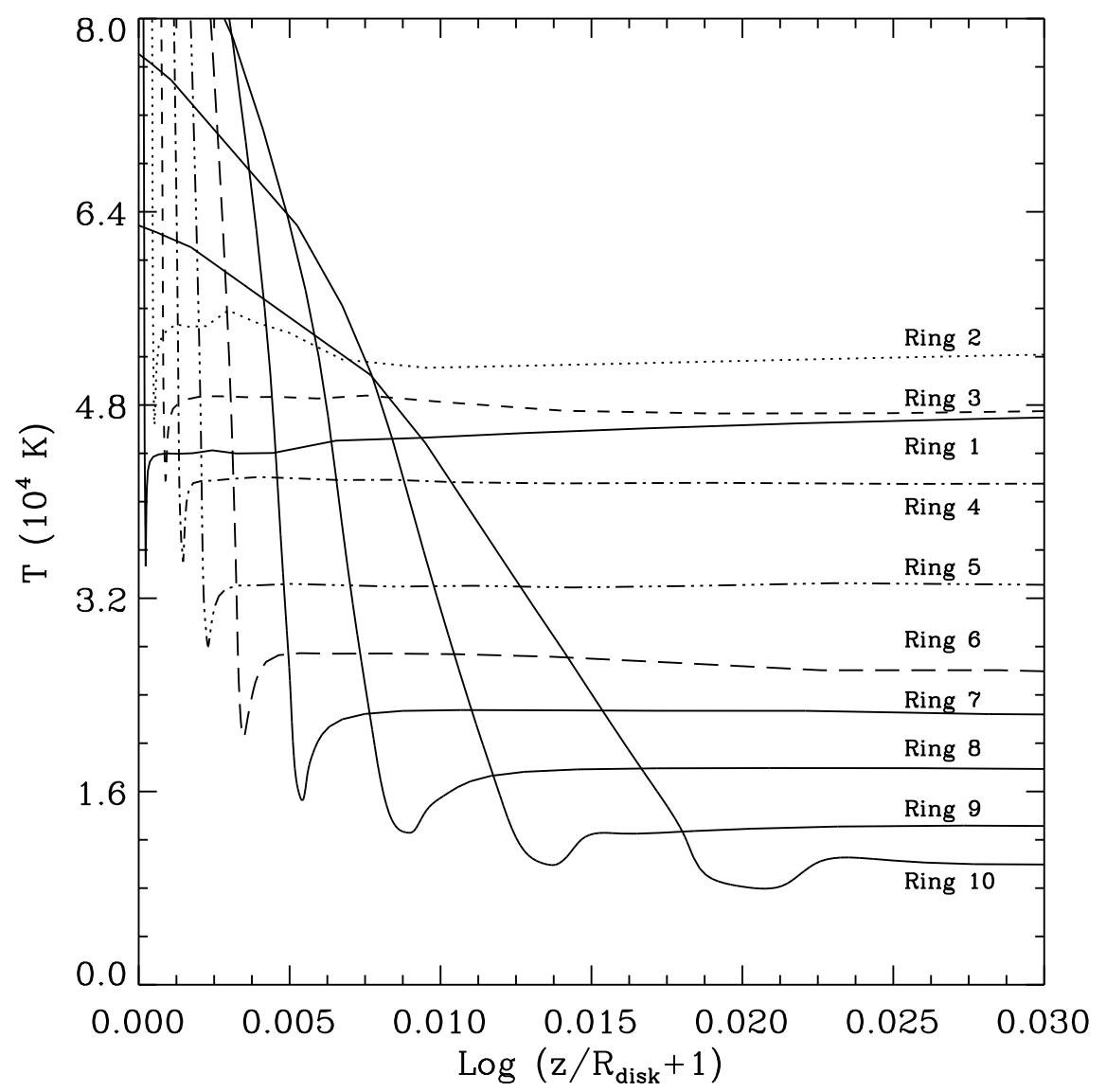

Figura 3.2: Perfis verticais de temperatura das atmosferas com vento para o modelo "e" na região de transição fotosfera-vento.

existente entre a nossa aproximação plano paralela e a esférica usada em estrelas quentes, tem base em dois motivos principais; a diluição da radiação e a presença de um disco finito. A primeira faz o aquecimento mais eficiente do que o resfriamento nas regiões externas de cada atmosfera. A última não leva em conta contribuições radiativas de regiões diferentes à vertical em cada ponto do vento, o que pode modificar a estrutura da atmosfera.

$\mathrm{Na}$ figura 3.4 os perfis de temperatura e densidade são mostrados para o anel 5 do modelo analisado. Este modelo tem uma temperatura efetiva de $38600 \mathrm{~K}$. O ponto onde a profundidade óptica de Rossland $\left(\tau_{R}=1\right)$ também é mostrado. É possível ver que o mínimo da temperatura encontra-se alem de $\tau_{R}=1$, na região do vento onde $\tau_{R}=5 \times 10^{-3}$.

Como é mostrado na figura 3.5, a região entre estes valores da profundidade óptica coincide com a região de máxima aceleração do vento, mesmo que o ponto de temperatura 


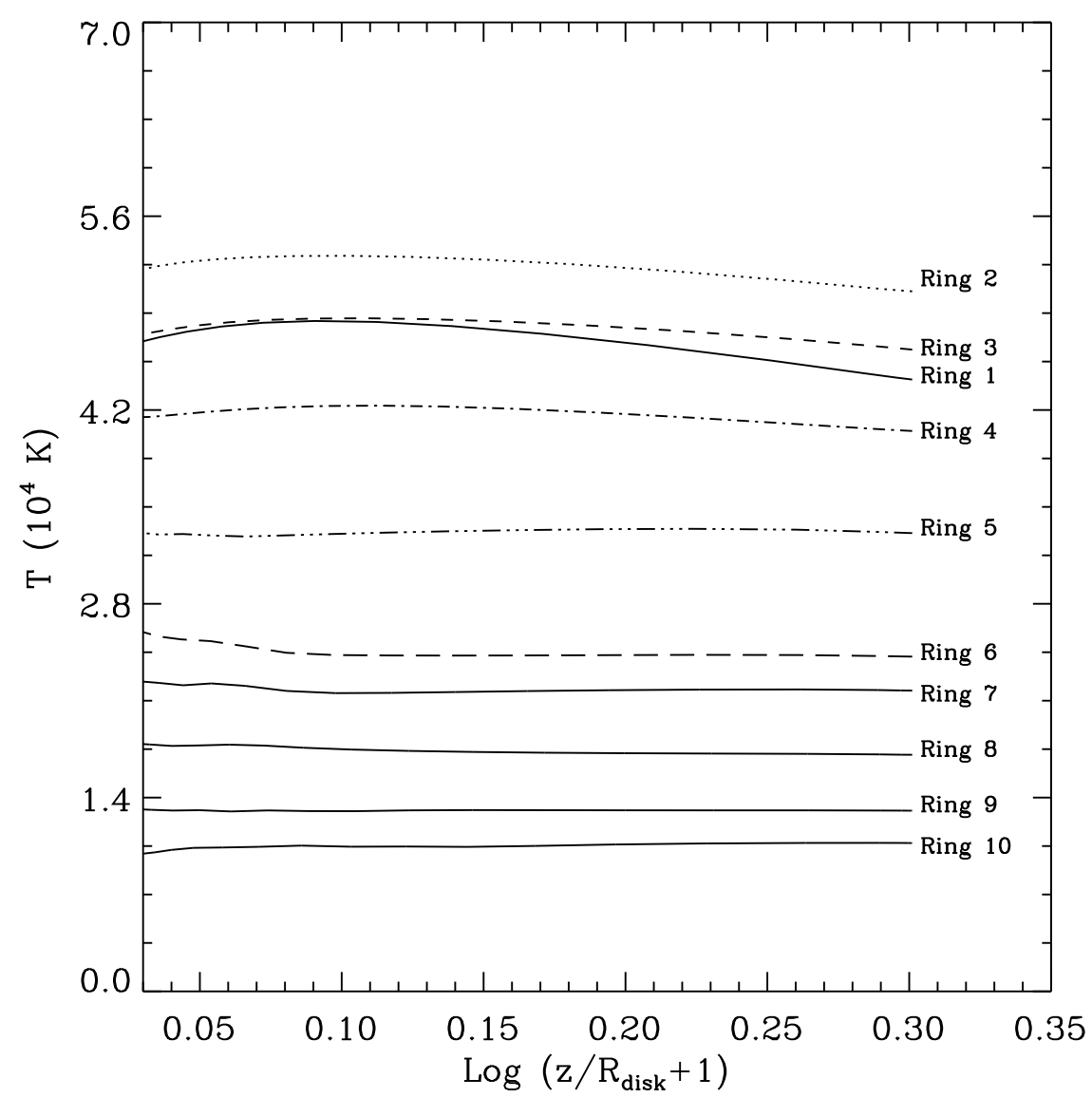

Figura 3.3: Perfis verticais de temperatura das atmosferas com vento para o modelo "e" na região vertical extensa do vento.

mínima não coincida com esse ponto como é visto no painel direito da mesma figura. Este comportamento é característico de atmosferas com vento na região de transição entre a fotosfera e o vento no cálculo NLTE e é similar tanto em modelos plano paralelos como esféricos. Para regiões externas, onde a geometria e a diluição da radiação têm uma forte influência, a estrutura nos dois casos é muito diferente; o que será tratado em detalhe na seção 4.8. Na figura 3.6 são comparados os perfis de temperatura em função da profundidade óptica para o modelo plano-paralelo do anel 5 e para uma estrela tipo $\mathrm{O}$ com temperatura efetiva de $40000 \mathrm{~K}$. Ali é possível ver o efeito que têm a geometria e a diluição da radiação sobre a estrutura de temperatura. No caso estelar (esférico) há uma queda na temperatura nas regiões externas e extensas, enquanto que no caso plano paralelo a temperatura mantém-se praticamente constante. 


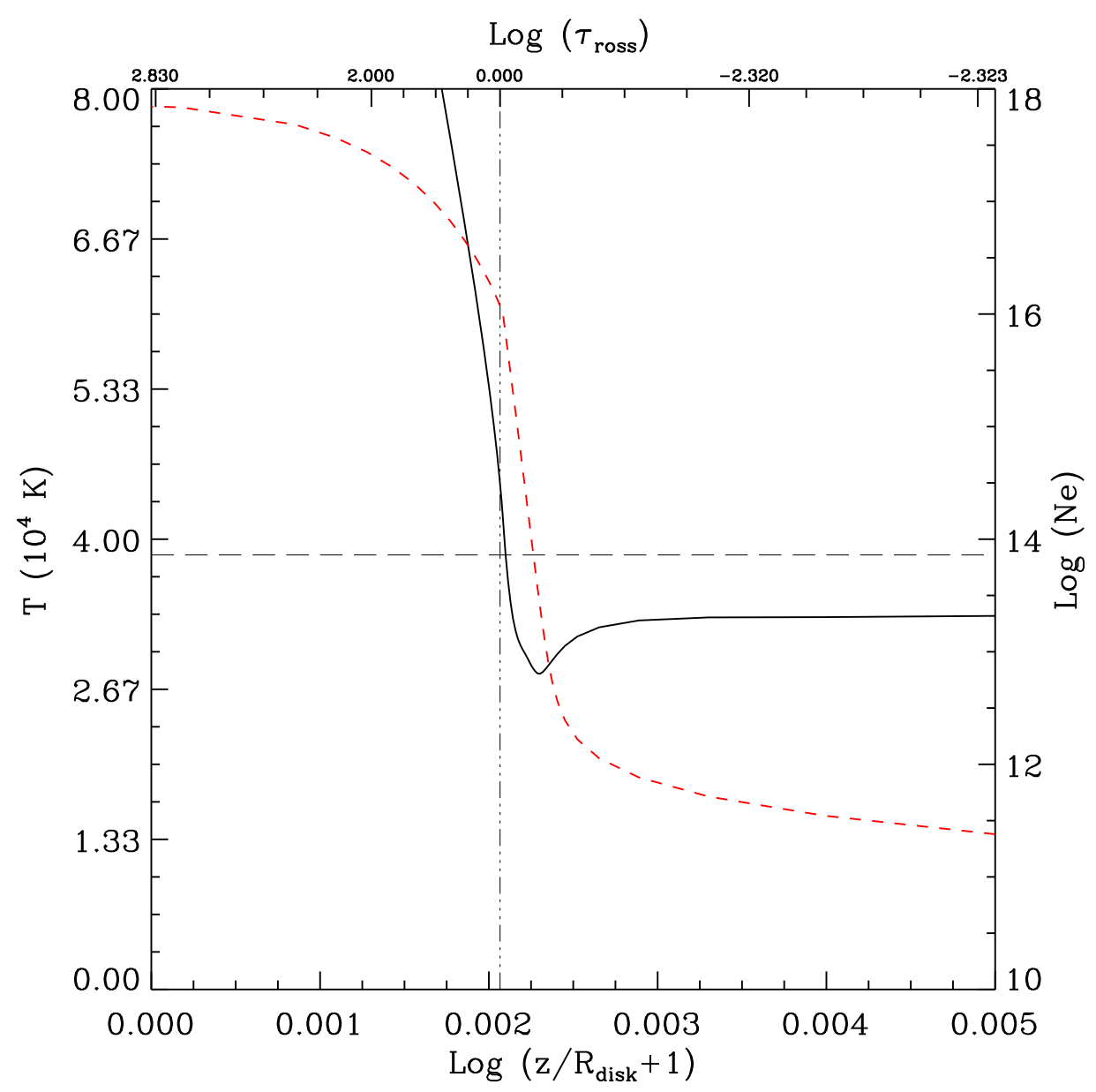

Figura 3.4: Perfil vertical da temperatura (lina preta) e densidade eletrônica (linha vermelha tracilhada) para o quinto anel do modelo. O eixo horizontal superior é profundidade óptica de Rossland $\left(\tau_{R}\right)$ e tem uma escala fortemente não linear. A linha vertical mostra onde a opacidade $\tau_{R}=1$ e a linha horizantal mostra a tepmeratura efetiva $\mathrm{T}=38600 \mathrm{~K}$. 

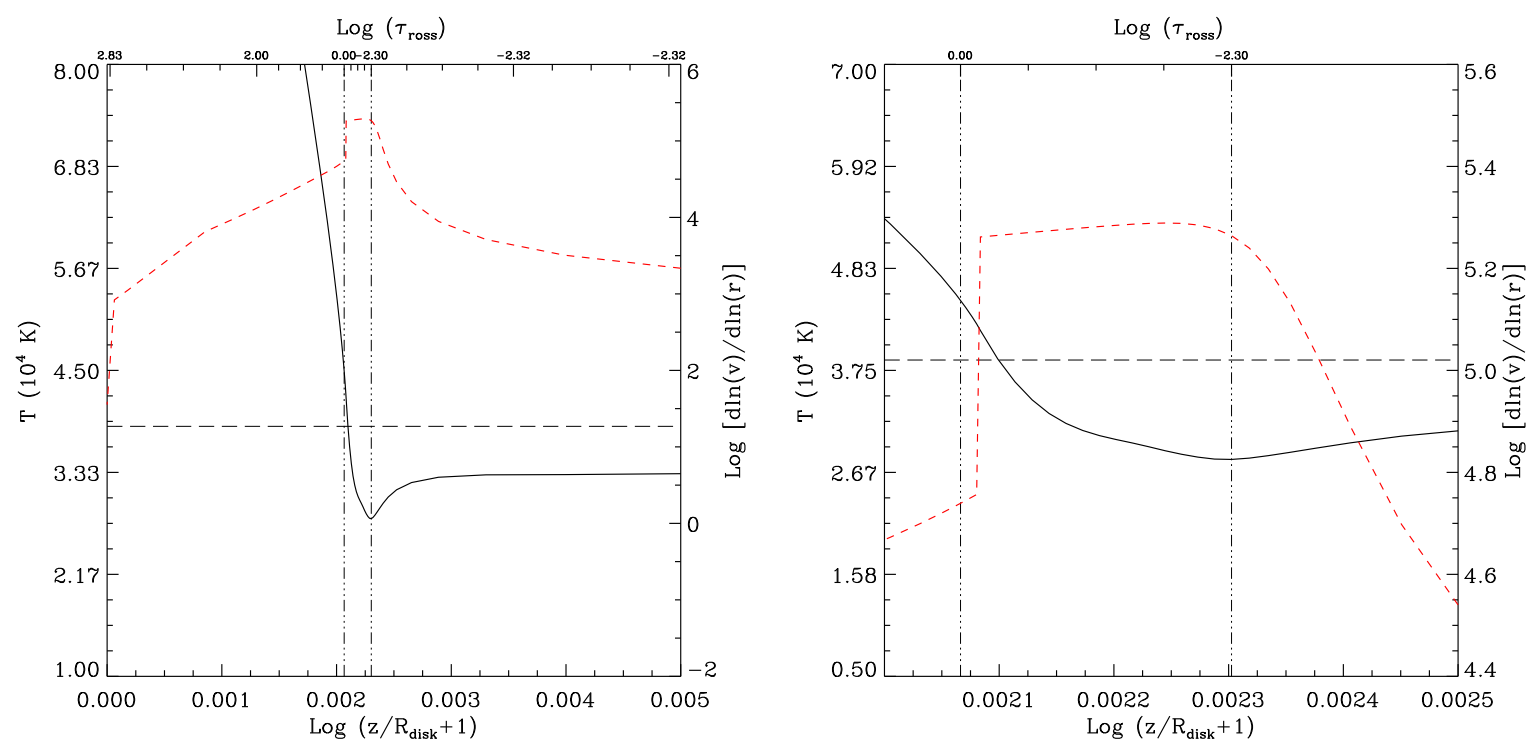

Figura 3.5: Perfil da aceleração vertical do vento $\log [d \ln v / d \ln z]$ no modelo da figura 3.4 junto com o perfil vertical de temperatura. No painel direito temos uma ampliação da região de máxima aceleração e temperatura mínima. 


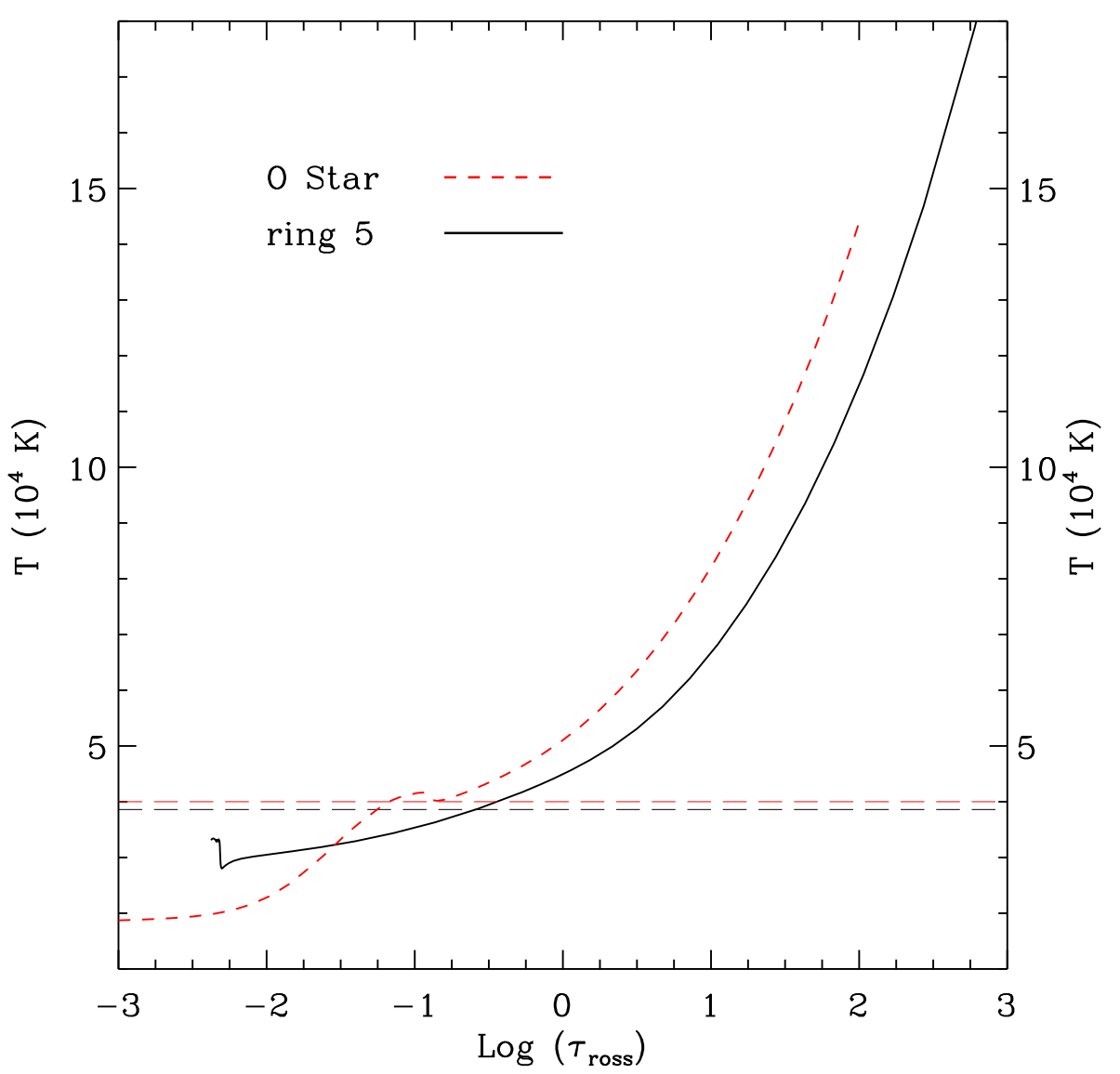

Figura 3.6: Perfil de temperatura em função da profundidade óptica para o modelos plano paralelo do anel 5 do modelo " $e$ " com temperatura efetiva de $38600 \mathrm{~K}$ (linha preta) junto com o perfil de temperatura calculado para uma estrela tipo O com temperatura efetiva de $40000 \mathrm{~K}$ (linha vermelha). 


\subsubsection{Estrutura de ionização}

Nesta seção analisaremos as estruturas de ionização dos modelos de atmosferas com vento. Isto nos dará uma ideia da estrutura bi-dimensional e suas propriedades radiativas. Novamente nos basearemos no modelo " $e$ " da tabela 3.1. No conjunto de figuras seguintes as estruturas de ionização para o carbono são mostradas para cada atmosfera calculada, correspondente a cada anel do disco.

Estas figuras mostram para cada anel a população dos íons do carbono C II, C III, C IV e C v normalizados para a população total desta espécie. Cada línea mostra dois painéis, o da esquerda correspondente à região de transição fotosfera-vento e o da direita correspondente à região extensa do vento. No primeiro caso nas regiões internas (fig. 3.7) do disco o íon dominante é o CV com uma recombinação para C IV no mínimo de temperatura na atmosfera correspondente ao primeiro anel. Nas regiões intermediárias (fig. 3.8) na região de transição mostra-se muito estruturada levando a recombinações na região de mínima temperatura que levam a que os íons dominantes passem a ser o C IV e CiII. Além da região de temperatura mínima os fótons das regiões mais internas voltam a ionizar o gás devido ao mecanismo de Cayrel (Mihalas, 1978) pelo qual o íon dominante volta a ser o $\mathrm{C} v$ até que a uma distancia $\mathrm{R}=6.70 \mathrm{R}_{W D}$ e uma temperatura efetiva de $\sim 30000 \mathrm{~K}$ onde o ion dominante passa a ser o C IV. Quando a temperatura desce até $23000 \mathrm{~K}$ a uma distância ao eixo de simetria de $\mathrm{R}=9.72 \mathrm{R}_{W D}$ na região do mínimo de temperatura tanto o C IV, C III e o C II passam a dominar em pequenas regiões sucessivas para depois, devido ao mesmo mecanismo o íon dominante volta a ser o C III. Este mesmo comportamento mantem-se nas atmosferas correspondentes às regiões mais externas e mais frias do vento, com a diferença de que as estruturas mostram-se cada vez menos ionizadas a causa de que a temperatura da radiação que provem das regiões inferiores é menor. As fortes variações na estrutura de ionização na região de transição são cada vez mais estendidas e mais distantes do plano do disco quanto mais afastada está a atmosfera do centro do disco. Isto devido a que os gradientes das magnitudes físicas, como a gravidade, são mais suaves com a altura ao aumentar $R$, comportamento conhecido já em fotosferas de discos de acresção. 

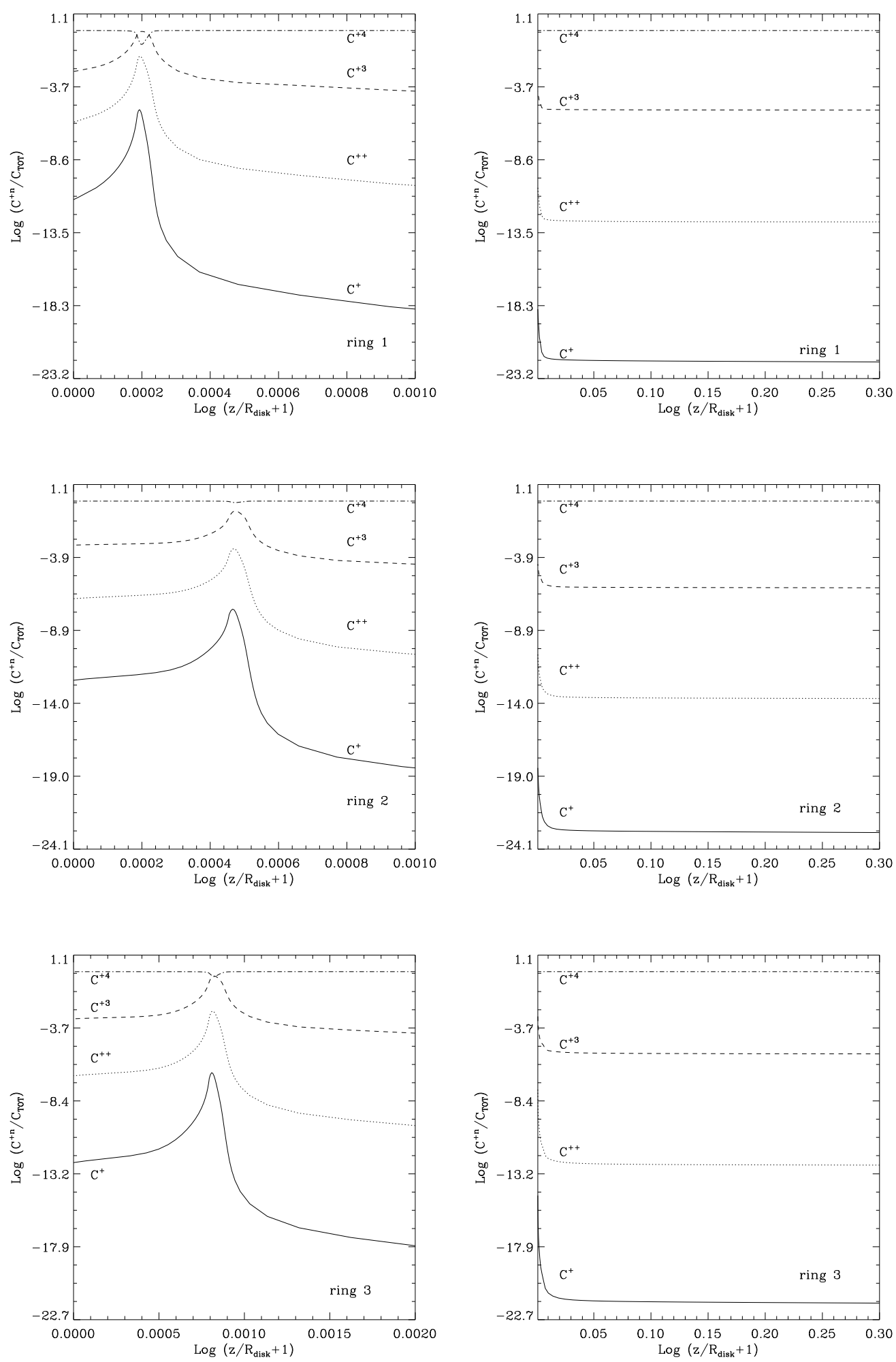

Figura 3.7: Estrutura de ionização do carbono para os anéis 1, 2 e 3 do modelo $e$. Nos painéis esquerdos a região de transição fotosfera vendo é mostrada. Nos painéis da direita é mostrada a região extensa do vento para cada modelo de atmosfera. 

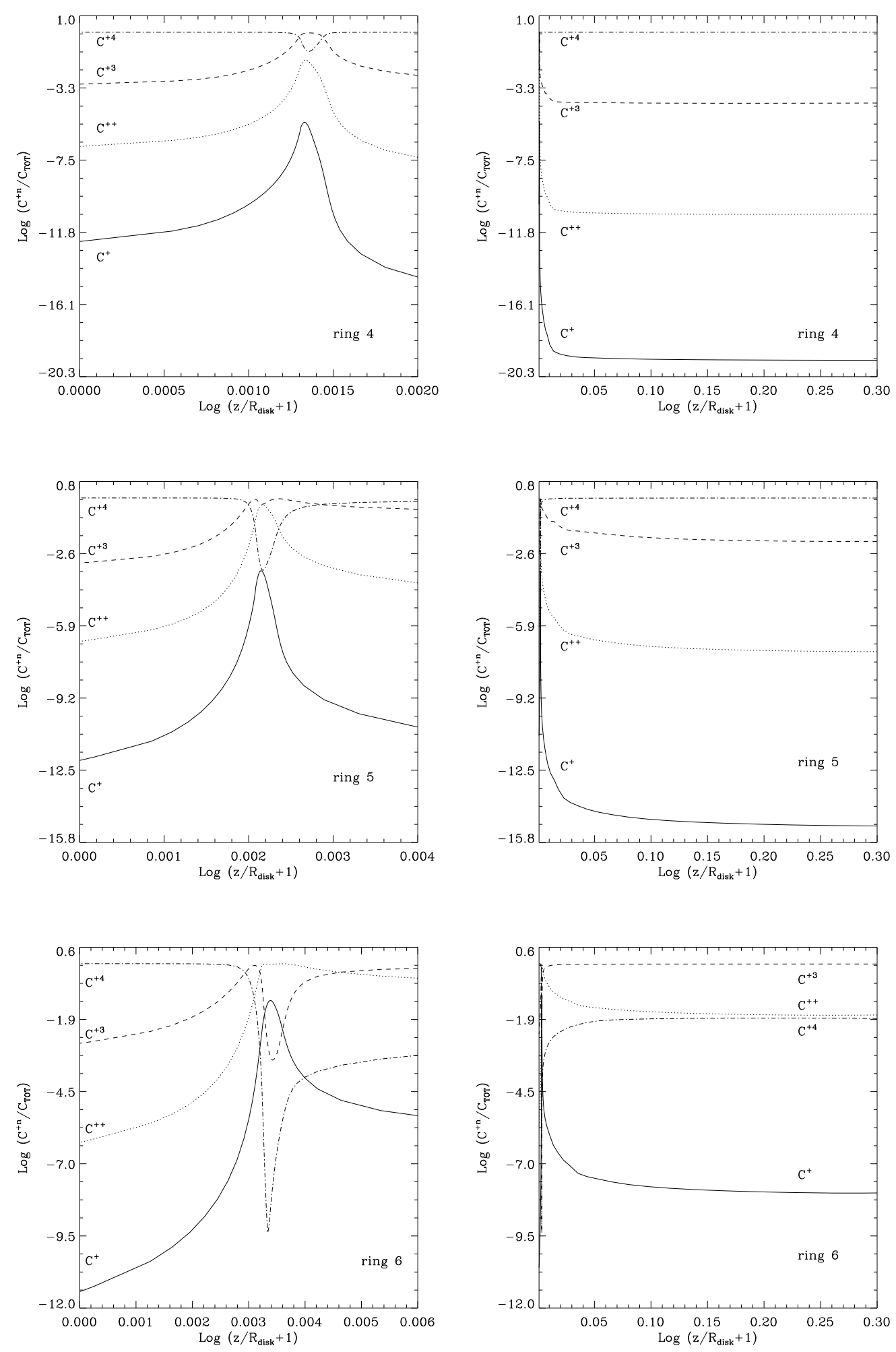

Figura 3.8: Estrutura de ionização do carbono para os anéis 4, 5 e 6 do modelo $e$. Nos painéis esquerdos a região de transição fotosfera vendo é mostrada. Nos painéis da direita é mostrada a região extensa do vento para cada modelo de atmosfera. 

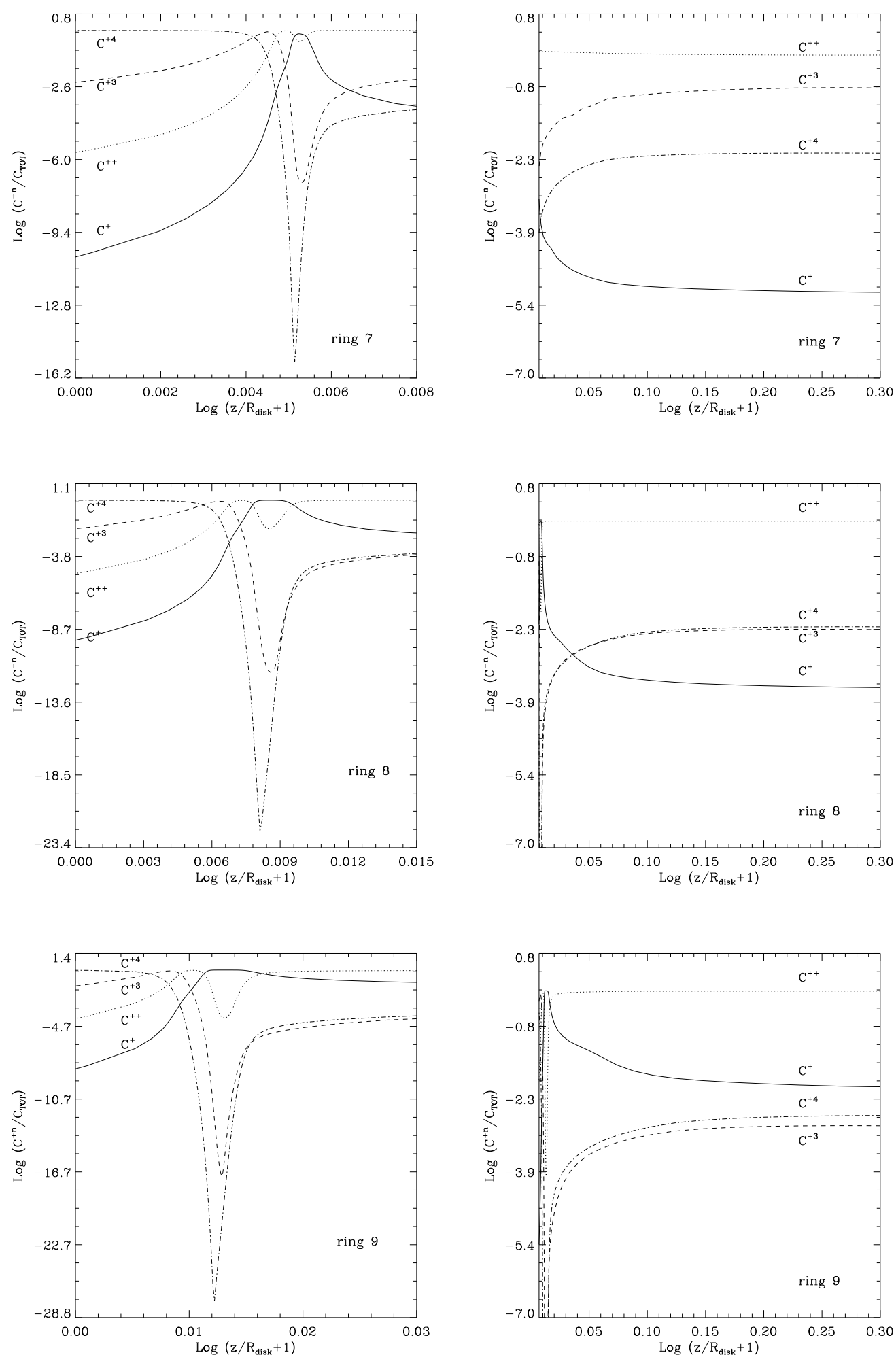

Figura 3.9: Estrutura de ionização do carbono para os anéis 7, 8 e 9 do modelo $e$. Nos painéis esquerdos a região de transição fotosfera vendo é mostrada. Nos painéis da direita é mostrada a região extensa do vento para cada modelo de atmosfera. 

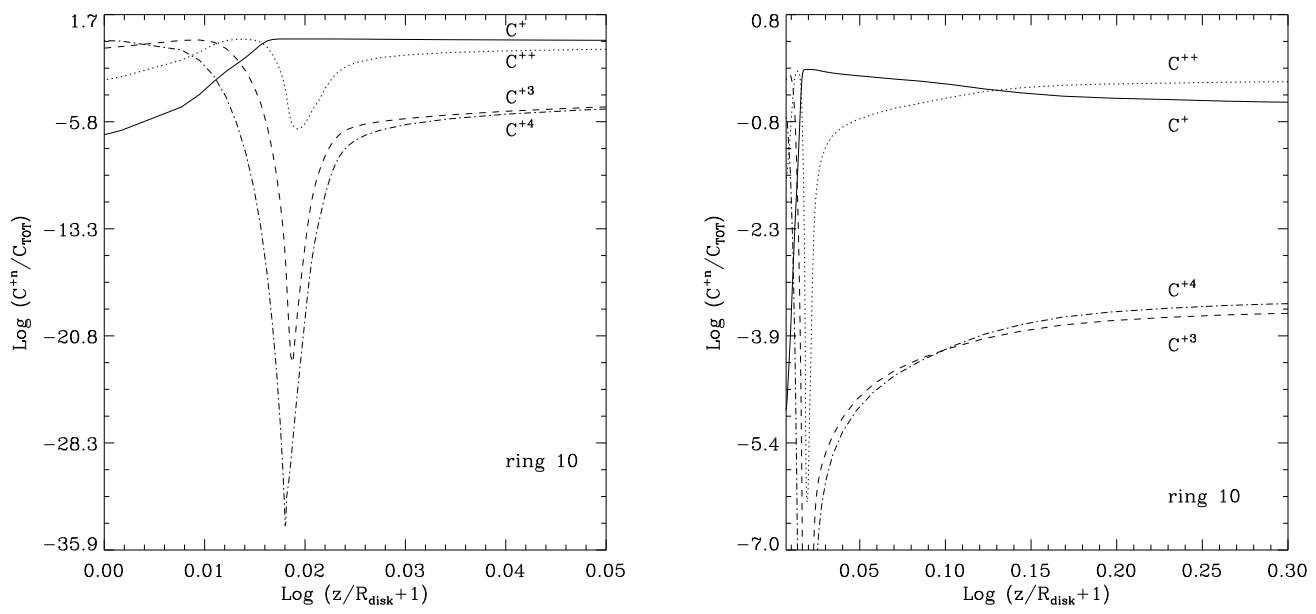

Figura 3.10: Estrutura de ionização do carbono para o anel 10 do modelo $e$. No painel esquerdo a região de transição fotosfera vendo é mostrada. Nos painel da direita a região extensa do vento é mostrada. 
Nas regiões estendidas das atmosferas (painéis da direita) a estrutura de ionização mostra-se fortemente constante com a altura, isto devido principalmente a que a temperatura no sentido vertical mantém-se constante como é mostrado da figura 3.2 produto da geometria aplicada ao modelo e ao forte afastamento da atmosfera do LTE. Radialmente as regiões estendidas mostram uma certa estruturação bem definida mudando o estado de ionização fortemente desde o interior até os raios mais externos. É interessante ressaltar que no caso do carbono nas regiões internas o gás é dominado pelo $\mathrm{C}$ V passando pelo $\mathrm{C}$ IV nas regiões intermediárias e finalmente para o C III para uma região muito extensa desde $9.72 \mathrm{R}_{W D}$ até $29.58 \mathrm{R}_{W D}$.

Nas figuras 3.11 e 3.12 a estrutura de ionização do He para as diferentes atmosferas correspondentes ao modelo "e" é mostrada. A estrutura de ionização tem um comportamento similar ao calculado para o carbono. Nas regiões internas o íon dominante praticamente em toda a superfície é o He III, até uma temperatura de $37000 \mathrm{~K}$ e uma distância de $6.7 \mathrm{R}_{W D}$. Alem dessa temperatura e até as regiões mais externas do disco o íon dominante do hélio vem a ser o He II com um incremento gradual da fração do He neutro para as regiões mais externas, mas sem ultrapassar a concentração de He II. Uma forte recombinação também é encontrada na região de temperatura mínima como no caso do carbono, chegando ao ponto que nos anéis mais externos o He neutro é dominante na região de transição, para depois ser ionizado novamente para He II. 

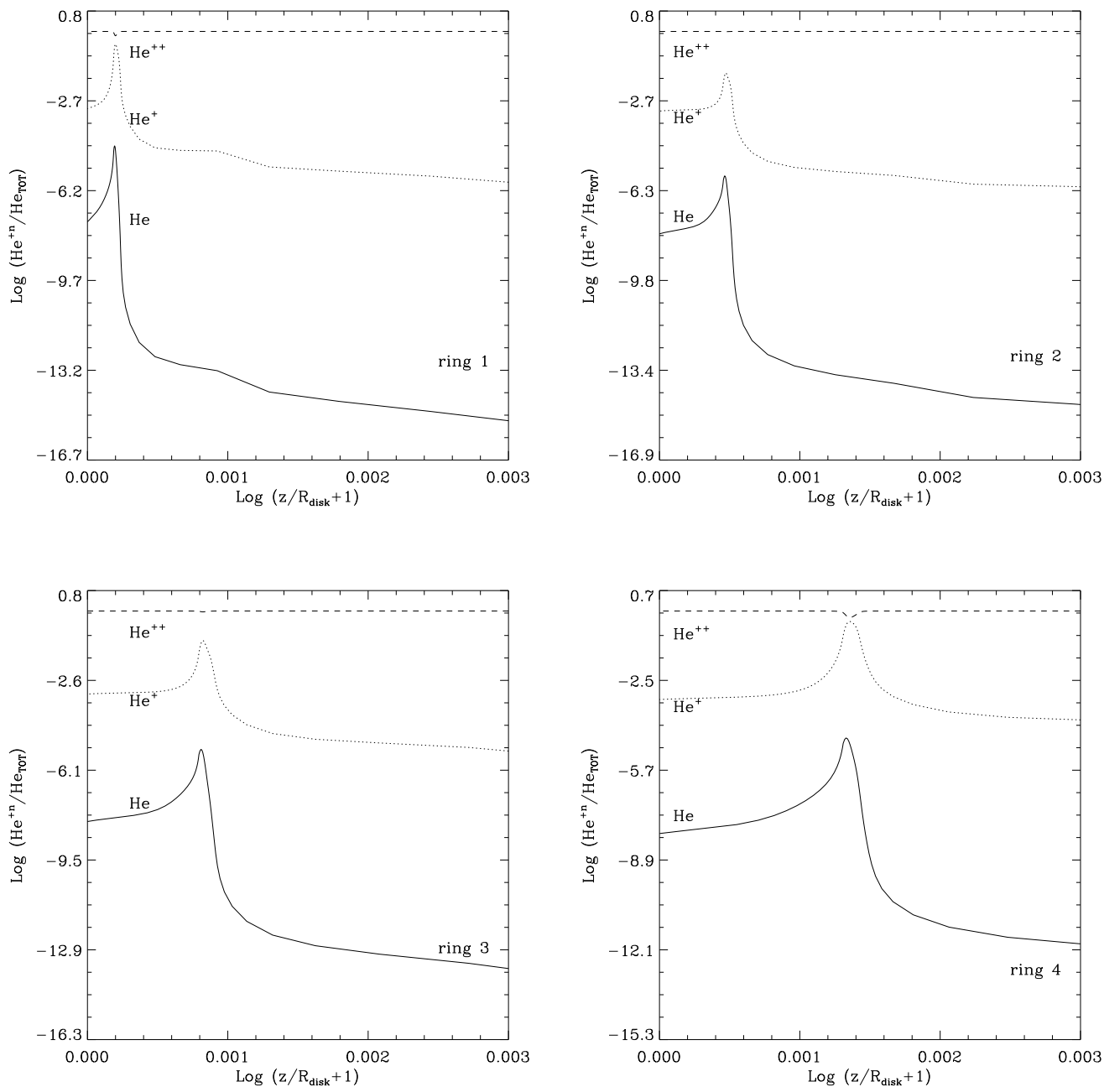

Figura 3.11: Estrutura de ionização do hélio para os anéis 1, 2, 3 e 4 do modelo $e$ na região de transição fotosfera-vento é mostrada. 

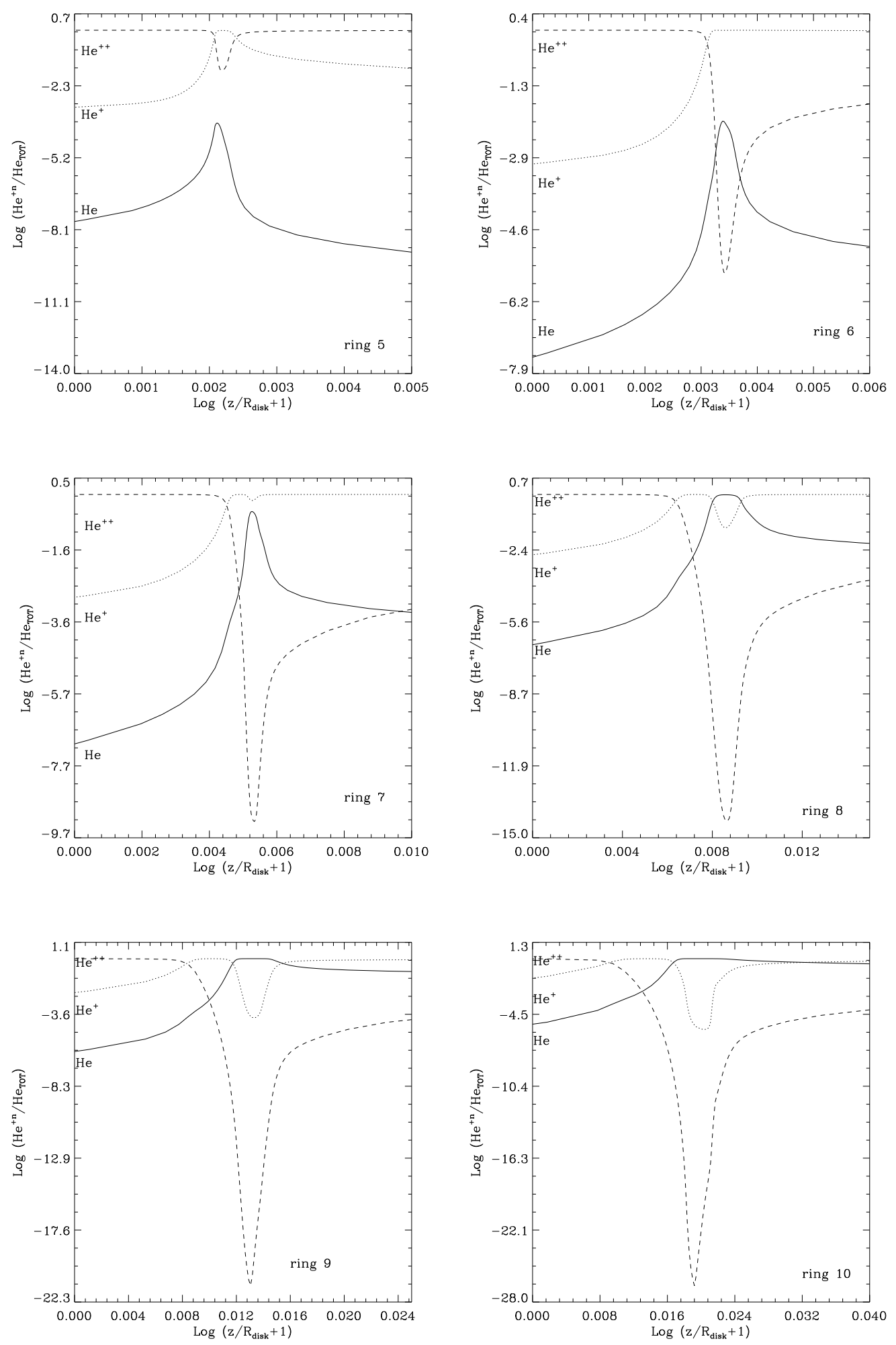

Figura 3.12: Estrutura de ionização do hélio para os anéis $5,6,7,8,9$ e 10 do modelo $e$ na região de transição fotosfera-vento é mostrada. 
Por último, para ilustrar o comportamento das estruturas de ionização deste tipo de atmosferas de disco com vento, na figura 3.13 é mostrada a estrutura de ionização para oxigênio no anel $5\left(\mathrm{R}=4.63 \mathrm{R}_{W D}\right.$ e $\left.\mathrm{T}(\mathrm{R})=38600 \mathrm{~K}\right)$ do mesmo modelo. Neste caso um comportamento similar na região de mínima temperatura é encontrado quando chegamos a ter um domínio de O III, voltando depois nas regiões mais extensas a dominar o íon de O IV pelo mesmo mecanismo, correspondendo a uma radiação com temperatura da ordem da $\mathrm{T}_{\text {ef }}$ deste modelo.
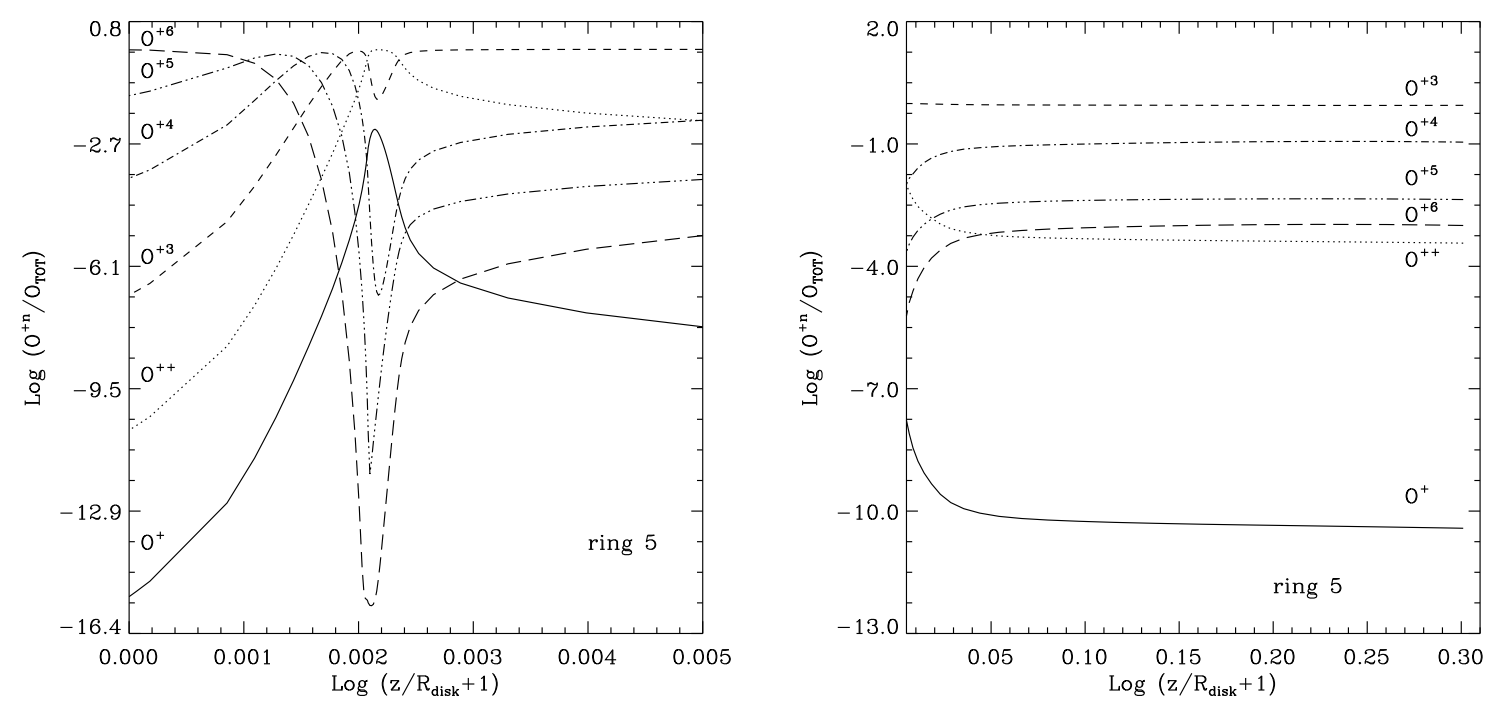

Figura 3.13: Estrutura de ionização do oxigeno para o anel 5 do modelo $e\left(\mathrm{~T}_{e f}(\mathrm{R})=38600 \mathrm{~K}\right)$. No painel esquerdo a região de transição fotosfera vendo é mostrada. Nos painel da direita a região extensa do vento é mostrada. 


\subsubsection{Populações de níveis}

Nesta seção a população dos níveis que formam as principais linhas observadas no UV em Variáveis Cataclísmicas quentes é analisada. As principais linhas investigadas são as dos íons N v (1238, 1240), C III (1175, 1908), Si III (1206, 1298, 1301), Si IV (1206, 1298, 1301), C IV $(1550.7,1548.2)$ e He II (1640).

CIII $(1175,1908)$

As transições responsáveis por estas linhas são dos níveis (1-3) para a linha em $1908 \AA$ e (3-6, 3-7) para a linha 1175, já que esta é um dupleto. Estas notações dos níveis estão na nomenclatura do código. As configurações eletrônicas dos níveis que produzem estas linhas são $1 \mathrm{~s}^{2} 2 \mathrm{~s}^{2}\left({ }^{1} \mathrm{~S}^{0}\right)-1 \mathrm{~s}^{2} 2 \mathrm{~s} 2 \mathrm{p}\left({ }^{1} \mathrm{P}^{1}\right)$ para a linha $1908 \AA$ e $1 \mathrm{~s}^{2} 2 \mathrm{~s} 2 \mathrm{p}\left({ }^{3} \mathrm{P}^{0}\right)-1 \mathrm{~s}^{2} 2 \mathrm{p}^{2}\left({ }^{3} \mathrm{P}^{1}\right.$, $\left.{ }^{3} \mathrm{P}^{2}\right)$ para a linha $1775 \AA$.
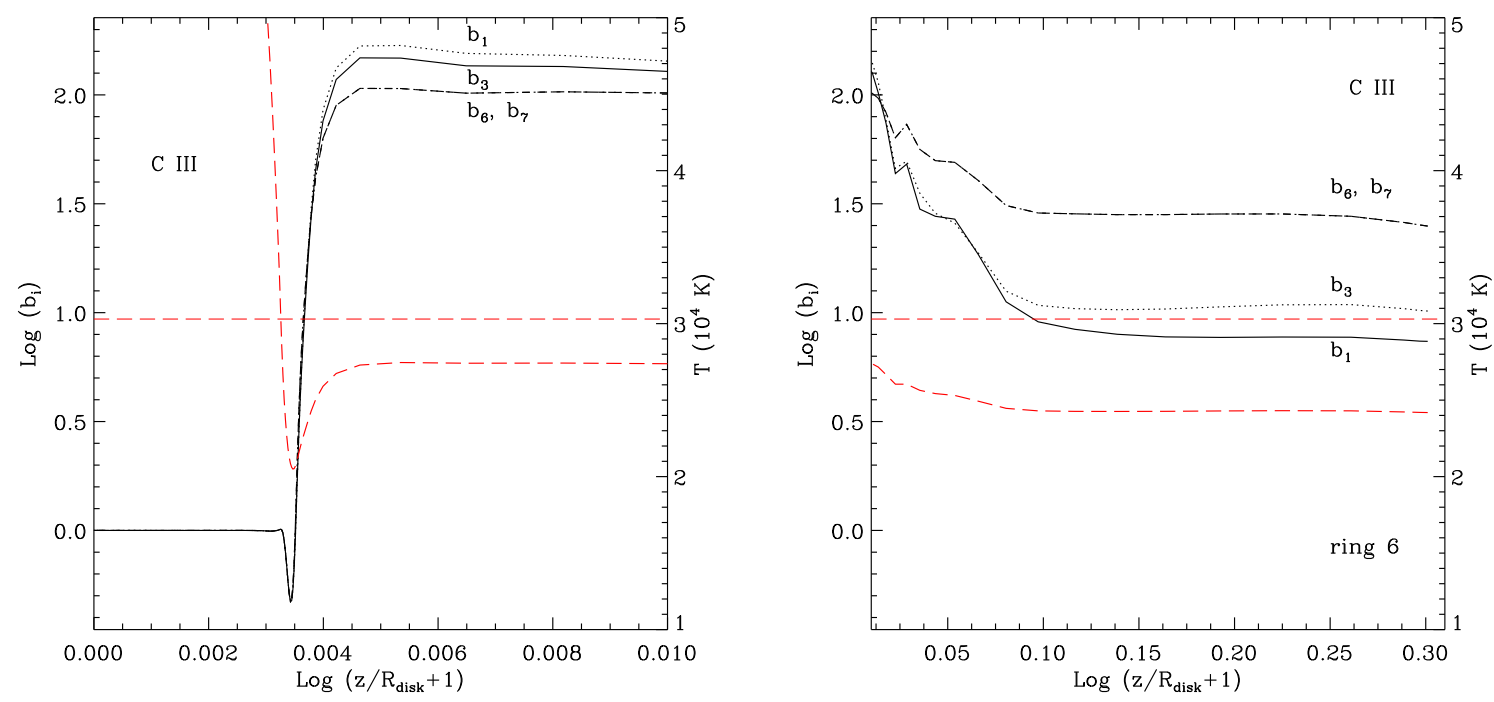

Figura 3.14: Coeficientes de desvio do LTE das populações nos níveis que formam as linhas do C III (1175, 1908). No painel esquerdo mostra-se a região de transição fotosfera-vento e no painel direito a região extensa do vento. A linha vermelha mostra o perfil vertical de temperatura nessa região da atmosfera.

Na figura 3.14 os coeficientes de desvio do equilíbrio termodinâmico local $\left(b_{i}\right)$, para estes níveis junto com a distribuição vertical de temperatura eletrônica são mostrados. Este gráfico corresponde ao anel 6 do modelo "e" a uma distância de $6.07 \mathrm{R}_{W D}$ do eixo de rotação do disco, com uma temperatura efetiva de 30300 K. Os gráficos mostram que além de $\tau_{R} \sim 1$ o sistema afasta-se muito do LTE. As populações destes níveis mostram-se sobre 
povoadas em toda a região extensa do vento depois de uma rápida depopulação de todos eles na região de temperatura mínima, mesmo que neste caso o mínimo dos coeficientes de desvio $b_{i}$ não coincide com o mínimo de temperatura. A sobre-população dos níveis vai caindo para as regiões mais externas depois de atingir o máximo onde a temperatura também é máxima. Mesmo assim os níveis mantêm-se sempre sobre povoados $\left(b_{i}>1\right)$. Analisando os valores absolutos das populações é evidente que a sobre-população dos níveis provém da alta recombinação e decaimento dos níveis superiores. Já radialmente, para regiões mais internas do vento estes níveis mostram-se fortemente despovoados e em regiões externas superpovoados no mesmo sentido que na região mostrada na figura 3.14.

\section{HeII (1640)}

A transição responsável pela emissão desta linha é entre os níveis $n=2$ e $n=3$. Os estados dos outros números quânticos são degenerados em energia devido a que o átomo é hidrogenóide com $\mathrm{Z}=2$.
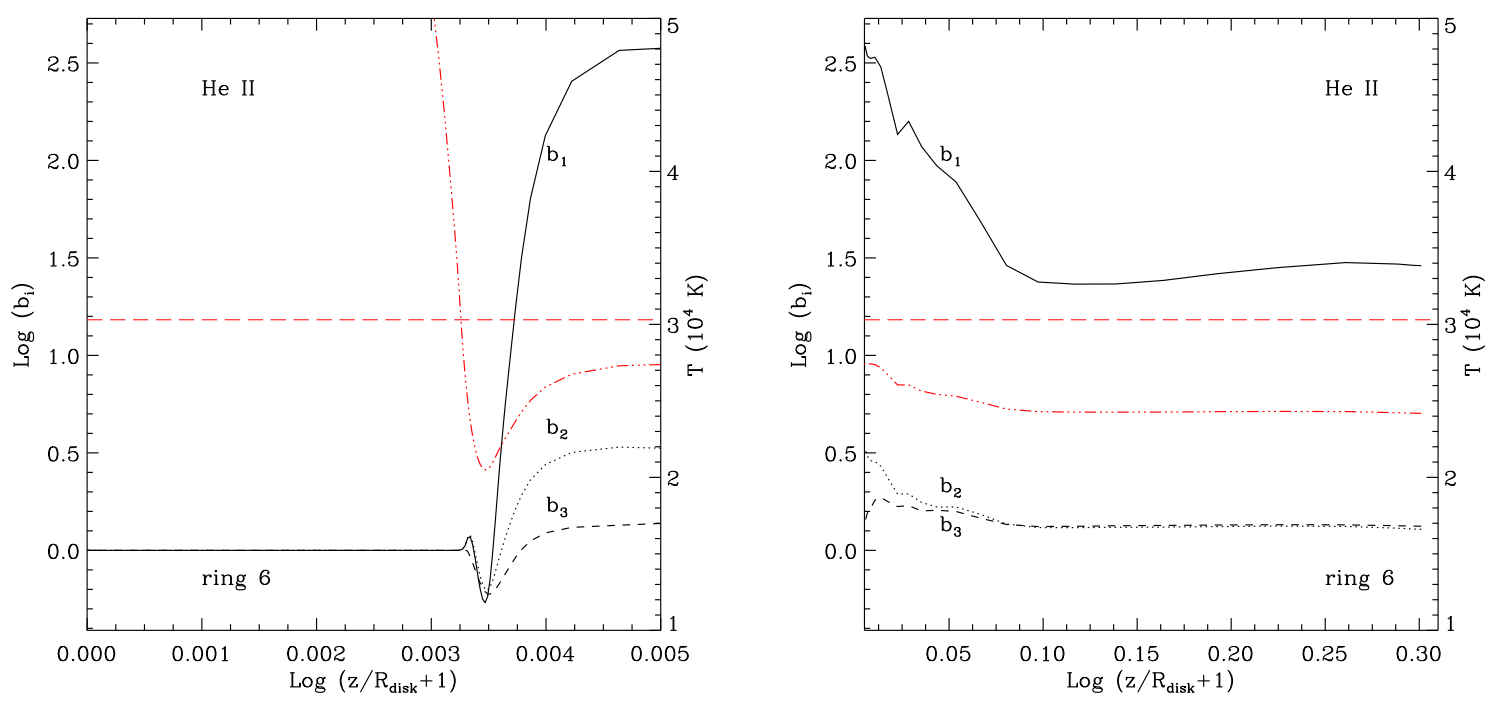

Figura 3.15: Coeficientes de desvio do LTE das populações nos níveis que formam a linha do He II (1640). No painel esquerdo mostra-se a região de transição fotosfera-vento e no painel direito a região extensa do vento. A linha vermelha mostra o perfil vertical de temperatura nessa região da atmosfera.

Na figura 3.15 os coeficientes de desvio do equilíbrio termodinâmico local $b_{i}$, para estes níveis junto com a distribuição vertical de temperatura eletrônica são mostrados. Este gráfico corresponde ao mesmo modelo de atmosfera do gráfico anterior. Também estes 
gráficos mostram que além de $\tau_{R} \sim 1$ o sistema afasta-se muito do LTE. O comportamento destes níveis é muito similar ao mostrado na figura 3.14, com os três níveis do He II sobre povoados na região extensa da atmosfera. O seu comportamento, como no caso anterior parece acompanhar a distribuição vertical da temperatura através do vento. Os níveis que formam a linha em $1640 \AA$ (2 e 3) conservam um comportamento similar em toda a atmosfera, mesmo que na região mais externa o nível $n=3$ passa a estar mais povoado do que o nível $\mathrm{n}=2$.

CIV $(1548,1551)$

As transições responsáveis por estas linhas são os níveis (1-2) para a linha em $1550.7 \AA$ e (1-3) para a linha 1548.2 A. As configurações eletrônicas dos níveis que produzem estas linhas são $1 \mathrm{~s}^{2} 2 \mathrm{~s}\left({ }^{2} \mathrm{~S}_{1 / 2}\right)-1 \mathrm{~s}^{2} 2 \mathrm{p}\left({ }^{2} \mathrm{P}_{1 / 2}\right)$ para a linha $1550.7 \AA$ e $1 \mathrm{~s}^{2} 2 \mathrm{~s}\left({ }^{2} \mathrm{~S}_{1 / 2}\right)-1 \mathrm{~s}^{2} 2 \mathrm{p}\left({ }^{2} \mathrm{P}_{3 / 2}\right)$ $1545.2 \AA$.
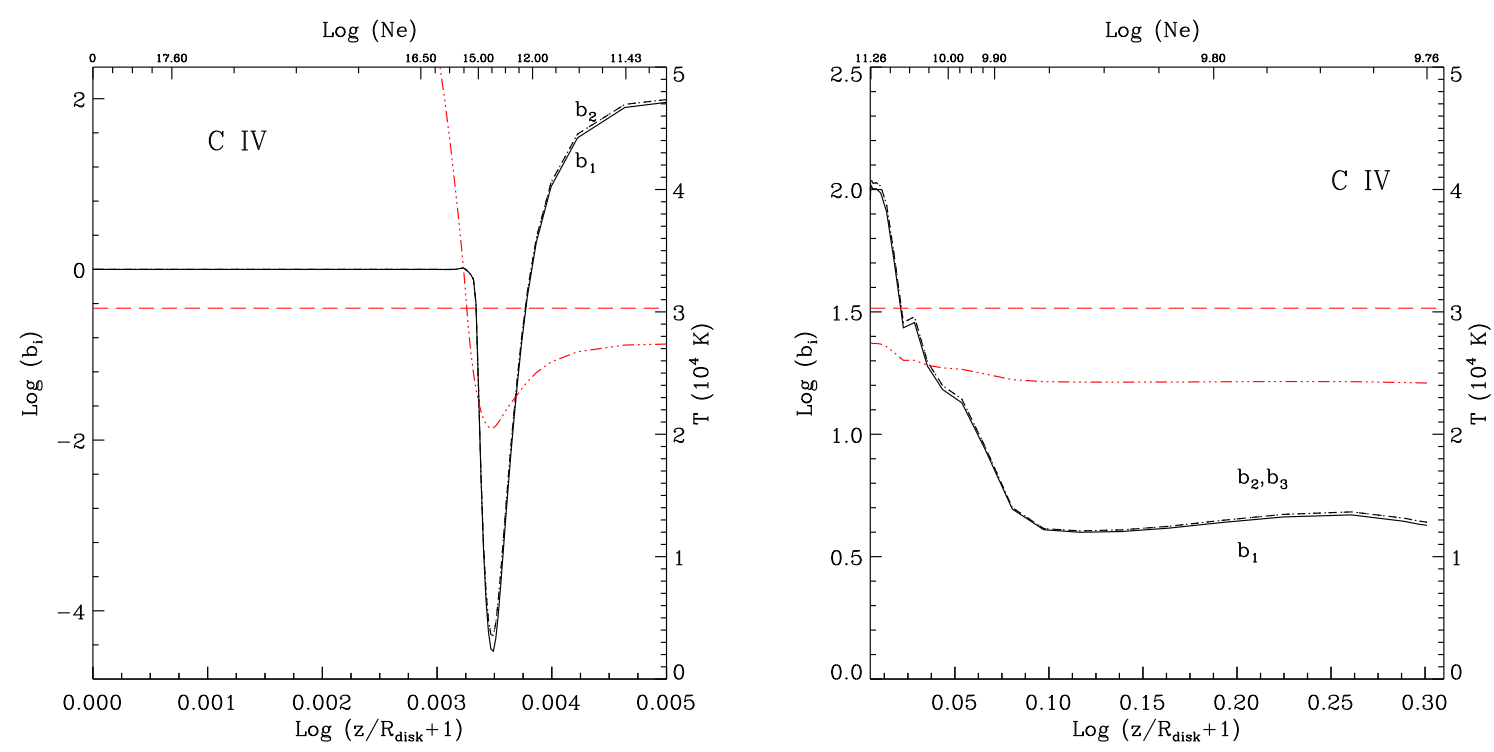

Figura 3.16: Coeficientes de desvio do LTE das populações nos níveis que formam as linhas do C IV $(1550.7,1548.2)$. No painel esquerdo mostra-se a região de transição fotosfera-vento e no painel direito a região extensa do vento. A linha vermelha mostra o perfil vertical de temperatura nessa região da atmosfera.

Na figura 3.16 os coeficientes $b_{i}$ são mostrados parar estes níveis. O desvio do LTE na região de transição é muito alta neste caso (mais que 4 ordens de magnitude). Este comportamento, já visto nos casos anteriores repete-se nos demais casos. Depois estes 
níveis são abrupta e fortemente povoados na região onde a temperatura cresce até atingir o seu máximo. Na região mais extensa do vento os coeficientes $b_{i}$ decrescem lentamente acompanhando também o comportamento da temperatura mas mantendo-se muito maiores do que 1. É interessante notar que tanto os níveis superiores $(2,3)$ como o nível inferior (1) das transições mantêm o mesmo comportamento através de toda a atmosfera. Também é importante notar que nesta região os coeficientes $b_{i}$ são maiores que 1 , mas que nas regiões radialmente mais internas do disco e também nas radialmente mais externas estes coeficientes são menores que 1, mostrando despopulação destes níveis nestas regiões com relação ao esperado em LTE.

NV $(1238,1242)$

As transições responsáveis por estas linhas são os níveis (1-2) para a linha em $1242.8 \AA$ e (1-3) para a linha $1238.8 \AA$. As configurações eletrônicas dos níveis que produzem estas linhas são $1 \mathrm{~s}^{2} 2 \mathrm{~s}\left({ }^{2} \mathrm{~S}_{1 / 2}\right)-1 \mathrm{~s}^{2} 2 \mathrm{p}\left({ }^{2} \mathrm{P}_{1 / 2}\right)$ para a linha $1242.8 \AA$ e $1 \mathrm{~s}^{2} 2 \mathrm{~s}\left({ }^{2} \mathrm{~S}_{1 / 2}\right)-1 \mathrm{~s}^{2} 2 \mathrm{p}\left({ }^{2} \mathrm{P}_{3 / 2}\right)$ $1238.8 \AA$.
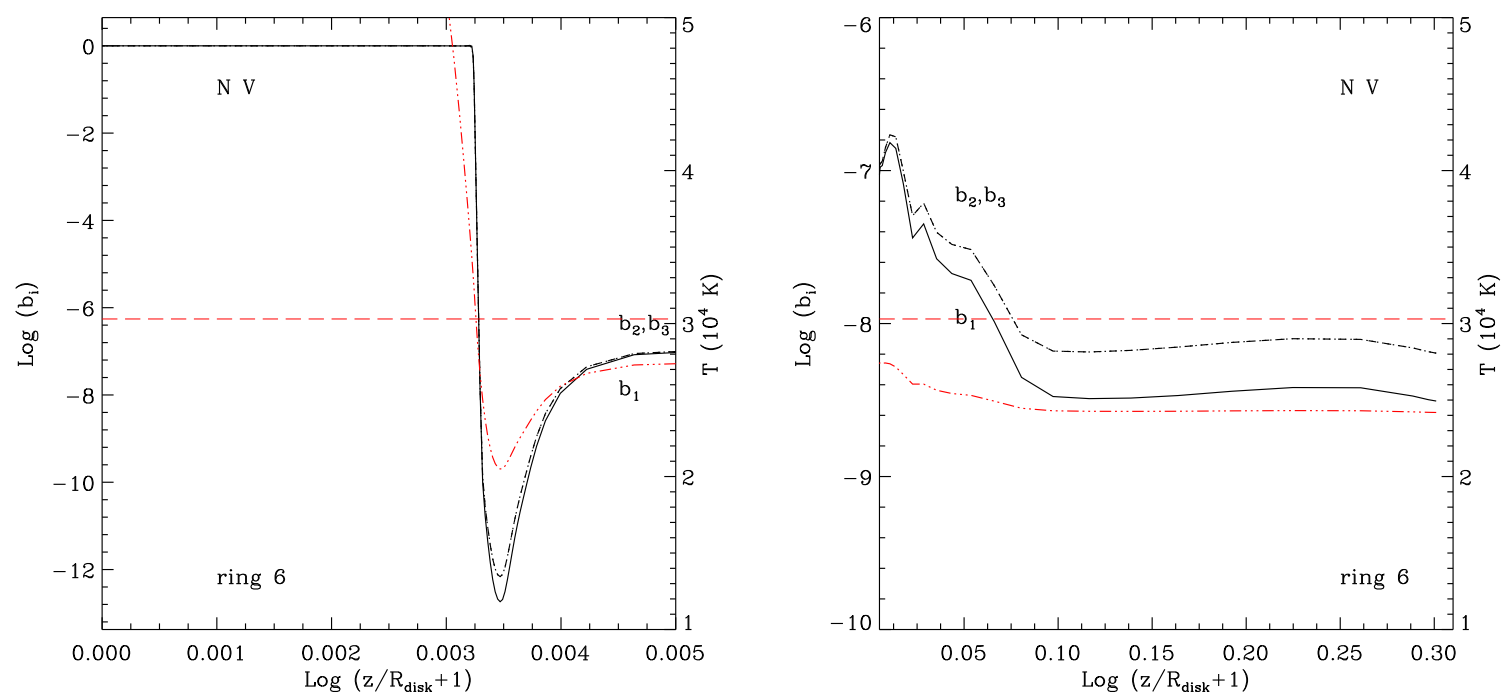

Figura 3.17: Coeficientes de desvio do LTE das populações nos níveis que formam as linhas do N v (1242.8, 1238.8). No painel esquerdo mostra-se a região de transição fotosfera-vento e no painel direito a região extensa do vento. A linha vermelha mostra o perfil vertical de temperatura nessa região da atmosfera.

Este caso é muito similar ao caso do C IV como é mostrado na figura 3.17, já que os níveis envolvidos nas transições têm as mesmas configurações eletrônicas. Entretanto é 
possível ver diferenças, por exemplo estes níveis mostram-se fortemente despovoados com respeito do LTE nesta região do vento. Em regiões com raios menores os coeficientes $b_{i}$ aumentam, mas sem atingir o seu valor LTE, decrescendo ainda mais nas regiões externas do disco.

Si III $(1206,1298,1301)$

As transições responsáveis por estas linhas são entre os níveis (1-5) para a linha em $1206.5 \AA$ (3-7) para a linha $1301.1 \AA$ e (3-8) para a linha $1298.8 \AA$. As configurações eletrônicas dos níveis que produzem estas linhas são $2 \mathrm{p}^{6} 3 \mathrm{~s}^{2}\left({ }^{1} \mathrm{~S}_{0}\right)-3 \mathrm{~s} 3 \mathrm{p}\left({ }^{1} \mathrm{P}_{1}\right)$ para a linha $1206.5 \AA$, 3s3p $\left({ }^{3} \mathrm{P}_{1}\right)-3 \mathrm{p}^{2}\left({ }^{3} \mathrm{P}_{0}\right)$ para a linha $1301.1 \AA$ e $3 \mathrm{~s} 3 \mathrm{p}\left({ }^{3} \mathrm{P}_{1}\right)-3 \mathrm{p}^{2}\left({ }^{3} \mathrm{P}_{1}\right)$ para a linha $1298.89 \AA$.
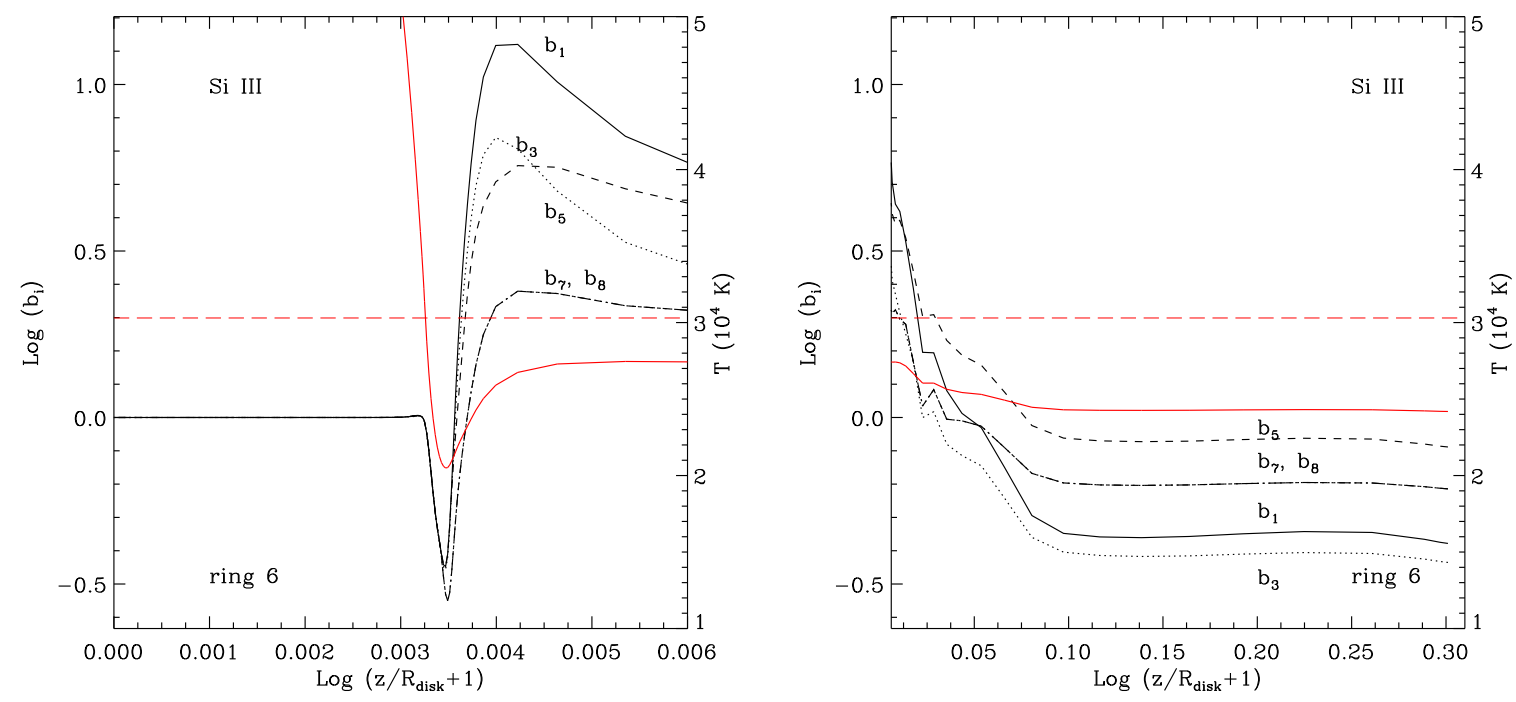

Figura 3.18: Coeficientes de desvio do LTE das populações nos níveis que formam as linhas do Si III $(1206.5,1301.1,1298.8)$. No painel esquerdo mostra-se a região de transição fotosfera-vento e no painel direito a região extensa do vento. A linha vermelha mostra o perfil vertical de temperatura nessa região da atmosfera.

Na figura 3.18 os coeficientes $b_{i}$ destes níveis são mostrados. Todos estes níveis apresentam a depopulação encontrada nos anteriores casos depois que o contínuo se torna transparente. Como esperado, os níveis são fortemente povoados ao aumentar a temperatura. Os níveis inferiores das transições estudadas (1 e 3) são os mais fortemente povoados nessa região, para depois ser fortemente despovoados na região extensa do vento. Os níveis 
superiores das transições (5, 7 e 8) também são despovoados nessa mesma região mas em menor grau do que os níveis inferiores.

$\operatorname{SiIV}(1393,1402)$

As transições responsáveis por estas linhas ocorrem entre os níveis (1-2) para a linha em $1402.7 \AA$ e (1-3) para a linha $1393.7 \AA$. As configurações eletrônicas dos níveis que produzem estas linhas são $2 \mathrm{p}^{6} 3 \mathrm{~s}^{2}\left({ }^{1} \mathrm{~S}_{1 / 2}\right)-2 \mathrm{~s}^{6} 3 \mathrm{p}\left({ }^{2} \mathrm{P}_{1 / 2}\right)$ para a linha $1402.7 \AA$, $2 \mathrm{p}^{6} 3 \mathrm{~s}$ $\left({ }^{3} \mathrm{P}_{1 / 2}\right)-2 \mathrm{p}^{6} 3 \mathrm{p}\left({ }^{2} \mathrm{P}_{3 / 2}\right)$ para a linha $1393.7 \AA$.
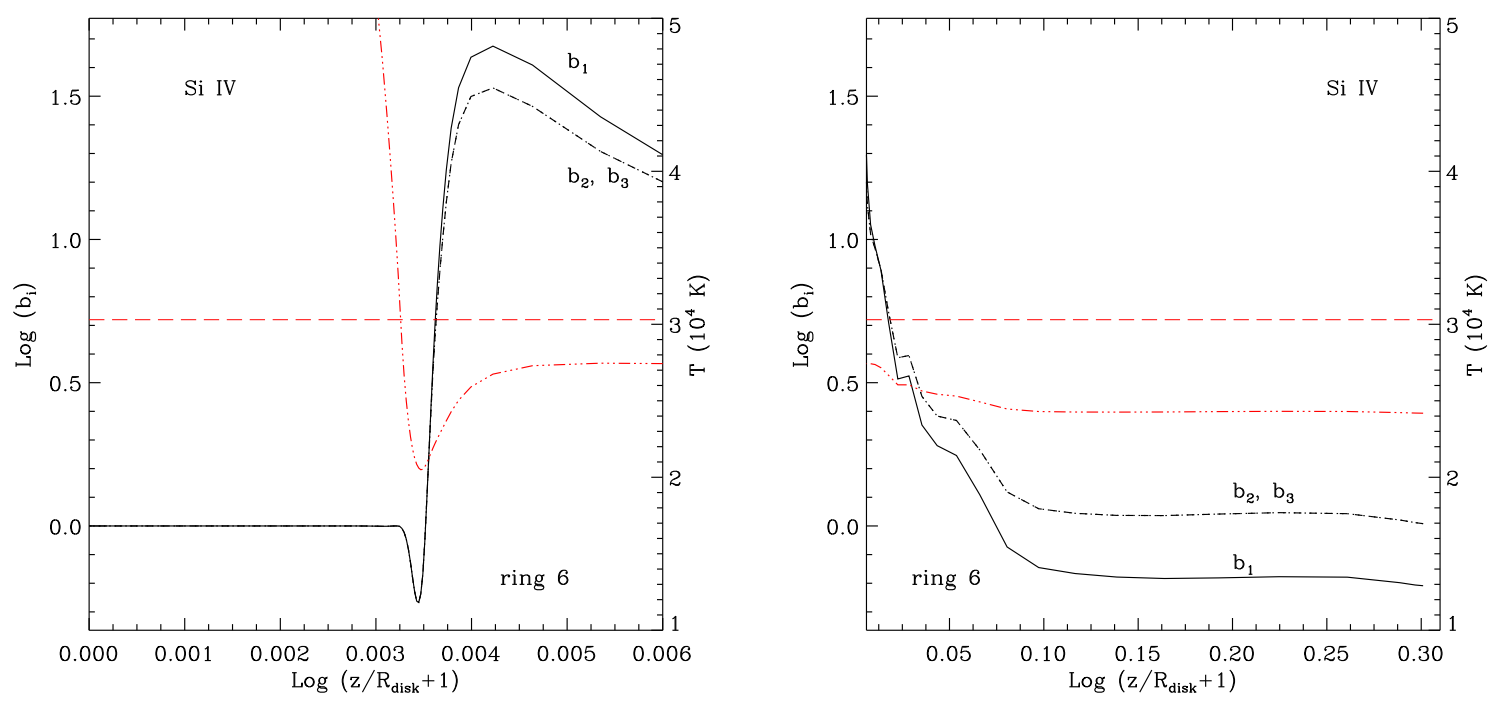

Figura 3.19: Coeficientes de desvio do LTE das populações nos níveis que formam as linhas do Si IV (1402, 1393). No painel esquerdo mostra-se a região de transição fotosfera-vento e no painel direito a região extensa do vento. A linha vermelha mostra o perfil vertical de temperatura nessa região da atmosfera.

Na figura 3.19 os coeficientes $b_{i}$ destes níveis são mostrados. Todos estes níveis apresentam a depopulação encontrada nos anteriores casos depois que o contínuo é opticamente fino. O comportamento das populações dos níveis é muito similar ao encontrado nos casos das transições do Si IV $\lambda 1300$ e C III $\lambda 1175$. O nível inferior das transições é fortemente sobrepovoado na região de transição fotosfera vento para depois ser despovoado nas regiões superiores. Os níveis superiores mantêm-se superpovoados em toda a atmosfera atingindo uns valores muito próximos aos correspondentes em LTE nas regiões mais altas do vento. 
HI $(1025,1216)$

As transições $\operatorname{Ly}_{\alpha}$ (1-2) e $\operatorname{Ly}_{\beta}$ (1-3) por estas linhas são os níveis (1-3) possuem configurações eletrônicas $1 \mathrm{~s}\left({ }^{2} \mathrm{~S}_{1 / 2}\right)-2 \mathrm{p}\left({ }^{2} \mathrm{P}_{1 / 2,3 / 2}\right)$ para a linha Ly $\alpha 1215.7 \AA$, $1 \mathrm{~s}\left({ }^{3} \mathrm{P}_{1 / 2}\right)-3 \mathrm{p}$ $\left({ }^{2} \mathrm{P}_{1 / 2}\right)$ para a linha $\operatorname{Ly} \beta 1025.7 \AA$.
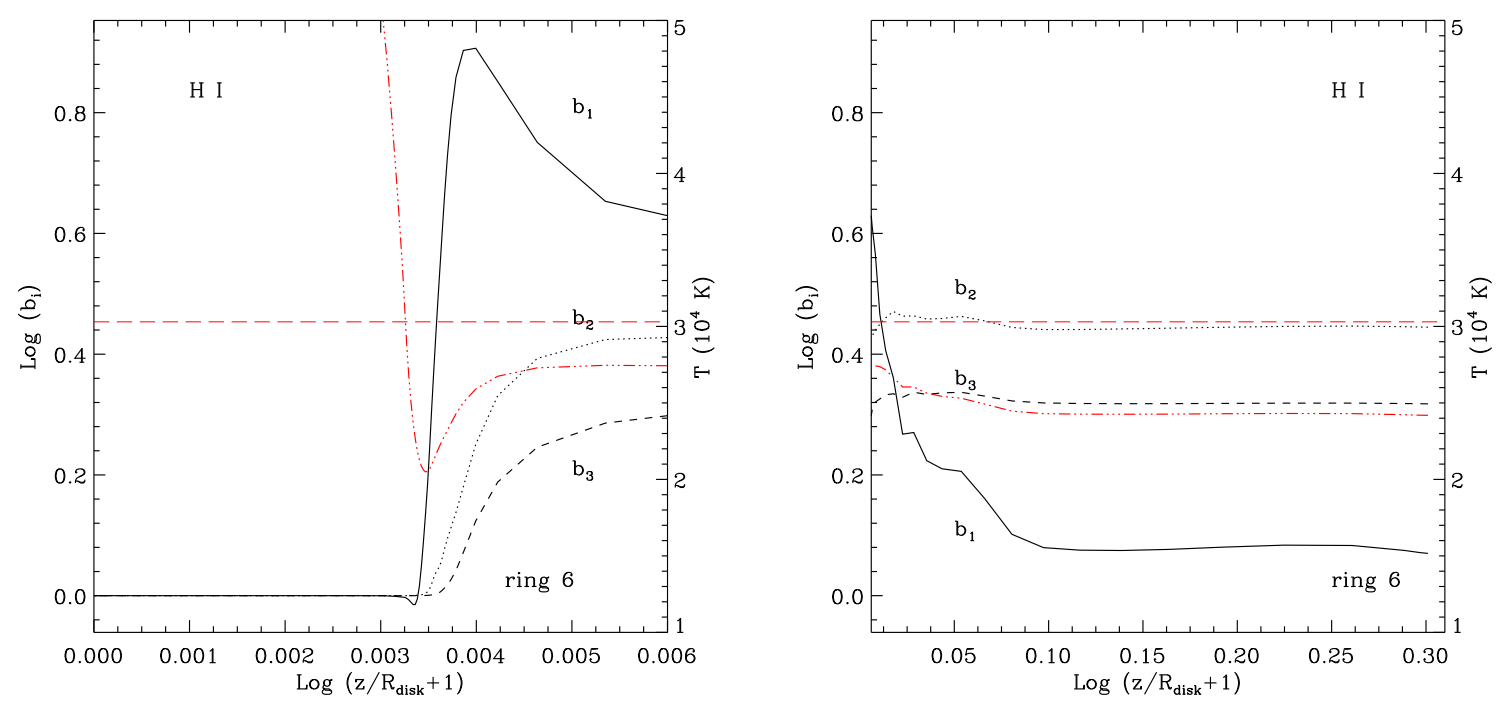

Figura 3.20: Coeficientes de desvio do LTE das populações nos níveis que formam as linhas do H I (1216, 1025). No painel esquerdo mostra-se a região de transição fotosfera-vento e no painel direito a região extensa do vento. A linha vermelha mostra o perfil vertical de temperatura nessa região da atmosfera.

Na figura 3.20 os coeficientes $b_{i}$ destes níveis são mostrados. No caso do H o comportamento das populações dos níveis obedece o mesmo comportamento já descrito anteriormente para as transições do He II. Tanto o nível fundamental quanto os níveis superiores são sobrepovoados devido à alta recombinação. 
Capítulo 4

\section{Análise da Síntese Espectral}

Neste capítulo são estudadas as propriedades fundamentais dos espectros sintéticos calculados para modelos de discos de acresção com vento, estes modelos estão descritos na tabela 3.1. A influência dos parâmetros físicos e geométricos sobre as características da emissão das linhas e do contínuo são analisadas, assim como localizadas as regiões emissoras das diferentes estruturas espectrais.

\subsection{Influência da taxa de acresção $\dot{M}_{a}$.}

Visando estudar a influência da taxa de acresção do disco sobre as estruturas espectrais no UV, foram utilizados os modelos $a, b, c$ e $d$ da tabela 3.1. Estes modelos consideram a mesma massa da primária, o que leva a um disco do mesmo tamanho, pelo qual a geometria do sistema seria a mesma. Os diferentes valores de $\dot{M}_{a}$ não estão linearmente separados mas cobrem quase todo o intervalo de taxas de acresção estimado para VC's (Puebla et al., 2007). A principal influência de $\dot{\mathrm{M}}_{a}$ ocorre sobre a temperatura efetiva do disco, que dita o fluxo de radiação emitido na fotosfera do mesmo. Este fluxo por sua vez, como foi apontado na seção 2.2, influi nas propriedades hidrodinâmicas do vento que ali é expelido, afetando a taxa de perda de massa e a distribuição espacial da densidade do vento. O perfil de velocidades assim como a velocidade terminal do vento são levemente influenciados por $\dot{\mathrm{M}}_{a}$. Assim, as estruturas espectrais estarão fortemente influenciadas pelo estado de ionização do gás (temperatura) e pela densidade (taxa de perda de massa).

Na figura 4.1 são mostrados os espectros sintéticos calculados para estes modelos. Nesses modelos foram utilizados os mesmos parâmetros geométricos. Especificamente, uma inclinação orbital $i=30^{\circ}$, ângulos de abertura do vento, $\theta_{1}=5^{\circ}$ e $\theta_{2}=45^{\circ}, Z_{\text {max }}=\mathrm{R}_{\text {disk }}$ e 

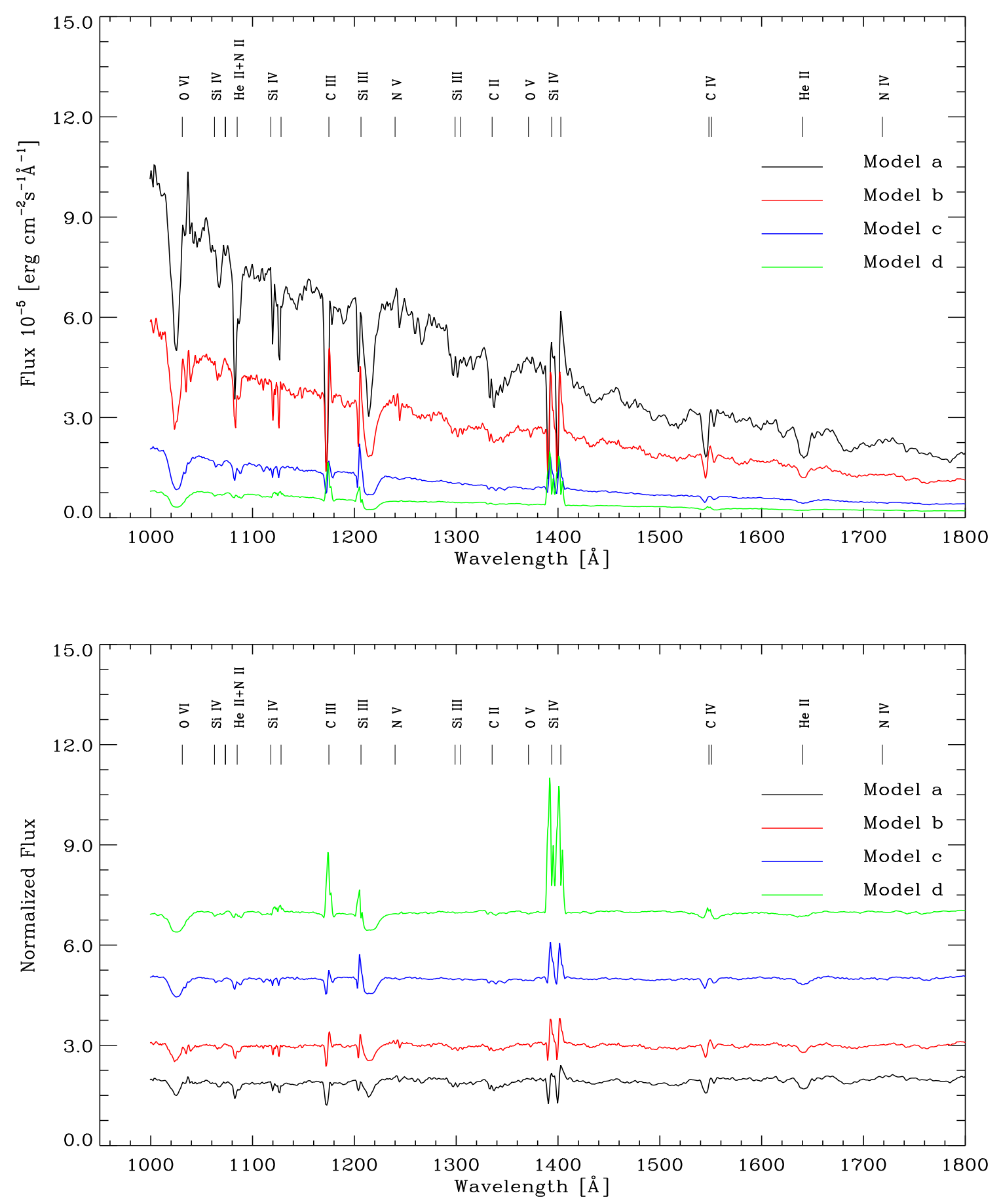

Figura 4.1: Espectros sintéticos UV para os modelos $a, b, c$ e $d$ com inclinação orbital $i=30^{\circ}$. No painel superior mostra-se os fluxos absolutos escalonados para uma distância arbitrária. No painel inferior mostra-se os fluxos normalizados pelo contínuo de cada modelo. A Identificação das diferentes linhas espectrais também é mostrada. 
$\mathrm{R}_{\text {max }}=\mathrm{R}_{\text {disk }}$. Como mostra a figura, a taxa de acresção no disco não só tem influência no nível de fluxo e na cor do espectro, mas também nas estruturas das linhas. No caso do contínuo, como já visto em modelos sem vento, o espectro é mais azul quanto maior é $\dot{M}_{a}$. Mas neste caso, quando a componente extensa do vento é incluída, vemos que o contínuo é afetado mais fortemente pelo "blanqueting" das linhas. No caso das linhas em geral, a figura mostra que quanto maior $\dot{\mathrm{M}}_{a}$ (e conseqüentemente $\dot{\mathrm{M}}_{w}$ ), ou seja mais quentes e densos, as linhas de absorção mostram-se mais profundas do que no caso de sistemas mais frios e/ou com ventos menos densos. É importante notar que estas linhas em absorção apresentam-se fortemente azuladas. Este deslocamento para o azul é provocado pelo vento e é observado na maioria dos espectros UV de VC's que apresentam características de vento em seu espectro. Uma caraterística interessante é que quanto menor é a taxa de acresção, mais intensas apresentam-se as linhas de emissão, especialmente no caso das linhas de baixa ionização Si III $\lambda 1206$ e C III $\lambda 1175$. Estas linhas passam de perfis em absorção ou P-Cyg em sistemas com alta taxa de acresção a perfis em forte emissão em sistemas com baixo $\dot{\mathrm{M}}_{a}$. Isto pode ser explicado, pelo menos em parte, pelo contínuo que decresce quase proporcionalmente a $\dot{\mathrm{M}}_{a}$. A intensidade das linhas depende obviamente do estado de ionização do gás. Mas a mudança do estado de ionização devido ao decréscimo da temperatura das regiões internas do vento faz com que a função fonte nas linhas de estados de ionização menores aumente no gás, relativamente ao contínuo. Na realidade, o vento vai tender a resfriar-se devido à expansão do gás depois de abandonar a superfície do disco, mas esta expansão não é levada em conta nas atmosferas plano-paralelas. Uma forma de mimetizar este resfriamento seria colocando mais atmosferas com vento em regiões mais externas. O efeito de destas atmosferas mais frias na região externa será estudado mais adiante.

Nas figuras 4.2 e 4.3 são mostrados com mais detalhe os perfis de linha normalizados pelo contínuo para as principais espécies iônicas observadas nos espectros UV de VC's correspondentes aos mesmos modelos $a, b, c$ e $d$. Todos os perfis são mostrados no espaço de velocidades, quando o caso de dupletos este espaço está centrado na componente vermelha do mesmo. Na primeira figura são mostrados os perfis das linhas correspondentes a C III $\lambda$ 1175, Si III $\lambda 1206$, Si IV $\lambda \lambda 1122,1128$ e Si IV $\lambda \lambda 1393,1402$. Estes perfis apresentam um comportamento similar entre eles quando a taxa de acresção é variada. Assim, quando a taxa de acresção é alta, os perfis são preferencialmente em absorção. Em todos os casos 

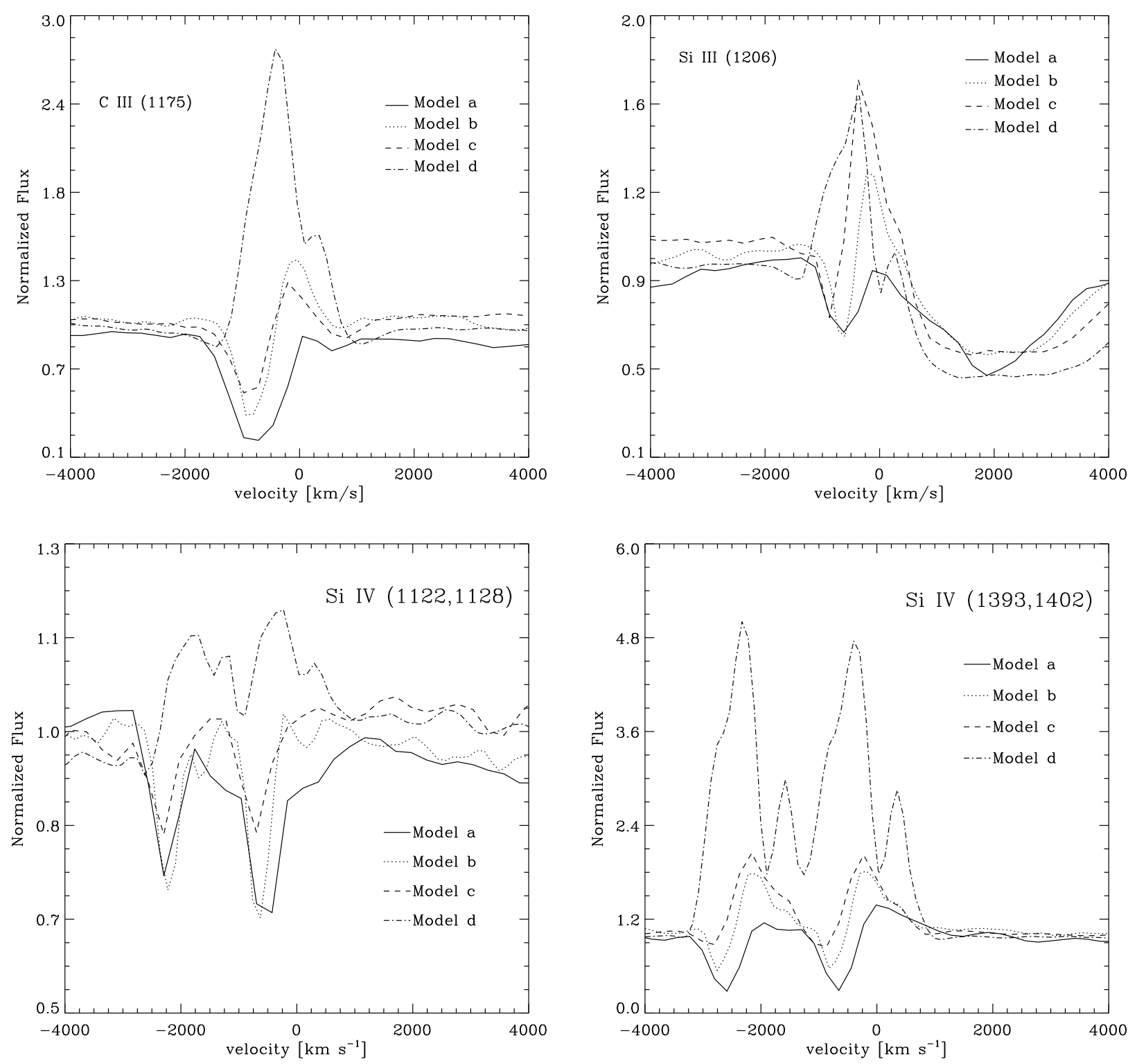

Figura 4.2: Perfís de linha normalizados pelo contínuo para as linhas do Si IV, C III, Si III e Nv. Os modelos $a, b, c$ e $d$ correspondem a diferentes taxas de acresção $\dot{\mathrm{M}}_{a}$, de $1.0 \times 10^{-8} \mathrm{M}_{\odot}$ ano ${ }^{-1}, 5.0 \times 10^{-9}$ $\mathrm{M}_{\odot}$ ano $^{-1}, 1.0 \times 10^{-9} \mathrm{M}_{\odot}$ ano $^{-1}$ e $5.0 \times 10^{-10} \mathrm{M}_{\odot}$ ano ${ }^{-1}$ respectivamente. Em todos os casos foi usada uma inclinação orbital de $i=30^{\circ}$.

este perfil aparece no lado azul do comprimento de onda de repouso da linha. Junto a esta componente, também é gerada uma componente em emissão, lembrando um perfil P-Cyg. Com exceção do C III $\lambda 1175$ e Si IV $\lambda \lambda 1393,1402$ as outras linhas não apresentam perfis desse tipo nas observações, que comumente são perfis preferentemente em absorção e azulados. A componente em emissão tem o pico perto do comprimento de repouso da linha, 

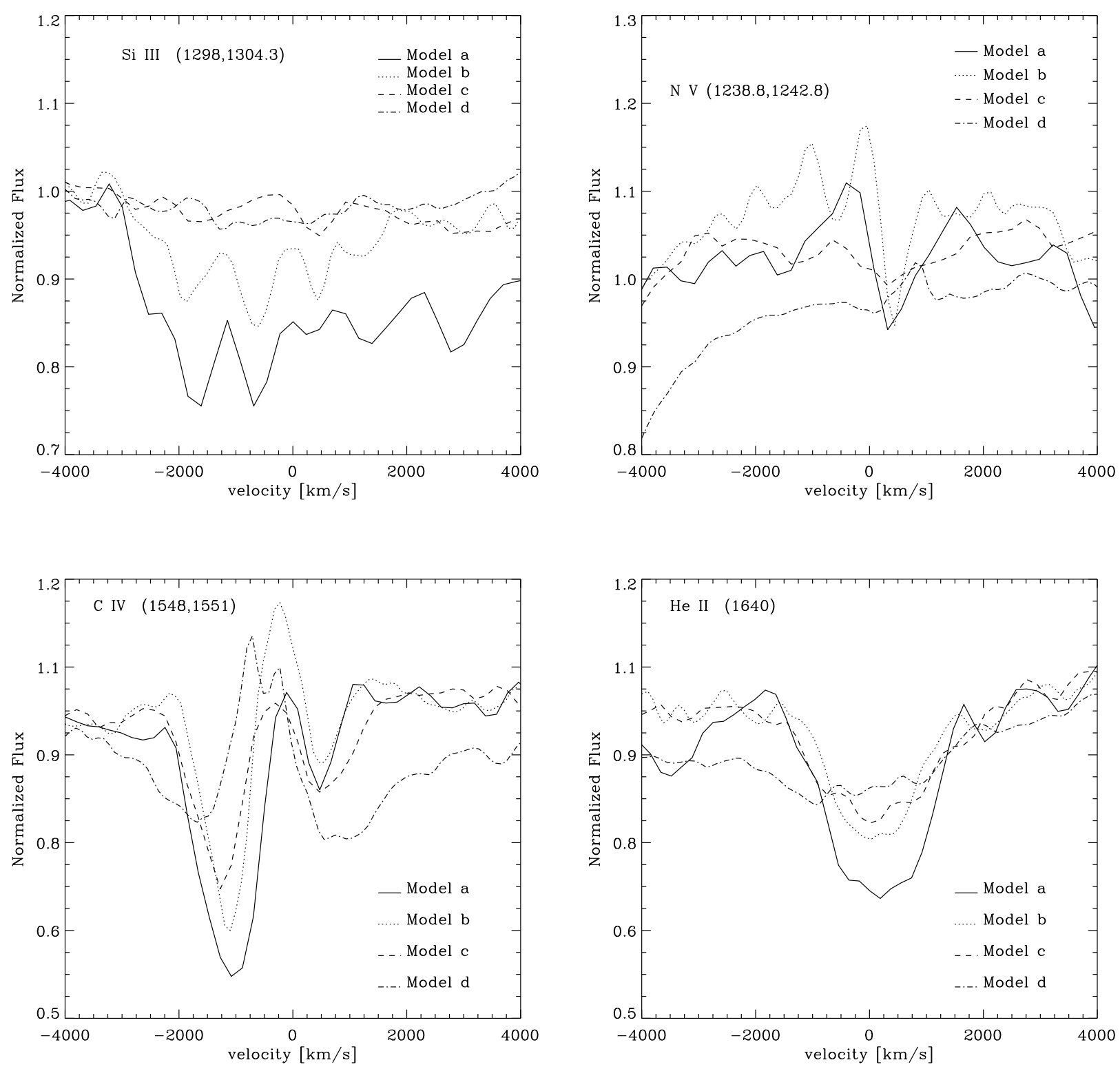

Figura 4.3: Perfís de linha normalizados pelo contínuo para as linhas do Si III, Si IV, C IV e He II. Os modelos $a, b, c$ e $d$ correspondem a diferentes taxas de acresção $\dot{\mathrm{M}}_{a}$, de $1.0 \times 10^{-8} \mathrm{M}_{\odot}$ ano ${ }^{-1}, 5.0 \times 10^{-9}$ $\mathrm{M}_{\odot}$ ano $^{-1}, 1.0 \times 10^{-9} \mathrm{M}_{\odot}$ ano ${ }^{-1}$ e $5.0 \times 10^{-10} \mathrm{M}_{\odot}$ ano ${ }^{-1}$ respectivamente. Em todos os casos foi usada uma inclinação orbital de $i=30^{\circ}$.

mas não é muito forte. Quando a taxa de acresção diminui, esta componente em emissão ganha força e começa a preencher as regiões da componente em absorção, formando perfis P-Cyg com uma componente em emissão principalmente no lado azul da linha. Quando a taxa de acresção é muito baixa, a componente em emissão é muito forte, cancelando quase totalmente a componente em absorção, e além disso, aparece uma estrutura adicional no 
lado vermelho da linha.

A componente em absorção, quando presente, apresenta um mínimo que é mais profundo quanto maior é a taxa de acresção. A localização deste mínimo está em -700 km $\mathrm{s}^{-1}$. Este mínimo desloca-se para o azul à medida que decresce a taxa de acresção. As asas destas linhas, quando o perfil está em absorção, encontram-se em -2000 $\mathrm{km} \mathrm{s}^{-1}$ (asa azul) e em $\sim 1500 \mathrm{~km} \mathrm{~s}^{-1}$ (asa vermelha). As componentes em emissão apresentam o máximo no lado azul da linha, em velocidades baixas. As asas destas componentes encontram-se dentro do perfil em absorção, pelo qual é difícil medir as velocidades correspondentes. Uma análise feita separando as componentes da linha que provém de diferentes parâmetros de impacto, mostra que as asas das componentes em emissão encontram-se em -1000 km $\mathrm{s}^{-1}$ e em $\sim 500 \mathrm{~km} \mathrm{~s}^{-1}$.

Na figura 4.3 são mostrados os perfis das linhas N v $\lambda \lambda 1238,1242$, C IV $\lambda \lambda 1548,1551$, He II $\lambda 1640$ e Si III $\lambda 1298,1304$. Os dois primeiros correspondem a especies de alta ionização, os outros dois últimos correspondem a linhas que apresentam um comportamento principalmente fotosférico ou seja, sem nenhuma emissão proveniente do vento. As espécies de alta ionização apresentam um comportamento diferente ao encontrado em linhas de espécies com ionização mais baixa analisadas no parágrafo anterior. A linha do N v não apresenta perfil em absorção, e apenas nos casos de alta taxa de acresção a linha apresenta uma pequena estrutura em emissão. Analisando as contribuições no espaço de parâmetros de impacto encontramos que a componente em absorção azulada, gerada nas regiões internas do disco, é logo apagada pelo preenchimento causado pela componente em emissão que também é azulada, porém das regiões imediatamente mais externas. Esta linha não apresenta uma componente em emissão vermelha, como nas linhas analisadas anteriormente. Isto é devido ao fato de que a região do gás que a emitiria está oculta pelo disco (região com $z<0$ ). A variação da linha do C IV com a taxa de acresção é mostrada na mesma figura (fig. 4.3). A componente em absorção mostra um comportamento similar àquelas analisadas no parágrafo anterior, mas com a diferença de que a asa e o mínimo do perfil encontram-se em velocidades maiores em módulo ( -1100 $\mathrm{km} \mathrm{s}^{-1}$ e $\sim-2000 \mathrm{~km} \mathrm{~s}^{-1}$ respectivamente). Estas velocidades mostram que a linha é gerada nas regiões interiores do vento onde tanto a velocidade vertical como a velocidade de rotação, são maiores. A componente em emissão também está do lado azul do repouso, com o máximo em -250 
$\mathrm{km} \mathrm{s}^{-1}$.

Estas características das linhas geradas nos modelos e a sua variação com a taxa de acresção mostra a forte relação que existe entre a temperatura da região emissora e seu campo de velocidades, com a estruturas do perfil da linha. Neste caso, os espectros foram calculados para um sistema com baixa inclinação orbital $\left(i=30^{\circ}\right)$ e as linhas encontra-se muito influenciadas pelo campo vertical de velocidades, daí o aparecimento das componentes em absorção azuladas. Estas componentes provém das regiões mais internas do disco, que são as mais quentes, cuja radiação atravessa regiões do vento mais frias que são expelidas mais externamente.

A componente em emissão gerada em algumas linhas deve-se principalmente ao gás que é ejetado das regiões internas mas que, na linha de visada do observador, encontram-se diante de regiões do disco mais frias. Como a temperatura do disco varia rapidamente das regiões internas para as externas, estas componentes começam a aparecer em raios que provém de regiões que ejetam vento. Os raios que saem de atmosferas de disco que não expelem vento atravessam o gás ejetado internamente que, como foi mostrado, reflete a temperatura fotosférica de onde foi expelido. Assim, como a função fonte na linha $S_{\nu}>J_{\nu}$ (sendo $J_{\nu}$ a intensidade específica que provém da fotosfera), uma linha de emissão é gerada. Esta componente em emissão vai refletir a dinâmica do gás na região de formação.

Para um sistema de baixa inclinação a principal fonte de emissão na linha provém do gás que é ejetado na direção do observador. O vento que é expelido da outra face do disco $(z<0)$, é observado parcialmente. Portanto, os modelos apresentam componentes em emissão principalmente azuladas nos espectros sintéticos. As componentes vermelhas encontradas nos perfis das linhas do Si III, Si IV e CiII, provém do gás que é expelido na direção contrária ao observador. Esta componente vermelha vai depender muito dos parâmetros geométricos $\theta_{2}$ e a inclinação orbital. A razão dela não aparecer nas linhas de espécies alta ionização é devido ao estado de ionização do gás nas regiões externas do vento, onde a concentração destas espécies é mínima, fazendo com que a função fonte dessas linhas seja pequena quando comparada com a de outras especies iônicas.

Para entender melhor a emissão destes modelos, na figura 4.4 os espectros sintéticos são mostrados também para uma inclinação orbital $i=70^{\circ}$. Como visto nas observações de variáveis cataclísmicas de alta inclinação, estes espectros mostram fortes linhas de emissão. 
Também pode ser notada mais claramente a dependência da intensidade das linhas com relação à temperatura ditada pela taxa de acresção. É importante porém, levar em conta a dependência com a geometria do vento usada para gerar essas como já foi levantado anteriormente.

Nas figuras 4.5 e 4.6 os perfis de linha para as principais transições observadas no UV são mostradas no espaço de velocidades. É possível ver que a intensidade das linhas de emissão (com exceção do He II $\lambda 1640$ ) varia com a taxa de acresção, dependendo da especie iônica. Por exemplo no caso das linhas de especies tais como o Si III, Si IV e CiII, que têm potenciais de ionização relativamente baixos, as intensidade dessas linhas é maior para baixos valores da taxa de acresção. Para íons com potenciais de ionização maiores tais como N V, C IV, O IV ou O v, as intensidades das linhas são maiores para valores altos de $\dot{\mathrm{M}}_{a}$. Este comportamento mostra a forte dependência da intensidade das linhas com a energia da radiação ionizante que provém do disco. A presença de todas estas especies iônicas é resultado de uma estrutura de ionização variável (no sentido radial) do gás.

Pode ser notado que a emissão das linhas provém de diferentes regiões levando em consideração a largura em velocidade das asas das linhas. Linhas de espécies de baixa ionização (C III, Si IV e Si III) têm as asas entre $\sim 1600 \mathrm{~km} \mathrm{~s}^{-1}$ e $\sim 1200 \mathrm{~km} \mathrm{~s}^{-1}$. As linhas de espécies de alta ionização (p.e. C IV e Nv) apresentam asas mais largas entre 3000 $\mathrm{km} \mathrm{s}^{-1}$ e $\sim 2100 \mathrm{~km} \mathrm{~s}^{-1}$. A largura das linhas é fortemente afetada pela rotação do gás na região de emissão já que o disco é altamente inclinado. As linhas que apresentam asas com velocidades maiores, indicam que provêm de regiões mais internas do disco que têm uma velocidade de rotação maior, e as linhas que apresentam asas com velocidades menores provêm das regiões mais externas. A linha do He II $\lambda 1640$ aparece em absorção nos modelos calculados ao contrário do observado em alguns sistemas com alta inclinação orbital.

Para finalizar, algumas conclusões adicionais podem ser tiradas desta análise. Como já foi apontado anteriormente, quanto maior é a taxa de acresção, maior é a densidade do gás na região extensa da atmosfera. Além disso, maior também é a temperatura desse gás nas regiões internas. Devido à limitação imposta neste trabalho de calcular atmosferas com vento até uma temperatura próxima de $\sim 14000 \mathrm{~K}$, o raio do anel correspondente a esse limite depende também da taxa de acresção de acordo com a equação (1.15). Pelo qual 

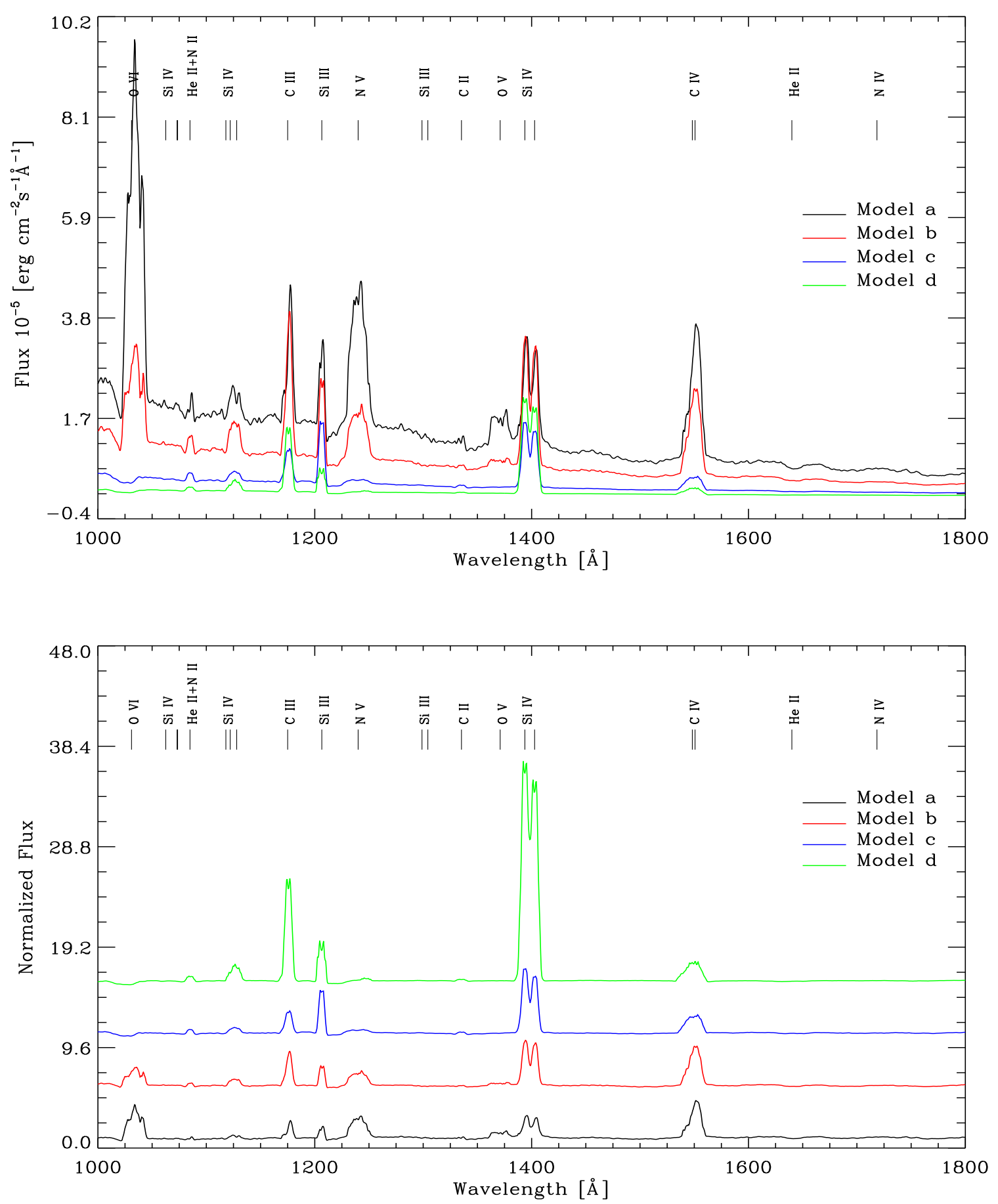

Figura 4.4: Espectros sintéticos UV para os modelos $a, b, c$ e $d$ com inclinação orbital $i=70^{\circ}$. No painel superior mostra-se os fluxos absolutos escalonados a uma distância arbitrária. No no painel inferior mostra-se os fluxos normalizados ao contínuo de cada modelo. A ubicação das diferentes linhas espectrais também é mostrada. 

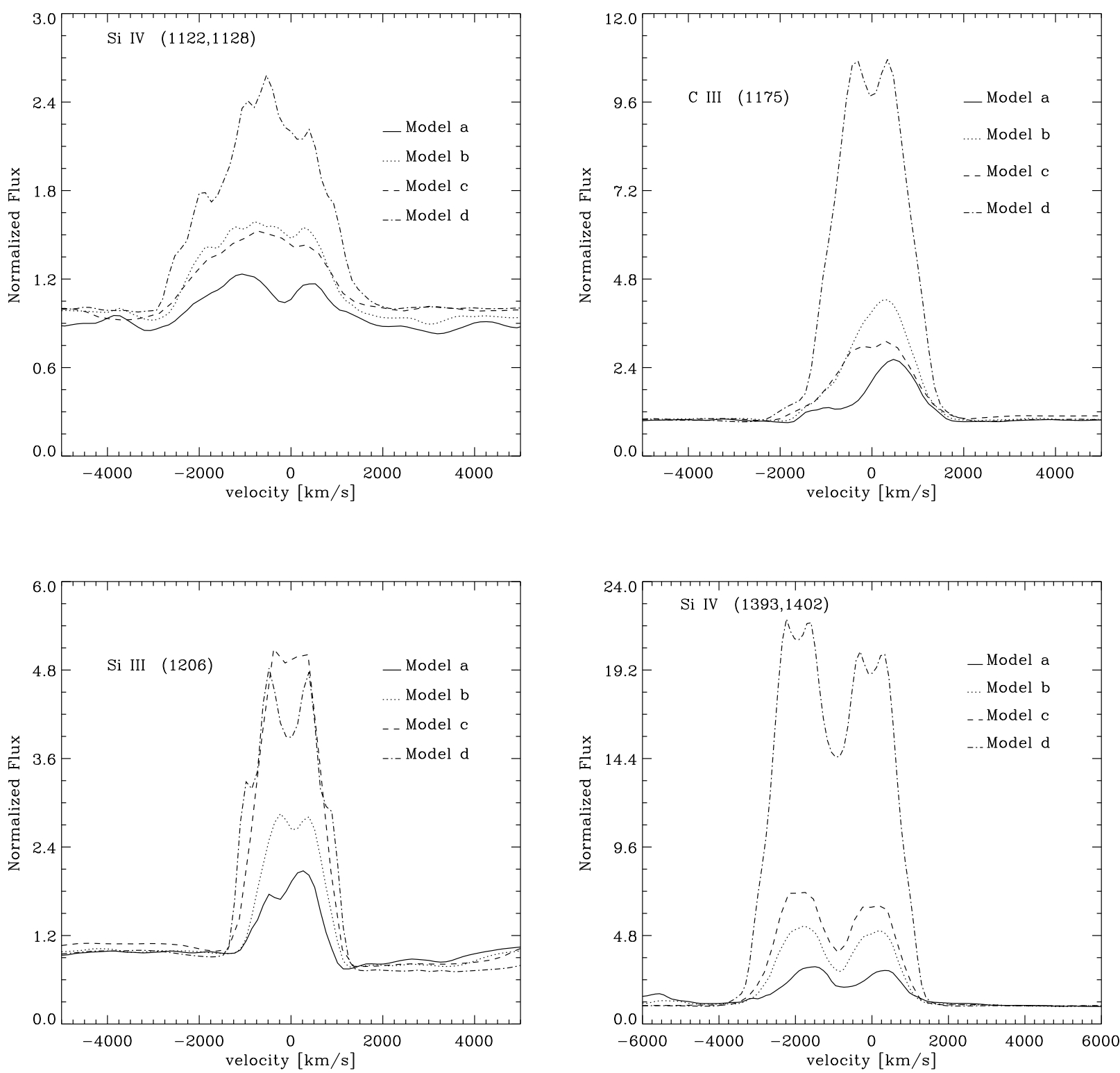

Figura 4.5: Perfís de linha normalizados pelo contínuo para as linhas do Si IV, C III, Si III e N v. Os modelos $a, b, c$ e $d$ correspondem a diferentes taxas de acresção $\dot{\mathrm{M}}_{a}$, de $1.0 \times 10^{-8} \mathrm{M}_{\odot}$ ano ${ }^{-1}, 5.0 \times 10^{-9}$ $\mathrm{M}_{\odot}$ ano $^{-1}, 1.0 \times 10^{-9} \mathrm{M}_{\odot}$ ano ${ }^{-1}$ e $5.0 \times 10^{-10} \mathrm{M}_{\odot}$ ano ${ }^{-1}$ respectivamente. Em todos os casos foi usada uma inclinação orbital de $i=70^{\circ}$.

também a região que expele vento vai ser maior nos casos de uma alta taxa de acresção. A taxa de acresção não apresenta uma forte influência sobre as asas das linhas para sistemas com baixa inclinação orbital. 

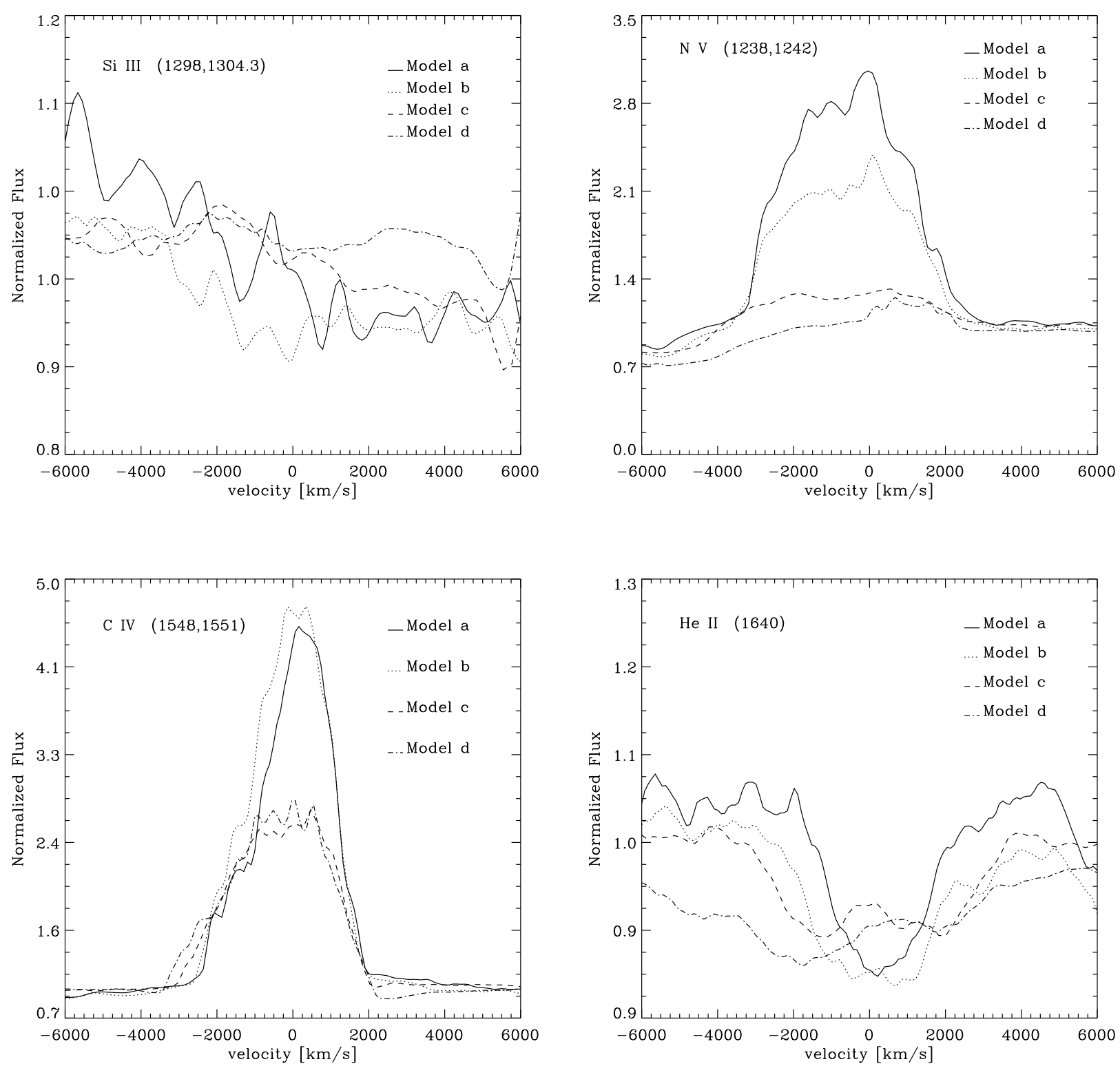

Figura 4.6: Perfís de linha normalizados pelo contínuo para as linhas do Si III, Si IV, C IV e He II. Os modelos $a, b, c$ e $d$ correspondem a diferentes taxas de acresção $\dot{\mathrm{M}}_{a}$, de $1.0 \times 10^{-8} \mathrm{M}_{\odot}$ ano ${ }^{-1}, 5.0 \times 10^{-9}$ $\mathrm{M}_{\odot}$ ano $^{-1}, 1.0 \times 10^{-9} \mathrm{M}_{\odot}$ ano ${ }^{-1}$ e $5.0 \times 10^{-10} \mathrm{M}_{\odot}$ ano $^{-1}$ respectivamente. Em todos os casos foi usada uma inclinação orbital de $i=70^{\circ}$.

\subsection{Efeito da massa da primária $M_{1}$.}

Nessa seção o efeito da massa da primária sobre as características espectrais é analisado. Como é conhecido a massa da primária vai influenciar principalmente sobre a temperatura do disco, e conseqüentemente, sobre a temperatura do vento através da equação (1.15). 
A massa da primária também altera o campo de velocidades já que atua principalmente sobre a velocidade de escape no disco. O intervalo de massas tem menor influência sobre a velocidade terminal, pelo menos sobre os modelos onde $\alpha=0.9$. Já quando $\alpha$ é menor a influência de $\mathrm{M}_{1}$ sobre a velocidade terminal é maior, o que geraria também uma forte dependência no perfil das linhas em emissão.

Na figura 4.7 mostram-se os espectros sintéticos para os modelos "c" e " $h$ ". De acordo com a tabela 3.1 , estes modelos têm massas da primária de $1.0 \mathrm{M}_{\odot}$ e $0.6 \mathrm{M}_{\odot}$ respectivamente. A inclinação orbital é de $i=30^{\circ}$ e os ângulos de abertura do vento são: $\theta_{1}=5^{\circ}$ e $\theta_{2}=45^{\circ}$. O modelo com $\mathrm{M}_{1}$ maior tem uma taxa de acresção menor, o que faz que a temperatura do disco seja similar nos dois modelos. Isto para tentar minimizar a influência dos outros parâmetros sobre o espectro e detetar somente àquela devida à aceleração da gravidade. Além da temperatura, $\mathrm{M}_{1}$ afeta o tamanho do disco pela dependência de $\mathrm{R}_{\text {disk }}$ com o raio do ponto interno de Lagrange. Assim, o raio do disco do sistema com maior $\mathrm{M}_{1}$ é de $0.66 \mathrm{R}_{\odot}$, enquanto que no outro caso é de $0.57 \mathrm{R}_{\odot}$. Já no caso da área do disco que emite vento acontece o contrário. Em discos com massa da primária menor esta região é maior por causa da dependência da temperatura efetiva com o raio da primária $\mathrm{R}_{1} \propto \mathrm{M}_{1}^{-0.7}$ no segundo e terceiro fatores da equação (1.15). Isto leva a que o disco atinge baixas temperaturas muito mais longe da anã branca. Por tanto no modelo " $c$ ", a região mais externa que emite vento encontra-se em $0.09 \mathrm{R}_{\odot}(\mathrm{T}(\mathrm{R})=14930 \mathrm{~K})$, enquanto que no caso do modelo " $h$ " está em $0.14 \mathrm{R}_{\odot}(\mathrm{T}(\mathrm{R})=13850 \mathrm{~K})$. A conseqüência direta disto é que, mesmo tendo os dois discos uma temperatura similar, a diferença no tamanho da região que ejeta vento provoca uma taxa de perda total de massa é de quase 6 vezes maior quando a massa da primária é menor.

A figura 4.7 mostra que o modelo com $\mathrm{M}_{1}=0.6 \mathrm{M}_{\odot}$ tem o nível de fluxo maior do que no caso do modelo com $\mathrm{M}_{1}=1.0 \mathrm{M}_{\odot}$. Isto devido à diferente distribuição de temperatura no disco. A diferença entre os perfis de linha entre os modelos são devidos principalmente ao efeito que a massa da primária tem sobre a geometria do vento, como já foi apontado. Os perfis de linha nos dois modelos mostram que as absorções são mais profundas quando a massa da primária é menor. Isto acontece em praticamente todas as linhas, especialmente as dos íons de C III, C II, Si IV e Si III. Ao contrário, quando a massa da primária é maior, os perfis em emissão são mais fortes nas linhas dessas mesmas espécies iônicas. 

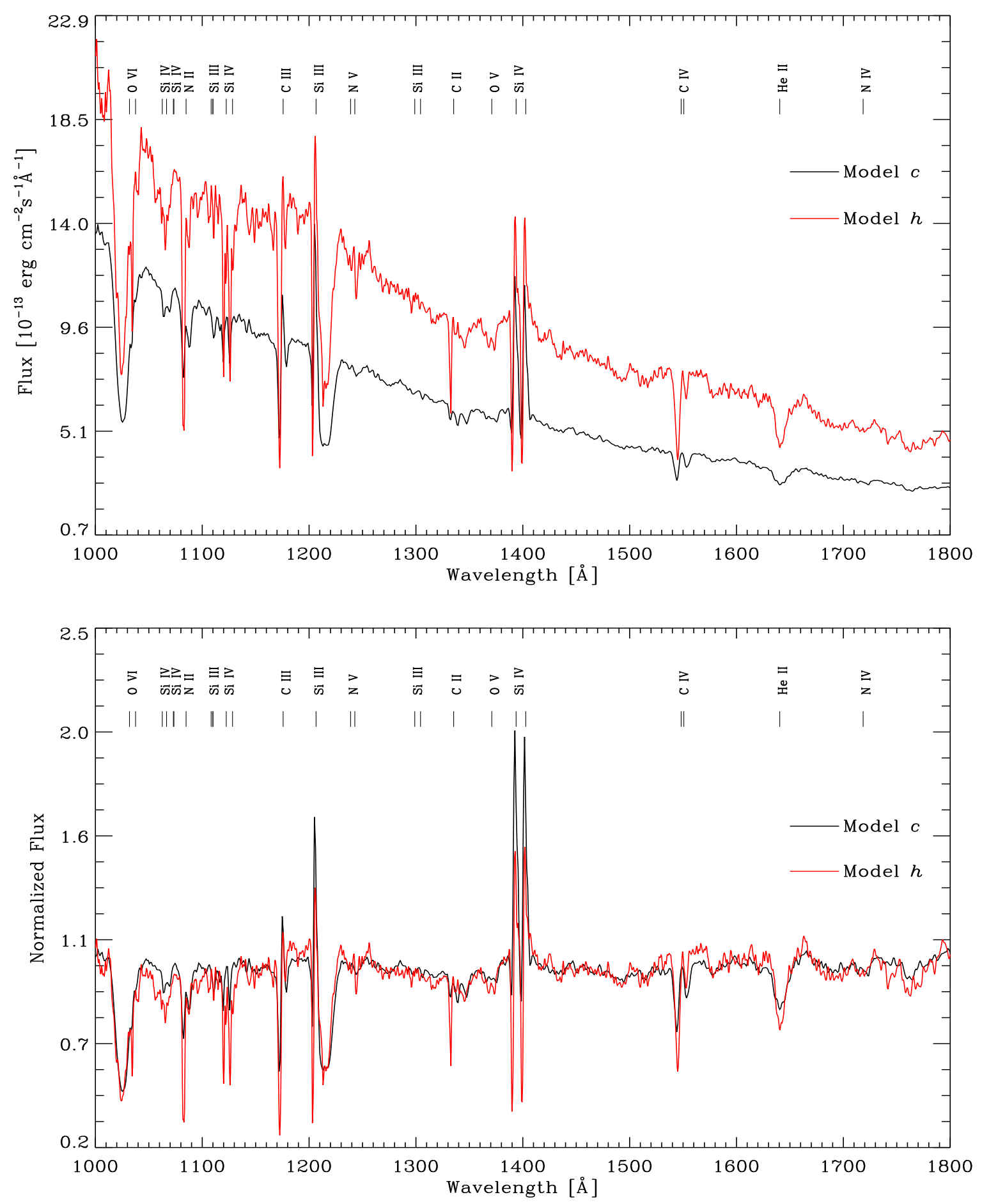

Figura 4.7: Espectros sintéticos UV para os modelos $c$ e $h$ com inclinação orbital $i=30^{\circ}$. No painel superior mostra-se os fluxos absolutos escalonados a uma distância arbitrária. No painel inferior mostra-se os fluxos normalizados pelo contínuo de cada modelo. A diferença principal entre estes modelos é a massa da primária $\mathrm{M}_{1}$, de $1.0 \mathrm{M}_{\odot}$ para o modelo $c$ e de $0.6 \mathrm{M}_{\odot}$ para o modelo $h$. 

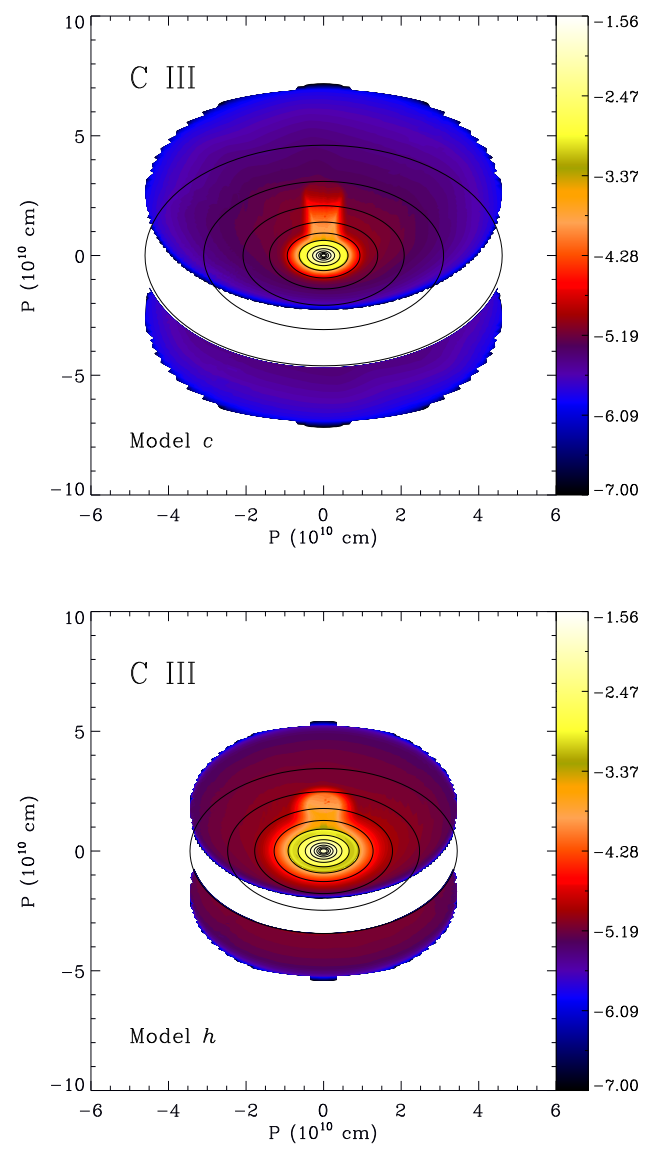

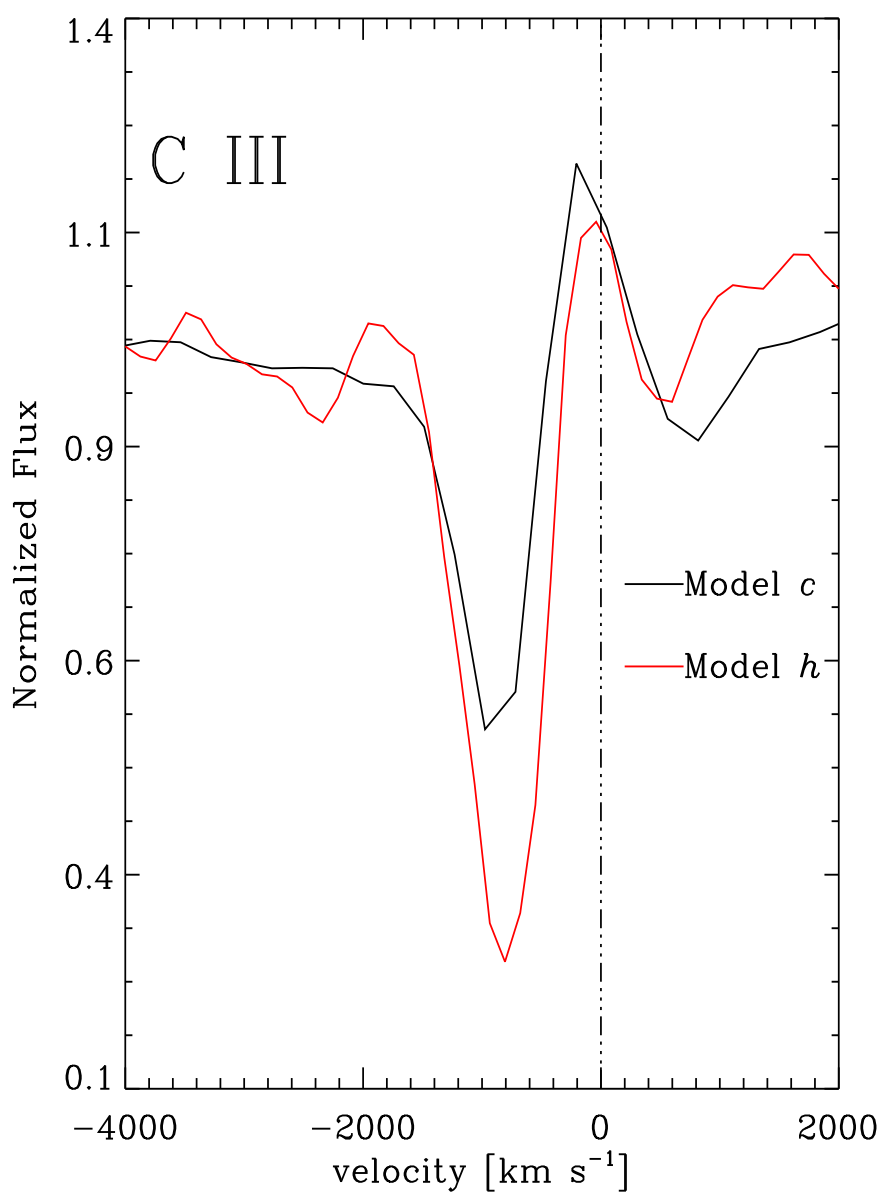

Figura 4.8: Emissão do dupleto do C III $\lambda 1175$ para os modelos $c$ e $h$. No painel direito é mostrado o logarítmo da intensidade específica média entre as freqüências correspondentes ao intervalo de $1172 \AA$ a $1178 \AA$ A. No painel direito mostra-se os perfis de linha integrados normalizados pelo contínuo centrada na componente vermelha.

Na figura 4.8 é mostrada a distribuição do logaritmo da intensidade específica média $\bar{I}=\log \left[1 /\left(\nu_{f}-\nu_{o}\right) \int_{\nu_{o}}^{\nu_{f}} I_{\nu} d \nu\right]$, entre os comprimentos de onda $1160 \AA$ e $1190 \AA$ para os modelos $c$ e $h$ no espaço dos parâmetros de impacto. Na figura 4.8 foram excluídas as emissões provenientes das regiões exteriores do disco. No painel direito são dados os perfis de emissão do dupleto do C III $\lambda 1175$. O limite das escalas da intensidade específica nos painéis da esquerda são as mesmas, visando comparar a magnitude da emissão em cada modelo. A figura mostra a clara diferença no tamanho do disco provocada pela diferença de massas. A intensidade de uma linha depende do tamanho da região emissora e do valor da função fonte. A intensidade específica dessa linha nessa região é menor que aquela vista quando $\mathrm{M}_{1}$ é menor. Na região mais interna do disco, é evidente uma grande intensidade específica no contínuo. Radiação do contínuo que escapa desta região do disco é absorvida 

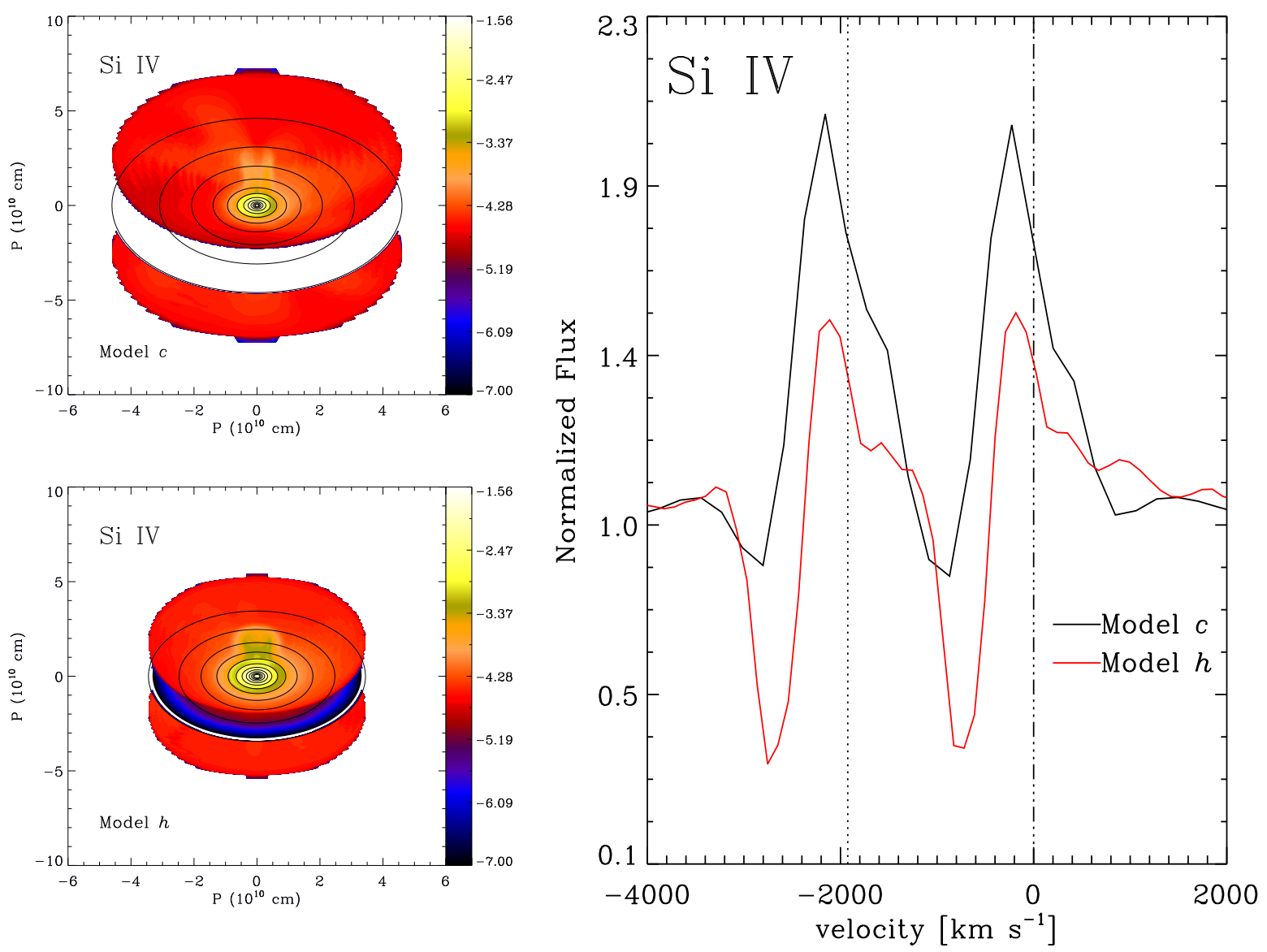

Figura 4.9: Emissão do dupleto do Si IV $\lambda \lambda 1393,1402$ para os modelos $c$ e $h$. No painel direito mostra-se o logaritmo da intensidade específica média entre as frequecias correspondentes entre o intervalo espectral entre os comprimentos de onda $1390 \AA$ e 1410 Å. No painel direito mostra-se os perfis de linha do dupleto no espaço de velocidades normalizados pelo contínuo e centralizado na componente vermelha do dupleto.

na linha pelo gás mais externo e mais frio. A intensidade dessa absorção depende da densidade colunar de absorvedores e do tamanho da região que emite o contínuo. Vimos que quando a massa da primária é menor, esta região é maior, o que leva a que a absorção seja mais profunda, como é mostrado no painel direito da figura 4.8. Nestes modelos, a componente em emissão invade a asa vermelha da componente em absorção porém, a intensidade da emissão não é igual à absorção real do contínuo proveniente das regiões mais internas.

Nas figuras 4.9 e 4.10 são mostradas duas das principais linhas do UV, que mostram características de vento. Estas linhas apresentam características morfológicas parecidas às analisadas no caso das linhas do C III. Nesses casos as componentes em absorção são mais profundas quando a massa é menor. Isto ocorre também pelo fato da região de absorção 

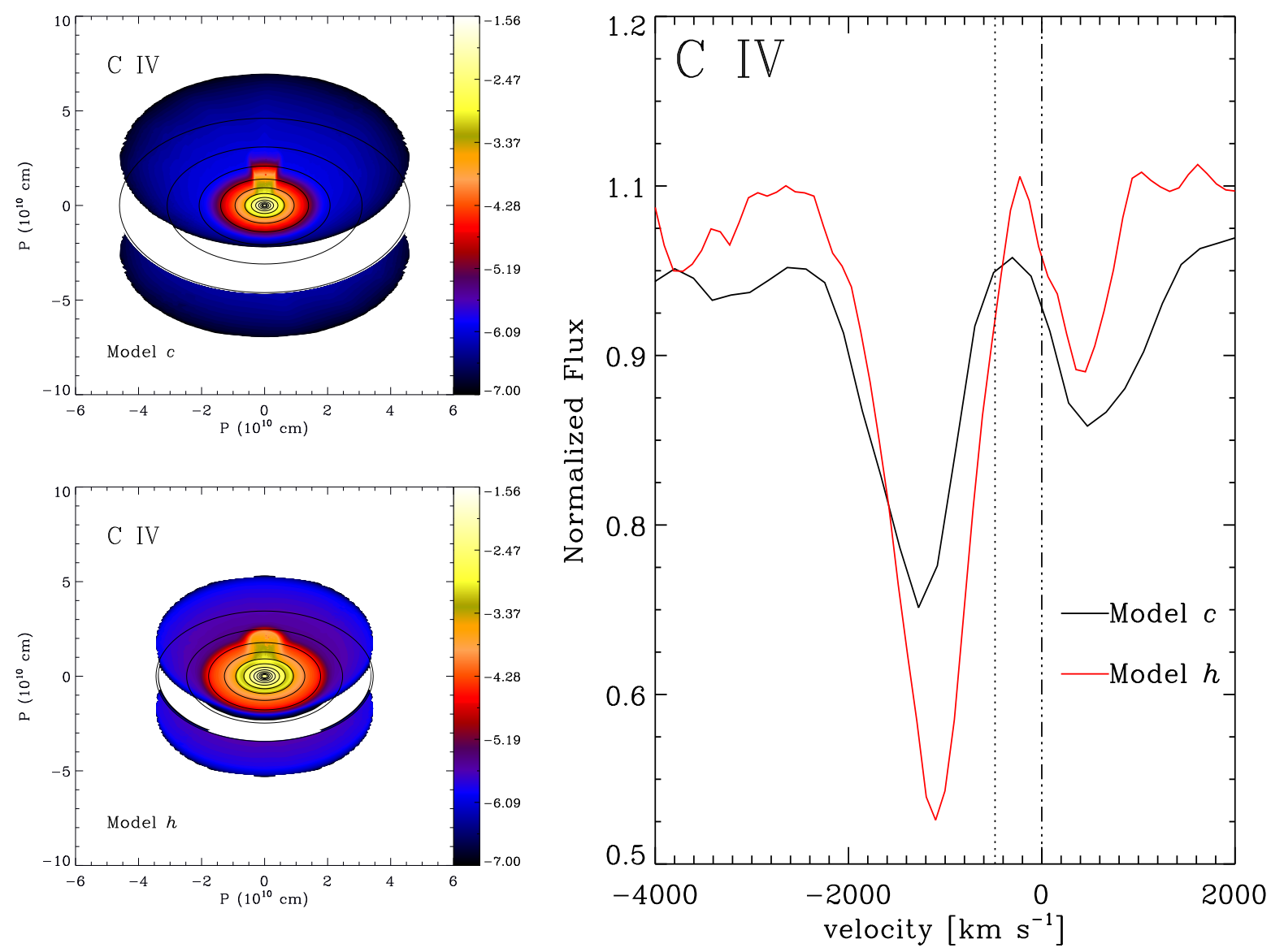

Figura 4.10: Emissão do dupleto do C IV $\lambda \lambda 1548,1551$ para os modelos $c$ e $h$. No painel direito mostra-se o logaritmo da intensidade específica média entre as frequecias correspondentes entre o intervalo espectral entre os comprimentos de onda $1530 \AA$ e $1560 \AA$. No painel direito mostra-se os perfis de linha do dupleto no espaço de velocidades normalizados pelo contínuo e centralizado na componente vermelha do dupleto.

do contínuo ser maior. Entre as linhas o mínimo da absorção encontram-se a diferentes velocidades devido à que as linhas são geradas em diferentes regiões. A linha do C IV é gerada mais internamente do que a linha do Si IV, pelo qual as velocidades características desse perfil são maiores. Vemos dos gráficos que as emissões dependem muito do tamanho da região emissora e do estado de ionização da mesma. As linhas do Si IV são muito mais fortes que as do C IV já a emissão destas últimas está concentrada no interior do vento, como mostram os mapas de intensidade média, já a intensidade das outras é alta também nas regiões externas. Nesse caso a massa da primária influi no tamanho da região emissora das linhas. É importante lembrar que também a massa $M_{1}$ altera a contribuição da componente radial da velocidade que aumenta o valor da velocidade máxima projetada na linha de visada. Outra dependência aparece na velocidade de rotação, que vem a ser 

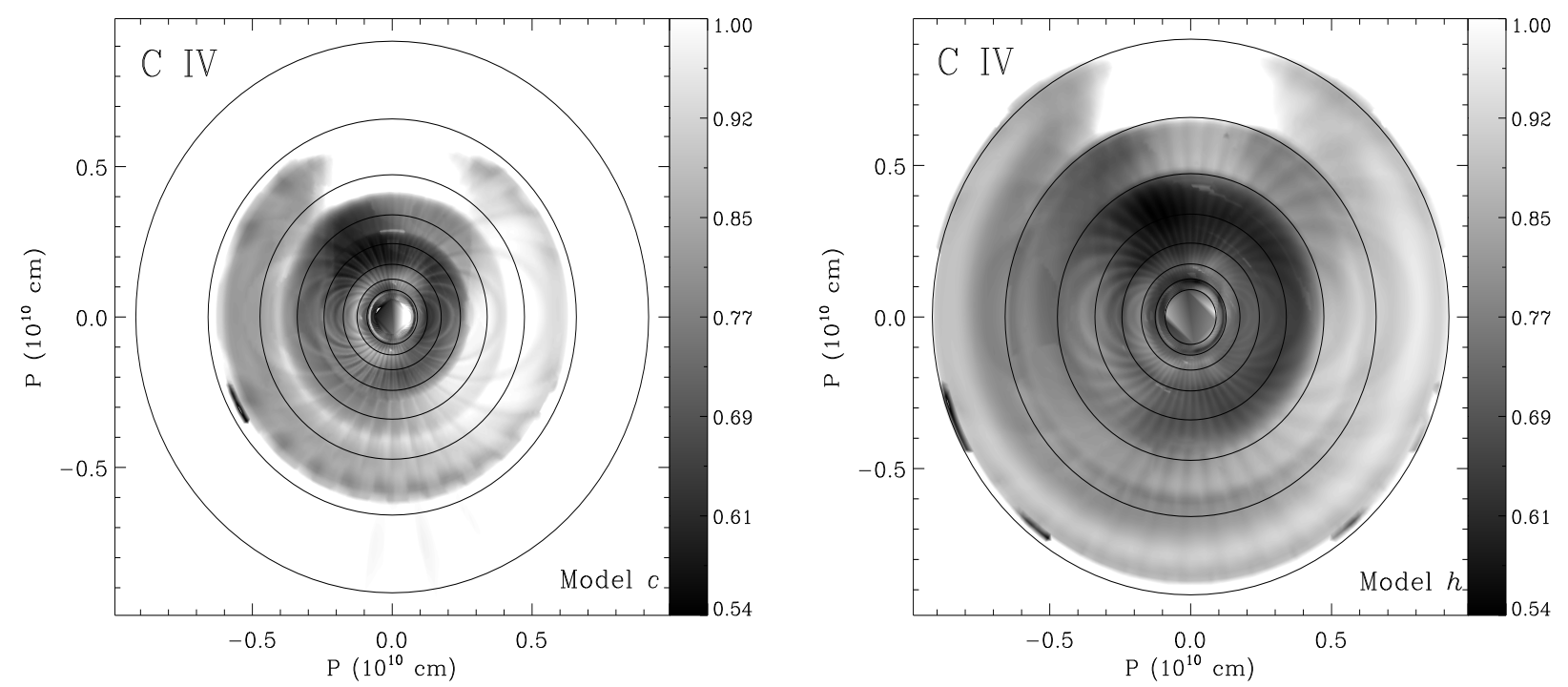

Figura 4.11: Emissão do dupleto do C IV $\lambda \lambda 1548,1551$ para os modelos $c$ e $h$. No painel direito mostra-se o logaritmo da intensidade específica média entre as frequecias correspondentes entre o intervalo espectral entre os comprimentos de onda $1530 \AA$ e $1560 \AA$. No painel direito mostra-se os perfis de linha do dupleto no espácio de velocidades normalizados pelo contínuo e centralizado na componente vermelha do dupleto.

maior quanto maior é a massa da primária. Isto não é muito evidente na asa azul dos perfis, mas sim nas asas vermelhas, onde velocidades maiores são atingidas quando $\mathrm{M}_{1}$ é maior.

Para ilustrar a dependência do perfil de absorção com a massa da anã branca, na figura 4.11 é mostrada a razão entre a intensidade média na linha e do contínuo na vizinhança da linha $\left(\mathrm{I}_{l} / \mathrm{I}_{c}\right)$ para o caso do C IV $\lambda \lambda 1548,1551$. Nesse gráfico é mostrada a distribuição desta razão para os parâmetros de impacto que saem da região interna do disco para os modelos $c$ e $h$. É claro que a absorção é maior quando $\mathrm{M}_{1}=0.6 \mathrm{M}_{\odot}$, nos raios que saem do interior quente do disco. Aparecem também as características próprias da fotosfera através dos traços que evidenciam a rotação do disco. Mas a principal absorção não acontece nesses traços, mas em parâmetros de impacto de regiões específicas, com maior quantidade de material entre o observador e o disco. Assim, podemos concluir que o efeito principal da massa da primária sobre as características do vento, e portanto sobre os perfis de linha, é de alterar a distribuição do fluxo de radiação através do disco, este fluxo por sua vez influi sobre a taxa de perda de massa local. Esta perda de massa define a quantidade de material que é colocado no vento entre a emissão do disco e o observador, o que leva à 
absorção nas linhas.

\subsection{Efeito da taxa de perda de massa.}

Nesta seção analisamos o efeito que a perda de massa no vento tem sobre o contínuo e linhas dos espectros sintéticos. Para isso usamos os modelos " $h$ " e "e". Como vemos na tabela 3.1 estes modelos têm uma taxa de perda de massa de $4.0 \times 10^{-11} \mathrm{M}_{\odot}$ ano $^{-1}$ e $9.3 \times 10^{-11} \mathrm{M}_{\odot}$ ano $^{-1}$ respectivamente, o que representa aproximadamente $\sim 1 \%$ da taxa de acresção nos dois casos. No primeiro modelo vamos incrementar a taxa de perda de massa em 5 vezes, ou seja até $5 \%$ da taxa de acresção, já no segundo modelo vamos incrementar esta taxa de perda de massa em 50 vezes, para um valor extremo de $\sim 50 \%$ da taxa de acresção.

Na figura 4.12 são mostrados os espectros sintéticos correspondentes ao modelo $h$ "estândar" e o mais denso. Os parâmetros geométricos do vento também são mantidos fixos nos dois modelos. Neste caso com $i=30^{\circ}, \mathrm{R}_{C}=\mathrm{R}_{f}, \theta_{1}=5^{\circ}$ e $\theta_{2}=45^{\circ}$. A linha vermelha corresponde a um modelo com perda de massa do vento 5 vezes maior do que a do modelo correspondente à linha preta. A figura mostra uma forte absorção para $\lambda<1500$ Å no modelo de maior perda de massa. Esta absorção provoca um claro avermelhamento do espectro causado pela alta densidade do vento, especialmente na região que limita com a fotosfera. Isto faz com que o contínuo, nessa região do espectro, se torne opticamente fino numa região mais externa da fotosfera. Um vento mais denso provoca também linhas opticamente muito mais espessas provocando fortes absorções e um forte efeito de blanketing.

O avermelhamento produzido pela presença do vento não conseguiria resolver o problema cor-magnitude. Encontramos que o vento atua principalmente para $\lambda \lesssim 1550 \AA$ e que produz um avermelhamento de $\sim 0.06$ mag (medido entre 1000-3000 $\AA$ ) para valores de perda de massa compatíveis com os modelos hidrodinâmicos. Este valor contrasta com os valores encontrados usando modelos de atmosferas de disco sem vento $\sim 0.3$ mag (medido entre 1400-3000 A) (Puebla et al., 2007; Wade, 1988).

Os perfis de linha são muito afetados pelo incremento da densidade do vento. Isto pode ser visto na figura 4.12. O modelo mais denso produz absorções mais fortes se comparadas com o modelo com taxa de perda de massa menor. O incremento de perda de 

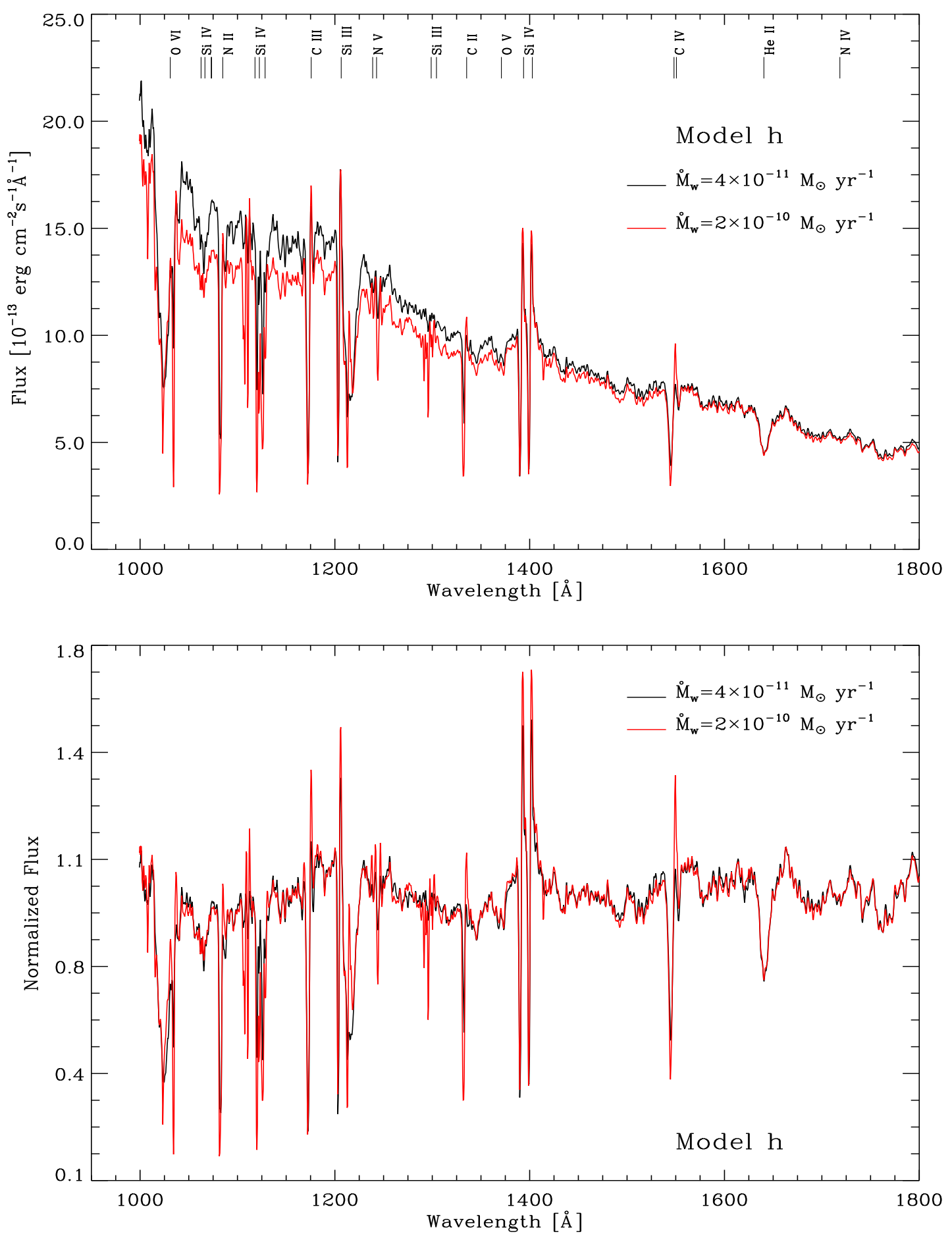

Figura 4.12: Espectros sintéticos UV para o modelo $h$ com inclinação orbital $i=30^{\circ}$. No painel superior mostra-se os fluxos absolutos escalonados a uma distância arbitrária. No painel inferior mostra-se os fluxos normalizados pelo contínuo de cada modelo. A diferença entre os modelos é taxa de perda total de massa no vento $\dot{\mathrm{M}}_{w}$. Um modelo com $\dot{\mathrm{M}}_{w}=4 \times 10^{-11} \mathrm{M}_{\odot}$ ano ${ }^{-1}$ (linha preta) e com $\dot{\mathrm{M}}_{w}=2 \times 10^{-10} \mathrm{M}_{\odot}$ ano $^{-1}$ (linha vermelha) são mostrados. 

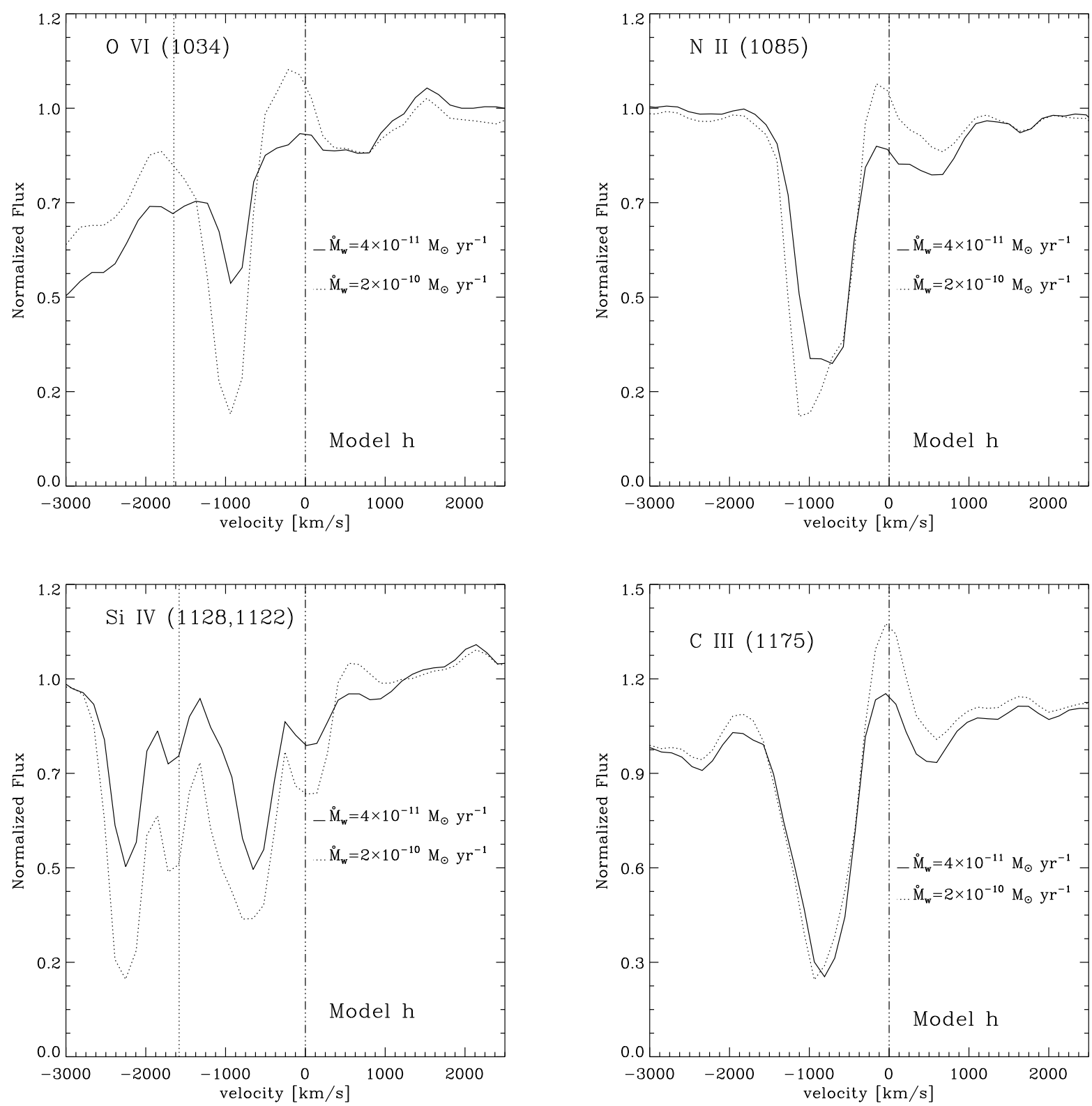

Figura 4.13: Perfís de linha normalizados pelo contínuo para as linhas do O VI, N II, Si IV e C II. Os modelos correspondem a diferentes taxas de perda de massa no vento $\dot{\mathrm{M}}_{w}$, de $\dot{\mathrm{M}}_{w}=4 \times 10^{-11} \mathrm{M}_{\odot}$ ano ${ }^{-1}$ (linha preta) e com $\dot{\mathrm{M}}_{w}=2 \times 10^{-10} \mathrm{M}_{\odot}$ ano $^{-1}$ (linha pontilhada). Em todos os casos foi usada uma inclinação orbital de $i=30^{\circ}$.

massa, ao colocar mais material na região estendida, também provoca fortes componentes em emissão em todas as linhas, tanto naquelas que provêm de regiões de alta velocidade como de baixa. Isto produz fortes perfis P-Cyg onde antes só eram produzidos perfis em absorção. Nas figuras 4.13 e 4.14 os perfis das principais linhas no UV são comparados. Estes perfis descrevem mais claramente o efeito da perda de massa sobre os diferentes 

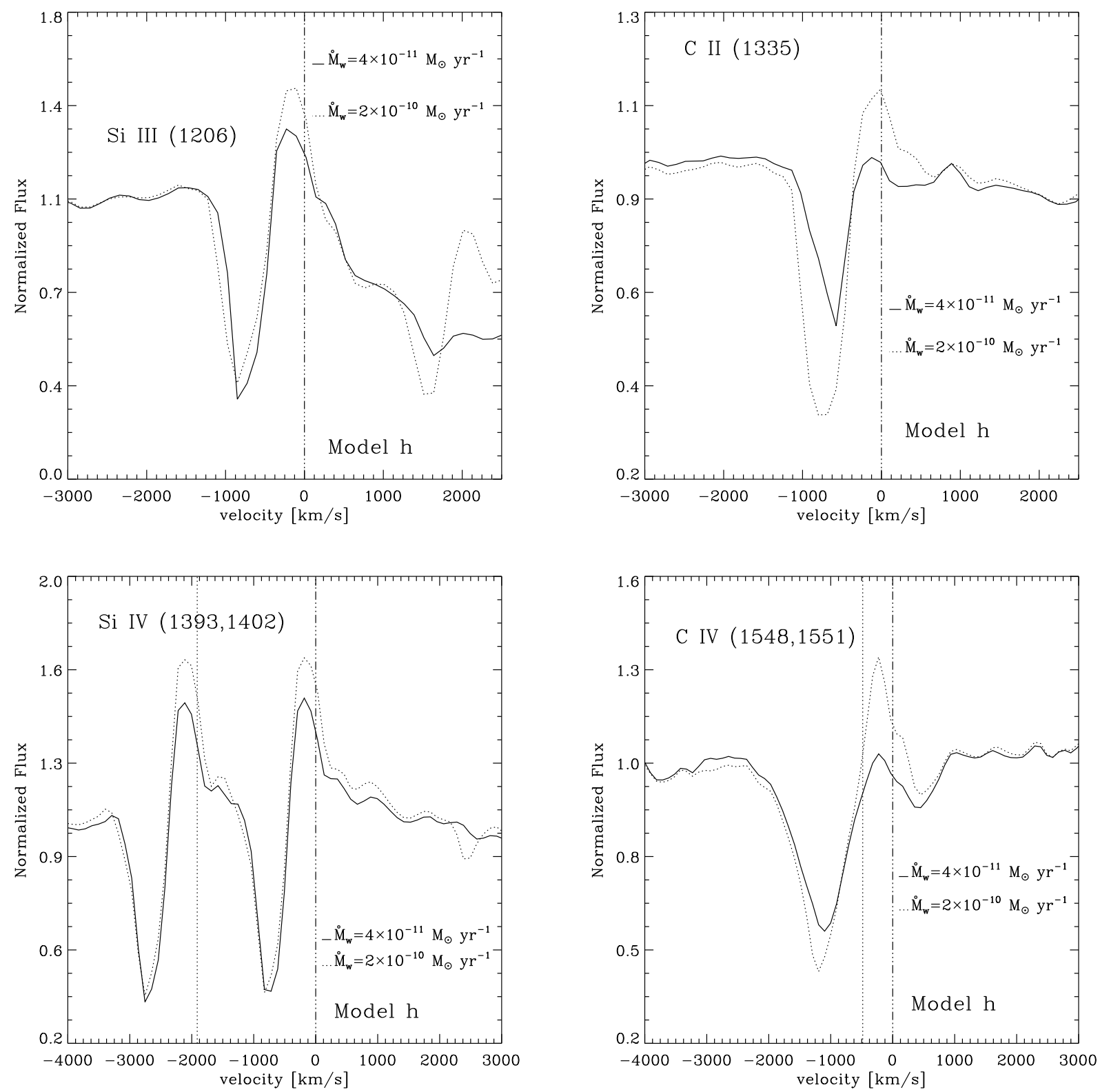

Figura 4.14: Perfís de linha normalizados pelo contínuo para as linhas do Si III, C II, Si Iv e C IV. Os modelos correspondem a diferentes taxas de perda de massa no vento $\dot{\mathrm{M}}_{w}$, de $\dot{\mathrm{M}}_{w}=4 \times 10^{-11} \mathrm{M}_{\odot}$ ano ${ }^{-1}$ (linha preta) e com $\dot{\mathrm{M}}_{w}=2 \times 10^{-10} \mathrm{M}_{\odot}$ ano ${ }^{-1}$ (linha pontilhada). Em todos os casos foi usada uma inclinação orbital de $i=30^{\circ}$.

estados de ionização dentro deste modelo de vento. Vemos que no caso do O vi $\lambda 1034$, N II $\lambda 1085$, C II $\lambda 1335$ e C III $\lambda 1175$, perfis preferentemente em absorção tornam-se perfis P-Cyg aumentando fortemente a profundidade da componente em absorção, além de uma forte emissão azulada ou no centro da linha. No caso do Si IV $\lambda 1398$, C IV $\lambda 1549$ e Si III $\lambda 1206$ o principal efeito é o aparecimento de uma forte emissão azulada. 
A figura 4.15 mostra os mesmos modelos mas agora com um ângulo de inclinação orbital $i=70^{\circ}$. É evidente aqui que a principal influência do incremento da taxa de perda de massa ocorre na intensidade das linhas de emissão. Uma linha fortemente intensificada é a linha do N v $\lambda 1240$ devido à alta densidade na região do vento proveniente do interior do disco. Esta alta densidade faz com que regiões estendidas que antes emitiam menos tenham esta emissão multiplicada. O limite das asas dos perfis de linha são praticamente inalterados com o aumento da taxa de perda de massa para altas inclinações, ao contrário do que acontece em sistemas de baixa inclinação orbital. O contínuo também é levemente avermelhado pelo aumento de $\dot{\mathrm{M}}_{w}$, mas em menor grau do que no caso dos sistemas de baixa inclinação orbital. Nos dois espectros mostrados na figura 4.15, o contínuo é afetado pelo escurecimento de bordo (limb darkening).

Para terminar esta seção, também foi pesquisado o efeito que um vento ultra-denso teria sobre o espectro. Devido ao efeito de avermelhamento que um vento denso produz sobre o contínuo, talvez esta seja uma das chaves para solucionar o problema da dicotomia cor-magnitude (seção 1.3). Para isso foi calculado um modelo com vento ultra-denso (com base no modelo " $e$ " da tabela 3.1). Neste modelo são mantidos os mesmos parâmetros físicos e geométricos do modelo original, mas neste caso com uma taxa de perda de massa de $\dot{\mathrm{M}}_{w}=4.6 \times 10^{-9} \mathrm{M}_{\odot}$ ano $^{-1}$ que é aproximadamente o $50 \%$ da taxa de acresção no disco. Este valor de taxa de perda de massa seria incompatível com um disco estacionário, mas nesse caso o cálculo foi feito para avaliar qualitativamente o efeito de um vento ultra-denso sobre as características espectrais no UV. Na figura 4.16 mostra-se o espectro sintético do modelo " $e$ " com uma inclinação orbital de $i=30^{\circ}$ (linha preta) e o espectro sintético para o modelo com alta taxa de perda de massa (linha vermelha). A principal caraterística encontrada é o forte avermelhamento no contínuo do espectro ( 0.2 mag medido entre 1000-2000 А).

Os perfis de linha mostram um comportamento semelhante ao descrito no caso dos modelos $h$ descritos anteriormente, mas com absorções muito mais profundas e azuladas. Neste caso o vento é mais acelerado tendo velocidades terminais até 6 vezes maiores. As linhas de emissão também aparecem azuladas, especialmente as linhas do C III e CiV. Assim, a componente em emissão do C IV $\lambda 1549$ tem o máximo em $-1000 \mathrm{~km} \mathrm{~s}^{-1}$ e a do C III $\lambda 1175$ em $-800 \mathrm{~km} \mathrm{~s}^{-1}$. Ao contrário, o dupleto do Si IV $\lambda 1398$ apresenta emissões 

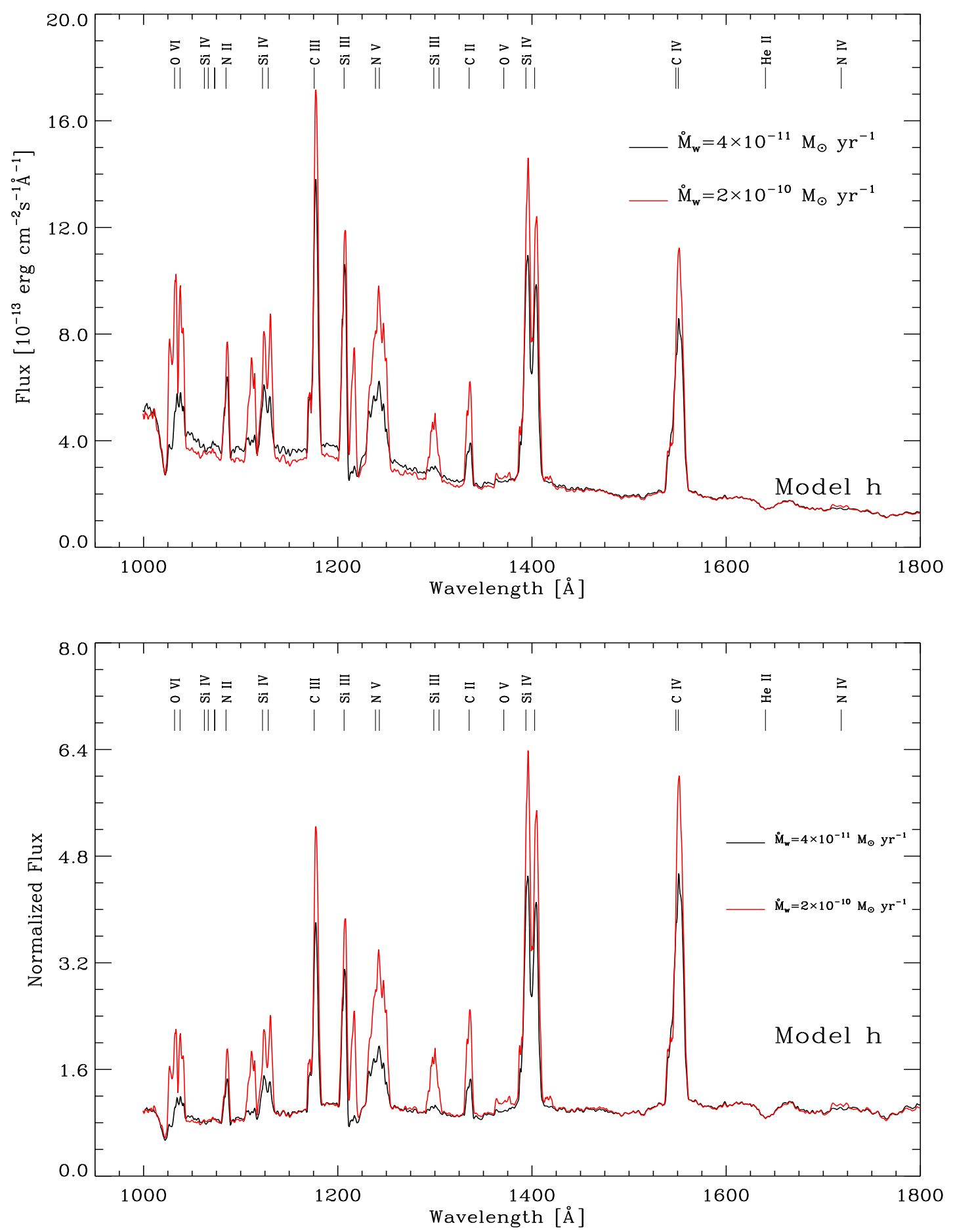

Figura 4.15: Espectros sintéticos UV para o modelo $h$ com inclinação orbital $i=70^{\circ}$. No painel superior mostra-se os fluxos absolutos escalonados a uma distância arbitrária. No painel inferior mostra-se os fluxos normalizados pelo contínuo de cada modelo. A diferença entre os modelos é taxa de perda total de massa no vento $\dot{\mathrm{M}}_{w}$. Um modelo com $\dot{\mathrm{M}}_{w}=4 \times 10^{-11} \mathrm{M}_{\odot}$ ano ${ }^{-1}$ (linha preta) e com $\dot{\mathrm{M}}_{w}=2 \times 10^{-10} \mathrm{M}_{\odot}$ ano $^{-1}$ (linha vermelha) são mostrados. 

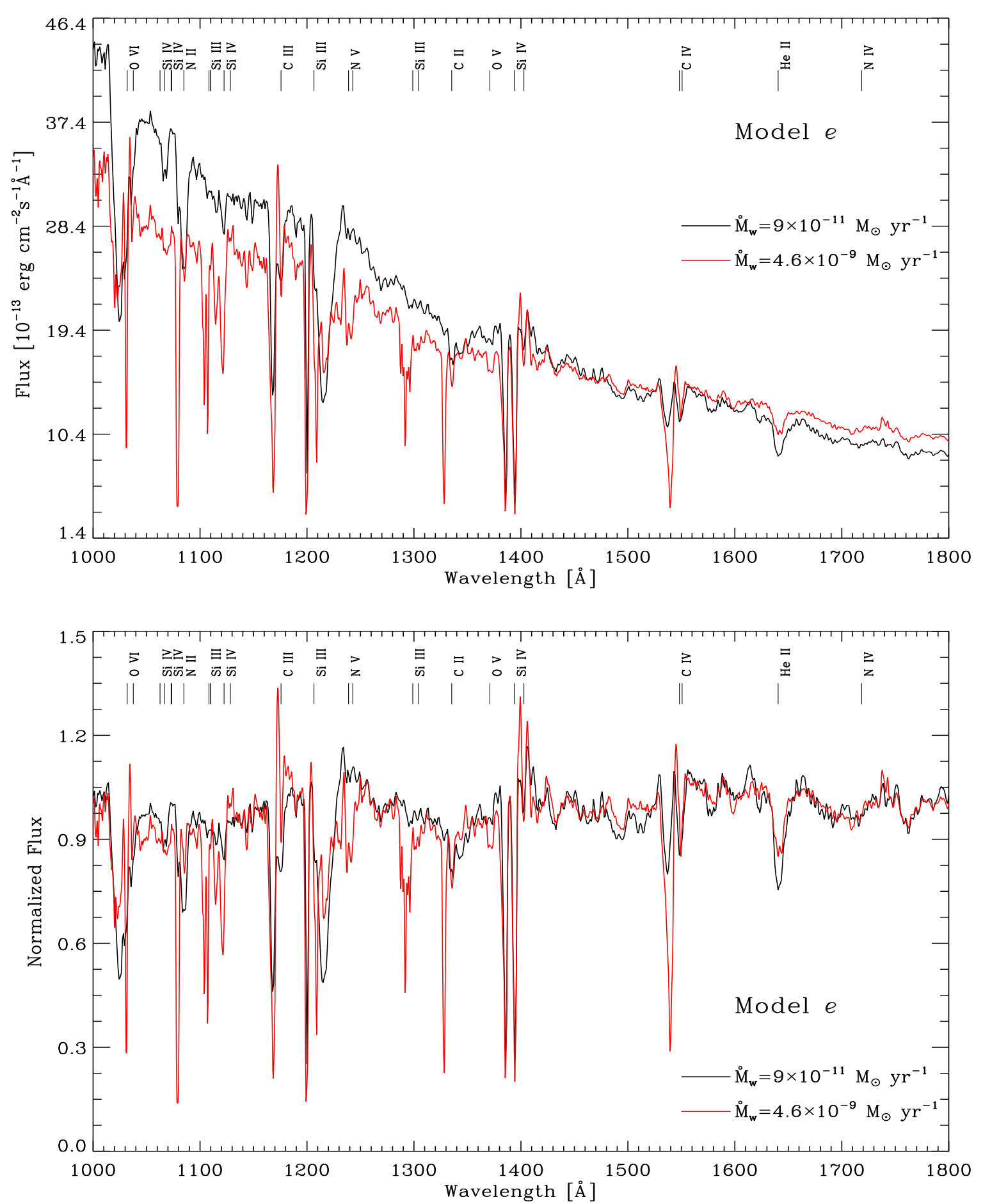

Figura 4.16: Espectros sintéticos UV para o modelo $e$ com inclinação orbital $i=30^{\circ}$. No painel superior mostra-se os fluxos absolutos escalonados a uma distância arbitrária. No painel inferior mostra-se os fluxos normalizados pelo contínuo de cada modelo. A diferença entre os modelos é taxa de perda total de massa no vento $\dot{\mathrm{M}}_{w}$. Um modelo com $\dot{\mathrm{M}}_{w}=9 \times 10^{-11} \mathrm{M}_{\odot}$ ano ${ }^{-1}$ (linha preta) e com $\dot{\mathrm{M}}_{w}=4.6 \times 10^{-9} \mathrm{M}_{\odot}$ ano $^{-1}$ (linha vermelha) são mostrados. 
avermelhadas em $\sim 700 \mathrm{~km} \mathrm{~s}^{-1}$. Isto pode ser explicado pela contribuição na linha da região mais externa que possui uma distribuição de velocidades mais larga. A linha do N v $\lambda 1240$, que aparece rasa no modelo de menor taxa de perda de massa, no outro caso aparece como uma pequena absorção. Muitos sistemas observados no UV apresentam uma forte absorção nessa linha, o que daria a ideia de que os ventos em VC's apresentariam regiões localizadas de alta densidade.

Mesmo que taxas de perda de massa da magnitude analisada neste parágrafo sejam muito altas para discos estacionários em VC's, as intensidades e os perfis de linha observados no UV sugerem a existência de condensações dentro do vento e/ou regiões de alta densidade, fato que foi predito por modelos hidrodinâmicos. Esta possibilidade, mesmo que de uma maneira muito simples, é explorada na seção 4.7. É importante notar também que no caso do modelo $e$, cujo valor de $\alpha$ é de 0.7 , o alto gradiente do campo de velocidades vertical mostra uma influência sobre o perfil das linhas. O campo de velocidades vertical afeta predominantemente os espectros de sistemas com baixa inclinação, e portanto o valor de $\alpha$ é importante para estes sistemas.

\subsection{Efeito da inclinação orbital}

Nesta seção é analisada a influência da inclinação orbital sobre as forma dos perfis de linha. Para isso fazemos uso dos modelos "c" e " $d$ " da tabela 3.1 com várias inclinações. A principal diferença entre estes modelos é a taxa de acresção e a taxa de perda de massa no vento, o que leva a uma temperatura e densidades diferentes. Cinematicamente, os dois modelos têm um mesmo valor de $\alpha=0.9$ e $k=0.6$ acarretando velocidades terminais similares tanto nas atmosferas internas como nas externas. No caso do modelo $c$ foram calculados espectros sintéticos para inclinações orbitais $i$ de $30^{\circ}$ até $80^{\circ}$ em intervalos de $10^{\circ}$. Estes espectros são mostrados na figura 4.17.

Estas figuras mostram que a forma dos perfis das linhas é fortemente dependente da inclinação orbital e, como foi apontado anteriormente, do estado de ionização do gás. Em geral vemos que a maioria das linhas aparecem em absorção ou com perfis P-Cyg para inclinações baixas ou intermediárias (por exemplo: C IV $\lambda 1549$, C II $\lambda 1335$, O v $\lambda 1371$, Si IV $\lambda 1070$ e Si IV $\lambda 1118$ ) e em emissão para inclinações altas. Este comportamento é similar ao observado e é devido principalmente à geometria do vento onde essas linhas são emitidas. 

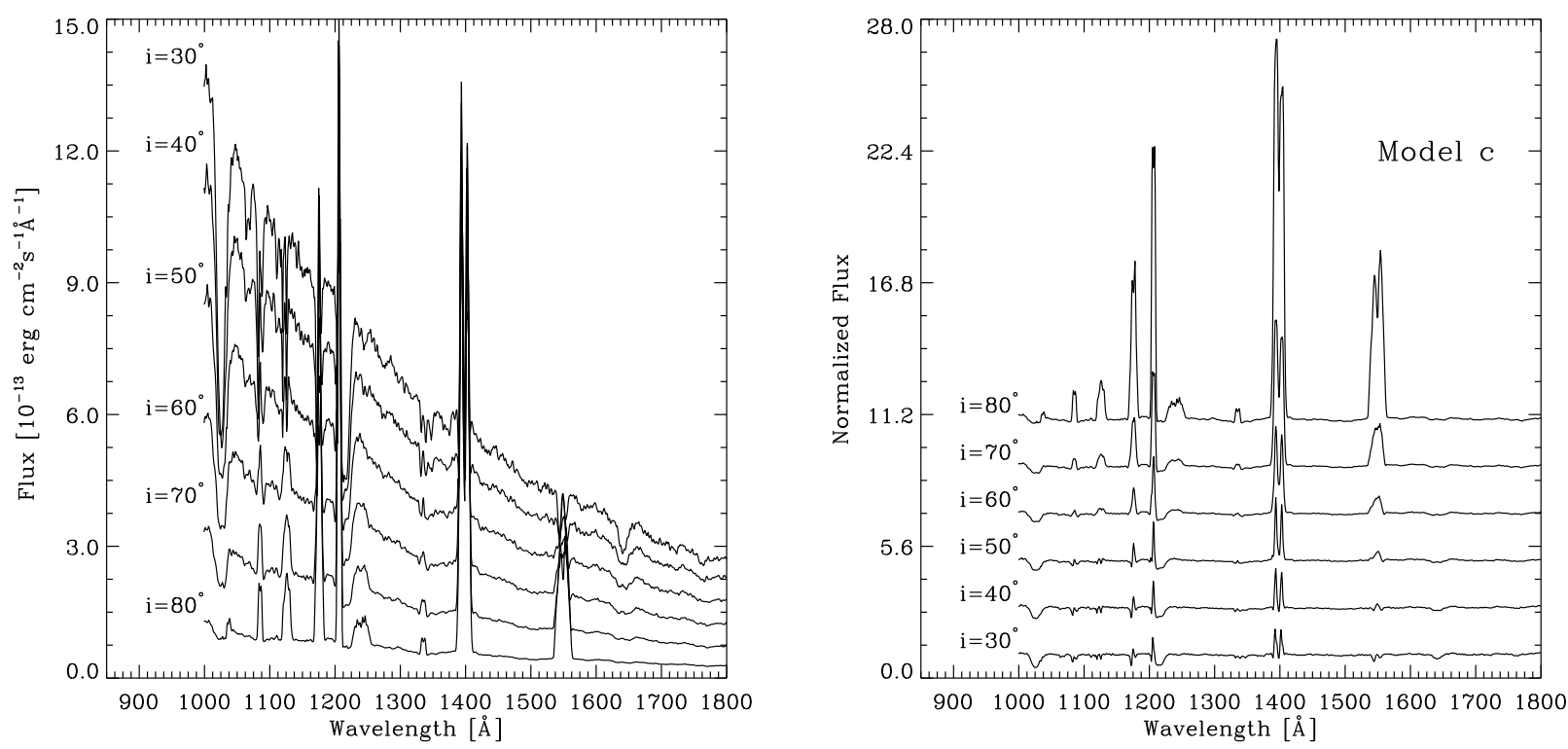

Figura 4.17: Espectros sintéticos calculados para o modelo "c" e para diferentes inclinações orbitais $i=30^{\circ}$, $40^{\circ}, 50^{\circ}$ e $60^{\circ}, 70^{\circ}$ e $80^{\circ}$. No painel esquerdo o fluxo é escalonado a 400 pcs e no painel direito é mostrado o fluxo normalizado pelo contínuo, descolado por uma constante para maior clareza.

Exitem linhas que aparecem em emissão mesmo em modelos com inclinações baixas $\sim 10^{\circ}$ $30^{\circ}$ como no caso mostrado na figura 4.18 nos painéis esquerdos superior e inferior, assim como na figura 4.17 para $i=30^{\circ}$. A intensidade destas linhas (especificamente Si III $\lambda 1206$ e Si IV $\lambda 1398$ ) está fortemente relacionada com as regiões mais externas e estendidas do vento e com a temperatura das mesmas. No caso do modelo $c$ a temperatura da região mais externa do vento é de $\sim 15000 \mathrm{~K}$ e mostra a linha de Si IV mais intensa do que a do Si III, enquanto no modelo $d$ a temperatura da região mais externa é de $\sim 12500 \mathrm{~K}$ e a linha do Si III apresenta-se mais intensa uma vez que nessa atmosfera o íon dominante do Si é o Si III.

Como esperado, a inclinação orbital também influencia a largura das linhas de emissão e de absorção. Esta influência provém principalmente da rotação do disco e do vento. A largura dos perfis de absorção e de emissão aumenta com a inclinação enquanto a profundidade das absorções diminui. Nas figuras 4.19 e 4.20 são dados os perfis de linha para o dupleto do Si IV $\lambda \lambda 1393,1402$ para diferentes valores da inclinação orbital. Para cada modelo é mostrado o perfil da linha e a intensidade específica média calculada de acordo com a equação (2.61) entre os comprimentos de onda de $1390 \AA$ e $1407 \AA$, dentro do espaço 

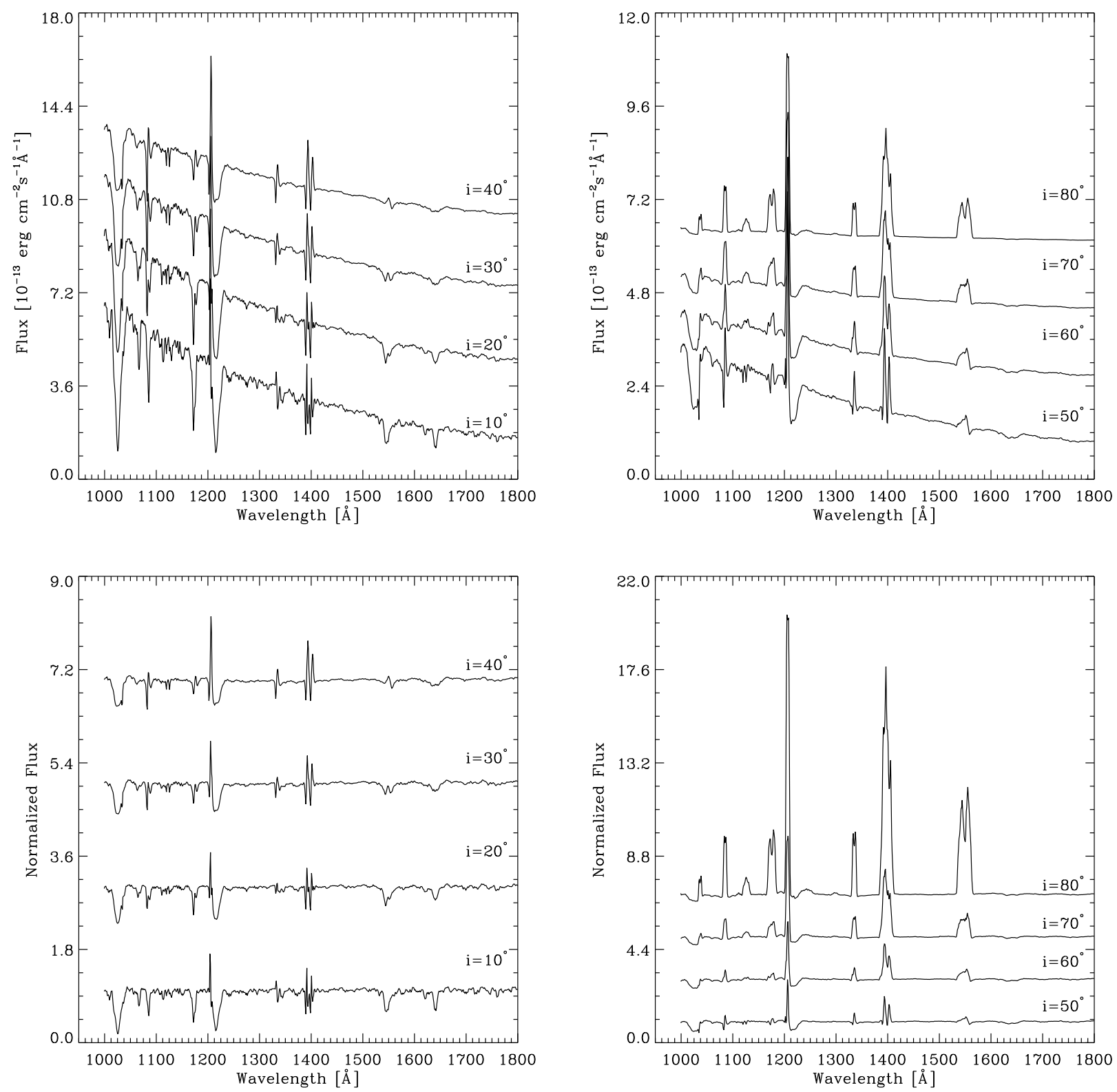

Figura 4.18: Espectros sintéticos calculados para o modelos " $d$ " e para diferentes inclinações orbitais $i=10^{\circ}, 20^{\circ}, 30^{\circ}$ e $40^{\circ}$ nos painéis esquerdos e $i=50^{\circ}, 60^{\circ}, 70^{\circ}$ e $80^{\circ}$ nos painéis direitos. Os painéis superiores o fluxo é escalonado a 400 pcs e nos painéis inferiores é mostrado o fluxo normalizado pelo contínuo.

de parâmetros de impacto. A escala de cores é a mesma entre os modelos para assim comparar a magnitude da emissão nessa região espectral. No caso dos modelos com inclinações baixas os perfis que formados são do tipo P-Cyg. Para o modelo "c" a intensidade das componentes em emissão é maior. Isto é devido princialmente à contribuição que provém de parâmetros de impacto mais externos e que atravessam a região da atmosfera com vento 
mais externa calculada. Esta região, mesmo com uma intensidade média menor se comparada com as regiões mais internas, é muito grande pelo qual sua contribuição prevalece sobre as contribuições das outras regiões. A diferença em intensidade da emissão dos dois modelos deve-se principalmente à diferença dos estados de ionização das atmosferas mais externas implicando em uma função fonte $S_{\nu}$, maior para essa linha no modelo $c$.

A variação da forma do perfil com a inclinação também é evidente nestes gráficos. No caso de inclinações baixas a estrutura dos perfis em absorção ou P-Cyg dependem principalmente do campo de velocidades vertical do vento $v_{z}$, levando para o azul o mínimo da absorção a uma fração da velocidade terminal $\left(v_{z \infty}\right)$. No caso dos perfis P-Cyg, dentro do contexto deste trabalho, a componente em emissão também aparece no lado azul do comprimento de onda de repouso, já que o gás visível é expelido principalmente na direção do observador. As asas das linhas encontram-se neste caso em $\sim 1000 \mathrm{~km} \mathrm{~s}^{-1}$. Quando $i$ aumenta as linhas apresentam-se mais largas e os núcleos das linhas cada vez mais perto do comprimento de onda de repouso como é mostrado na figura 4.19. Quando $i=50^{\circ}$ a diferença dos perfis entre os dois modelos é devida à alta emissividade na região extensa do modelo $c$ comparada com a do modelo $d$.

Para modelos com alta inclinação (figura 4.20) as linhas mostram uma morfologia diferente entre os modelos. O modelo $c$ mostra as duas componentes do dupleto fortemente em emissão e o modelo $d$ mostra as duas componentes misturadas numa estrutura única. Das figuras correspondentes às intensidades específicas pode-se ver que esta diferença é devida principalmente a que no último caso a linha é gerada principalmente nas regiões internas do vento onde a rotação é maior, o que alarga significativamente as duas componentes do dupleto. Ao contrário, no modelo $c$ a linha tem fortes contribuições das regiões estendidas que rotacionam mais lentamente. As asas das linhas do modelo $d$ são mais alargadas do que as do modelo $c$, pois provêm de regiões de alta rotação muito próximas da fotosfera do disco. As regiões que emitem as asas nos dois modelos têm aproximadamente as mesmas temperaturas, mas no caso do modelo mais frio estas regiões estão localizadas mais internamente (eq.(1.15)) resultando com linhas mais alargadas. 

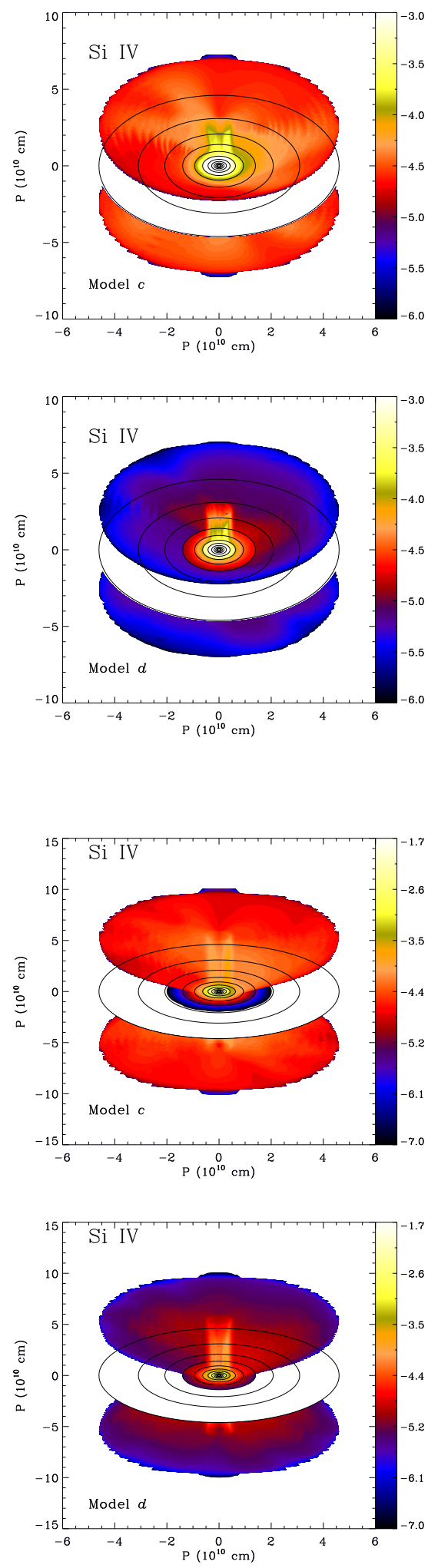
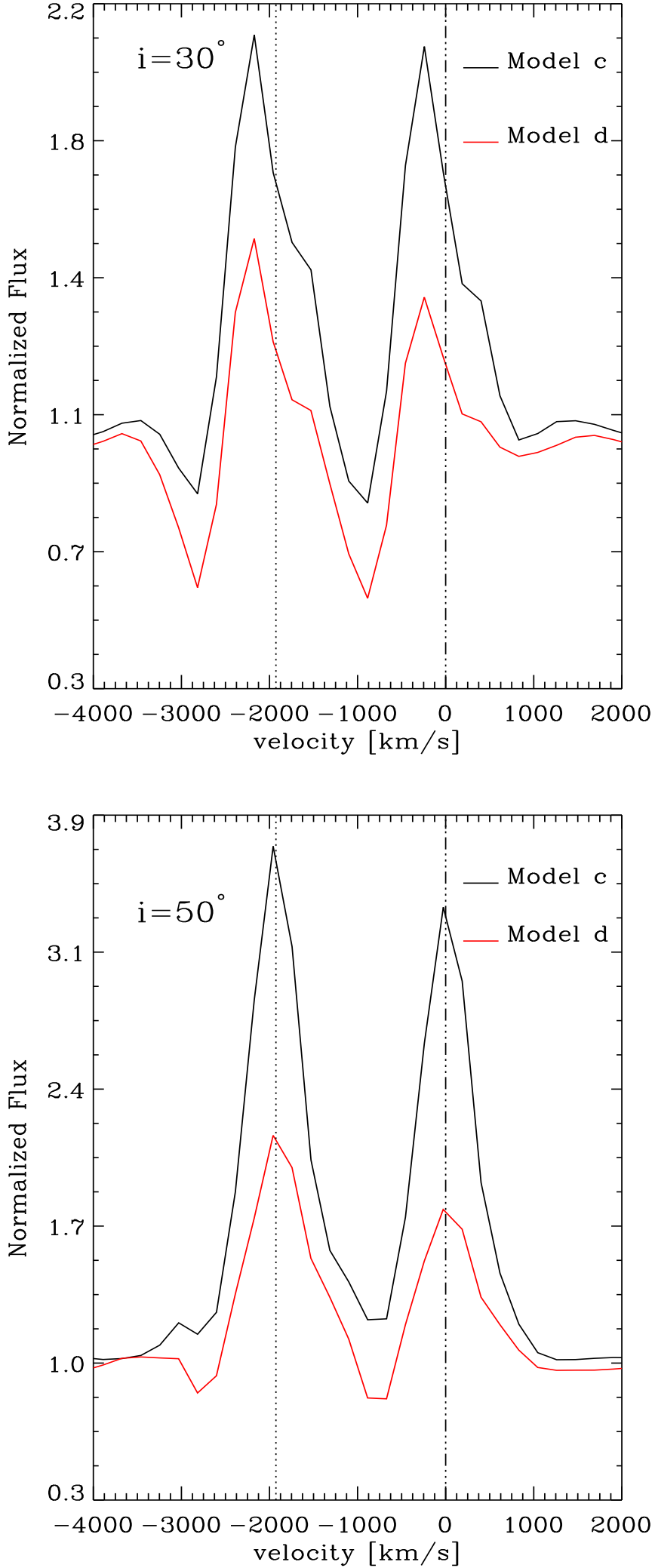

Figura 4.19: Emissão do dupleto do Si IV $\lambda \lambda 1393,1402$ para os modelos $c$ e $d$ para os ângulos $i=30^{\circ}$ (painel superior) e $50^{\circ}$ (painel inferior). Os painéis esquerdo mostram o logaritmo da intensidade específica média entre 1390 Åe 1407 Å. Os painéis direitos mostram os perfis de linha no espaço de velocidades normalizados pelo contínuo. 

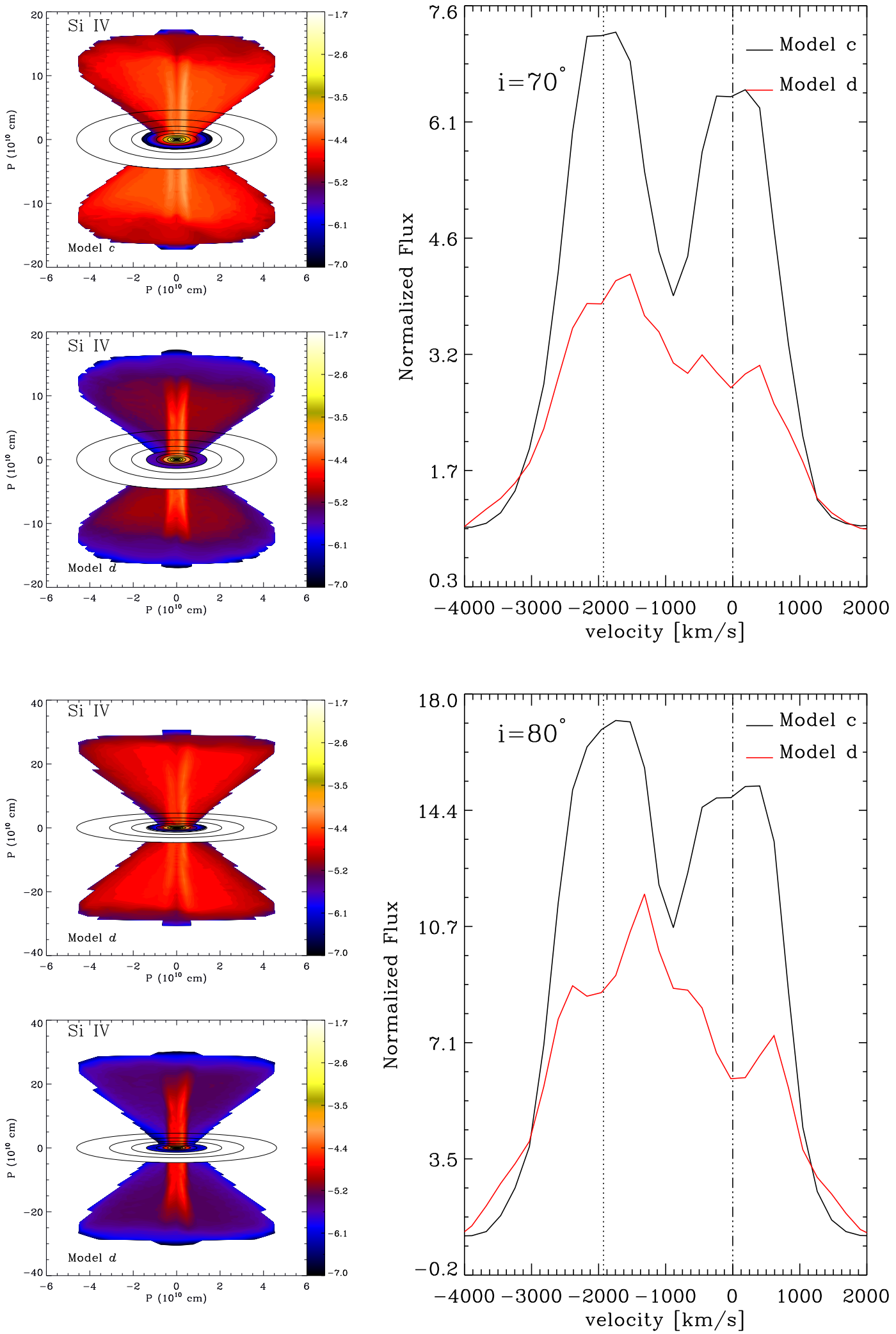

Figura 4.20: Emissão do dupleto do Si IV $\lambda \lambda 1393,1402$ para os modelos $c$ e $d$ para os ângulos $i=70^{\circ}$ (painel superior) e $80^{\circ}$ (painel inferior). Os painéis esquerdo mostram o logaritmo da intensidade específica média entre $1390 \AA$ e e 1407 Å. Os painéis direitos mostram os perfis de linha no espaço de velocidades normalizados pelo contínuo. 


\subsection{Efeito da geometria do vento - Os ângulos de abertura}

Nessa seção é analisado o efeito sobre os perfis de linha dos ângulos de abertura do vento como o descrito na figura $3.1, \theta_{1}$ e $\theta_{2}$. Para isso usaremos modelos calculados com distintos valores desses parâmetros no modelo $b$ da tabela 3.1. Os perfis das principais linhas no UV para diferentes valores de $\theta_{1}$ e $\theta_{2}$ são mostrados na figura 4.21. Vemos nessa figura que $\theta_{1}$ e $\theta_{2}$ influem sobre linhas diferentes; devido principalmente a que estes ângulos excluem ou incluem regiões do vento distintas no cálculo da transferência radiativa.

O ângulo $\theta_{1}$ exclui regiões polares, que são zonas geralmente dominadas por íons altamente ionizados. De acordo com o modelo planteado neste trabalho, o interior do vento muda de estado de ionização rapidamente no sentido radial, daí que um valor pequeno para o ângulo $\theta_{1}$ tem uma forte influência sobre a forma e a intensidade dos perfis de linha para as espécies altamente ionizadas. Na figura 4.21 mostra-se claramente como este ângulo afeta os perfis dos ions C IV $\lambda \lambda 1548,1551$ e N v $\lambda \lambda 1238,1242$. Quando este ângulo aumenta a componente em emissão do perfil é substancialmente reduzida pela diminuição do tamanho da região emissora nas áreas onde a emissividade da linha é grande. A componente em absorção também é mais profunda pois a emissão não consegue preencher as regiões mais azuis do perfil, pela ausência de emissão na região de maior velocidade. No caso do $\mathrm{N} \mathrm{v}$ quando $\theta_{1}=15^{\circ}$ forma-se um raso perfil em absorção devido a que foram retiradas as regiões do vento que preenchiam o perfil em absorção. Isto pode ser explicado fisicamente de duas maneiras, pelo esvazamento das regiões interiores do vento por forças rotacionais e de Coriolis (Pereyra et al., 1997, 2000) e/ou pela mudança do estado de ionização do gás devido ao resfriamento associado à expansão do gás e diluição do campo de radiação. As linhas que provém de regiões com estados de ionização menor não são fortemente afetadas pelo valor de $\theta_{1}$. A sua formação ocorre principalmente nas regiões mais externas.

As linhas que são mais afetadas pelo valor de $\theta_{2}$ são as de Si III $\lambda 1206$, C III $\lambda 1175$ e Si IV $\lambda \lambda 1393,1402$ como é mostrado pela figura 4.21. A linha do C IV $\lambda \lambda 1548,1551$ também é afetada pelo valor desse ângulo, mas em menor grau. Isto indica que essa linha é gerada em uma região muito extensa do vento, como inferido da observação de sistemas eclipsantes. Como é visto na figura 4.21, o principal efeito ocorre sobre a componente em emissão dos perfis, passando de perfis P-Cyg a perfis preferentemente em absorção com uma pequena componente em emissão. Isto é causado princialmente pela alteração do tamanho da região 

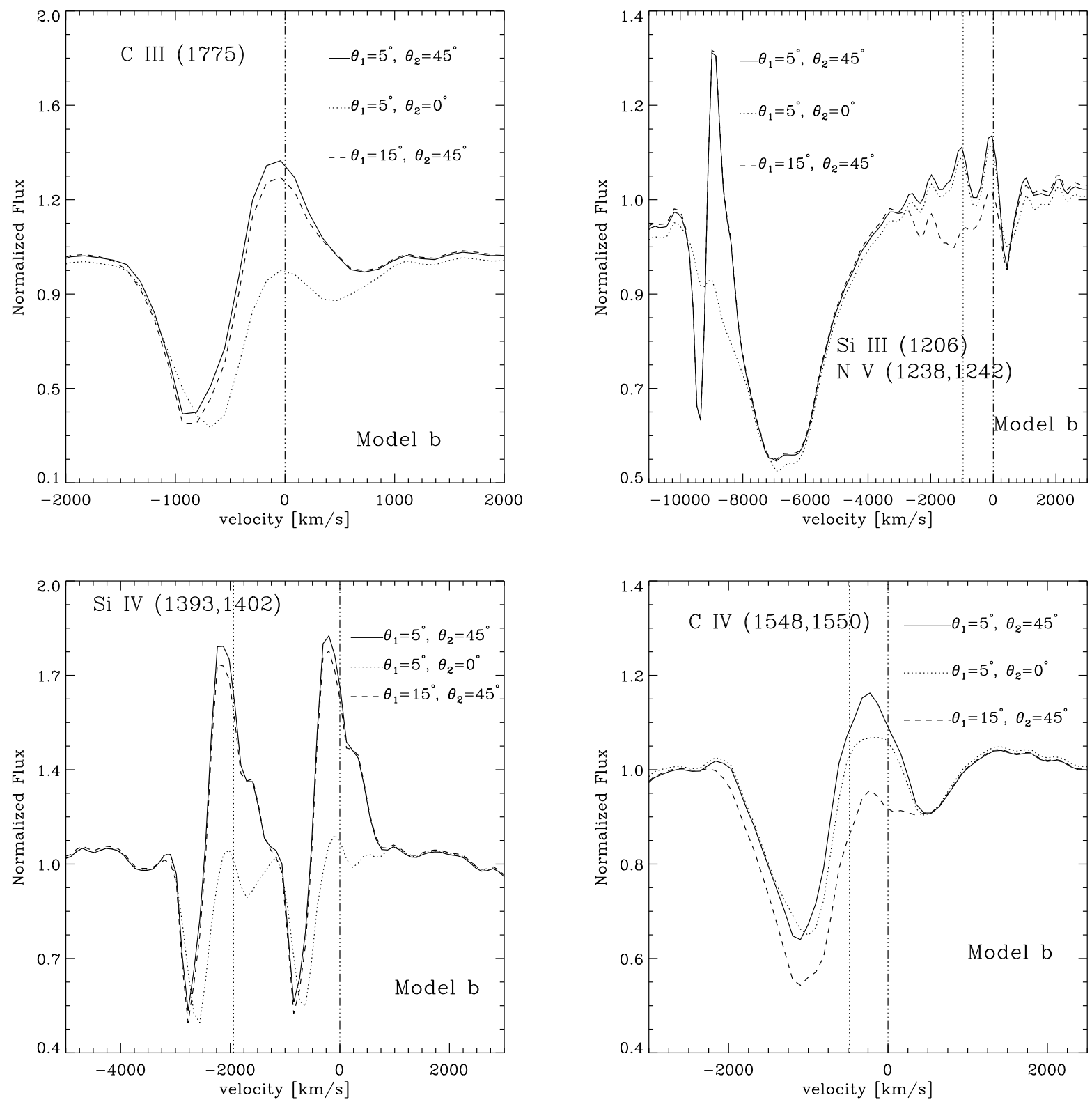

Figura 4.21: Perfis de linha normalizados pelo contínuo para as linhas do CiII, Si III, Nv, Si Iv e Civ. Estes perfis correspondem ao modelo $b$ com inclinação orbital $i=30^{\circ}$. O efeito dos ângulos de abertura são mostrados em cada caso para valores de $\theta_{1}=5^{\circ}, 15^{\circ}$ e $\theta_{2}=0^{\circ}$ e $45^{\circ}$.

emissora. Vemos que os perfis das linhas de Si III $\lambda 1206$, Si IV $\lambda \lambda 1393,1402$ e C III $\lambda 1175$ dependem fortemente do valor de $\theta_{2}$. Estas linhas são observadas preferentemente em absorção em sistemas com baixa inclinação orbital, muito parecidas àquelas calculadas com $\theta_{2}=0^{\circ}$. Isto sugere que o volume da região emissora dessas linhas em geral deve ser muito pequeno. Modelos sem a presença das regiões mais externas e frias do vento foram calculados para comparação. Nestes modelos a atmosfera com vento mais externa tem uma 
temperatura aproximada de $\sim 20000 \mathrm{~K}$. Esta atmosfera foi estendida até $\mathrm{R}=\mathrm{R}_{\text {disk }}$ segundo um ângulo de abertura $\theta_{2}=45^{\circ}$. Nesses casos encontrou-se que apesar das intensidades das linhas de emissão de espécies como o C IV e N V aparecerem fortes, como decorrência do enorme tamanho da região emissora, o perfil P-Cyg procurado é destruído. Conclui-se daqui que a estrutura de ionização do vento deve que ser espacialmente complexa. No modelo aqui proposto, a estrutura de ionização assim como a temperatura variam pouco ao longo da região estendida do vento no sentido vertical, variando predominantemente no sentido radial. Na realidade deve existir uma variação maior tanto da estrutura de ionização como da temperatura no sentido vertical. A observação de linhas com velocidades maiores centradas no repouso nos leva à conclusão de que a geometria dos modelos deve ser a de atmosferas com vento inclinadas que no espaço tridimensional formando uma estrutura de vento bi-cônico.

\subsection{Efeito da inclusão de uma atmosfera externa fria}

Visando estudar o efeito de uma variação na estrutura iônica da região externa do vento foram calculados modelos de atmosferas com vento com temperaturas menores que 14000 K. Estas temperaturas foram associadas aos anéis mais externos àqueles considerados nos modelos originais. O modelo de atmosfera com vento resultante deste cálculo foi estendido também até $\mathrm{R}_{\text {disk }}$ da mesma forma como foi feito com os modelos originais. Os modelos usados nessa análise foram os $b, c$ e $d$ da tabela 3.1. Uma comparação das temperaturas características dos modelos de vento externos originais e estes são mostrados na tabela 4.1. Para estes modelos foram utilizados os mesmos parâmetros geométricos $\theta_{1}=5^{\circ}$ e $\theta_{2}=45^{\circ}$.

As figuras 4.22, 4.23 e 4.24 mostram que em todos os casos a linhas afetadas pela inclusão da atmosfera mais fria são as linhas do Si III, Si IV, C III e C II além da linha do N II. Como esperado, as linhas de espécies de alta ionização não são consideravelmente afetadas pela inclusão desta atmosfera, tais como C IV e Nv. O principal efeito sobre as linhas das espécies de baixa ionização é a supressão da componente em emissão em quase todas as linhas, deixando apenas uma emissão muito rasa, quando presente. Estas características apontam na direção correta considerando os espectros UV de discos quentes observados. De fato podemos sugerir que existem regiões de gás frio extenso no vento de discos. Este resfriamento do gás pode ser causado pela presença de espécies de baixa 
Tabela 4.1 - Comparação das temperaturas das atmosferas mais externas

\begin{tabular}{ccccc}
\hline \hline Modelo & $\mathrm{R}_{f_{o}}$ & $\mathrm{~T}_{o}$ & $\mathrm{R}_{f_{f}}$ & $\mathrm{~T}_{f}$ \\
& {$\left[\mathrm{R}_{W D}\right]$} & $10^{4} \mathrm{~K}$ & {$\left[\mathrm{R}_{W D}\right]$} & $10^{4} \mathrm{~K}$ \\
\hline$b$ & 17.0 & 1.69 & 25.0 & 1.27 \\
$c$ & 11.4 & 1.50 & 17.0 & 1.13 \\
$d$ & 7.7 & 1.65 & 11.4 & 1.25 \\
\hline
\end{tabular}

ionização que contribuem com mais níveis para o resfriamento radiativo e pela também diluição da radiação emitida pelo disco a alturas elevadas no vento. 

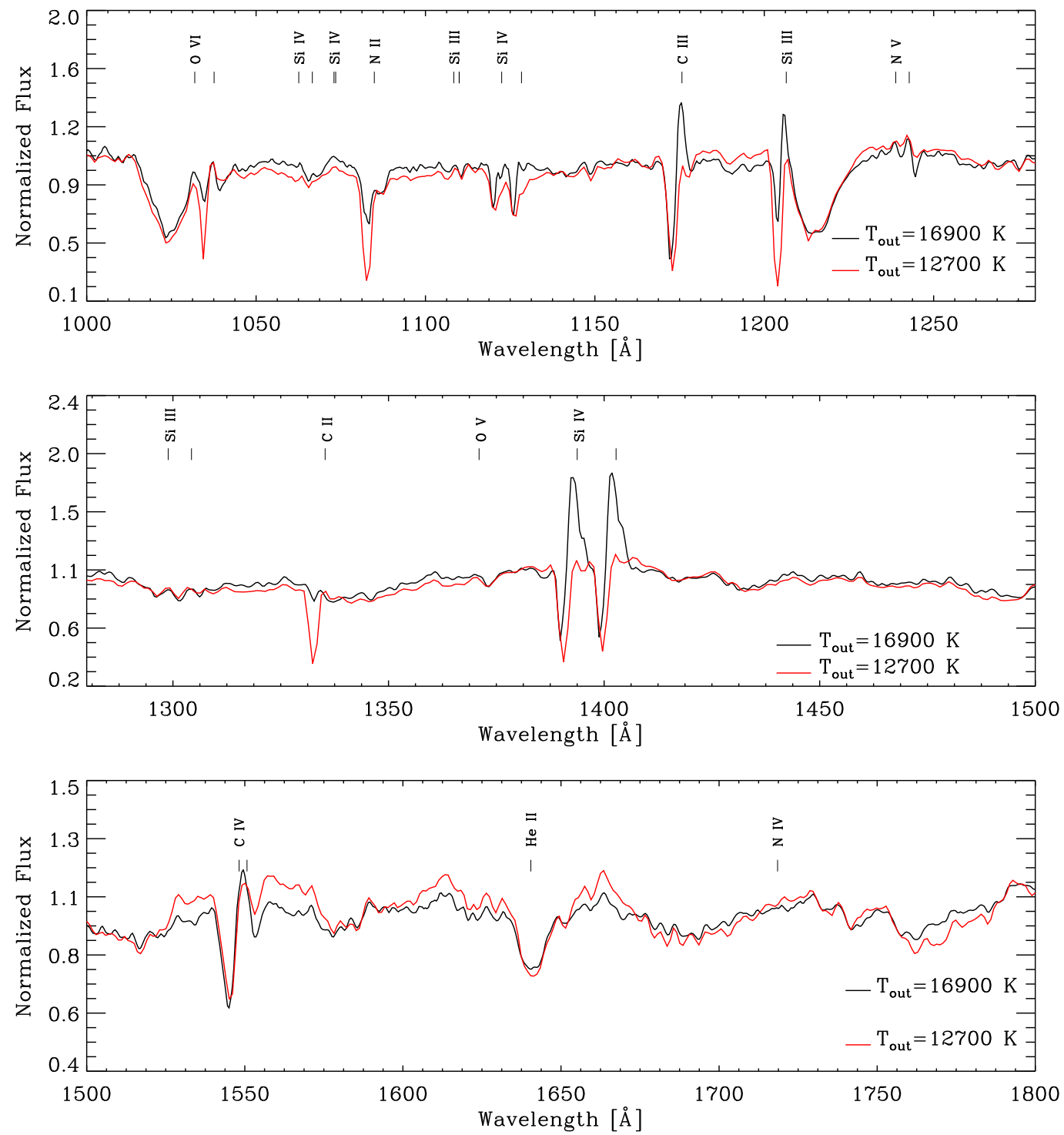

Figura 4.22: Efeito de colocar uma atmosfera fria com vento na região externa do modelo original $b$. A linha preta é o espectro sintético onde a atmosfera mais externa tem uma temperatura de $16900 \mathrm{~K}$. A linha vermelha representa o espectro sintético onde a atmosfera mais externa tem uma temperatura de $\sim 12700 \mathrm{~K}$. 

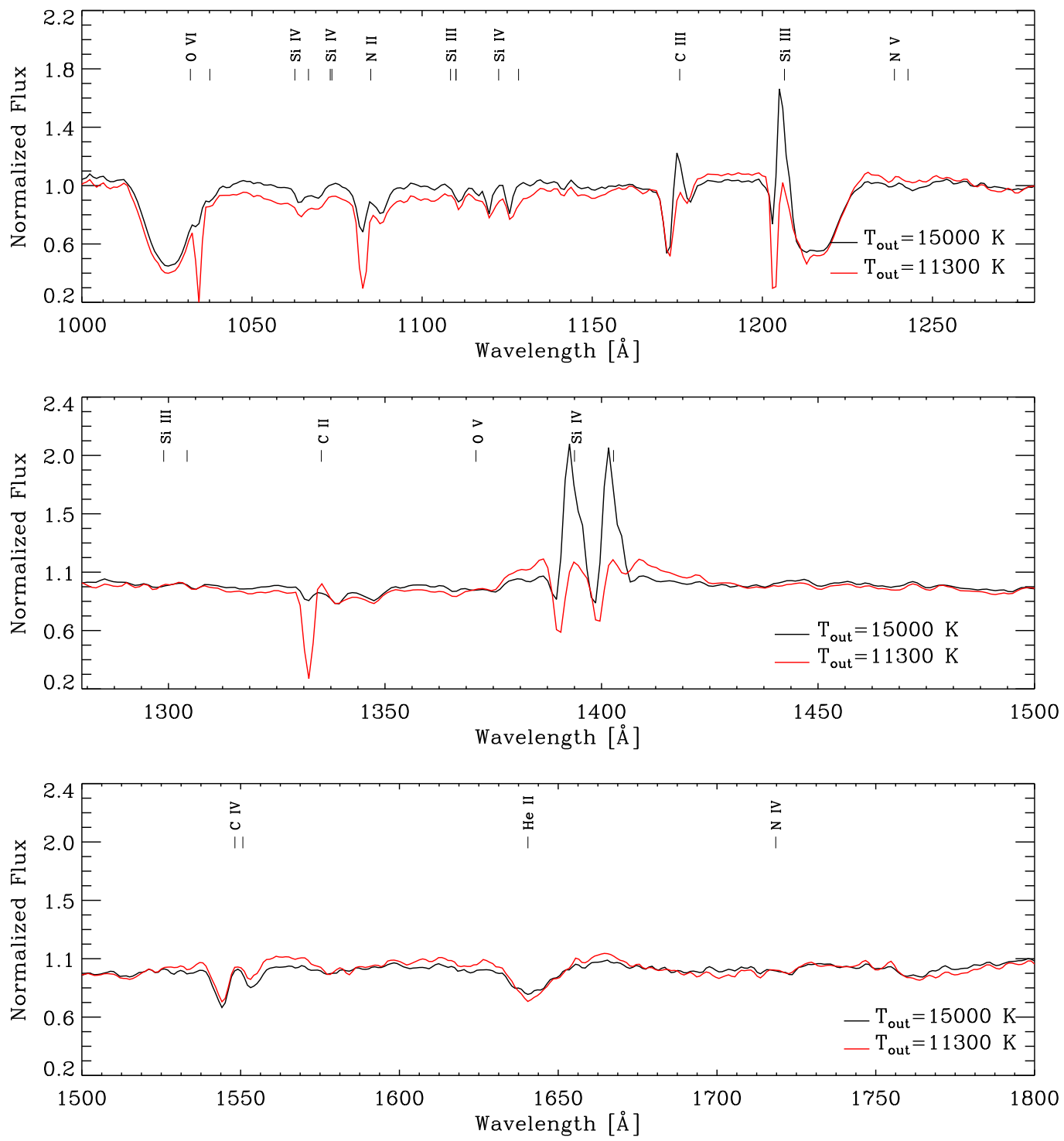

Figura 4.23: Efeito de colocar uma atmosfera fria com vento na região externa do modelo original $c$. A linha preta é o espectro sintético onde a atmosfera mais externa tem uma temperatura de $\sim 15000 \mathrm{~K}$. A linha vermelha representa o espectro sintético onde a atmosfera mais externa tem uma temperatura de $\sim 11300 \mathrm{~K}$. 

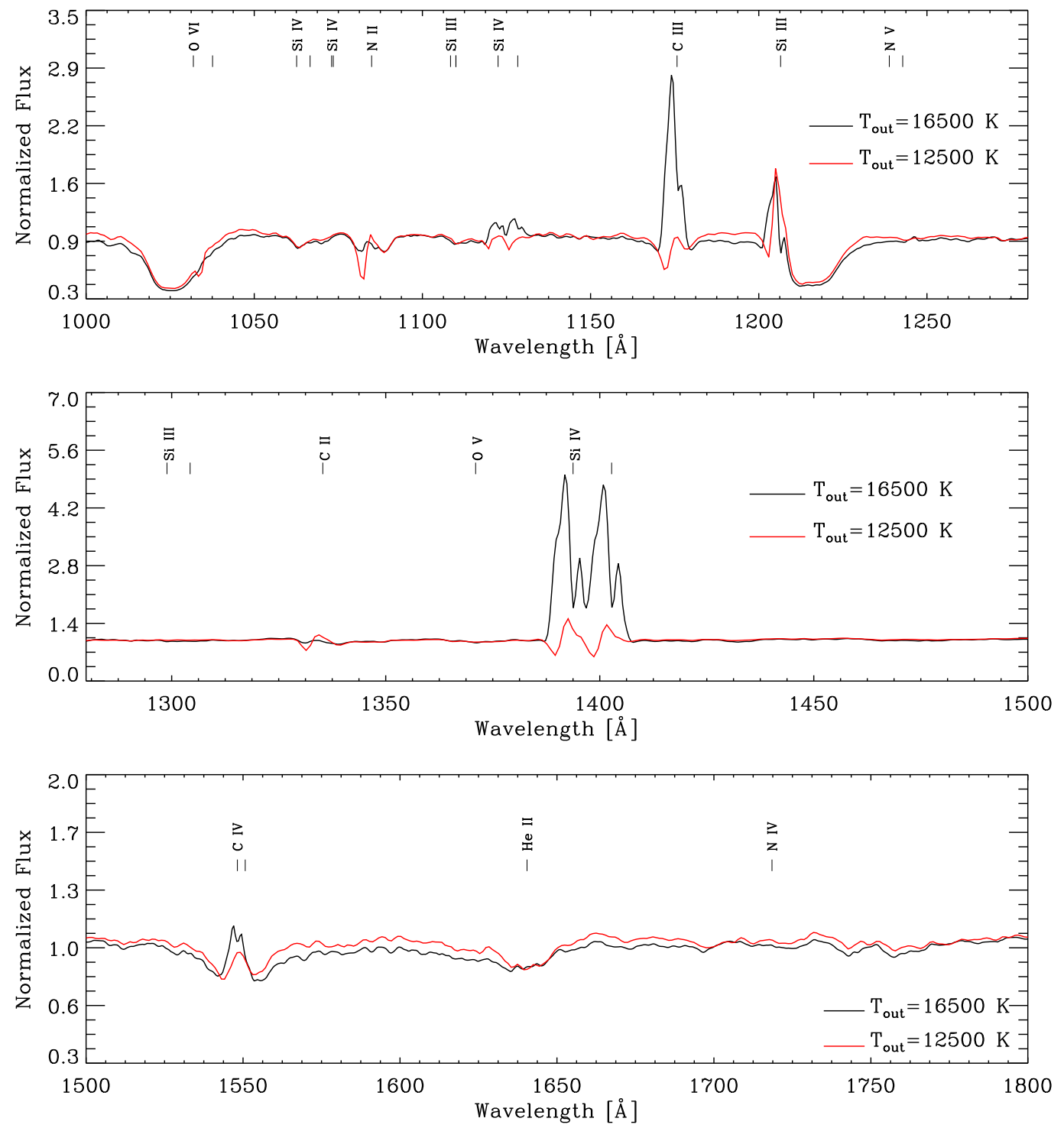

Figura 4.24: Efeito de colocar uma atmosfera fria com vento na região externa do modelo original $d$. A linha preta é o espectro sintético onde a atmosfera mais externa tem uma temperatura de $16500 \mathrm{~K}$. A linha vermelha representa o espectro sintético onde a atmosfera mais externa tem uma temperatura de $\sim 12500 \mathrm{~K}$. 


\subsection{Espectros de ventos heterogêneos}

Visando explorar opções de modelos com estruturas mais complexas, foi adicionado um tratamento aproximado para a presença de regiões mais densas no vento. Modelos de atmosferas com uma maior perda de massa local foram utilizados na simulação de regiões densas. Estes modelos também foram utilizados na seção 4.3 de uma maneira global. Agora serão escolhidos certos anéis, os quais terão a perda de massa aumentada, mantendo os outros anéis com a perda de massa original calculada mediante a equação de movimento. Analisaremos aqui o caso do modelo $e$ da tabela 3.1 com uma inclinação orbital $i=30^{\circ}$ e ângulos de abertura $\theta_{1}=5^{\circ}$ e $\theta_{2}=45^{\circ}$. Para esse modelo seis modelos extras foram calculados, cada um deles com uma região mais densa diferente, compreendida entre dois valores da distância ao centro do disco $R$. Neste caso cada região mais densa emite $500 \%$ mais massa do que no modelo original. Na figura 4.25 os espectros sintéticos destes seis modelos são mostrados junto com o espectro do modelo original (linha preta). A distribuição radial das regiões densas para cada modelo pode ser vista na tabela 4.2.

Nos espectros sintéticos normalizados pelo contínuo (figura 4.25) é possível notar como estas regiões densas afetam diferentes linhas dependendo de onde as mesmas são formadas. Em geral o principal efeito da inclusão destas regiões sobre as linhas é a de aumentar a profundidade das absorções e a intensidade das emissões. Qualitativamente, a principal linha afetada pela inclusão destas estruturas é a do C IV $\lambda \lambda 1548,1551$. Quando uma região densa passa para raios mais externos $\left(\mathrm{R}>5 \mathrm{R}_{W D}\right)$ são alteradas as linhas de espécies como o C III, Si IV e Si III. É importante notar que quanto mais externa é a região de alta densidade, maior é a profundidade das absorções e a intensidade das emissões. Quanto mais externa a condensação, maior é a quantidade de gás frio na frente das fontes mais quentes e internas do disco devido a que a área que expele este vento mais denso é maior (tabela 4.2). As intensidades aumentam devido ao incremento de emissores e ao tamanho da região emissora, especialmente no caso em que a região densa inclui a atmosfera mais fria que é estendida até $\mathrm{R}_{\text {disk }}$.

Na figura 4.26 as regiões de absorção para a linha C IV $\lambda 1550$ são mostradas. Esta figura mostra a razão entre a intensidade específica média na região azul da linha e a intensidade específica média no contínuo próximo da linha. Especificamente estas regiões espectrais estão entre $1530 \AA$ e $1550 \AA$ para a linha e $1560 \AA$ e $1570 \AA$ para o contínuo. A grandeza 
Tabela 4.2 - Modelos com regiões densas

\begin{tabular}{lcc}
\hline \hline Modelo $^{\mathrm{a}}$ & limites da região densa & Área \\
& $\mathrm{R}_{1}-\mathrm{R}_{2}$ & $\frac{\left(R_{2}^{2}-R_{1}^{2}\right)}{2}$ \\
& {$\left[\mathrm{R}_{W D}\right]$} & {$\left[2 \pi \mathrm{R}_{W D}^{2}\right]$} \\
\hline & & \\
vermelho & $1.05-2.2$ & 1.9 \\
laranja & $1.52-3.2$ & 3.4 \\
azul & $2.2-4.6$ & 8.2 \\
verde & $3.1-6.7$ & 13.0 \\
ciano & $4.6-9.7$ & 36.5 \\
amarelo & $6.7-14.0$ & 75.5 \\
magenta & $9.7-20.4$ & 152.9 \\
\hline
\end{tabular}

${ }^{a}$ Cores correspondem aos espectros sintéticos da figura 4.25 .

mostrada na figura é razão entre as intensidades nestas regiões calculadas de acordo com a equação:

$$
\frac{I_{l}}{I_{c}}=\frac{\left[\frac{1}{\left(\nu_{f_{l}}-\nu_{o_{l}}\right)} \int_{\nu_{o_{l}}}^{\nu_{f_{l}}} I_{\nu} d \nu\right]}{\left[\frac{1}{\left(\nu_{f_{c}}-\nu_{o_{c}}\right)} \int_{\nu_{o_{c}}}^{\nu_{f_{c}}} I_{\nu} d \nu\right]} .
$$

Esta razão é mostrada no espaço dos parâmetros de impacto correspondentes à região do disco que expele vento entre $1.05 \mathrm{R}_{W D}$ e $20.4 \mathrm{R}_{W D}\left(1 \times 10^{-2}-1.43 \mathrm{R}_{\odot}\right)$, para cada um dos modelos da tabela 4.2. A região de absorção na linha mostra-se mais extensa e mais profunda conforme a parte densa do vento ocupa regiões mais externas do disco. Esta absorção ocorre principalmente até o anel 7 e ao longo dos raios provenientes de regiões opostas a do observador, que atravessam uma quantidade maior de gás. Isto explica o comportamento da linha C IV $\lambda \lambda 1548,1551$ mostrado na figura 4.25.

As regiões totalmente brancas correspondem àquelas nas quais a emissão da linha é maior do que a do contínuo $\left(I_{l} / I_{c}>1\right)$ nas regiões espectrais indicadas. A intensa emissão 
na linha que aparece na região oposta ao observador corresponde ao "feixe" de vento que sai das regiões mais internas de alta temperatura.

A componente em emissão provém principalmente dos parâmetros de impacto correspondentes a regiões do disco que praticamente não emitem vento e também daquelas com parâmetros de impacto $\mathrm{P}>\mathrm{R}_{\text {disk }}$. Esta componente aumenta por causa do incremento de material com $S_{\nu}>J_{\nu}$ na linha que está na frente daquelas regiões. No espectro sintético total as duas componentes (absorção e emissão) superpõem-se fazendo que o mínimo da absorção sofra um deslocamento gradual para o centro da linha ao mesmo tempo que aumenta a sua profundidade. Mesmo que a componente em emissão seja cada vez mais forte, esta praticamente não é observada devido à profundidade cada vez maior da componente em absorção.

Em conclusão, a inclusão de regiões de densidade maior no vento provoca uma forte influência sobre os perfis de linha principalmente nas linhas do Civ, CIII, C II, Si III e Si IV. Esta influência é dependente do tamanho da região de densidade maior e da sua temperatura. O principal problema encontrado com os modelos desenvolvidos nesta simulação é que a geometria destas regiões, principalmente as interiores, ainda mantêm-se praticamente cilíndricas, razão pela qual a maior parte da emissão concentra-se nas regiões internas com altas velocidades verticais e rotacionais. Quando coloca-se uma maior quantidade de material da região estendida além da última atmosfera com vento, produzimos o aparecimento de estruturas de linha com velocidades mais dispersas, por exemplo os perfis de Civ $\lambda 1550$ ou CiII $\lambda 1175$. 

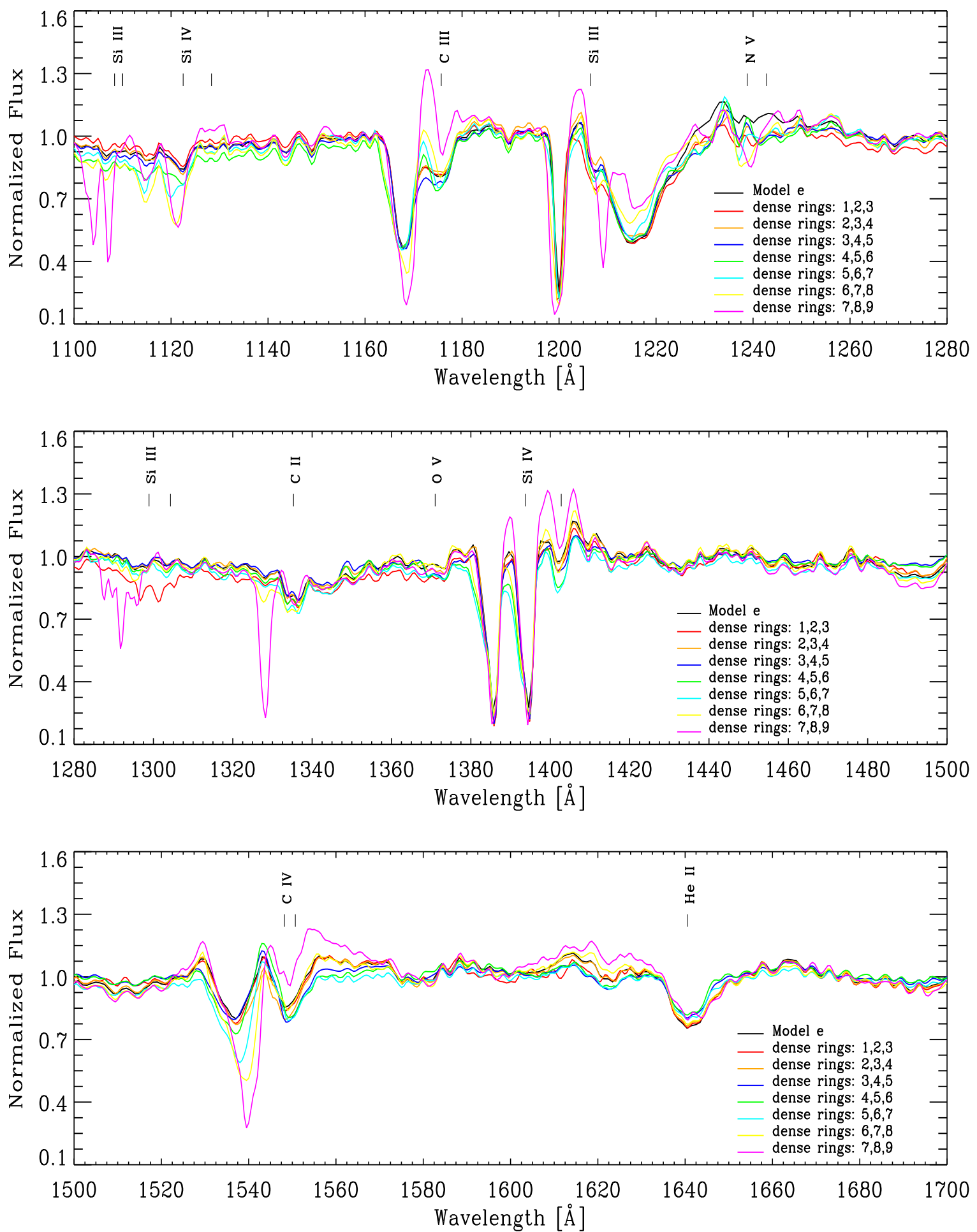

Figura 4.25: Efeito de uma região de alta densidade através do disco sobre os perfis de linha é mostrado para o modelo $e$. Cada cor corresponde a cada modelo onde um conjunto de atmosferas com vento de alto fluxo de perda de massa foi calculado em diferentes regiões do vento de acordo com o descrito na tabela 4.2. Para comparação também é plotado o modelo $e$ (linha preta). 


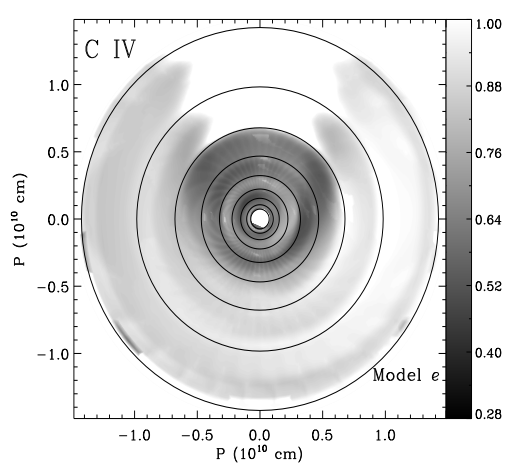

(a) Vermelho

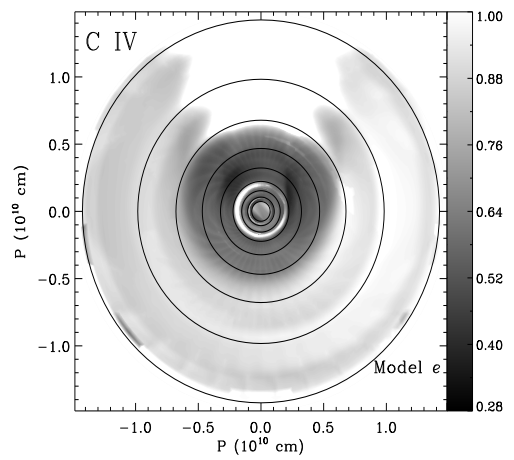

(d) Verde

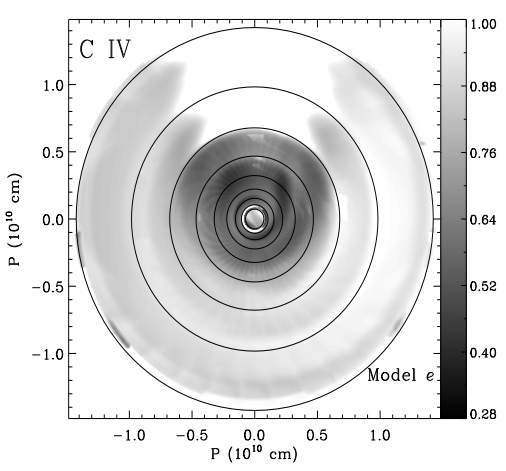

(b) Laranja

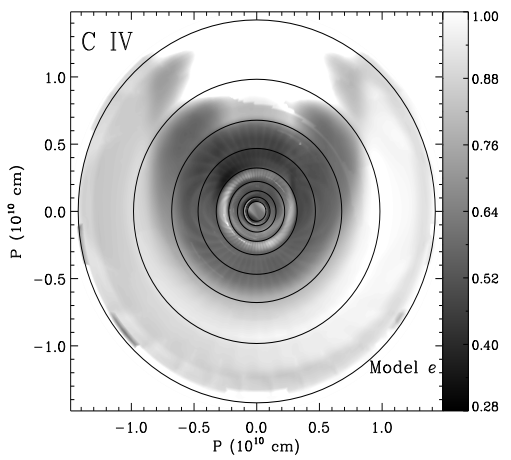

(e) Ciano

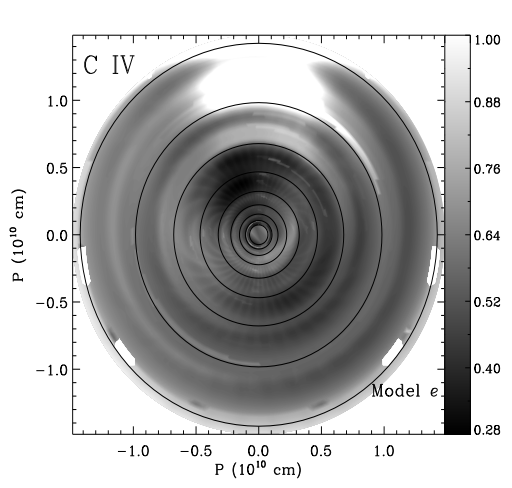

(g) Magenta

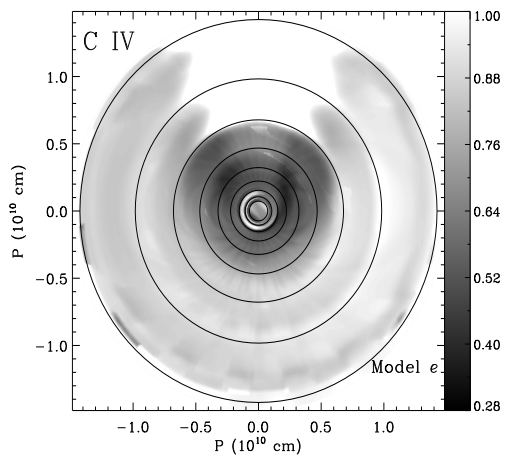

(c) Azul

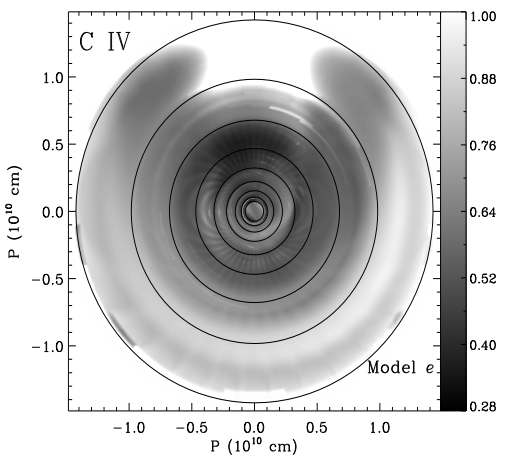

(f) Amarelo 


\subsection{Efeito da diluição na radiação na estrutura do vento}

Como foi mostrado nas seções anteriores é necessário que o vento do disco tenha uma estrutura mais complexa que a cilíndrica tanto em temperatura como em estado de ionização. Esta estrutura na realidade deveria provir de um cálculo hidrodinâmico auto-consistente seguido da solução das equações de equilíbrio e de trasporte radiativo num sistema tridimensional. Uma das limitações deste trabalho, que também já foi apontada, é que nosso modelo de estrutura não contempla a variação do campo de radiação no espaço devido à diluição geométrica ou transferência radial. Outra componente da radiação que deveria ser levada em conta é da emissão da anã branca e da boundary layer. Nessa direção, é analisado o efeito de introduzir uma diluição geométrica do tipo estelar sobre a radiação que provém do anel correspondente a cada modelo de atmosfera. Nestes testes a radiação para cada modelo varia de acordo com a seguinte equação:

$$
F(z)=\sigma T_{e f f}^{4}(R)\left[\frac{R_{\text {disk }}^{2}}{\left(R_{\text {disk }}+z\right)^{2}}\right]
$$

Por esta equação a radiação cai de um fator de $\frac{1}{4}$ no limite superior do vento. Os parâmetros do modelo e da tabela 3.1 foram utilizados e novos modelos de atmosferas com vento foram calculados. Porém uma geometria esférica foi utilizada na resolução das equações de equilíbrio e transferência radiativa. Os parâmetros estelares análogos destes novos modelos são: $\mathrm{R}_{*}=\mathrm{R}_{\text {disk }}$ e $\mathrm{R}_{P}=2 \mathrm{R}_{\text {disk }}$.

A diluição da radiação tem um efeito significativo sobre a estrutura vertical das atmosferas com vento calculadas, especialmente sobre as estruturas mais internas do disco. $\mathrm{Na}$ figura 4.27 é mostrada a comparação entre as estruturas de temperatura calculadas com a geometria plano paralela e com uma diluição esférica da radiação. O modelo corresponde ao anel 6 do modelo $e$, com temperatura efetiva de $30000 \mathrm{~K}$. A temperatura eletrônica no caso diluído $\left(\mathrm{T}_{\circ_{d}}\right)$ sofre uma queda que pode chegar a $\approx 0.56 \mathrm{~T}_{\circ}$, onde $\mathrm{T}_{\circ}$ é a temperatura eletrônica mais externa dos modelos plano paralelos de atmosfera. No caso particular do modelo da figura, temos $\mathrm{T}_{\circ_{d}}=0.67 \mathrm{~T}_{\circ}$. Estas variações na temperatura afetam a estrutura de ionização, principalmente nas regiões extensas do vento como é mostrado na figura 4.28 para o carbono. No modelo $e$ original, a estrutura de ionização do gás mantém as razões iônicas constantes através de quase toda a região extensa do vento. Quando a diluição da 

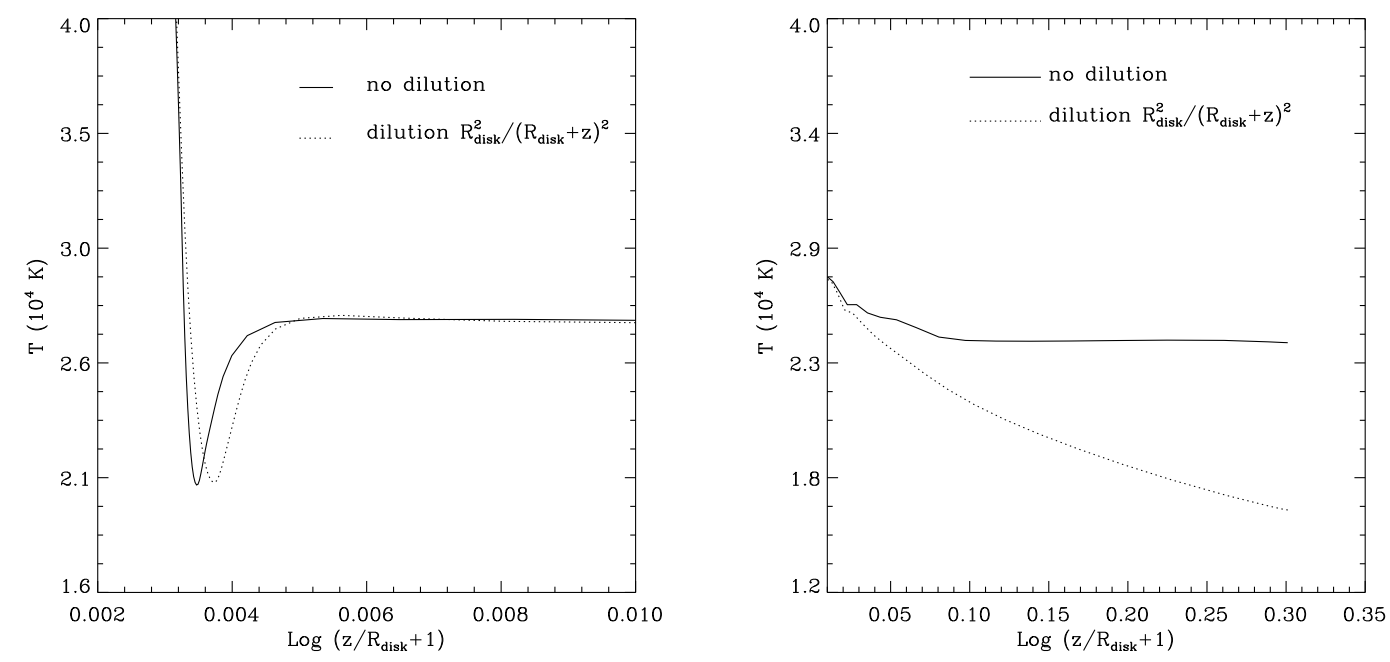

Figura 4.27: Estrutura vertical da temperatura para o anel 6 do modelo $e$. No painel esquerdo a região de transição fotosfera vendo é mostrada. Nos painel da direita a região extensa do vento é mostrada. Aqui são comparadas as temperaturas eletrônicas para o modelo calculado usando a geometria plano paralela (linha preta) e a estrutura considerando uma diluição esférica da radiação que provém do anel correspondente (linha pontilhada).

radiação é aplicada a concentração de íons de baixa ionização aumenta consideravelmente. Isto leva a que o íon dominante nessa região do vento seja o C III e não o C IV.

A figura 4.29 mostra o efeito da diluição da radiação sobre a função fonte da componente vermelha do dupleto C III $\lambda 1551$ no sistema co-móvel. É claro o efeito que esta diluição provoca na estrutura do vento, e vemos que agora essa estrutura não é mais aquela praticamente uniforme (no sentido vertical) para cada atmosfera como no caso plano paralelo.

$\mathrm{Na}$ figura 4.30 são mostrados os espectros sintéticos para o modelo $e$ original junto com o modelo calculado usando atmosferas estelares com diluição radiativa esférica. O principal efeito da inclusão da diluição radiativa sobre as estruturas dos perfis de linha é uma forte redução da intensidade das componentes em emissão, praticamente em todas as linhas do espectro. As linhas mais sensíveis neste sentido são C IV $\lambda \lambda 1548,1551$, C III $\lambda 1175$ e Si IV $\lambda \lambda 1393,1402$. Outro efeito importante é a diminuição na profundidade da absorção nas linhas do C III $\lambda 1175$ e Si IV $\lambda \lambda 1393,1402$. Ao contrário, nas linhas do Si III $\lambda 1206$ e C II $\lambda 1335$ a absorção aparece mais profunda no modelo modificado.

Na figura 4.31 são comparados modelos com uma inclinação orbital $i=70^{\circ}$. Pode-se ver 

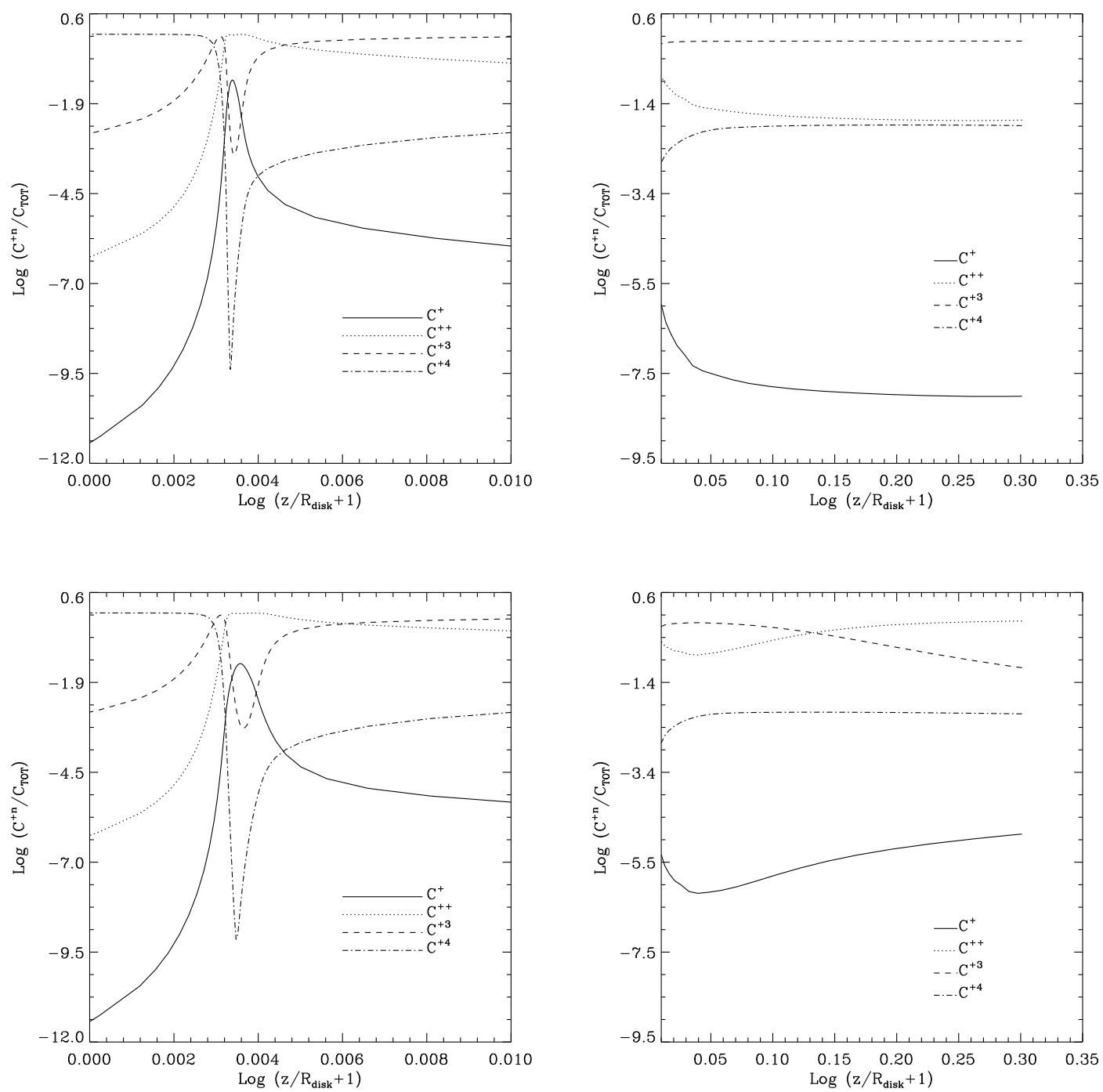

Figura 4.28: Estrutura de ionização do carbono para o anel 6 do modelo $e$. No painel esquerdo a região de transição fotosfera vendo é mostrada. Nos painel da direita a região extensa do vento é mostrada. Nos painéis superiores a estrutura calculada usando a geometria plano paralela é mostrada, e nos painéis inferiores a estrutura usando uma diluição esférica da radiação que provém do anel correspondente.

que a intensidade das emissões são significativamente enfraquecidas por causa da diluição radiativa. Algumas linhas trocam o tipo de perfil de emissão por outro em absorção, por exemplo o C III $\lambda 1175$ e Si III $\lambda 1206$.

Vemos que aplicar uma diluição radiativa nos modelos tem um efeito significativo sobre as características dos perfis de linha. Para sistemas com baixa inclinação orbital este efeito em algumas linhas vai no sentido correto ao eliminar estruturas em emissão que não são encontradas nas observações (p.e. no C III $\lambda 1175$ ), mas também prejudica a estrutura 

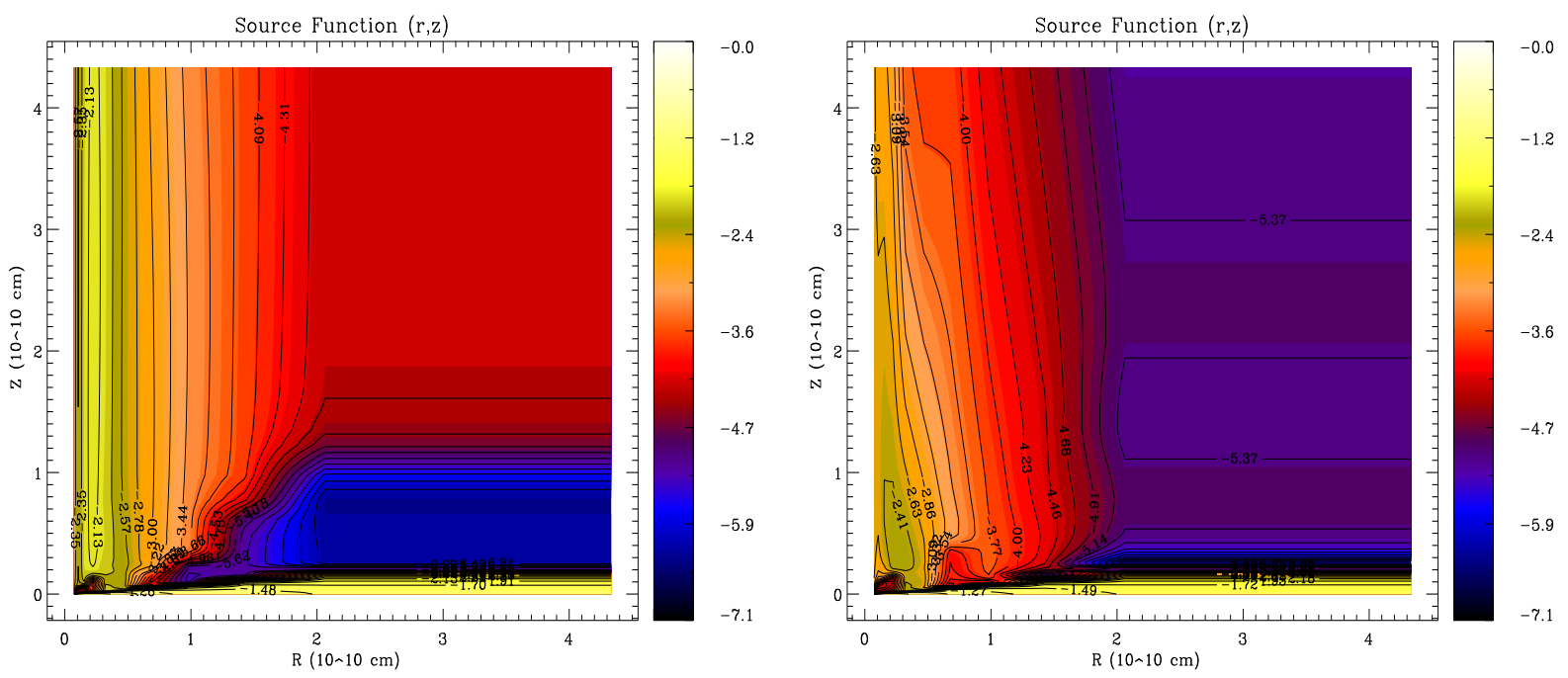

Figura 4.29: Distribuição espacial da função fonte para a linha C IV $\lambda 1551$ de dos modelos calculados usando os parâmetros físicos do modelo $e$. O painel esquerdo mostra a função fonte quando modelos plano paralelos são usados e no painel direito é mostrada quando é usada uma geometria esférica para a diluição da radiação de acordo com a equação (4.2).

de outras que apresentam componentes em emissão (pe. C IV $\lambda \lambda 1548,1551$ ). Ao calcular discos com alta inclinação este efeito é mais evidente, provocando uma queda considerável na intensidade das linhas o que vai no sentido contrário das observações. Estes resultados sugerem que tanto uma distribuição da radiação como uma consequente estrutura de ionização mais sofisticada deve ser incorporada ao modelo. 

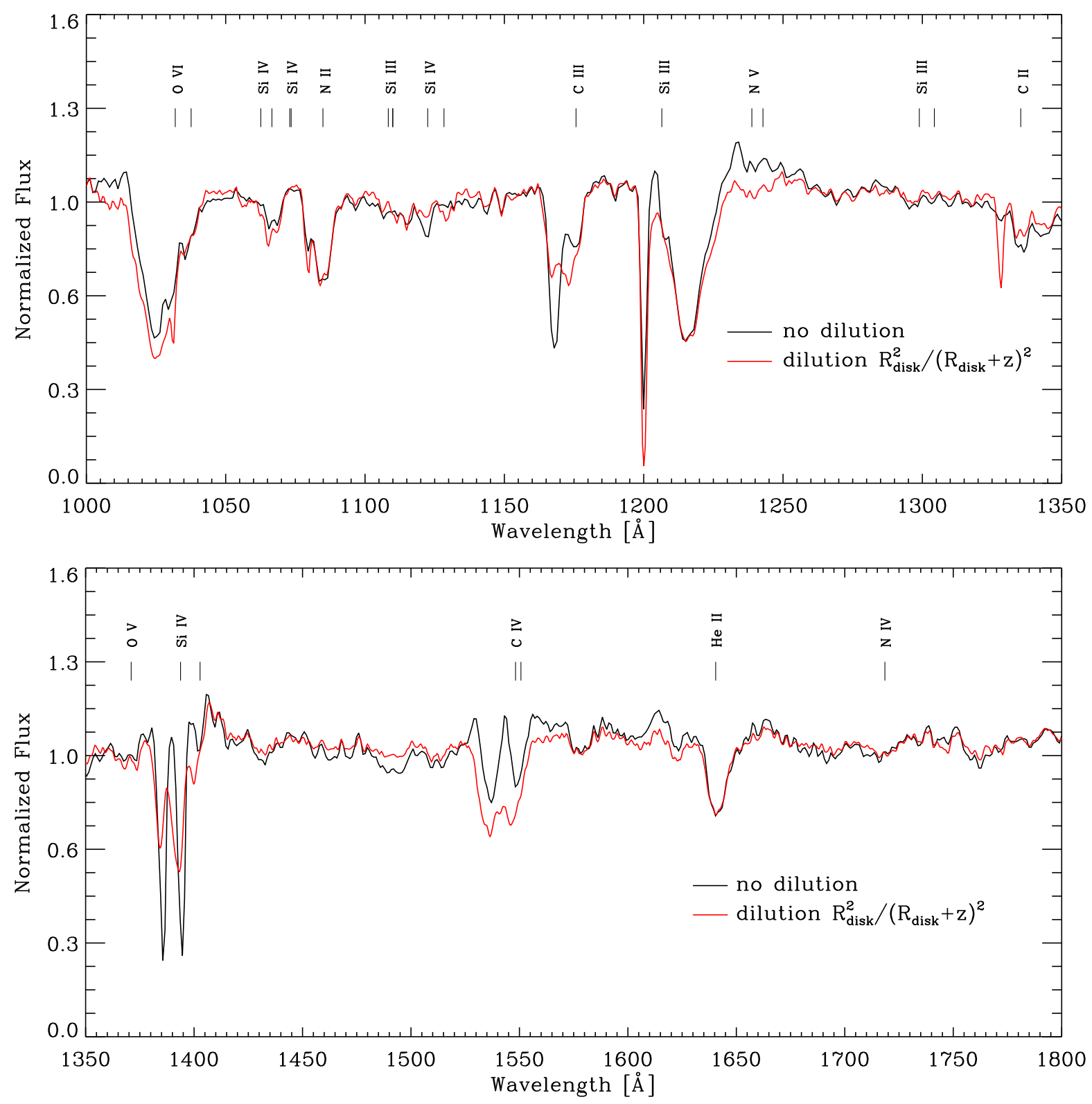

Figura 4.30: Efeito da diluição geométrica da radiação de acordo com a equação (4.2) sobre o modelo $e$. A linha preta corresponde ao modelo original sem diluição da radiação. A linha vermelha corresponde ao modelos onde cada modelo de atmosfera é calculado com uma diluição geométrica de tipo estelar. 

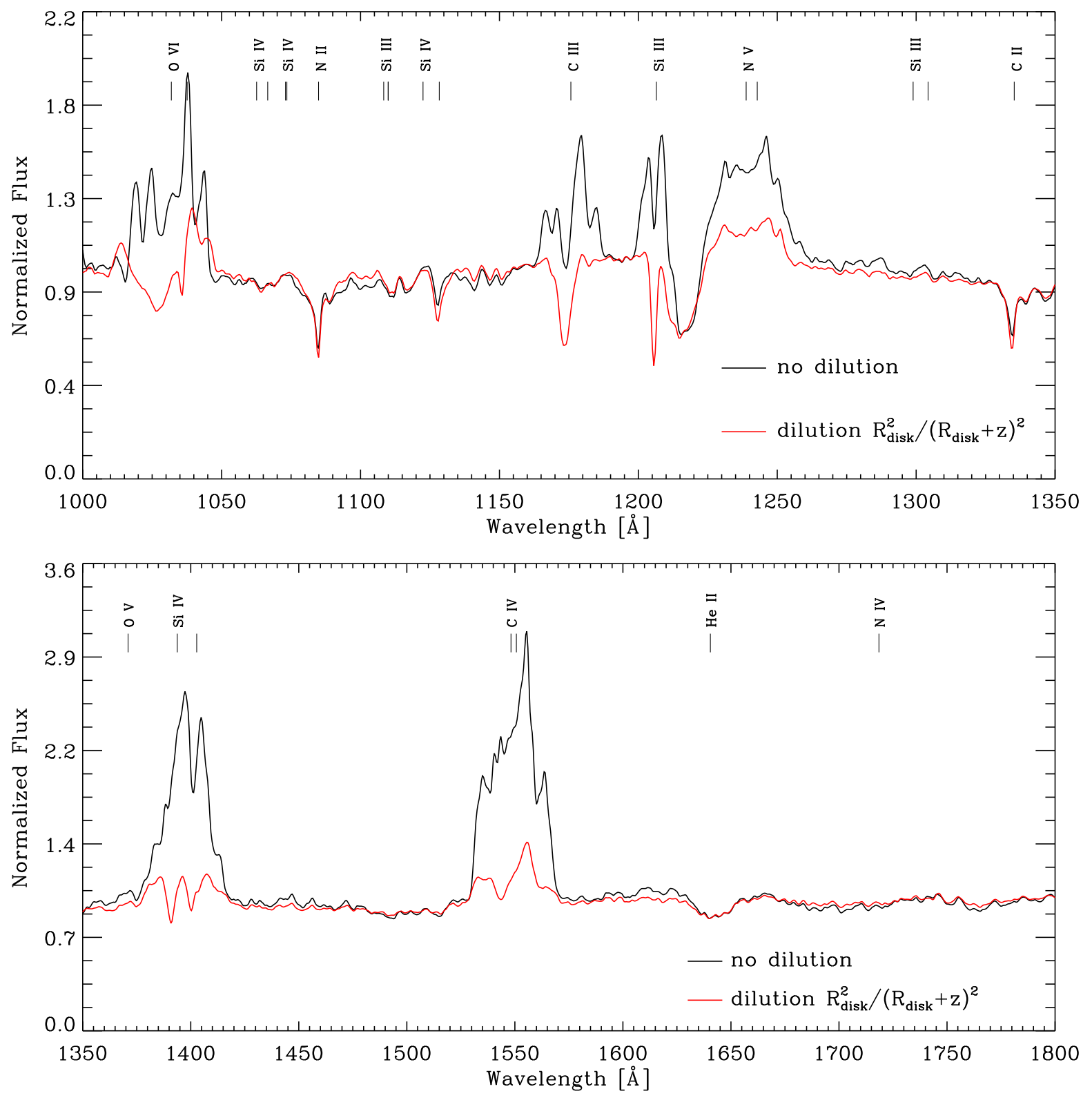

Figura 4.31: Efeito da diluição geométrica da radiação de acordo com a equação (4.2) sobre o modelo e. A linha preta corresponde ao modelo original sem diluição da radiação. A linha vermelha corresponde ao modelos onde cada modelo de atmosfera é calculado com uma diluição geométrica de tipo estelar. Os modelos foram calculados usando uma inclinhação orbital $i=70^{\circ}$. 
Capítulo 5

\section{Comparação com as Observações}

Neste capítulo nós propomos a comparação dos modelos resultantes do método desenvolvido neste trabalho com os dados espectrais no UV de algumas VC's do tipo Nova-Like. Estes modelos estão em rápida evolução em função destas comparações. Para isso, foram escolhidos quatro sistemas, dois com alta inclinação orbital, de acordo com os dados encontrados na literatura, e dois de inclinação baixa ou intermediária. As capacidades e limitações do método são colocadas em evidência ao longo deste capítulo. A importância de certos parâmetros físicos sobre os espectros resultantes é apontada quando comparados com as observações. Por exemplo, a real influência da geometria ou do campo vertical de velocidades quando o sistema é visto com alta ou baixa inclinação. As modificações adicionais necessárias para um melhor ajuste das observações são sugeridas, quando possível. Os dois sistemas com alta inclinação escolhidos são RW Tri e V347 Pup. Estes sistemas apresentam parâmetros físicos similares o que facilitou o uso dos mesmos modelos estruturais para a comparação. Depois serão apresentados os casos de RW Sex e de V3885 Sgr, dois sistemas de baixa inclinação também com características físicas e espectrais próximas.

\subsection{Sistemas de baixa inclinação}

\subsubsection{RW Sex}

A variável cataclísmica RW Sex é um sistema do tipo Nova-Like de baixa inclinação. O seu período orbital é de 0.25 dias (6.0 horas). Com uma massa da primária $\mathrm{M}_{1}=0.8 \mathrm{M}_{\odot}$, uma inclinação orbital $i \sim 34^{\circ}$ e a uma distância de 150 pc (Ritter e Kolb, 2003; Beuermann et al., 1992). Temos uma possível extinção interestelar $E(B-V) \sim 0.02$ (Bruch e Engel, 1994; Prinja et al., 2003). Na análise do contínuo UV através de modelos de atmosferas 
de disco, Puebla et al. (2007) encontraram que a taxa de acresção deste sistema seria da ordem de $\sim 1.0 \times 10^{-8} \mathrm{M}_{\odot}$ ano ${ }^{-1}$. Este valor foi calculado usando uma distância de 300 pc. Beuermann et al. (1992) usando a magnitude K da secundária calcularam uma distância de 150 pc, o que reduziria o valor da taxa de acresção para $\sim 3 \times 10^{-9} \mathrm{M}_{\odot}$ ano ${ }^{-1}$. Outro valor da distância calculado por Greenstein e Oke (1982) de 400 pc aumentaria a taxa de acresção a um valor mais próximo do calculado por Puebla et al. (2007).

No UV este sistema apresenta fortes absorções nas linhas de C III $\lambda 1175, \mathrm{~N}$ V $\lambda \lambda 1238,1242$, Si IV $\lambda \lambda 1393,1402$, além de um forte perfil P-Cyg na linha do C IV $\lambda \lambda 1548,1551$. A asa azul da componente em absorção desta linha aparece em $\sim-5000 \mathrm{~km} \mathrm{~s}^{-1}$, enquanto que e a asa vermelha da componente em emissão está em $\sim 1900 \mathrm{~km} \mathrm{~s}^{-1}$. Os dados espectrais foram obtidos da câmera GHRS do HST, observados no modo RAPID em baixa resolução ( 1 $\AA$ ) com a grade G140L e com uma cobertura espectral de $1150 \AA$ a $1660 \AA$.

Inicialmente, modelos de atmosferas com vento foram calculados usando um perfil de velocidades tipo estelar para cada anel do disco diferente dos outros modelos neste trabalho (vide eq. 2.27). Os outros parâmetros físicos do disco utilizados neste modelo são similares ao modelo " $b$ " da tabela 3.1. Neste novo modelo, as velocidades terminais correspondentes ao primeiro e ao último anel são $6700 \mathrm{~km} \mathrm{~s}^{-1}$ e $1000 \mathrm{~km} \mathrm{~s}^{-1}$. A taxa de perda de massa no vento adotada é de $4.3 \times 10^{-11} \mathrm{M}_{\odot}$ ano ${ }^{-1}$. O vento pode ser emitido desde o raio $\mathrm{R}=8 \times 10^{-3}$ $\mathrm{R}_{\odot}$ até $\mathrm{R}=0.2 \mathrm{R}_{\odot}$.

Na figura 5.1 é mostrada a comparação das dados observacionais no UV com três modelos calculados. A linha cinza mostra um modelo calculado usando uma superposição de atmosferas de disco sem vento do tipo calculado por Wade e Hubeny (1998). A linha vermelha mostra um modelo de atmosferas com vento, calculado com $\mathrm{R}_{C}=2.7 \times 10^{-2} \mathrm{R}_{\odot} \mathrm{e}$ com o campo de velocidades vertical do tipo estelar dado pela equação 2.27. A linha azul mostra o mesmo modelo, mas com $\mathrm{R}_{C}=0.13 \mathrm{R}_{\odot}$. Os ângulos de abertura do vento para estes modelos são $\theta_{1}=\theta_{2}=10^{\circ}$.

Vemos que nestas primeiras aproximações usando com os novos modelos calculados com atmosferas com vento, são melhorados os perfis de absorção de espécies de baixa ionização (C III, C II e Si III) e o perfil da linha do Si IV $\lambda 1400$. Porém, as linhas de espécies de alta ionização ( C IV e Nv), não conseguem ser reproduzidas. Estes modelos indicam que os perfis de absorção do Si III $\lambda 1300$ e C II $\lambda 1335$ são fotosféricos. 

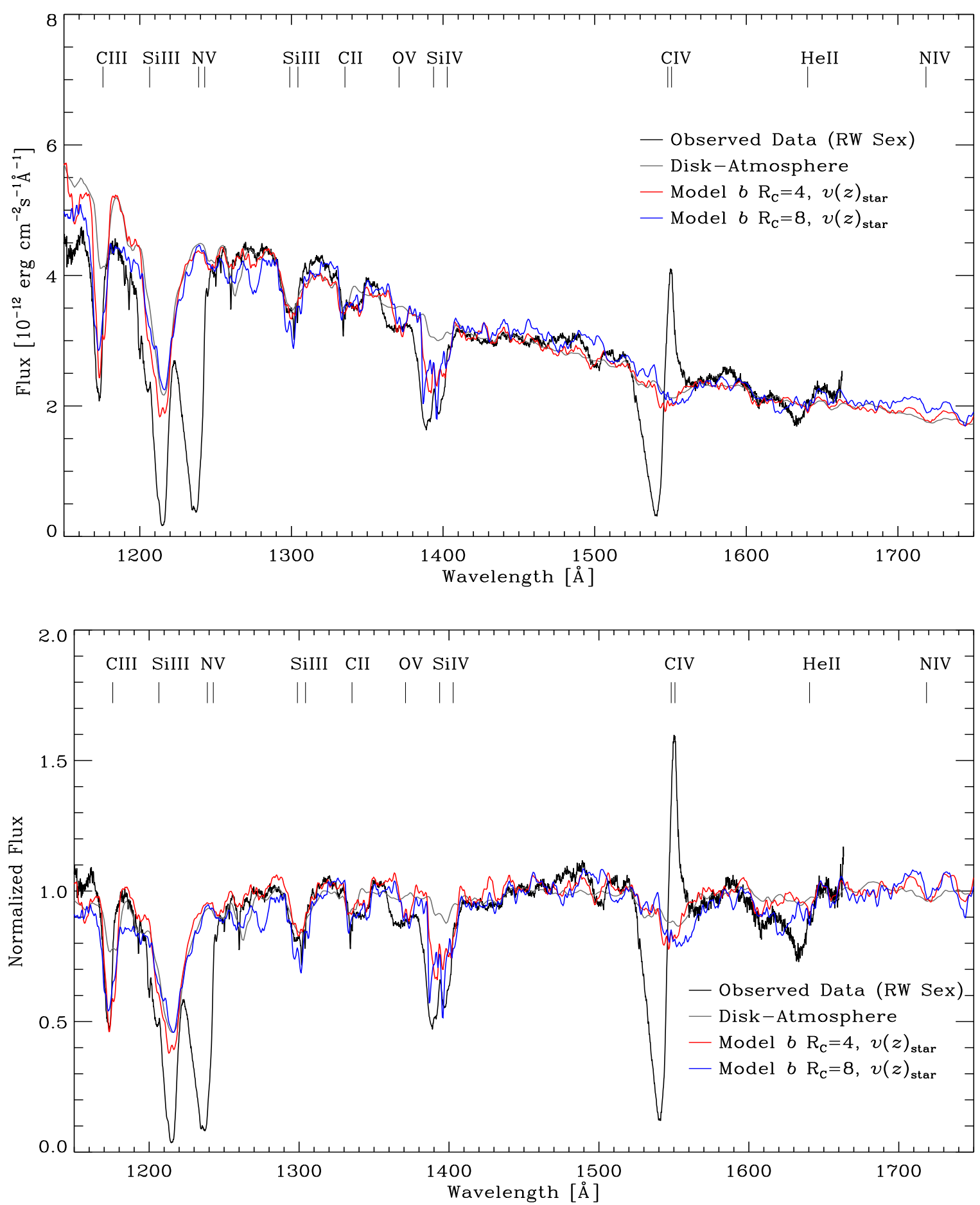

Figura 5.1: Comparação de diferentes espectros sintéticos com os dados observados pelo HST (linha preta) para RW Sex. A linha cinza representa um modelo de atmosfera de disco sem vento. As linhas vermelha e azul representam modelos de atmosfera de disco com vento usando um campo de velocidades tipo estelar no sentido vertical $v(z)$, a diferença entre eles é o parâmetro geométrico $\mathrm{R}_{C}$. No painel superior mostra-se os modelos em fluxo. No painel inferior mostra-se os modelos e os dados normalizados pelo contínuo. 
Visando reproduzir os perfis de linha das espécies de alta ionização, foram calculados modelos de atmosferas com vento usando o modelo de aceleração de vento discutido neste trabalho (seção 2.2). Na figura 5.2, junto como os dados espectrais (linha preta), mostramse dois modelos com os mesmos parâmetros do modelo "e" com uma inclinação orbital $i=30^{\circ}$. A diferença entre eles é o ângulo de abertura externo $\theta_{2}$, com um valor de $45^{\circ}$ (linha azul) e $10^{\circ}$ (linha vermelha). Neste caso, para o cálculo da transferência radiativa o campo de velocidades vertical $v_{z}$ foi ajustado de forma a melhorar a descrição das linhas. A componente em emissão do perfil da linha de C IV $\lambda \lambda 1548,1551$ inicialmente gerada por estes modelos estava principalmente no lado azul do valor de repouso, o que impedia a formação dos perfis P-Cyg. Ao multiplicar o perfil vertical de velocidade por $\sim 0.7$ a componente em emissão é deslocada para o vermelho, gerando assim um perfil P-Cyg, que pode ser comparado com os dados.

A figura mostra que os modelos produzem fortes perfis P-Cyg praticamente em todas as linhas observadas no UV. Isto não é o encontrado nos dados espectrais, nos quais praticamente só a linha do C IV $\lambda \lambda 1548,1551$ apresenta um forte perfil P-Cyg, enquanto que as outras linhas apresentam perfis preferentemente em absorção. Além disso, o modelo apresenta linhas mais estreitas do que aquelas observadas. Isto levaria a ideia de que as linhas observadas seriam geradas numa região com velocidades mais dispersas. Os mínimos das absorções dos modelos encontram-se a diferentes velocidades daqueles achados nos dados. A componente em emissão do C IV é fraca no modelo se comparada com os dados e também levemente azulada.

Todas estas discrepâncias evidenciam que as regiões de emissão de linha do sistema devem ser diferentes daquelas calculadas no modelo. O modelo plano paralelo gera uma estrutura de ionização e temperatura muito simplificada espacialmente. Isto leva à presença de estruturas que não são observadas nos dados. Concluímos que é necessária uma descrição mais sofisticada do vento, que leve em conta uma geometria mais realista e a correspondente diluição da radiação.

Na figura 5.3 são mostrados os perfis das linhas do C III, C IV, Si IV e N v no espaço de velocidades. Pode-se notar mais claramente as discrepâncias entre os modelos e os dados observados. Testes adicionais mostram que estas diferenças são devidas principalmente à geometria do modelo. A geometria utilizada neste trabalho utiliza um vento praticamente 

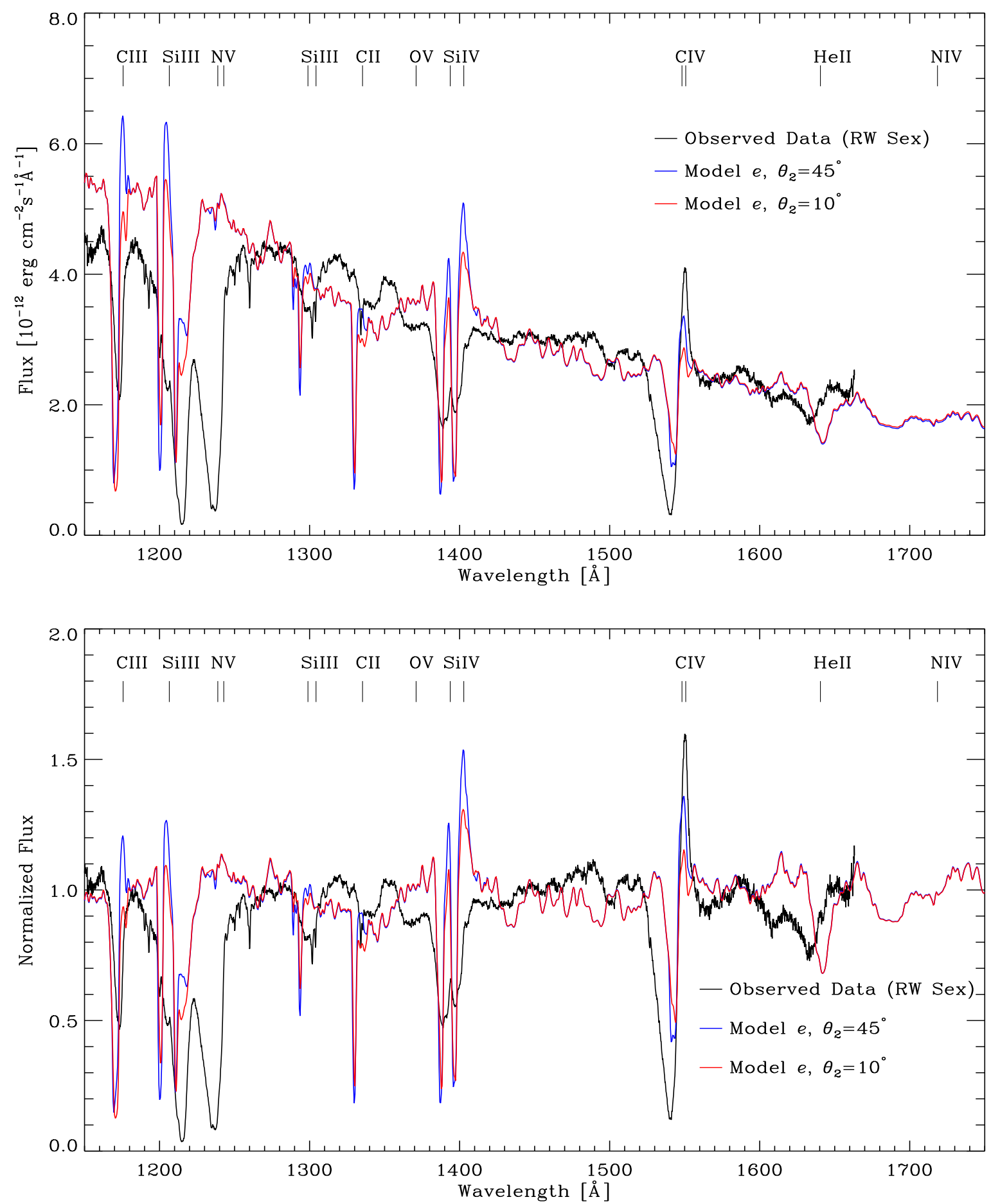

Figura 5.2: Comparação do modelo "e" (linha azul com $\theta_{2}=45^{\circ}$ e linha vermelha com $\theta_{2}=10^{\circ}$ ) com os dados observados pelo HST (linha preta) para RW Sex. No painel superior mostra-se os modelos em fluxo. No painel inferior mostra-se os modelo e os dados normalizados pelo contínuo.

cilíndrico. Esta geometria faz com que os perfis de linha mostrem-se mais estreitos, devido à concentração das regiões emissoras em regiões restritas a certos valores de velocidade. 

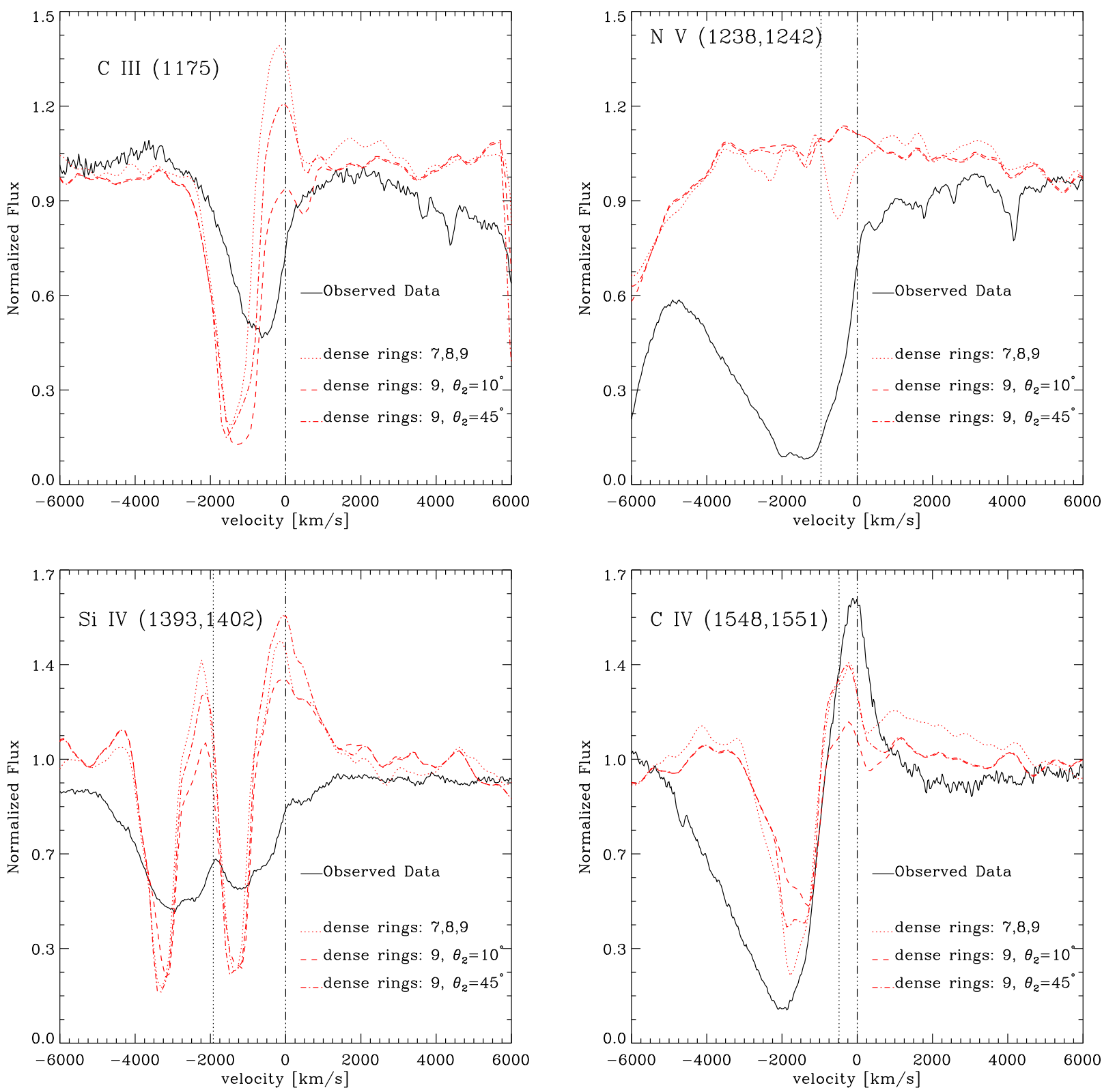

Figura 5.3: Perfis de linha normalizados pelo contínuo para as linhas do C III, Nv, Si IV e C IV para o modelo "e" com diferentes regiões de alta densidade e os dados observados (linha preta). Os modelos têm uma inclinação orbital $i=30^{\circ}$.

\subsubsection{V3885 Sgr}

A variável cataclísmica V3885 Sgr é outro sistema do tipo Nova-Like de baixa inclinação. No UV este objeto apresenta fortes linhas de absorção nas linhas de C III $\lambda 1175, \mathrm{NV}$ $\lambda \lambda 1238,1242$, e Si IV $\lambda \lambda 1393,1402$, além de um forte perfil P-Cyg na linha do CIV $\lambda \lambda$ 1548,1551. O período orbital deste sistema é de 0.207 dias ( 5.0 horas), a massa da 
primária é de $\mathrm{M}_{1} \sim 0.7 \mathrm{M}_{\odot}$, e a inclinação orbital de $i<50^{\circ}$ (Cowley et al., 1977; Ribeiro e Diaz, 2007; Linnell et al., 2009). A distância à este sistema é de 110 pc (Duerbeck, 1999), mas Meliani et al. (2000) sugere uma distância diferente, de 280 pc. A extinção interestelar reportada por Bruch e Engel (1994) é $E(B-V) \sim 0.02$. Em uma análise do contínuo usando atmosferas de disco Puebla et al. (2007) encontraram que a taxa de acresção deste sistema seria da ordem de $\sim 9 \times 10^{-9} \mathrm{M}_{\odot}$ ano ${ }^{-1}$ para uma distância de 200 pc. Os dados espectrofotométricos foram obtidos pelo espectrógrafo STIS do HST, no modo Echelle com a rede E140M e o detetor FUV-MAMA na faixa espectral de 1150-1730 $\AA$, os mesmos têm uma resolução espectral de $\sim 0.02 \AA$.

Na figura 5.4 mostra-se dois modelos com parâmetros físicos iguais aos do modelo "e" com uma inclinação orbital $i=30^{\circ}$. A diferença entre eles é o ângulo de abertura externo $\theta_{2}$, com um valor de $45^{\circ}$ (linha azul) e $10^{\circ}$ (linha vermelha). A figura mostra que perfis P-Cyg, principalmente na linha C IV $\lambda \lambda 1548,1551$ são formados, mas neste caso a componente em absorção do perfil tem o mínimo muito azulado quando comparado com o perfil observado. O mesmo ocorre com as principais linhas de absorção encontradas nos dados. Também neste caso, mesmo que em menor grau, as linhas em absorção do modelo apresentam-se mais estreitas do que as observadas. O modelo mostra uma forte emissão no vermelho do Si IV $\lambda \lambda 1393,1402$. Esta emissão provém da região mais externa do vento e é provocada pela alta temperatura mantida nessas regiões pelo modelo plano paralelo. Devido a que estas estruturas espectrais não são observadas em VC's que apresentam vento, isto nós leva à ideia de que os ventos expelidos por discos em VC's têm que ter uma estrutura de temperatura e de ionização mais pronunciada, sendo mais frios externamente. Esta estrutura mais complexa pode ser conseqüência de dois fenômenos não levados em conta neste trabalho, a diluição da radiação que deve acontecer na região dominada pelo vento e o efeito da radiação de outras regiões do disco sobre um determinado ponto principalmente na base do vento. Outro efeito também importante que deve ser levado em conta é a interação radial entre as diferentes regiões do vento no cálculo da estrutura e das populações dos níveis. Se o vento é opticamente fino nas principais linhas (ou seja nas regiões mais externas) esta influência seria mínima. Porem, na região de transição fotosfera-vento, esse efeito pode ser determinante na estrutura, nas populações dos níveis e emissividade local.

Foram primeiramente testados modelos com aceleração vertical do tipo estelar dada 

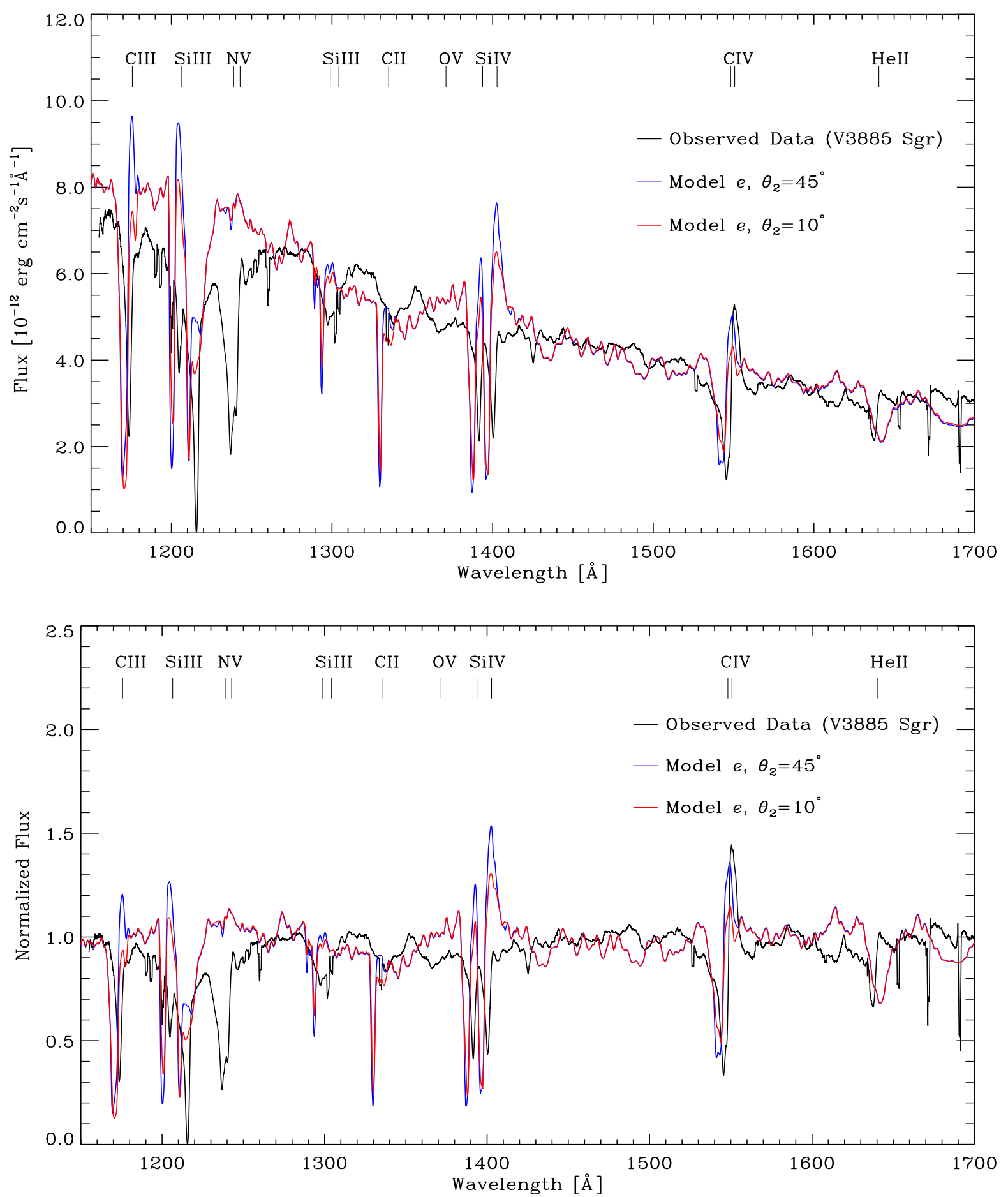

Figura 5.4: Comparação do modelo "e" (linha azul com $\theta_{2}=45^{\circ}$ e linha vermelha com $\theta_{2}=10^{\circ}$ ) com os dados observados pelo HST (linha preta) para V3885 Sgr. No painel superior mostram-se os modelos em fluxo. No painel inferior mostram-se os modelos e os dados normalizados pelo contínuo.

pela equação (2.27). Estes modelos não conseguiram reproduzir a estruturas dos perfis de linha encontradas nos dados. As linhas apresentam-se muito largas e também não se 
consegue reproduzir as estruturas das linhas do Nv e do C IV como no caso de RW Sex. Da mesma maneira, as linhas fotosféricas do Si III e C II são bem reproduzidas por este modelo. Quando uma diluição radiativa foi usada, os perfis em absorção apresentam-se muito azulados e largos quando comparados com os dados e como foi mostrado na seção 4.8 o modelo não consegue produzir emissões fortes como as observadas.

Um teste observacional do vento em VC's foi realizado recentemente por Hartley et al. (2002). Estes autores estudaram os dados espectrofotométricos das VC's IX Vel e V3885 Sgr e encontraram variabilidades tanto nos perfis das linhas como no contínuo. Estas variabilidades evidenciam um comportamento pouco compatível com os modelos de vento em discos elaborados até agora. Por exemplo, V3885 Sgr apresenta uma queda no nível de fluxo que não é acompanhada pelo esperado enfraquecimento das linhas de vento. Também no caso de IX Vel, estes autores encontram que existem épocas nas quais as características de vento no espectro desaparecem totalmente. Uma variabilidade nestas características é vista quando o vento é opticamente mais fino, como, segundo eles, é o caso do vento de V3885 Sgr. Isto mostra a complexidade do problema ao tentar reproduzir as linhas de vento observadas em discos de acresção. Complexidade que passa como foi explicado não somente pela geometria e a estrutura, mas também pela sua variabilidade. 


\subsection{Sistemas de alta inclinação}

\subsubsection{RW Tri}

A variável cataclísmica RW Tri é um sistema do tipo Nova-Like com alta inclinação orbital. Esta VC apresenta linhas de emissão particularmente intensas tanto no óptico como no UV. Observações feitas no UV mostram que, durante os eclipses, o contínuo é mais fortemente afetado do que as linhas (Cordova e Mason, 1985; Drew e Verbunt, 1985) o que leva a pensar que estas linhas são produzidas numa região extensa. O período orbital deste sistema é de 0.23 dias ( $\sim 5.5$ horas) com uma massa da primária $\mathrm{M}_{1} \sim 0.55$ $\mathrm{M}_{\odot}$ e uma inclinação orbital de $i \sim 70^{\circ}$ (Ritter e Kolb, 2003; Poole et al., 2003). Está a uma distância entre 310 e 380 pc (McArthur et al., 1999), com uma extinção interestelar $E(B-V) \sim 0.1$ (Bruch e Engel, 1994). Em uma analise do contínuo usando atmosferas de disco Puebla et al. (2007) encontraram que a taxa de acresção deste sistema seria da

ordem de $\sim 4.6 \times 10^{-9} \mathrm{M}_{\odot}$ ano ${ }^{-1}$, valor que é compatível com outros estudos (p.e. Groot et al. (2004) e Mizusawa et al. (2010)).

Os dados espectrográficos no UV foram obtidos do arquivo do espectrógrafo GHRS do HST, observados no modo RAPID em baixa resolução $(\sim 1 \AA)$ com a grade G140L e resultando em uma cobertura espectral entre $1150 \AA$ e $1660 \AA$.

Os modelos básicos utilizados para estudar o vento em RW Tri têm as estruturas dos modelos " $b "$ e " $h$ " da tabela 3.1. Estes modelos possuem parâmetros físicos parecidos àqueles encontrados para RW Tri na literatura. No caso deste sistema foi necessário variar amplamente alguns dos parâmetros para encontrar um espectro sintético que consiga descrever a intensidade e a forma das linhas observadas no UV.

Nas figuras 5.5, 5.6, 5.7 e 5.10 são mostrados os melhores modelos para o espectro UV de RW Tri. A figura 5.5 mostra o modelo $b$ escalonado a uma distância de 640 pc (linha vermelha) e o espectro observado pelo GHRS como descrito anteriormente. Esta distância pareceria muito alta se comparada com os valores da literatura, próximos de $\sim 350$ pc. Mas o modelo $b$ como mostra a tabela 3.1 , tem uma massa da primária $M_{1}=1 M_{\odot}$, que é consideravelmente maior que a massa estimada para RW Tri $\left(\sim 0.6 \mathrm{M}_{\odot}\right)$. Esta massa elevada produz um melhor ajuste implicando, entretanto, em um valor alto para a distância de escalonamento do modelo. Neste caso, para o cálculo da transferência radiativa foram 

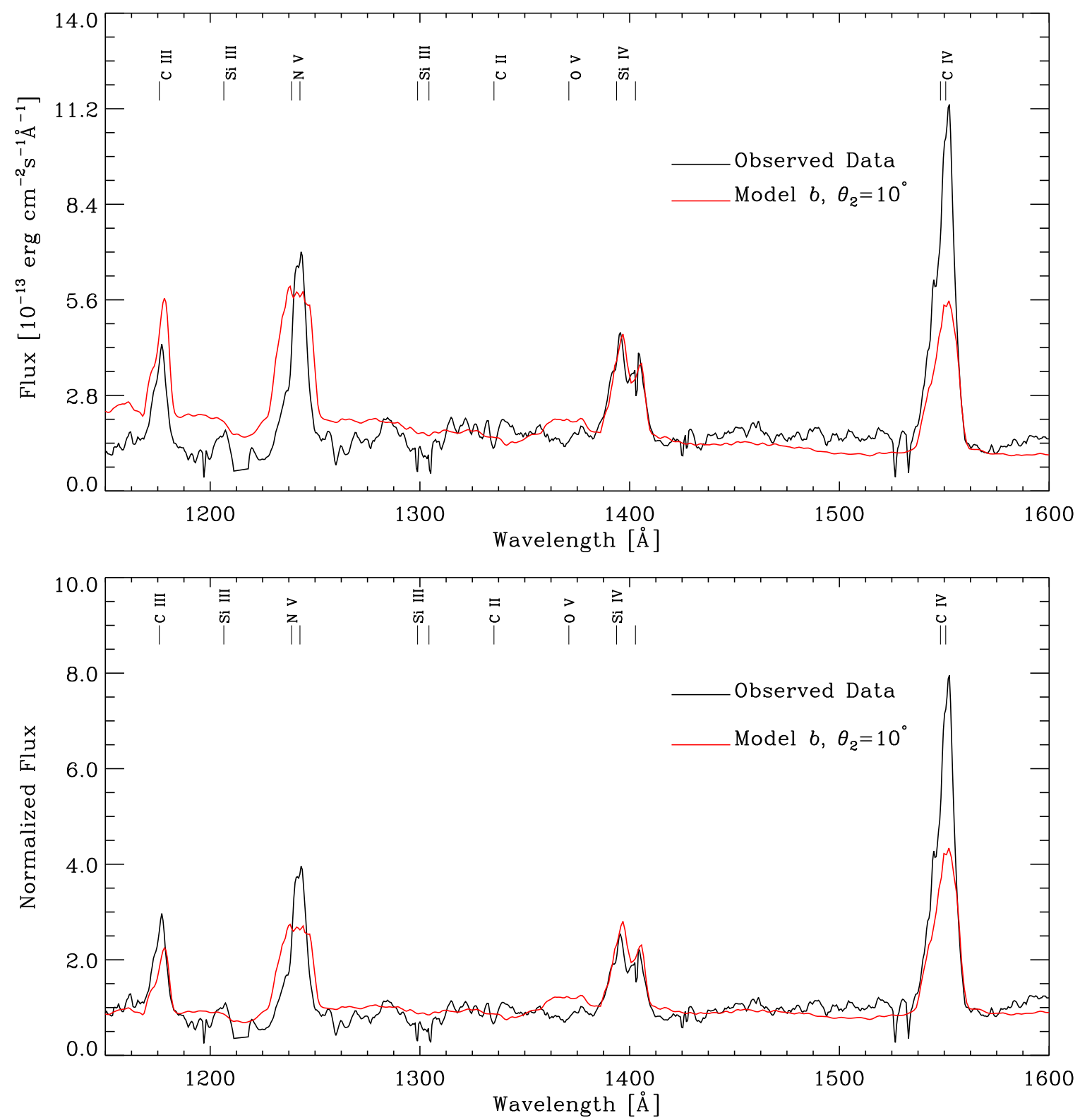

Figura 5.5: Comparação do modelo " $b$ " (linha vermelha) com os dados observados pelo HST (linha preta) para RW Tri. No painel superior mostra-se os modelos em fluxo, o modelo foi escalonado a uma distância de $640 \mathrm{pc}$ e foi calculado com uma inclinação orbital de $i=70^{\circ}$. No painel inferior mostra-se os modelo e os dados normalizados pelo contínuo.

usados os ângulos de abertura $\theta_{1}=5^{\circ}$ e $\theta_{2}=10^{\circ}, \mathrm{R}_{C}=\mathrm{R}_{f}=0.2 \mathrm{R}_{\odot}$ e a inclinação $i=70^{\circ}$. A linha do C IV é melhor ajustada em modelos com regiões do vento mais densas. Mesmo assim é difícil ajustar a intensidade dessa linha já que ao incrementar a densidade nas regiões mais externas do vento as outras linhas também vêm-se afetadas, afastando-se do que é observado. A linha N v $\lambda 1240$ aparece mais larga no modelo do que é observado, além 
disso o núcleo da linha no modelo é menos intenso. As larguras equivalentes dessa linha tando no modelo quanto nos dados é da mesma ordem $(\sim 28 \AA)$. Estes fatos levam a pensar que esta linha é produzida muito provavelmente numa região de menor velocidade e mais extensa do vento, talvez em regiões mais externas. No modelo $b$ esta linha é produzida em regiões internas do vento, muito próximas ao eixo de simetria do disco. Estas regiões possuem alta rotação o que alarga a linha de maneira considerável. Além disso, devido à falta de resfriamento nas regiões superiores do vento no modelo, esta linha também é intensa nessas regiões, correspondendo a atmosferas mais quentes.

Nas figuras 5.6 e 5.7, mais dois modelos são comparados com os dados. Nesses casos só foram modificados os parâmetros geométricos, no primeiro caso $\mathrm{R}_{C}=2.7 \times 10^{-2} \mathrm{R}_{\odot} \mathrm{e}$ $\theta_{2}=5^{\circ}$ no segundo caso. Quando $\mathrm{R}_{C}<\mathrm{R}_{f}$ (veja figura 3.1), uma região fotosférica capaz de produzir vento é excluída do cálculo do espectro sintético. Estas regiões produzem estruturas em absorção azuladas como já foi analisado e a região de transição fotosferavento influi levemente no nível do contínuo. Este efeito é o de abaixar levemente o seu nível e também deixá-lo mais azul, principalmente em $\lambda<1400 \AA$ As. Isto faz com que as linhas sejam mais intensas quando o espectro é normalizado. A interpretação física da emissão de uma distribuição geométrica deste tipo, seria que o vento é emitido pelo disco até um raio $\mathrm{R}_{C}$, com os respectivos ângulos de abertura $\theta_{1}$ e $\theta_{2}$; nas regiões do gás correspondentes às atmosferas mais externas com abertura $\theta_{2}$ a base do vento é truncada em $R_{C}$, sobrando apenas as partes mais altas e frias do próprio vento (fig. 3.1). Nestes modelos truncados a intensidade da linha C IV $\lambda 1549$ é aumentada o que leva a melhorar o ajuste, assim como também as outras linhas C III $\lambda 1175$ e Si IV $\lambda 1398$. A mudança do ângulo $\theta_{2}$ de $10^{\circ}$ para $5^{\circ}$ não produz nenhuma diferença relevante no espectro como é mostrado na figura 5.7.

Na figura 5.8 são mostrados dois espectros sintéticos calculados usando o modelo $h$, que tem uma massa da primária $\mathrm{M}_{1}=0.6 \mathrm{M}_{\odot}$, ou seja, próxima à media dos valores encontrados na literatura. A linha vermelha na figura representa o modelo com $\mathrm{R}_{f}=12 \mathrm{R}_{W D}\left(0.14 \mathrm{R}_{\odot}\right)$ onde o modelo de atmosfera com vento tem uma temperatura fotosférica de $15000 \mathrm{~K}$. A linha laranja representa o modelo com $\mathrm{R}_{f}=17 \mathrm{R}_{W D}\left(0.2 \mathrm{R}_{\odot}\right)$ cuja atmosfera mais externa tem uma temperatura de $11000 \mathrm{~K}$. Os parâmetros geométricos destes dois modelos são os mesmos: $\theta_{1}=2^{\circ}$ e $\theta_{2}=10^{\circ}$ e inclinação orbital $i=70^{\circ}$. Uma boa concordância é encontrada nestes casos para as linhas do Si IV e C III. A mesma carência de fluxo é verificada na 

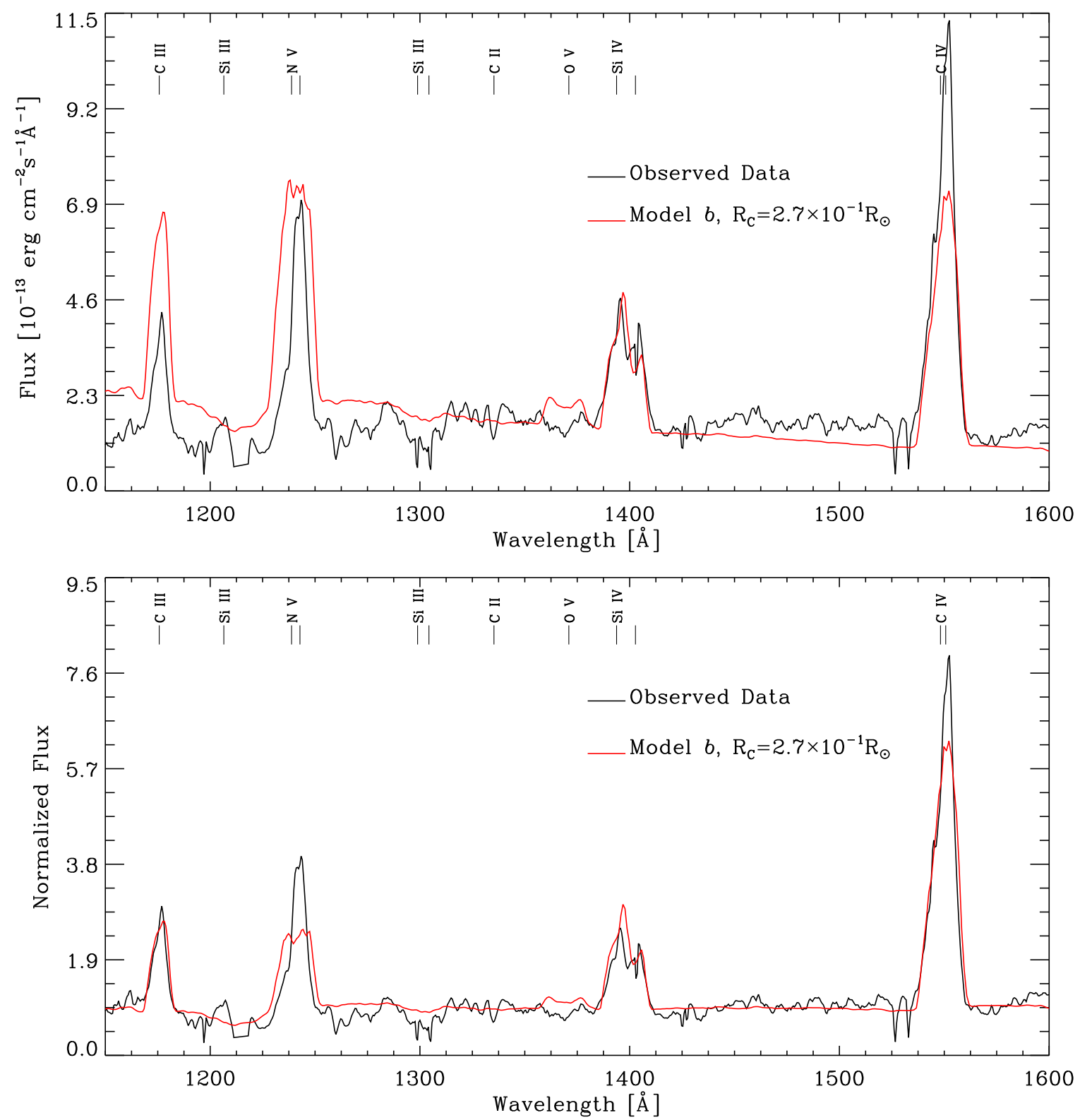

Figura 5.6: Comparação do modelo "b" (linha vermelha) com os dados observados pelo HST (linha preta) para RW Tri. No painel superior mostra-se os modelos em fluxo. Neste caso o raio $\mathrm{R}_{C}$ foi considerado igual $2.7 \times 10^{-2} R_{\odot}$. No painel inferior mostra-se os modelo e os dados normalizados pelo contínuo.

linha do C IV, como nos casos anteriores. Quando a região densa é limitada aos anéis 2 e 3 (correspondendo a uma região entre $\mathrm{R}=1.8 \times 10^{-2} \mathrm{R}_{\odot}$ e $\mathrm{R}=2.5 \times 10^{-2} \mathrm{R}_{\odot}$ ) as principais linhas afetadas são as do Nv $\lambda 1240$ e C IV $\lambda 1549$. A intensidade da primeira delas é reduzida por esta mudança mantendo a largura das asas da linha, que são mais largas que as observadas (figura 5.9).

Na figura 5.10 os perfis das principais linhas observadas no UV em RW Tri são mos- 

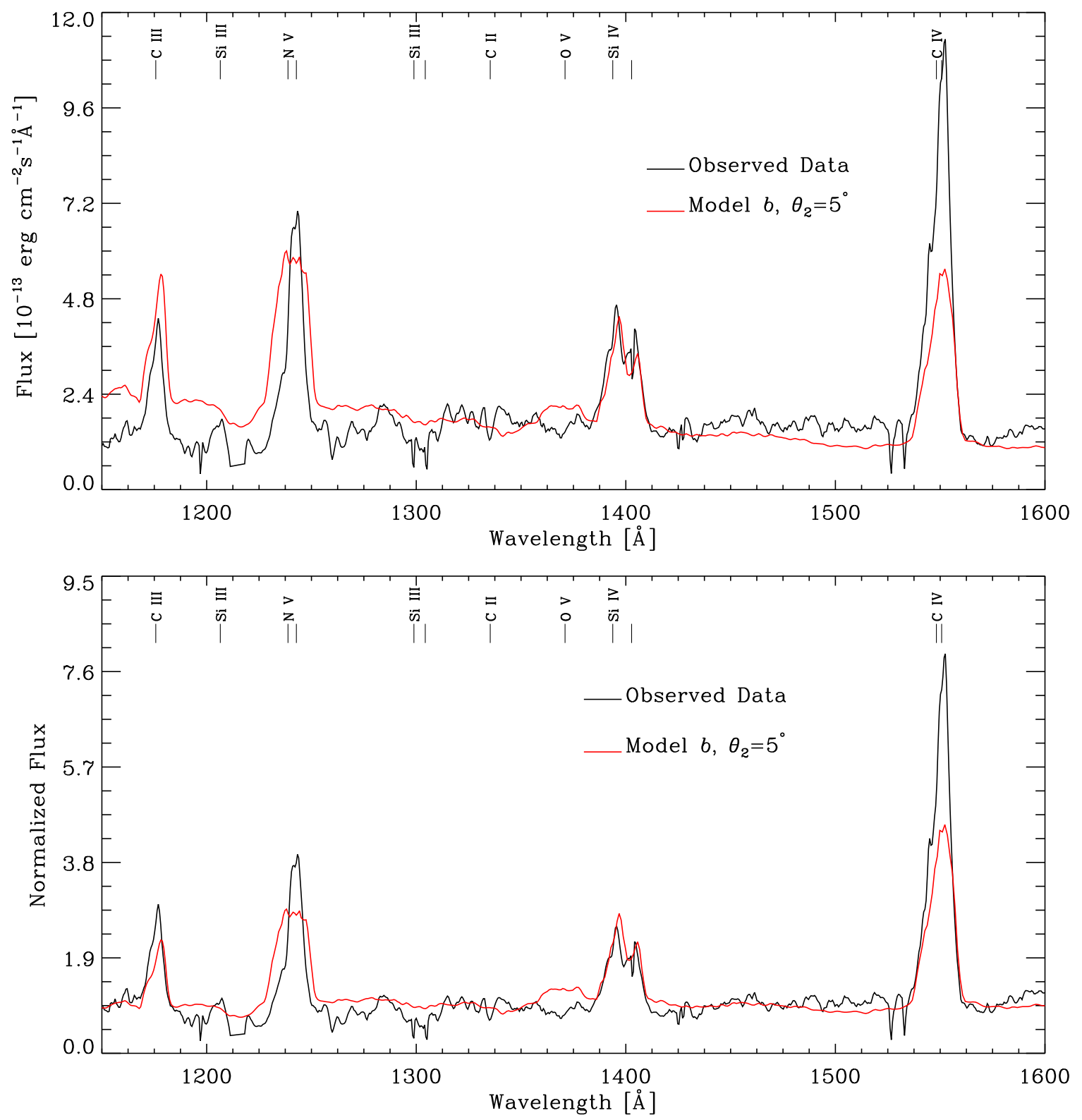

Figura 5.7: Comparação do modelo "b" (linha vermelha) com os dados observados pelo HST (linha preta) para RW Tri. No painel superior mostra-se os modelos em fluxo. Neste caso foi considerado um ângulo de $\theta_{2}=5^{\circ}$. No painel inferior mostra-se o modelo e os dados normalizados pelo contínuo.

tradas junto com os perfis calculados com os modelos descritos anteriormente. Os perfis estão no espaço de velocidades, centrados no comprimento de onda de repouso da linha e, no caso de dupletos, na componente vermelha. A distinção feita na figura com $\alpha$ e $\beta$ para os perfis baseados no modelo $b$ faz referência aos dois valores do ângulo de abertura $\theta_{2}$ utilizados, $10^{\circ}$ no caso $\alpha$ e $5^{\circ}$ no caso $\beta$, e $\gamma$ é o modelo com $R_{C}=2.7 \times 10^{-2} \mathrm{R}_{\odot}$. Os parêntesis indicam os anéis de alta densidade com relação ao modelo original. 

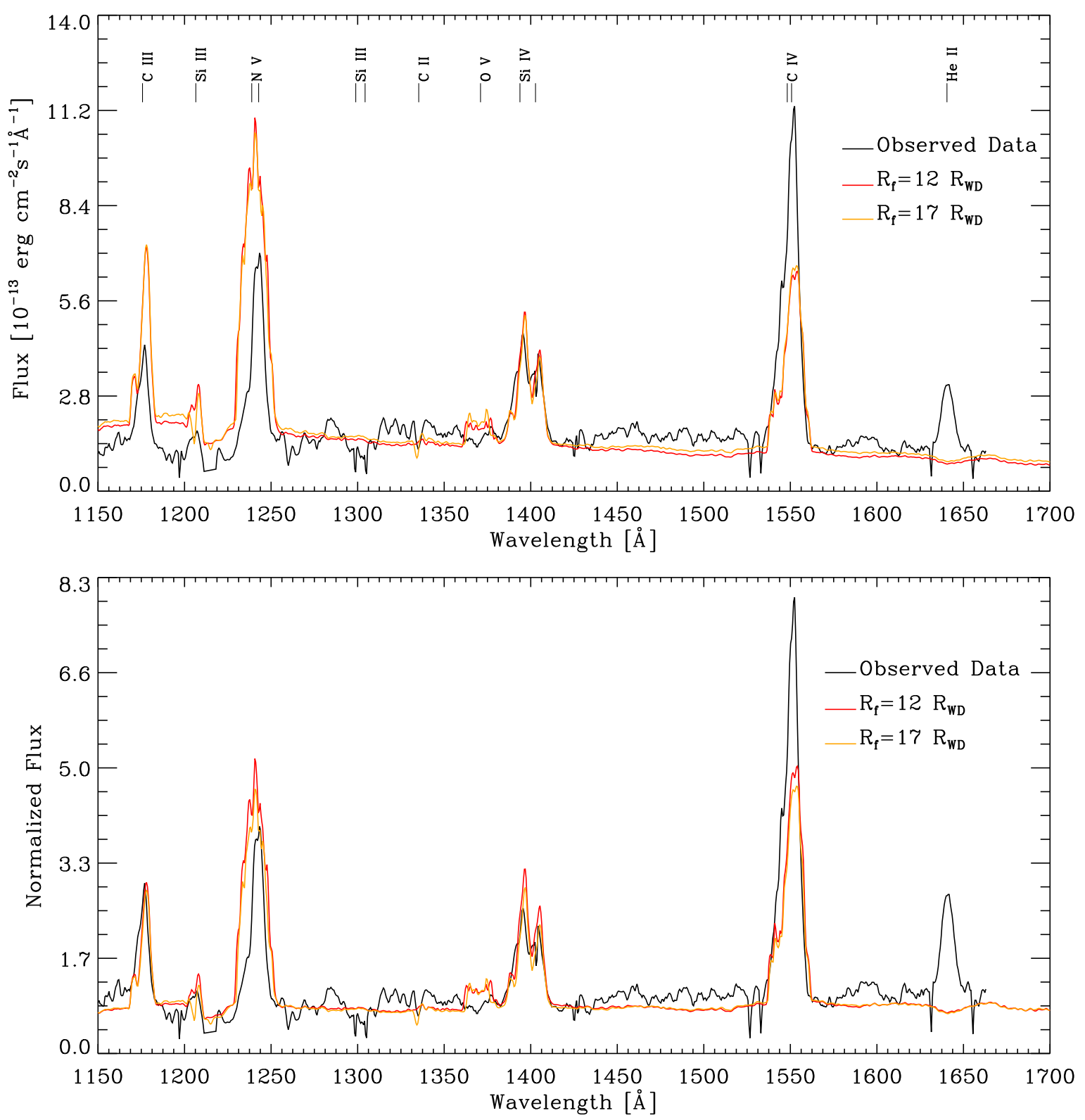

Figura 5.8: Comparação do modelo " $h$ " (linha vermelha com $\mathrm{R}_{f}=0.14 \mathrm{R}_{\odot}$ e linha laranja com $\mathrm{R}_{f}=0.2$ $\mathrm{R}_{\odot}$.) com os dados observados pelo HST (linha preta) para RW Tri. No painel superior mostra-se os modelos em fluxo. No painel inferior mostra-se o modelo e os dados normalizados pelo contínuo.

Encontra-se boa concordância dos modelos com os perfis observados para as linhas do C III $\lambda 1175$ e Si IV $\lambda 1398$. Para a linha N v $\lambda 1240$ todos os modelos geram uma linha muito larga, com as asas em $\sim 3000 \mathrm{~km} \mathrm{~s}^{-1}$, quando no perfil observado as asas se estendem até $\sim 1800 \mathrm{~km} \mathrm{~s}^{-1}$. A intensidade da linha sintética é muito grande quando comparada com a observada. Isto é resultado dessa linha ser gerada numa região quente e extensa do vento correspondente às atmosferas com vento radialmente mais internas. Nas linhas 

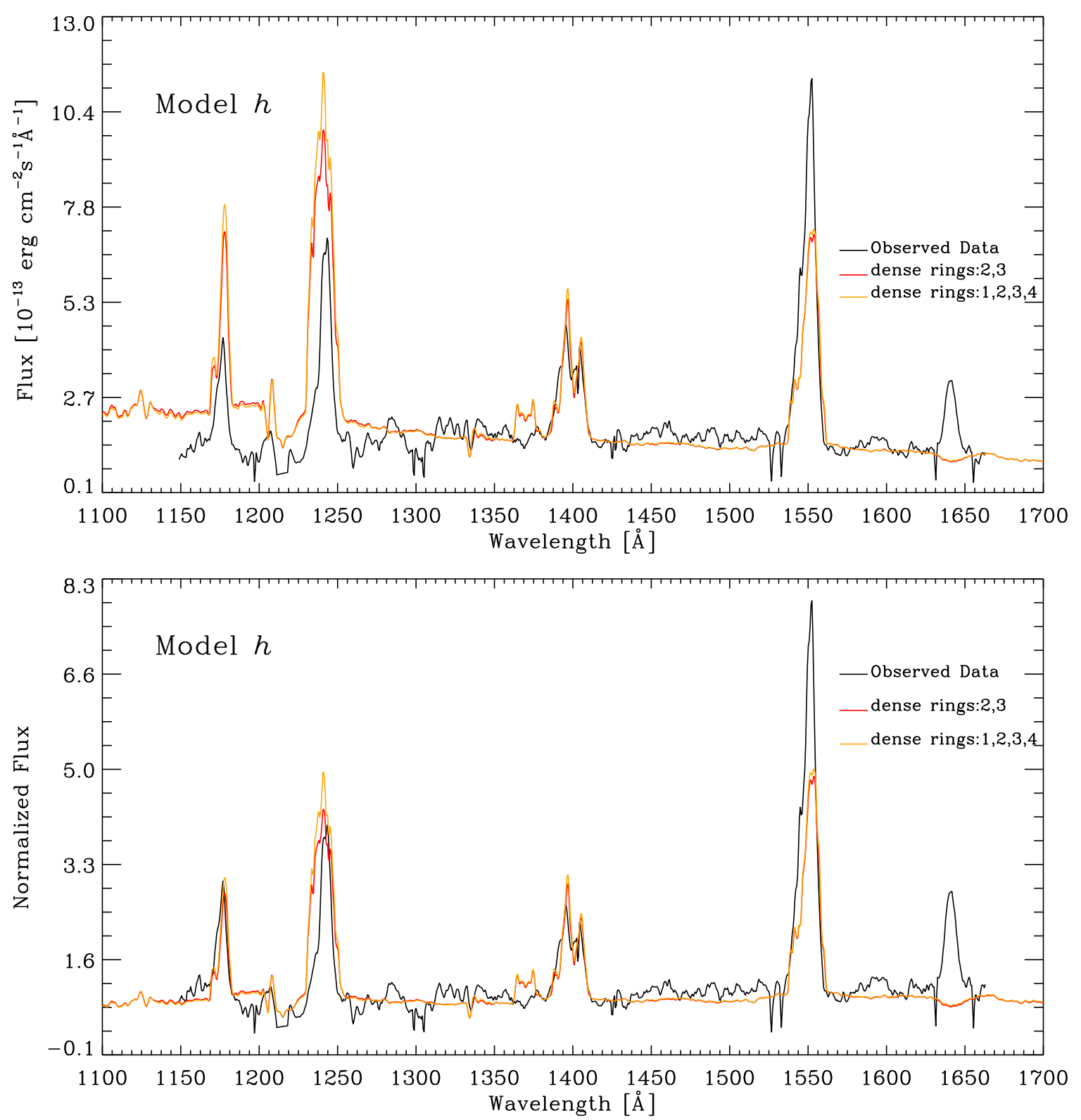

Figura 5.9: Comparação do modelo " $h$ " (linha vermelha com uma região densa entre os anéis 2 e3 e a linha azul com a região densa entre os anéis 1 e 4) com os dados observados pelo HST (linha preta) para RW Tri. No painel inferior mostra-se o modelo e os dados normalizados pelo contínuo.

sintéticas é observada uma componente em emissão bem azulada nos perfis correspondentes ao modelo $h$, para as linhas do C III, Si IV e C IV. Esta componente de alta velocidade provém das regiões internas com alta aceleração vertical. Estas regiões de alta temperatura encontram-se concentradas nessa região, daí que aparecem como uma estrutura concentrada nas altas velocidades. Esta estrutura não é observada, o que evidencia que regiões de alta temperatura devem estar concentradas em volumes menores. 

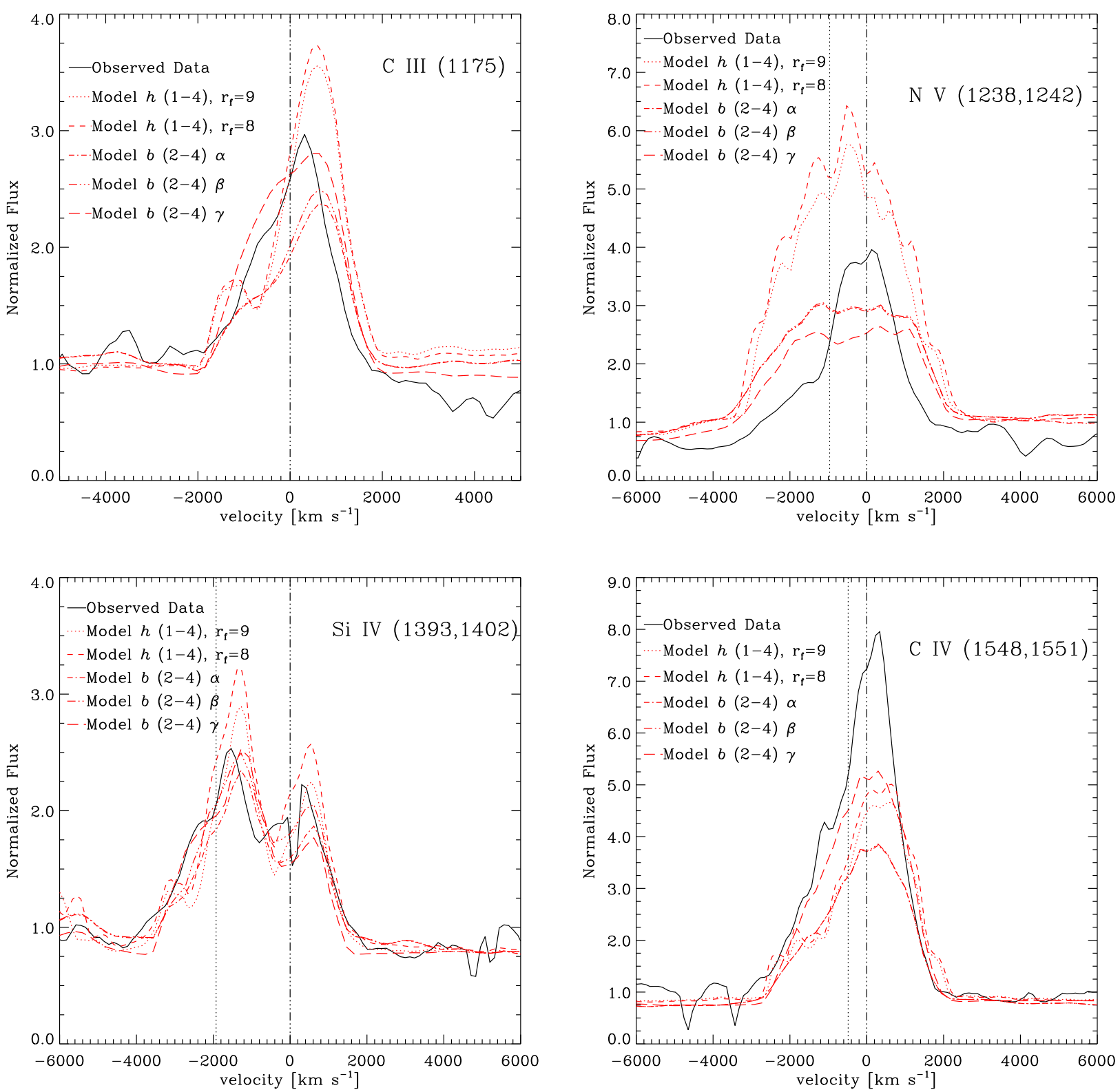

Figura 5.10: Perfis de linha normalizados pelo contínuo para as linhas do CIII, Nv, Si IV e C IV para vários dos modelos descritos no texto e os dados observados. O modelo tem uma inclinação orbital $i=70^{\circ}$. 


\subsubsection{V347 Pup}

A variável cataclísmica V347 Pup é um sistema do tipo Nova-Like de alta inclinação orbital. O período orbital deste sistema é de 0.23 dias ( $~ 5.5$ horas), a massa da primária $\mathrm{M}_{1}=0.63 \mathrm{M}_{\odot}$, e a inclinação orbital $i \sim 80^{\circ}$, Uma distância de $\sim 510$ pc e uma extinção interestelar $E(B-V) \sim 0.05$ foram estimadas (Diaz e Hubeny, 1999; Thoroughgood et al., 2005). A analise do contínuo UV usando atmosferas de disco, revelou uma taxa de acresção seria da ordem de $\sim 6 \times 10^{-9} \mathrm{M}_{\odot}$ ano ${ }^{-1}$ (Puebla et al., 2007). Os dados utilizados foram obtidos com a câmera SWP do IUE em baixa resolução ( 6 Å) com uma cobertura espectral de $1150 \AA$ a $1950 \AA$.

Na figura 5.11 mostra-se a comparação do modelo $b$ com uma inclinação de $70^{\circ}$ com o espectro observado de V347 Pup. Este modelo mostra linhas de formatos similares aos observados nos dados, mas com intensidades menores. A inclinação do modelo é menor que a estimada na literatura o que também afeta o nível de fluxo e a cor do contínuo. Na figura 5.12 a comparação com o mesmo modelo com inclinação orbital $i=80^{\circ}$, é mostrado. Nesse caso as linhas são muito mais intensas, da ordem daquelas encontradas nos dados. O espectro sintético foi agora escalonado para uma distância de 710 pc. O excesso de fluxo encontrado é devido possivelmente à massa da primária dos modelos que, é superior ao valor da literatura. Vemos no painel inferior que a intensidade da linha de C III $\lambda$ 1175 é muito bem reproduzida pelo modelo, mas temos um excesso de fluxo para a linha Si IV $\lambda \lambda 1393,1402$ e uma carência para a linha do C IV $\lambda \lambda 1548,1551$, da mesma ordem à encontrada no caso de RW Tri. Já a largura da linha do N v $\lambda \lambda 1238,1242$ é bem reproduzida pelo modelo mas o núcleo da linha ainda é muito fraco.

Na figura 5.13 é visto um modelo com menor massa da primária. Este corresponde ao modelo " $h$ ", com $\mathrm{M}_{1}=0.6 \mathrm{M}_{\odot}, \dot{\mathrm{M}}_{a}=5 \times 10^{-9} \mathrm{M}_{\odot} \mathrm{ano}^{-1}$ e $\dot{\mathrm{M}}_{w}=4.0 \times 10^{-11} \mathrm{M}_{\odot}$ ano $^{-1} \mathrm{com}$ $\alpha=0.9$. Neste caso uma inclinação orbital de $i=80^{\circ}$ também foi usada. No painel superior da figura o espectro sintético (linha vermelha), foi escalonado a uma distância de 570 pc, valor dentro da margem de erro da literatura. Neste caso uma região mais densa no vento foi incluída para raios entre $1.8 \times 10^{-2} \mathrm{R}_{\odot}$ e $3.5 \times 10^{-2} \mathrm{R}_{\odot}$ e o ângulo foi aumentado para $45^{\circ}$. Da figura vemos que tanto o nível de fluxo como a forma das linhas estão em melhor concordância com os dados, mesmo que a discrepância na intensidade nas linhas N v, Si IV e C IV persistam. A largura das linhas também estão em melhor acordo do que no caso 
anterior, devido principalmente a que neste modelo a massa da primária é menor o que leva a uma velocidade de rotação menor do disco e do vento. O excesso de fluxo na linha Si IV $\lambda 1398$ pode ser corrigido mudando o valor do ângulo de abertura $\theta_{2}$, pois esta linha é afetada fortemente pelas regiões radialmente mais externas do vento. Assim $\theta_{2}$ ajusta o volume dessa região emissora. Este procedimento também afeta a intensidade da linha do C III $\lambda 1175$, que está bem reproduzida pelo modelo. A falta de intensidade em C IV $\lambda 1550$, poderia ser corrigida parcialmente aumentando a densidade das regiões radialmente internas do vento, mas isso acaba afetando fortemente também as outras linhas de alta ionização, afastando-as do perfil observado. 

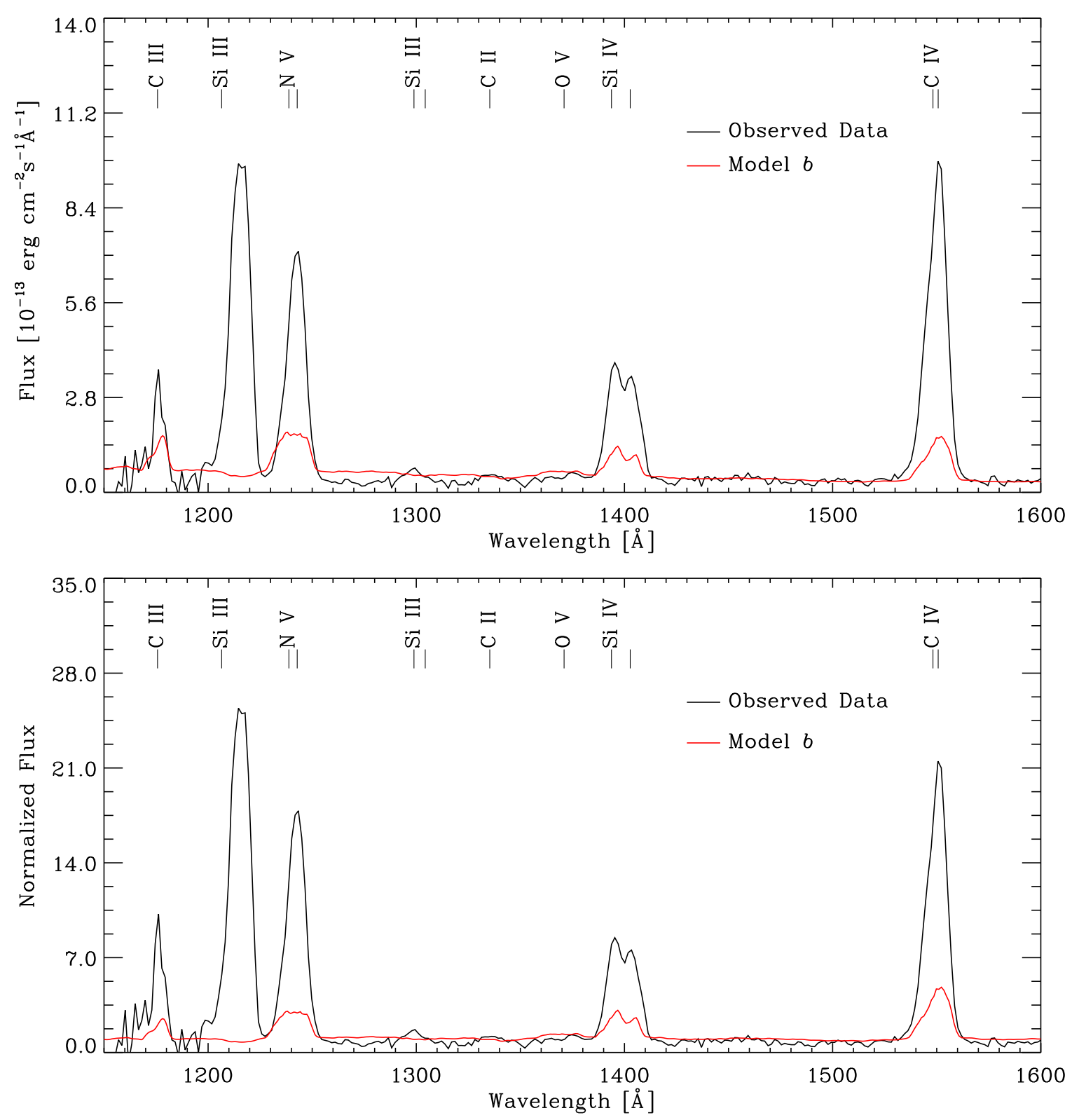

Figura 5.11: Comparação do modelo " $b$ " (linha vermelha) com inclinação orbital $i=70^{\circ}$ com os dados observados pelo HST (linha preta) para V347 Pup. No painel superior mostra-se os modelos em fluxo. O modelo é o mesmo mostrado na figura 5.6. No painel inferior mostra-se o modelo e os dados normalizados pelo contínuo. 

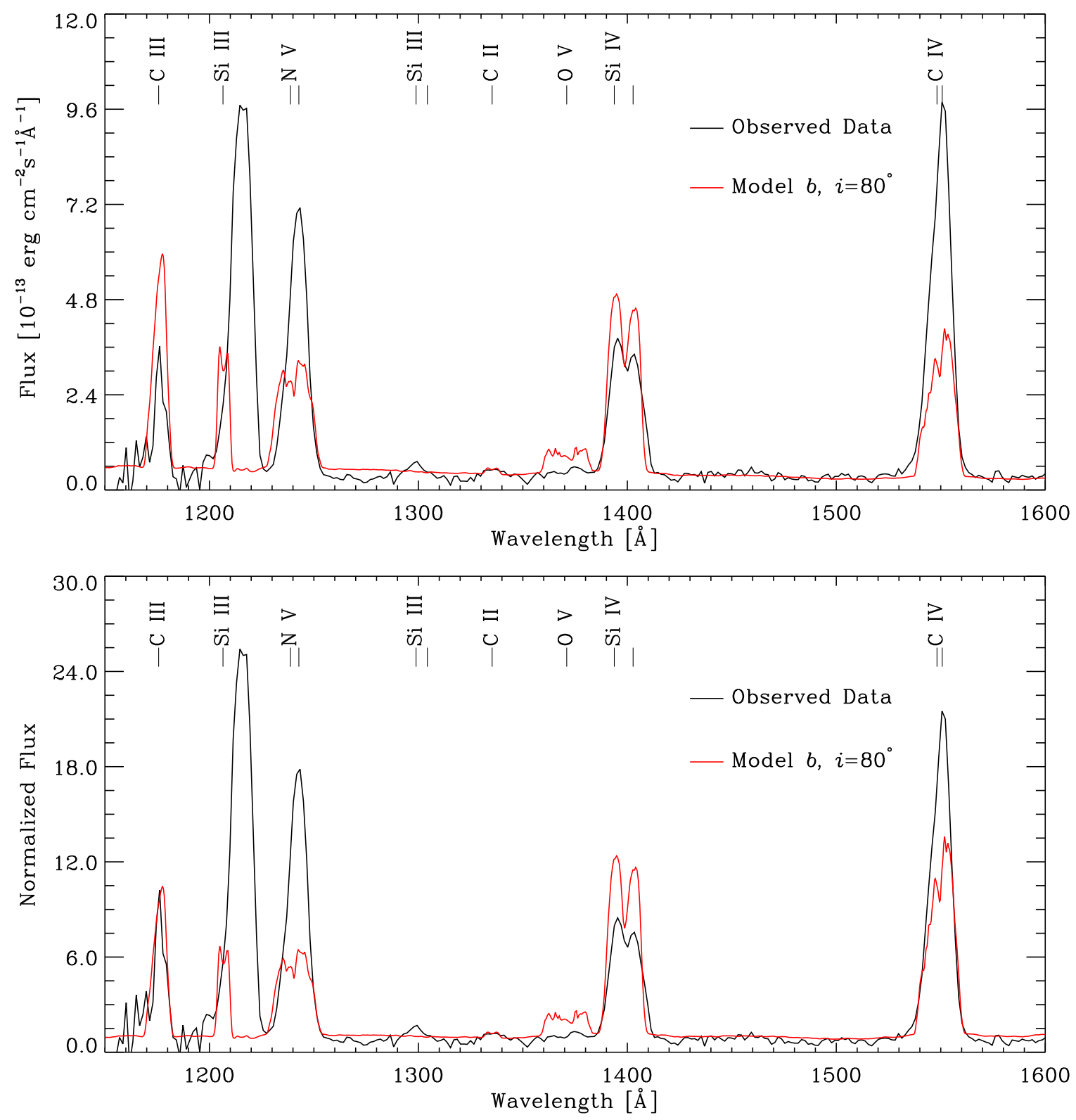

Figura 5.12: Comparação do modelo " $b$ " (linha vermelha) com os dados observados pelo HST (linha preta) para V347 Pup. No painel superior mostra-se os modelos em fluxo. O modelo é o mesmo mostrado na figura 5.11, mas com uma inclinação orbital de $i=80^{\circ}$. No painel inferior mostra-se o modelo e os dados normalizados pelo contínuo. 

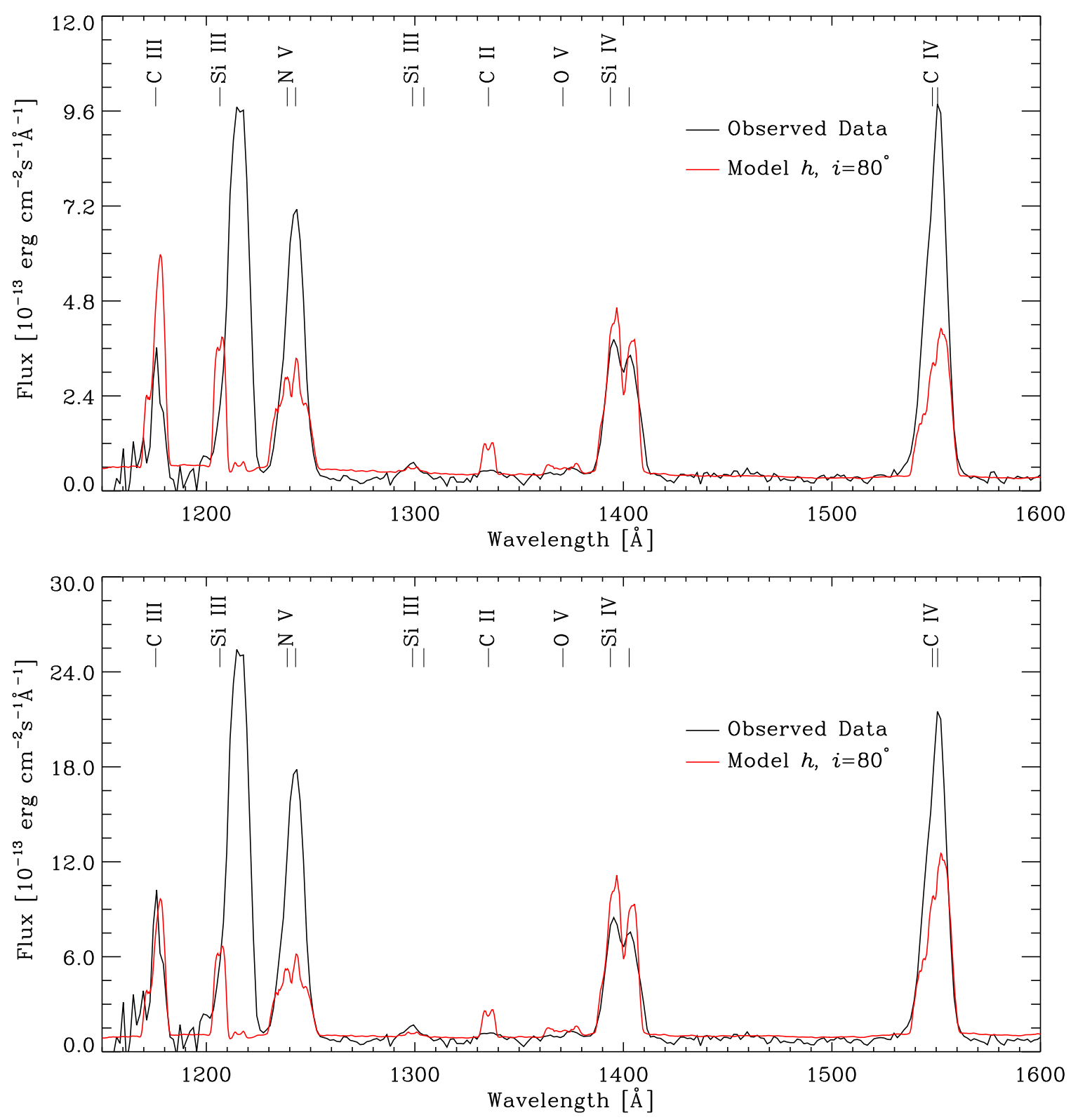

Figura 5.13: Comparação do modelo " $h$ " (linha vermelha) com os dados observados pelo HST (linha preta) para V347 Pup. No painel superior mostra-se os modelos em fluxo. O modelo tem como parâmetros: $\mathrm{M}_{1}=0.6 \mathrm{M}_{\odot}, \dot{\mathrm{M}}_{a}=5 \times 10^{-9} \mathrm{M}_{\odot}$ ano ${ }^{-1}$ e $\dot{\mathrm{M}}_{w}=4.0 \times 10^{-11} \mathrm{M}_{\odot}$ ano $^{-1}$, com $i=80^{\circ}$. No painel inferior mostrase o modelo e os dados normalizados pelo contínuo. 


\subsection{Discussão}

Nesta capítulo temos confrontado os resultados do método desenvolvido neste trabalho com as observações no UV de algumas variáveis cataclísmicas quentes. O modelo desenvolvido simula um vento expelido pelas regiões internas do disco de acresção e sintetiza o espectro gerado pelo sistema disco+vento. Temos encontrado que as estruturas espectrais das simulações reproduzem o comportamento geral do contínuo e das linhas observado nos espectros UV de discos.

Nesses dois casos de sistemas com alta inclinação foram encontrados espectros sintéticos que conseguem reproduzir, em primeira aproximação, a forma dos perfis das linhas observadas. Os parâmetros principais que influenciam os espectros são os ângulos de abertura, a densidade e a massa da primária. Estes parâmetros controlam a intensidade das linhas e a largura das asas das linhas. O campo vertical de velocidades não exerce uma influencia apreciável no caso de sistemas com alta inclinação, como pode-se concluir da equação da velocidade projetada (eq. 2.57). Para reproduzir a forma dos perfis e a intensidade das linhas foi necessário introduzir regiões de alta densidade no vento. Isto revela que condensações estão presentes dentro de ventos de discos de acresção, como é predito nos modelos de hidrodinâmicos (Pereyra et al., 1997, 2000; Pereyra e Kallman, 2003).

Exitem porém, certas carências no modelo que precisam ser resolvidas. É verificado que, em geral, há uma falta de fluxo nas linhas correspondentes à espécies de alta ionização, especialmente na linha do C IV $\lambda \lambda 1548,1551$. Isto pode ser provocado pela presença de uma região altamente ionizada devida à boudary layer. Outra possibilidade seria uma distribuição mais complexa da estrutura de ionização do gás provocada pela própria irradiação do disco sobre o vento.

Para sistemas de baixa inclinação, os modelos calculados usando o método desenvolvido neste trabalho não produz as estruturas de linha observadas na maior parte das principais linhas no UV. Isto é devido principalmente à geometria utilizada no cálculo da estrutura iônica e das populações atômicas em cada atmosfera. Os modelos produzem estruturas em emissão que não são encontradas nos dados. Estas estruturas em emissão provém principalmente de regiões altas do vento. Estas regiões mantém, nos modelos, a mesmas características térmicas da radiação que escapa da fotosfera do anel correspondente a cada modelo de atmosfera, sem levar em conta o resfriamento que o gás sofreria pela expansão 
e a diluição radiativa. Outra característica importante nesses modelos é que o campo de velocidades vertical utilizado neste trabalho possui uma gradiente muito alto. Isto faz com que a região de transição entre a fotosfera e o vento seja pouco estendida. Um cálculo feito usando um campo de velocidades do tipo estelar mostrou que este têm uma influência tão forte na estrutura do vento que consegue alterar os perfis das linhas comumente observadas em absorção nas espécies de baixa ionização. Esta mesma lei de aceleração falha porém, ao reproduzir as linhas de alta de ionização, especialmente o perfil P-Cyg da linha C IV $\lambda \lambda 1548,1551$. Estes resultados mostram que é necessário desenvolver um modelo de vento mais sofisticado, tanto geometricamente quanto no cálculo da estrutura de ionização, fato já apontado especificamente nos capítulos anteriores.

Neste trabalho foi feito um primeiro esforço no sentido de diagnosticar e incluir estas influencias. Foram calculados modelos que incluem uma atmosfera mais fria no exterior do vento e também a influência de uma diluição radiativa nos modelos de atmosferas com vento. Mesmo que estas aproximações gerem estruturas mais realistas nos modelos, os espectros sintéticos gerados ainda apresentam algumas discrepâncias com relação aos dados observados.

Outro obstáculo importante no desenvolvimento de modelos de discos com vento é a variabilidade das características espectrais nas linhas. Esta variabilidade, como foi mostrado, nem sempre tem origem orbital. Muitas vezes representam variações na geometria da região emissora. Por isso seria necessária uma analise detalhada das observações ao longo do tempo antes de fazer uma comparação com os espectros sintéticos.

O método apresentado neste trabalho aparece então como um dos primeiros passos na direção de entender com mais detalhe a física da produção de linhas em discos de acresção e a natureza do vento do disco. A evolução destes modelos ocorre rapidamente. Os primeiros resultados mostram que estes modelos precisam de maior sofisticação, mas já conseguem reproduzir razoavelmente bem os perfis de sistemas de alta inclinação. Isto nos leva à conclusão que os perfis de linha nos sistemas de alta inclinação é menos dependente da estrutura vertical do vento e mais dos parâmetros físicos do disco de acresção, pelo que podem ser usados com mais confiança nesses sistemas. 
Capítulo 6

\section{Conclusões e Perspectivas}

\subsection{Conclusões}

Neste trabalho foi desenvolvido um novo método para o cálculo da síntese espectral de discos de acresção com vento. Este método é baseado naqueles utilizados atualmente para a análise espectral de estrelas quentes com vento tipo OB, que têm demostrado alta sofisticação e precisão. Aqui, estes métodos foram adaptados ao problema de emissão fotosférica e de vento em discos de acresção. Em discos o problema é muito mais complexo, já que tem que ser levada em conta a dissipação viscosa interna, a dependência da gravidade com a altura que leva a uma diferente lei de aceleração no vento. Também, a geometria já não permite um tratamento uni-dimensional, existe uma acentuada estrutura ao longo do raio, além de que deve ser incluído um campo de velocidades com uma grande variação na direção radial e vertical. Todos estes fatores vão afetar tanto a estrutura da atmosfera quanto a transferência radiativa. Neste trabalho foi feito um primeiro esforço de transportar a completeza física dos modelos usados em estrelas ao problema da emissão de discos de acresção.

O disco de acresção é divido em uma série de anéis concêntricos e cada anel é associado a um modelo de atmosfera com vento. Cada modelo de atmosfera é calculado usando a estrutura de uma fotosfera de disco até $\tau_{R}=1$ e uma estrutura de vento até uma altura igual ao raio do disco $R_{d i s k}$. Para estes modelos é calculado um perfil vertical de velocidades que provém da resolução da equação de movimento para um vento vertical sob as condições de gravidade e temperatura efetiva encontradas em um disco de acresção geometricamente fino. Esta maneira de calcular as estruturas verticais leva em conta consistentemente as contribuições tanto do disco quando do vento. Pode-se encontrar assim as influências 
que têm a região de transição entre a fotosfera-vento sobre o contínuo e as linhas. Esta região exerce uma forte influência sobre todos os perfis de absorção sintéticos, sendo muito dependente da aceleração e do campo de velocidades utilizado. A síntese espectral é feita usando a opacidade, a emissividade e a função fonte interpoladas numa grade espacial mais fina e numa grade de frequências no sistema co-móvel usando os modelos de atmosfera. A intensidade específica resultante é integrada no ângulo sólido subtendido pelo disco e vento para obter o espectro sintético.

As soluções da equação de Euler geram perfis de velocidade fortemente acelerados, atingindo a velocidade terminal e a uma altura que depende da distância ao eixo do disco. Este perfil, no caso do ramo inferior das soluções, atinge a metade velocidade terminal em aproximadamente $\frac{z}{R} \sim 0.5$ e a região de máxima aceleração está muito próxima da fotosfera do disco. Foram calculadas as velocidades terminais das duas soluções existentes além do ponto crítico. As velocidades terminais do ramo superior são muito maiores do que as velocidades encontradas nas observações, pelo qual nestes modelos foi usado o ramo inferior das soluções que geram velocidades terminais da ordem das observadas nos espectros UV. Para $\alpha \sim 0.5-0.6$ o ramo superior das soluções, geram velocidades terminais próximas à aquelas observadas, mas as taxas de perda de massa são muito pequenas para gerar ventos que emitam linhas da intensidade encontrada nos dados.

A estrutura de ionização e temperatura dependem fortemente do perfil vertical de velocidades e da geometria utilizada para calculá-los. A temperatura sofre uma queda profunda na região de transição fotosfera vento que coincide também com a região de máxima aceleração. Nas regiões mais externas do vento esta temperatura mantém uma estrutura praticamente uniforme devido a que a radiação que escapa da fotosfera não sofre diluição geométrica nos modelos plano-paralelos. A estrutura de ionização do gás acompanha o comportamento da estrutura de temperatura. A concentração das espécies de baixa ionização cresce na região de transição coincidindo com a queda da temperatura na mesma região. Nas regiões externas a estrutura de ionização mantém-se praticamente uniforme, dependendo da temperatura da radiação que provém do disco. Do ponto de vista espacial, as estruturas de ionização resultantes dos modelos calculados neste trabalho apresentam uma forte estratificação no sentido radial, mas muito pouca no sentido vertical.

A síntese espectral é dependente desta estrutura pelas populações dos níveis de energia 
e abundância de cada íon. Estas populações mantém uma estrutura que acompanha a estrutura de ionização, pelo qual o espectro sintético reflete a estrutura na forma dos perfis de linha calculados.

Foram calculados vários modelos visando estudar o comportamento das características espectrais com os diferentes parâmetros físicos e geométricos do sistema disco+vento. O principal fator que determina a forma e a intensidade das linhas é a distribuição da temperatura no vento. Esta vai determinar a estrutura das espécies presentes no vento e daí a emissão do mesmo. Esta temperatura depende principalmente da taxa de acresção do disco e da massa da anã branca. Esta distribuição de temperatura afeta também a taxa de perda de massa do vento, influenciando a densidade do gás na região extensa e alterando a função fonte nas linhas. Para altas taxas de acresção a temperatura do vento é alta, pelo qual as linhas de espécies de alta ionização são fortalecidas. Quando a taxa de acresção decresce, as linhas de especies de baixa ionização ocupam mais volume no gás, o que provoca que estas sejam fortalecidas quando comparadas com as de alta ionização.

Em sistemas com temperaturas de disco similares, mas com diferentes massas da primária, o efeito desta diferença está na distribuição radial de temperatura, o que leva a uma diferença no nível do contínuo e na forma das linhas. O principal efeito é que quando a massa de primária é menor a região de absorção das linhas também é maior, o que leva a absorções mais profundas em todo o espectro. Para sistemas com massas da primária menor, também o tamanho da região emissora é menor devido a que o tamanho do disco é menor. Isto faz com que a intensidade das componentes em emissão nesse caso sejam menores.

Foi testada a influência do aumento da taxa de perda de massa sobre as características dos espectros sintéticos. Podemos concluir que este aumento na densidade incrementa as características de vento nas linhas. O contínuo também é afetado pelo aumento de densidade, foi encontrado um leve avermelhamento no espectro especialmente para $\lambda<$ $1400 \AA$ A. Mas este avermelhamento é ainda pequeno para resolver o problema da dicotomia cor-magnitude dos modelos de atmosfera de disco.

Foi estudado o comportamento das linhas com os parâmetros geométricos do sistema disco+vento. A inclinação orbital influi fortemente na forma do perfil das linhas. Como o observado, em sistemas com alta inclinação o espectro é preferentemente em emissão, e em 
sistemas com inclinações intermediárias e baixas o espectro apresenta perfis em absorção ou P-Cyg. Porem, nestes sistemas também foram encontrados fortes componentes em emissão que não são observadas nos dados. Isto é devido a que o tamanho da região emissora é grande para algumas linhas, especialmente para as linhas de baixa ionização que são geradas nas regiões mais externas e frias do vento, o que é provocado intrinsecamente pelo modelo, já que ao usar uma geometria plano paralela a função fonte das linhas mantém-se elevada mesmo em regiões afastadas da fonte ionizante.

Também foram analisados os efeitos dos ângulos de abertura $\theta_{1}$ e $\theta_{2}$, sobre as linhas. Assim, $\theta_{1}$ afeta principalmente as linhas de espécies de alta ionização que são produzidas nas regiões mais próximas ao eixo do disco, e $\theta_{2}$ afeta principalmente às linhas de espécies de baixa ionização também o Si IV que são produzidas nas regiões mais afastadas desse eixo.

Destas análises podem ser tiradas algumas conclusões. O modelo de estrutura de vento é muito rígido no que corresponde à geometria. Isso provoca que regiões de emissão tenham um formato principalmente cilíndrico, quando espera-se um formato mais complexo na região extensa do vento. Isto também contribui para a geração de uma componente azulada em emissão em praticamente todas as linhas associadas ao vento. Esta componente é produzida devido a que as emissões estão concentradas principalmente nas regiões internas que, no caso de sistemas com baixa inclinação, estão sendo expelidas na direção do observador. Estas características estruturais provocam, por exemplo, grande emissão em regiões concentradas no vento, restringindo as estruturas dos perfis de linha a certos intervalos de velocidade, quando as observações sugerem que existem contribuições na linha de um amplo intervalo de velocidades.

No capítulo anterior, os modelos calculados neste trabalho foram confrontados com os dados observacionais no UV de quatro VC's do tipo NL. Dois destes sistemas com inclinações orbitais baixas ou intermediárias e dois com sistemas de alta inclinação. No primeiro caso foi encontrada uma forte discrepância entre los perfis calculados e os observados embora o ajuste do contínuo seja razoável. Nestes sistemas a estrutura vertical do vento influi fortemente no perfil das linhas. Já para sistemas de alta inclinação foi encontrada uma razoável concordância entre os perfis calculados e os observados. Para isso foi necessário incluir regiões de alta densidade no vento. Isto mostra a existência des- 
tas condensações em ventos de discos de acresção. Os resultados mostram também que a estrutura vertical do vento não influi fortemente nos perfis de linha em sistemas com alta inclinação orbital.

Visando melhorar os perfis de linha encontrados neste trabalho, foram feitas modificações aos modelos originais. Uma atmosfera mais fria foi incluída na região mais externa do disco para aumentar a estratificação radial de temperatura. Regiões de alta densidade foram incluídas no vento, visando incrementar a emissão de certas linhas. Também foram calculados os primeiros modelos que incluem uma diluição radiativa no sentido vertical. Estes novos modelos apontam no sentido correto, como o observado em algumas linhas (p.e. Si IV e C III), mas outras linhas perdem as componentes em emissão observadas nos dados UV (p.e. CIV), o que mostra que a estrutura do vento teria que ter uma mistura mais complexa destas propriedades incluindo uma fonte quente central, como foi comentado no capítulo 5 .

\subsection{Perspectivas}

Das conclusões expostas podem ser apontadas as direções no sentido de melhorar o método desenvolvido neste trabalho. Seria necessário flexibilizar a geometria do modelo de vento que é expelido do disco. Modificar a geometria das atmosferas calculadas para faze-las inclinadas num determinado ângulo ou ângulos de colimação.

Os modelos de atmosfera devem contar com uma distribuição da radiação mais realista. Em primeira aproximação esta distribuição mimetizará a diluição radiativa e a contribuição de regiões do disco diferentes à da atmosfera que encontra-se no pé das linhas de fluxo do vento. Estes novos modelos serão novamente confrontados com dados espectrais de sistemas de alta e baixa inclinação.

Novos perfis de velocidade, tanto no sentido poloidal como azimutal serão explorados, levando em consideração as estruturas de ionização calculadas visando uma melhor aproximação dos modelos com os dados observacionais. Isto para encontrar uma melhor compreensão da cinemática dos ventos e da região de transição entre fotosfera e vento. A influência destes novos perfis de velocidade sobre a região de transição será investigada para a melhoria do ajuste das linhas.

A contribuição da boundary layer pode ser adicionada a este estudo, para entender 
melhor a composição do espectro no UV. Para isso a síntese será estendida para comprimentos de onda no UV longínquo (FUV) nas regiões do espectro cobertas pelo satélite Far Ultraviolet Espectroscopic Explorer FUSE. 


\section{Referências Bibliográficas}

Abbott D. C., The theory of radiatively driven stellar winds. I - A physical interpretation, ApJ, 1980, vol. 242, p. 1183

Abbott D. C., The theory of radiatively driven stellar winds. II - The line acceleration, ApJ, 1982, vol. 259, p. 282

Anderson L., Line Blanketing Without Lts - Simple and Complex Spectra. In NATO ASIC Proc. 341: Stellar Atmospheres - Beyond Classical Models , 1991, p. 29

Anderson L. S., Line blanketing without local thermodynamic equilibrium. II - A solar-type model in radiative equilibrium, ApJ, 1989, vol. 339, p. 558

Auer L. H., Mihalas D., Non-Lte Model Atmospheres. I. Radiative Equilibrium Models with - Alpha, ApJ, 1969a, vol. 156, p. 157

Auer L. H., Mihalas D., Non-Lte Model Atmospheres. II. Effects of Balmer $\alpha$, ApJ, 1969b, vol. 156, p. 681

Auer L. H., Mihalas D., Non-Lte Model Atmospheres. III. a Complete-Linearization Method, ApJ, 1969c, vol. 158, p. 641

Balbus S. A., Hawley J. F., A powerful local shear instability in weakly magnetized disks. I - Linear analysis. II - Nonlinear evolution, ApJ, 1991, vol. 376, p. 214

Begelman M. C., McKee C. F., Shields G. A., Compton heated winds and coronae above accretion disks. I Dynamics, ApJ, 1983, vol. 271, p. 70 
Beuermann K., Stasiewski U., Schwope A. D., Phase-resolved spectroscopy of the novalike cataclysmic variable RW Sextantis, A\&A, 1992, vol. 256, p. 433

Bruch A., Engel A., A catalogue of UBV colours of cataclysmic variables., A\&AS, 1994, vol. 104, p. 79

Busche J. R., Hillier D. J., Spectroscopic Effects of Rotation in Extended Stellar Atmospheres, AJ, 2005, vol. 129, p. 454

Castor J. I., Abbott D. C., Klein R. I., Radiation-driven winds in Of stars, ApJ, 1975, vol. 195 , p. 157

Cordova F. A., Mason K. O., High-velocity winds from a dwarf nova during outburst, ApJ, 1982, vol. 260 , p. 716

Cordova F. A., Mason K. O., High-velocity winds in close binaries with accretion disks. II - The view along the plane of the disk, ApJ, 1985, vol. 290, p. 671

Cowley A. P., Crampton D., Hesser J. E., The flickering white dwarf CD -42 14462: a noneruptive close binary., ApJ, 1977, vol. 214, p. 471

Diaz M. P., Hubeny I., The Eclipsing Cataclysmic Variable V347 Puppis Revisited, ApJ, 1999, vol. 523, p. 786

Diaz M. P., Wade R. A., Hubeny I., Ultraviolet Limb Darkening and Spectra for Accretion Disks in Cataclysmic Variables, ApJ, 1996, vol. 459, p. 236

Drew J., Verbunt F., Investigation of a wind model for cataclysmic variable ultraviolet resonance line emission, MNRAS, 1985, vol. 213, p. 191

Drew J. E., Inclination and orbital-phase-dependent resonance line-profile calculations applied to cataclysmic variable winds, MNRAS, 1987, vol. 224, p. 595

Duerbeck H. W., Hipparcos parallaxes of cataclysmic binaries and the quest for their absolute magnitudes, Information Bulletin on Variable Stars, 1999, vol. 4731, p. 1

Eggleton P. P., Approximations to the radii of Roche lobes, ApJ, 1983, vol. 268, p. 368 
Engle S. G., Sion E. M., A Far-Ultraviolet Study of the Old Nova V841 Ophiuchi, PASP, 2005, vol. 117, p. 1230

Feldmeier A., Shlosman I., Dynamics of Line-driven Winds from Disks in Cataclysmic Variables. I. Solution Topology and Wind Geometry, ApJ, 1999, vol. 526, p. 344

Feldmeier A., Shlosman I., Hamann W., Runaway Acceleration of Line-driven Winds: The Role of the Outer Boundary, ApJ, 2002, vol. 566, p. 392

Feldmeier A., Shlosman I., Vitello P., Dynamics of Line-driven Winds from Disks in Cataclysmic Variables. II. Mass-Loss Rates and Velocity Laws, ApJ, 1999, vol. 526, p. 357

Frank J., King A., Raine D. J., Accretion Power in Astrophysics: Third Edition, 2002

Froning C. S., Long K. S., Knigge C., Accretion and Outflow in Interacting Binary Systems: Far Ultraviolet Spectroscopic Explorer Observations of the Nova-like Cataclysmic Variable UX Ursae Majoris, ApJ, 2003, vol. 584, p. 433

Gayley K. G., An Improved Line-Strength Parameterization in Hot-Star Winds, ApJ, 1995, vol. 454 , p. 410

Gayley K. G., Owocki S. P., Cranmer S. R., Line-driven Ablation and Wind Tilting by External Irradiation, ApJ, 1999, vol. 513, p. 442

Greenstein J. L., Oke J. B., RW Sextantis, a disk with a hot, high-velocity wind, ApJ, 1982, vol. 258, p. 209

Groot P. J., Rutten R. G. M., van Paradijs J., A spectrophotometric study of RW Trianguli, A\&A, 2004, vol. 417, p. 283

Hamada T., Salpeter E. E., Models for Zero-Temperature Stars., ApJ, 1961, vol. 134, p. 683

Hartley L. E., Drew J. E., Long K. S., Knigge C., Proga D., Testing the line-driven disc wind model: time-resolved ultraviolet spectroscopy of IX Vel and V3885Sgr, MNRAS, 2002, vol. 332, p. 127 
Hillier D. J., Modeling the extended atmospheres of WN stars, ApJS, 1987, vol. 63, p. 947

Hillier D. J., Line blanketing, and the computation of line equivalent widths in the comoving frame, A\&A, 1990, vol. 231, p. 111

Hillier D. J., On the Solution of the Statistical Equilibrium Equations. In Stellar Atmosphere Modeling, vol. 288 of Astronomical Society of the Pacific Conference Series, 2003, p. 199

Hillier D. J., Miller D. L., The Treatment of Non-LTE Line Blanketing in Spherically Expanding Outflows, ApJ, 1998, vol. 496, p. 407

Hillier D. J., Miller D. L., Constraints on the Evolution of Massive Stars through Spectral Analysis. I. The WC5 Star HD 165763, ApJ, 1999, vol. 519, p. 354

Hoare M. G., Drew J. E., Boundary-layer temperatures in high accretion rate cataclysmic variables, MNRAS, 1991, vol. 249, p. 452

Hoare M. G., Drew J. E., The ionization state of the winds from cataclysmic variables without classical boundary layers, MNRAS, 1993, vol. 260, p. 647

Hubeny I., Vertical structure of accretion disks - A simplified analytical model, ApJ, 1990, vol. 351 , p. 632

Hubeny I., Lanz T., Non-LTE line-blanketed model atmospheres of hot stars. 1: Hybrid complete linearization/accelerated lambda iteration method, ApJ, 1995, vol. 439, p. 875

Jameson R. F., King A. R., Sherrington M. R., The UV spectrum of AE AQR, MNRAS, 1980, vol. 191, p. 559

Knigge C., The donor stars of cataclysmic variables, MNRAS, 2006, vol. 373, p. 484

Knigge C., Long K. S., Blair W. P., Wade R. A., Disks, Winds, and Veiling Curtains: Dissecting the Ultraviolet Spectrum of the Dwarf Nova Z Camelopardalis in Outburst, ApJ, 1997, vol. 476, p. 291

Knigge C., Woods J. A., Drew J. E., The application of Monte Carlo methods to the synthesis of spectral line profiles arising from accretion disc winds, MNRAS, 1995, vol. 273, p. 225 
Ko Y., Lee Y. P., Schlegel E. M., Kallman T. R., Modeling Emission Lines from Dwarf Novae in Quiescence, ApJ, 1996, vol. 457, p. 363

Kriz S., Hubeny I., Models and theoretical spectra of accretion discs in dwarf novae, Bulletin of the Astronomical Institutes of Czechoslovakia, 1986, vol. 37, p. 129

Kudritzki R. P., Pauldrach A., Puls J., Abbott D. C., Radiation-driven winds of hot stars. VI - Analytical solutions for wind models including the finite cone angle effect, A\&A, 1989, vol. 219 , p. 205

La Dous C., Synthetic optical and ultraviolet spectra of stationary accretion disks, A\&A, 1989, vol. 211 , p. 131

La Dous C., New insights from a statistical analysis of IUE spectra of dwarf novae and nova-like stars. I - Inclination effects in lines and continua, A\&A, 1991, vol. 252, p. 100

Linnell A. P., Godon P., Hubeny I., Sion E. M., Szkody P., Modeling UX Ursae Majoris: An Abundance of Challenges, ApJ, 2008, vol. 688, p. 568

Linnell A. P., Godon P., Hubeny I., Sion E. M., Szkody P., Barrett P. E., V3885 Sagittarius: A Comparison with a Range of Standard Model Accretion Disks, ApJ, 2009, vol. 703, p. 1839

Linnell A. P., Hoard D. W., Szkody P., Long K. S., Hubeny I., Gänsicke B., Sion E. M., An Illustration of Modeling Cataclysmic Variables: HST, FUSE, and SDSS Spectra of SDSS J080908.39+381406.2, ApJ, 2007, vol. 654, p. 1036

Linnell A. P., Hubeny I., A Spectrum Synthesis and Light Synthesis Program for Binary Stars with Optically Thick Accretion Disks, ApJ, 1996, vol. 471, p. 958

Long K. S., Knigge C., Modeling the Spectral Signatures of Accretion Disk Winds: A New Monte Carlo Approach, ApJ, 2002, vol. 579, p. 725

Long K. S., Wade R. A., Blair W. P., Davidsen A. F., Hubeny I., Observations of the bright novalike variable IX Velorum with the Hopkins Ultraviolet Telescope, ApJ, 1994, vol. 426 , p. 704

Lynden-Bell D., Galactic Nuclei as Collapsed Old Quasars, Nature, 1969, vol. 223, p. 690 
Lynden-Bell D., Pringle J. E., The evolution of viscous discs and the origin of the nebular variables., MNRAS, 1974, vol. 168, p. 603

Mason K. O., Drew J. E., Cordova F. A., Horne K., Hilditch R., Knigge C., Lanz T., Meylan T., Eclipse observations of an accretion disc wind, MNRAS, 1995, vol. 274, p. 271

Mauche C. W., High-resolution IUE spectra of the nova-like variable IX Velorum, ApJ, 1991, vol. 373, p. 624

Mauche C. W., Raymond J. C., IUE observations of HL CMa and the winds of cataclysmic variables, Ap\&SS, 1987, vol. 130, p. 269

McArthur B. E., Benedict G. F., Lee J., Lu C., van Altena W. F., Deliyannis C. P., Girard T., Fredrick L. W., Nelan E., Duncombe R. L., Hemenway P. D., Jefferys W. H., Shelus P. J., Franz O. G., Wasserman L. H., Astrometry with Hubble Space Telescope Fine Guidance Sensor 3: The Parallax of the Cataclysmic Variable RW Triangulum, ApJ, 1999, vol. 520, p. L59

Meliani M. T., de Araujo J. C. N., Aguiar O. D., Cataclysmic variables as sources of gravitational waves, A\&A, 2000, vol. 358, p. 417

Mihalas D., Stellar atmospheres /2nd edition/, 1978

Mihalas D., Kunasz P. B., Hummer D. G., Solution of the comoving frame equation of transfer in spherically symmetric flows. I - Computational method for equivalent-twolevel-atom source functions, ApJ, 1975, vol. 202, p. 465

Mihalas D., Kunasz P. B., Hummer D. G., Solution of the comoving-frame equation of transfer in spherically symmetric flows. II - Picket-fence models, ApJ, 1976a, vol. 203, p. 647

Mihalas D., Kunasz P. B., Hummer D. G., Solution of the Comoving-Frame Equation of Transfer in Spherically Symmetric Flows. III. Effect of Aberration and Advection Terms, ApJ, 1976b, vol. 206, p. 515 
Mizusawa T., Merritt J., Ballouz R., Bonaro M., Foran S., Plumberg C., Stewart H., Wiley T., Sion E. M., Far Ultraviolet Spectroscopy of Seven Nova-Like Variables, PASP, 2010, vol. 122 , p. 299

Nadalin I., Sion E. M., The Accretion Disk and White Dwarf in the Short-Period Dwarf Novae TY Piscium and V436 Centauri during Quiescence, PASP, 2001, vol. 113, p. 829

Patterson J., The evolution of cataclysmic and low-mass X-ray binaries, ApJS, 1984, vol. 54 , p. 443

Patterson J., Raymond J. C., X-Ray Emission from Cataclysmic Variables with Accretion Disks - Part Two - Extreme Ultraviolet Soft X-Ray Radiation, ApJ, 1985a, vol. 292, p. 550

Patterson J., Raymond J. C., X-ray emission from cataclysmic variables with accretion disks. I - Hard X-rays. II - EUV/soft X-ray radiation, ApJ, 1985b, vol. 292, p. 535

Pereyra N. A., Further Criteria for the Existence of Steady Line-driven Winds, ApJ, 2005, vol. 622 , p. 577

Pereyra N. A., Kallman T. R., Hydrodynamic Models of Line-driven Accretion Disk Winds. III. Local Ionization Equilibrium, ApJ, 2003, vol. 582, p. 984

Pereyra N. A., Kallman T. R., Blondin J. M., Hydrodynamical Models of Line-driven Accretion Disk Winds, ApJ, 1997, vol. 477, p. 368

Pereyra N. A., Kallman T. R., Blondin J. M., Hydrodynamic Models of Line-driven Accretion Disk Winds. II. Adiabatic Winds from Nonisothermal Disks, ApJ, 2000, vol. 532, p. 563

Pereyra N. A., Owocki S. P., Hillier D. J., Turnshek D. A., On the Steady Nature of Line-Driven Disk Winds, ApJ, 2004, vol. 608, p. 454

Poole T., Mason K. O., Ramsay G., Drew J. E., Smith R. C., The component star masses in RW Tri, MNRAS, 2003, vol. 340, p. 499

Pringle J. E., Accretion discs in astrophysics, ARA\&A, 1981, vol. 19, p. 137 
Prinja R. K., Knigge C., Ringwald F. A., Wade R. A., Episodic absorption in the outflow of the old nova V603 Aquilae, MNRAS, 2000, vol. 318, p. 368

Prinja R. K., Long K. S., Froning C. S., Knigge C., Witherick D. K., Clark J. S., Ringwald F. A., FUSE and HST ultraviolet observations of the disc wind of RW Sextantis, MNRAS, 2003, vol. 340, p. 551

Prinja R. K., Ringwald F. A., Wade R. A., Knigge C., HST ultraviolet observations of rapid variability in the accretion-disc wind of BZ Cam, MNRAS, 2000, vol. 312, p. 316

Prinja R. K., Rosen R., High-resolution IUE spectroscopy of fast winds from cataclysmic variables, MNRAS, 1995, vol. 273, p. 461

Proga D., Stone J. M., Drew J. E., Radiation-driven winds from luminous accretion discs, MNRAS, 1998, vol. 295, p. 595

Proga D., Stone J. M., Drew J. E., Line-driven disc wind models with an improved line force, MNRAS, 1999, vol. 310, p. 476

Pudritz R. E., Star formation in rotating, magnetized molecular disks, ApJ, 1985, vol. 293, p. 216

Puebla R. E., Sobre a Taxa de Transfêrencia de Massa em Variáveis Cataclísmicas Quiescentes, São Paulo: Universidade 1, 2005, Dissertação de Mestrado, 125 p.

Puebla R. E., Diaz M. P., Hubeny I., A Statistical Study of Accretion Disk Model Spectra for Cataclysmic Variables, AJ, 2007, vol. 134

Ribeiro F. M. A., Diaz M. P., Emission-Line Flickering from the Secondary Star in Cataclysmic Variables? A Study of V3885 Sagittarii, AJ, 2007, vol. 133, p. 2659

Ritter H., Kolb U., Catalogue of cataclysmic binaries, low-mass X-ray binaries and related objects (Seventh edition), A\&A, 2003, vol. 404, p. 301

Rybicki G. B., Hummer D. G., A generalization of the Sobolev method for flows with nonlocal radiative coupling, ApJ, 1978, vol. 219, p. 654 
Schmidt G. D., Bergeron P., Liebert J., Saffer R. A., Two ultramassive white dwarfs found among candidates for magnetic fields, ApJ, 1992, vol. 394, p. 603

Sen Wilson S. J. K. K., Radiative transfer in moving media : basic mathematical methods for radiative transfer in spherically symmetrical moving media, 1998

Shakura N. I., Sunyaev R. A., Black holes in binary systems. Observational appearance., A\&A, 1973, vol. 24, p. 337

Shaviv G., Wehrse R., The vertical temperature stratification and corona formation of accretion disc atmospheres, A\&A, 1986, vol. 159, p. L5

Shimada M. R., Ito M., Hirata B., Horaguchi T., Radiatively driven winds of OB stars. In Pulsation; Rotation; and Mass Loss in Early-Type Stars , vol. 162 of IAU Symposium, 1994, p. 487

Shlosman I., Vitello P., Winds from accretion disks - Ultraviolet line formation in cataclysmic variables, ApJ, 1993, vol. 409, p. 372

Shlosman I., Vitello P. A., Shaviv G., Active galactic nuclei - Internal dynamics and formation of emission clouds, ApJ, 1985, vol. 294, p. 96

Sobolev V. V., The Diffusion of L $\alpha$ Radiation in Nebulae and Stellar Envelopes., Soviet Astronomy, 1957, vol. 1, p. 678

Thoroughgood T. D., Dhillon V. S., Steeghs D., Watson C. A., Buckley D. A. H., Littlefair S. P., Smith D. A., Still M., van der Heyden K. J., Warner B., The component masses of the cataclysmic variable V347 Puppis, MNRAS, 2005, vol. 357, p. 881

Tylenda R., Radiation from Optically Thin Accretion Discs, Acta Astronomica, 1981, vol. 31, p. 127

Verbunt F., Accretion disks in stellar X-ray sources - A review of the basic theory of accretion disks and its problems, Space Science Reviews, 1982, vol. 32, p. 379

Vitello P. A. J., Shlosman I., Line-driven winds from accretion disks. I - Effects of the ionization structure, ApJ, 1988, vol. 327, p. 680 
Wade R. A., A double grid of accretion disc model spectra for cataclysmic variable stars, MNRAS, 1984, vol. 208, p. 381

Wade R. A., A test of synthetic accretion disk spectra using ultraviolet flux distributions of novalike variables, ApJ, 1988, vol. 335, p. 394

Wade R. A., Hubeny I., Detailed Mid- and Far-Ultraviolet Model Spectra for Accretion Disks in Cataclysmic Binaries, ApJ, 1998, vol. 509, p. 350

Warner B., Cataclysmic variable stars. Cambridge Astrophysics Series, Cambridge, New York: Cambridge University Press, —c1995, 1995

Webbink R. F., Absolute Parameters of Cataclysmic Binaries. In Accretion-Powered Compact Binaries , 1990, p. 177

Williams G. A., Shipman H. L., Hydrogen line emission from optically thin accretion disks, ApJ, 1988, vol. 326 , p. 738

Williams R. E., Emission lines from the accretion disks of cataclysmic variables, ApJ, 1980, vol. 235 , p. 939

Williams R. E., Ferguson D. H., He I line emission and the helium abundance in cataclysmic variables, ApJ, 1982, vol. 257, p. 672

Woods J. A., Verbunt F., Collier Cameron A., Drew J. E., Piters A., Time dependence of the UV resonance lines in the cataclysmic variables YZ Cnc, IR GEM and V3885 SGR, MNRAS, 1992, vol. 255, p. 237 
Apêndice 

Apêndice A

\section{Estudo Estatístico do Modelo de Síntese Espectral de Discos de Acrasção em Variáveis Cataclísmicas}

Neste trabalho é apresentado um teste estatístico do modelo de disco de acresção utilizado atualmente no estudo de VC's. Uma mostra de 33 CV's (10 novas velhas e 23 "nova-like") foi utilizada. A taxa de acresção é calculada para cada sistema utilizando o modelo de disco de acresção de Wade e Hubeny (1998) e um método de optimização multi-paramétrica. Encontrou-se que a taxa média de acresção deste tipo de sistemas é de $\dot{\mathrm{M}}_{a} \sim 1 \times 10^{-8} \mathrm{M}_{\odot}$ ano ${ }^{-1}$. Importantes degenerescências entre os parâmetros básicos do modelo são analisadas nos ajustes. Nossas simulações sugerem que para reproduzir as observações um novo perfil radial temperatura efetiva é necessário, principalmente nas regiões internas do disco. Adicionalmente, uma componente opticamente fina ou uma componente extensa do disco deve ser considerada. Esta componente pode ser fisicamente representada por um vento ou uma cromosfera. Não foi encontrada uma correlação clara entre a taxa de acresção e o período orbital como a encontrada por Patterson (1984). Estudando a intensidade das linas de emissão, foi encontrada uma carência de sistemas com baixa taxa de acresção e fortes linha. de emissão. Estes comportamentos nos leva a pensar numa certa correlação entre a luminosidade do disco e a intensidade das linhas de emissão observadas no UV de VC's. Também foi estudada a influência que teria sobre os espectros UV a emissão de uma anã branca quente e também a estabilidade dos discos de acresção neste tipo de VC's. 
The Astronomical Journal, 134:1923-1933, 2007 November

C) 2007. The American Astronomical Society. All rights reserved. Printed in U.S.A.

\title{
A STATISTICAL STUDY OF ACCRETION DISK MODEL SPECTRA FOR CATACLYSMIC VARIABLES
}

\author{
Raúl E. Puebla and Marcos P. Diaz \\ Instituto de Astronomia, Geofísica, e Ciências Atmosféricas, Universidade de São Paulo, Rua de Matão 1226, \\ Cidade Universitária, 05508-900 São Paulo, SP, Brazil; raul@astro.iag.usp.br, marcos@astro.iag.usp.br \\ AND \\ Ivan HuBEnY \\ Department of Astronomy, Steward Observatory, The University of Arizona, 933 North Cherry Avenue, \\ Tucson, AZ 85721-0065, USA; hubeny@ as.arizona.edu \\ Received 2007 April 4; accepted 2007 August 3
}

\begin{abstract}
We have performed a statistical test of the currently used accretion disk models for cataclysmic variables $(\mathrm{CVs})$ using a set of $33 \mathrm{CVs}$ with steady disks (10 old novae and 23 nova-like systems). The mass transfer rate $(\dot{M})$ for each system was also calculated. Ultraviolet (UV) data were fitted by model spectra using a multiparametric optimization method, aiming to constrain the $\dot{M}$ values. It was verified that these accretion disk models fail to fit both color and flux simultaneously, as previously noted when composite stellar atmosphere models were fitted to the UV spectra of CVs by Wade. By applying such models to a sample of novae and nova-like CVs, we confirm that the limb-darkening effect must be taken into account when estimating mass transfer rates, especially for high-inclination systems. Important fitting degeneracies of the basic disk parameters are analyzed. Our simulations suggest that to reproduce the observations a revision of the temperature profile, at least in the innermost parts of the disk, seems to be required, and possibly the vertical distribution of the viscosity should be revised. In addition, an optically thin layer or an extended disk component should be considered. This component may be physically represented by a disk wind and/or a chromosphere. A physical description of the emission-line profiles may help to break the degeneracies that appear when only the continuum is analyzed. The average value of $\dot{M}$ found for nova-like systems is $\sim 9.3 \times 10^{-9} M_{\odot} \mathrm{yr}^{-1}$, while $\sim 1.3 \times$ $10^{-8} M_{\odot} \mathrm{yr}^{-1}$ is found for old classical novae. No clear evidence is found for either the presence or absence of a correlation between $\dot{M}$ and the orbital period. Such correlation analysis was performed for high accretion rate systems (15 nova-like systems and 10 old novae), but we were not able to find a well-defined correlation as found by Patterson. By measuring the equivalent width of the emission lines ( $\mathrm{C}$ IV $\lambda 1550$ and $\mathrm{He}$ II $\lambda 1640$ ) we found a lack of systems with low $\dot{M}$ and strong UV emission lines. A correlation between the equivalent width of such lines and the orbital inclination $(i)$ was also confirmed.
\end{abstract}

Key words: accretion, accretion disks — novae, cataclysmic variables — ultraviolet: general

\section{INTRODUCTION}

Nonmagnetic cataclysmic variables (CVs) are semidetached binary systems in which a Roche lobe-filling star transfers mass onto a white dwarf (WD), or primary, through an accretion disk. The secondary star is close to the main sequence for most CVs. Commonly, the disk is the most luminous element in the system, especially for nova-like systems and old classical novae. These CV types show a steady continuum radiation that comes from the disk's surface, which dominates the ultraviolet and visible spectra. They are the brightest type of CVs and have been widely used to study the properties of accretion disks in binary systems. For decades several disk models and methods of spectral synthesis have been developed trying to fit the observed spectra. In the first attempts the disk was approximated by a superposition of blackbody radiating rings that obeyed the standard temperature radial distribution (eq. [1]) (Lynden-Bell 1969; Lynden-Bell \& Pringle 1974; Tylenda 1977; Pringle 1981; La Dous 1989). In the case of an infinite disk the spectral energy distribution takes the wellknown form $f_{\lambda} \propto \lambda^{-2.33}$ (Lynden-Bell 1969). Subsequently, in order to reproduce the emission lines observed in the optical and UV spectra, the disk was assumed to be optically thin in the vertical direction, or an optically thin layer was added, keeping a homogeneous vertical structure (Tylenda 1981; Williams 1980; Williams \& Ferguson 1982; Williams \& Shipman 1988). The observed resonance lines in the UV may correspond to high-ionization states that are Doppler-widened. A P Cygni profile with a wide and deep absorption component is often present in systems with low orbital inclination, which would be evidence of the presence of a wind arising from the disk. The disk regions capable of driving a wind with the observed velocities $\left(\sim 3000-5000 \mathrm{~km} \mathrm{~s}^{-1}\right)$ would be the inner disk and/or the boundary layer (BL). Patterson $\&$ Raymond (1985) found a correlation between the He II ( $\lambda 4686$ ) emission-line intensity and the X-ray flux, but they did not find the same correlation for He II ( $\lambda 1640)$. The hybrid disk/chromosphere models by Ko et al. (1996) suggest that in order to explain the intensity of the emission lines, significant disk irradiation by the $\mathrm{BL}$ is necessary.

Other kinds of models have been developed in order to reproduce the shape of the continuum and absorption lines using the approximation of an optically thick disk. The first models of this type made use of Kurucz (1979) atmospheres. Although these models describe a few spectral details, they present problems when the observed data are fitted over a broad wavelength range (Wade 1984, 1988; Verbunt 1997). The latest generation of models are solved for the whole vertical structure of the disk, assuming that the disk properties vary much faster in the vertical than in the radial direction. Computing the model vertical structure for a given radial distance resembles computing a model stellar atmosphere; the approach thus gained the name "disk atmospheres." However, 
although this term is widely used, it is quite misleading, because it suggests that one considers only the outer layer (atmosphere) of a disk, while in fact the whole disk is being treated. Unlike the standard atmosphere models, these atmospheres take into account the dependence of gravity on depth and the internal generation of energy by viscous processes. Limb darkening is also taken into account (Kriz \& Hubeny 1986; Shaviv \& Wehrse 1986; Hubeny 1989, 1990a; Diaz et al. 1996; Wade \& Hubeny 1998). From the spectral synthesis of such disk atmosphere models, one may extract a few relations between the spectral features and the physical properties of the disk. These models follow the standard disk temperature profile, and therefore, the flux level and continuum shape are strongly coupled to the mass of the white dwarf, the mass accretion rate, and the orbital inclination. The absorption-line intensities and Balmer discontinuity are also affected (La Dous 1989). Due to these dependencies the continuum is widely used to estimate the mass transfer rate, although this estimate requires a measurement of the primary mass by independent methods. The orbital inclination also impacts the flux level and the slope (color) of the continuum emission. In particular, systems with high orbital inclination are strongly affected by limb darkening, as described by Diaz et al. (1996). Although the atmosphere disk models may be better able to describe the disk spectrum features, problems already found using classical atmosphere models (Wade 1988) do persist in the current disk atmosphere models (Diaz \& Hubeny 1999). However, these models have been effectively used to study disk properties and to estimate the basic parameters of CVs (e.g., Long et al. 1994; Diaz \& Hubeny 1999; Nadalin \& Sion 2001; Moyer et al. 2003; Hamilton \& Sion 2004; Engle \& Sion 2005; Godon et al. 2006). It is worth evaluating to which degree the estimates based on such models are accurate and reliable

In this work we have tested disk atmosphere models using a sample of $33 \mathrm{CVs}$, by modeling their UV spectra as observed by IUE and the Hubble Space Telescope (HST). We have used a controlled sample of CVs, with the aim of identifying future improvements to the current generation of models. This kind of analysis led us to investigate systematic trends of the model and to discover its weaknesses. We have also calculated $\dot{M}$ using a homogeneous method, trying to reproduce Patterson's (1984) relation between the accretion rate and orbital period using these revised $\dot{M}$ values. This relation is predicted by the most accepted CV evolution theories (e.g., Rappaport et al. 1983; Howell et al. 2001). Nevertheless, it has been tested and criticized as new $\dot{M}$ values have been calculated using different methods (e.g., Verbunt \& Wade 1984; King 1996). Warner (1987) suggested that this correlation would actually be the product of a selection effect caused by the strong dependence of the secondary star absolute magnitude $M_{V}$ on the orbital period (Patterson 1984). More recently, Rutten et al. (1992) calculated $\dot{M}$ for a set of six cataclysmic stars. They did not find such a correlation. However, it is difficult to derive statistically reliable conclusions from the small sample employed in that study. It is also relevant to analyze the stability of the disks in our sample, since there exists, according to the disk instability model (DIM; see Lasota 2001 for a review), conditions that limit the $\dot{M}$ values in order to avoid dwarf nova outbursts, and our disks should fulfill those conditions. We have made an instability analysis of our sample, and the results are shown in $\S 4.2 .1$.

In order to reach the goal of constraining $\dot{M}$, one needs to know, among other parameters, the value of $M_{1}, i$, and the distance $d$ for each system with reasonable accuracy. The UV spectra were collected from the IUE data archive and from STIS and GHRS spectrograph data in the $H S T$ database. The details of each parameter, their uncertainties, and the UV spectra used in this work are pre- sented in the next section. The disk model and spectral synthesis details, as well as the multiparametric optimization method employed, are described in $\S 3$. The results of the disk model test, including its reach and limitations, as well as the new $\dot{M}$ estimates, are presented in $\S 4$. A brief summary and perspectives are given in $\S 5$.

\section{THE DATA \\ 2.1. Spectral Data}

Only UV spectra were used in the presented simulations. We have compiled a sample of steady CVs with known orbital periods as large as possible that fulfill certain conditions. Systems with steady behavior such as nova-like systems and old classical novae were selected. Additional criteria were $m_{V}<17$ in order to have a reasonable signal-to-noise ratio with $H S T$ and $I U E$, and orbital inclination $i<80^{\circ}$ in order to avoid partial viewing of the inner disk. At least 10 years after the last eruption were required for selection of old novae. Some VY Scl-type nova-like systems in a high state were included in the sample. This search produces a set of $47 \mathrm{CVs}$. Table 1 shows a list of the systems with their observation dates and data sources.

The main source of UV spectra for this work was the IUE satellite database. The selected IUE spectra were observed with the SWP and LWP (or LWR) cameras on the same date, or on very close dates. We basically tried to fit the continuum shape. Therefore, a low dispersion and large aperture were chosen in order to obtain the widest spectral coverage, the best flux calibration, and the highest possible signal-to-noise ratio. In this operation mode, the IUE spectrograph had a resolution of $\sim 6 \AA(R=270$ at $1500 \AA)$. The spectral coverage using this instrument is $1150-3350 \AA$.

Spectra from the HST STIS were used for BK Lyn and V794 Aql. The data collected were observed with the grid G140L at first order and the FUV-MAMA detector. Those have a spectral resolution of $\sim 1 \AA$ and coverage from 1150 to $1700 \AA$.

\subsection{The System Parameters}

In order to generate a meaningful grid of models for each system, it is necessary to know with certain accuracy a few basic system parameters. These parameters were obtained from an extensive search in the published literature (Table 1). The parameters taken from previous studies are the primary mass $M_{1}$, the orbital inclination $i$, the distance $d$, and the orbital period $P_{\text {orb }}$. Furthermore, the spectra need to be corrected for interstellar extinction, since it strongly affects the UV band. The color excess $E(B-V)$ or the interstellar extinction coefficient $A_{V}$ was used, as well as the standard extinction law of Cardelli et al. (1989). The values found in that search through the literature are shown in Table 1, including an error estimate for each parameter if available. Those parameter values and their errors helped us to constrain the parameter space for which the grid of models for each system was generated. Knowledge of the parameter errors is essential in order to evaluate the errors in the $\dot{M}$ values. In that sense it is important to note that the uncertainty in the primary mass depends strongly on the orbital inclination, being lower for high-inclination and eclipsing systems. In the case of the distance, a multiplicity of methods are employed, but most of them have poor accuracy. For example, completely different distance values were found in the cases of HR Del and RR Pic. This fact points toward a strong dependency of the method on premises that were weak or not verified. As already mentioned, interstellar extinction strongly affects the UV spectra. For instance, the determination of $E(B-V)$ with an error between $\sim 0.02$ and 0.05 would produce an error in $\dot{M}$ between $\sim 30 \%$ and $50 \%$. 
TABLE 1

System Parameters Taken from the Literature for the Selected CVs

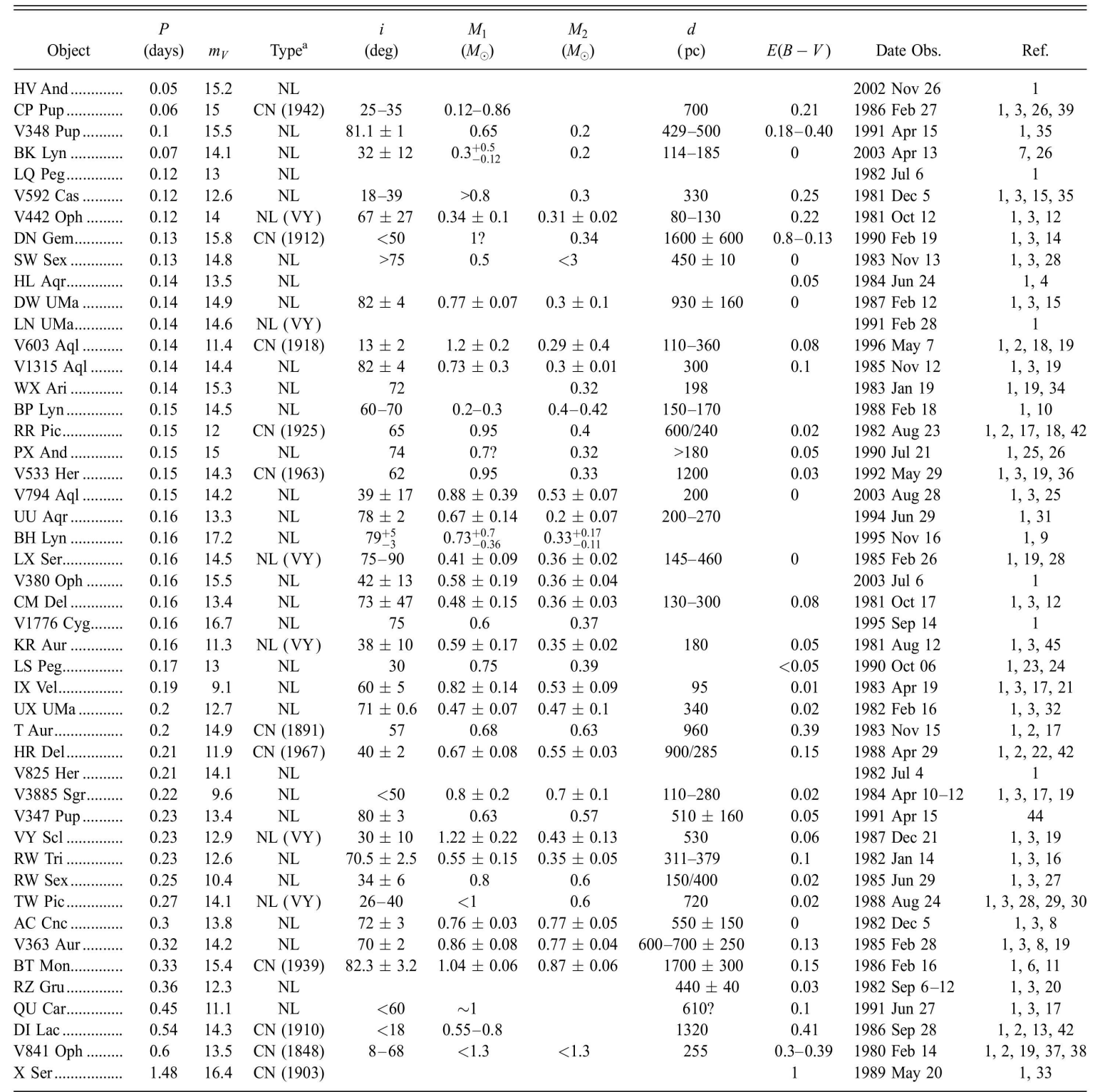

NoTES.-The columns are object name, orbital period $P$, apparent magnitude, orbital inclination, primary mass, secondary mass, interstellar extinction $E(B-V)$, and observation date.

a (NL) Nova-like system; (CN) classical nova.

REFERENCES.-(1) Ritter \& Kolb 2003; (2) Diaz \& Bruch 1997; (3) Bruch \& Engel 1994; (4) Hunger et al. 1985; (5) Taylor et al. 1998; (6) Downes \& Duerbeck 2000; (7) Dobrzycka \& Howell 1992; (8) Thoroughgood et al. 2004; (9) Hoard \& Szkody 1997; (10) Hoard \& Szkody 1996; (11) Smith et al. 1998; (12) Berriman et al. 1985; (13) Moyer et al. 2003; (14) Retter et al. 1999; (15) Araujo-Betancor et al. 2003; (16) McArthur et al. 1999; (17) Duerbeck 1999; (18) Barret 1996; (19) Meliani et al. 2000; (20) Stickland et al. 1984; (21) Long et al. 1994; (22) Selvelli \& Friedjung 2003; (23) Szkody et al. 1997; (24) Taylor et al. 1999; (25) Greiner 1998; (26) Retter \& Naylor 2000; (27) Prinja et al. 2003; (28) Rutten et al. 1992; (29) Buckley \& Tuohy 1990; (30) Mouchet et al. 1991; (31) Baptista et al. 1996; (32) Patterson 1984; (33) Weight etal. 1994; (34) Rodríguez-Gil etal. 2000; (35) Froming et al. 2003; (36) Rodríguez-Gil \& Martinez 2002; (37) Huber et al. 1998; (38) Diaz \& Ribeiro 2003; (39) Verbunt et al. 1997; (40) Eracleous et al. 1991; (41) Vande et al. 2003; (42) Warner 1987; (43) Greenstein \& Oke 1982; (44) Diaz \& Hubeny 1999; (45) Wade 1988. 


\section{METHODS}

\subsection{Disk Model}

The disk model used in this work has been widely described and discussed in the literature (Hubeny 1989, 1990a, 1990b; Diaz et al. 1996; Wade \& Hubeny 1998). This model describes a steady, Keplerian-rotating, geometrically thin, optically thick disk, which is divided into a set of concentric rings. Each of these rings radiates like a modified stellar atmosphere, such as mentioned in $\S 1$, and has an effective temperature following the standard disk model temperature law:

$$
T(R)=\left(\frac{3 G M_{1} \dot{M}}{8 \pi \sigma R_{1}^{3}}\right)^{1 / 4}\left(\frac{R_{1}}{r}\right)^{3 / 4}\left[1-\left(\frac{R_{1}}{r}\right)^{1 / 2}\right]^{1 / 4}
$$

(see Shakura \& Sunyaev 1973; Lynden-Bell \& Pringle 1974), where $R_{1}$ is the compact star radius, $\sigma$ is the Stefan-Boltzmann constant, and $G$ is the gravitational constant. The vertical structure of each ring is calculated assuming a plane-parallel atmosphere in hydrostatic equilibrium. The gravity is depth-dependent and arises from the vertical component of the compact star gravitational force. The depth dependence of the internal viscosity dissipation is parameterized through $\zeta$ as a power law, given by equations (2) and (3):

$$
\begin{gathered}
w(m)=\bar{w}(\zeta+1)\left(\frac{2 m}{\Sigma}\right)^{\zeta}, \\
\bar{w}=\frac{\left(G M_{1} R\right)^{1 / 2}}{\operatorname{Re}},
\end{gathered}
$$

where $\bar{w}$ is the depth-averaged kinematic viscosity, which can be expressed in terms of the Reynolds number Re (Lynden-Bell \& Pringle 1974; Williams \& Ferguson 1982), $m$ is the mass column density above a certain physical depth, and $\Sigma$ is the column density, which in the standard disk model is related to $\bar{w}, \dot{M}$, and $R_{1}$ as follows (for details see Hubeny 1989, 1990a, 1990b):

$$
\Sigma=\frac{\dot{M}}{3 \pi \bar{w}}\left[1-\left(\frac{R_{1}}{r}\right)^{1 / 2}\right] .
$$

The presence of a depth-dependent viscosity, expressed by equation (2), causes internal energy generation, implying a nonconservative radiative flux in the atmosphere interior.

The structure equations plus the radiative transfer equation are solved self-consistently in local thermodynamic equilibrium (LTE) by the complete linearization method, using the universal code TLUSTY $^{1}$ (Hubeny 1988; Hubeny \& Lanz 1995), which is able to compute stellar atmosphere as well as accretion disk models (in the past, a different variant called TLUSDISK [ Kriz \& Hubeny 1986; Hubeny 1990a, 1990b] was employed for the same problems, specifically dealing with disks). Following Diaz et al. (1996) only $\mathrm{H}, \mathrm{He}$, and continuum opacities were taken into account for the atmosphere structure calculation, along with free-particle processes and scattering. We also assumed that there was no radial radiative energy transfer and no disk irradiation by the BL or by the white dwarf.

Once the structure variables, like the temperature, density, and opacity, are calculated, the radiative transfer equation is solved again, including elements up to $Z=30$, for all frequencies in the

\footnotetext{
${ }^{1}$ See http://nova.astro.umd.edu.
}

selected UV band. The specific intensities are calculated by the general spectral synthesis program SYNSPEC (Hubeny et al. 1994), taking into account the temperature, pressure, and density effects on opacity and line broadening. A set of spectra is assembled for a range of $\mu=\cos i$ values. The final integrated spectrum is the sum of all ring spectra corrected for Keplerian velocity and inclination (for more details see Diaz et al. 1996; Wade \& Hubeny 1998).

Following others authors (e.g., Diaz et al. 1996; Diaz \& Hubeny 1999; Long et al. 1994), $\zeta=\frac{2}{3}$ and $R e=5000$ were used in this work as representative values. The resulting model spectra are not sensitive to these two parameters over a reasonable range of values. The internal radius of the disk was taken as equal to the WD radius, calculated with the mass-radius relation for carbon white dwarfs from Hamada \& Salpeter (1961). Eight log-spaced rings were used for each disk model. This scale produces an appropriate sampling of the regions where the radial gradients are larger. The external radius was limited by two conditions: the last ring cannot have a temperature lower than $8000 \mathrm{~K}$, or its radius cannot be larger than 0.7 times the primary Roche lobe radius. The former condition arises from the negligible contribution of the cooler regions in the UV. Those cool regions are possibly optically thin (Williams 1980). The latter condition is imposed by the tidal forces that disrupt the disk at larger radii (Osaki et al. 1993).

In order to estimate the WD contribution to the UV spectra of our sample, WD atmosphere model spectra were also calculated. These models consist of a hydrogen WD atmosphere with $\log g=8$. The atmosphere structure was calculated with the TLUSTY code (Hubeny 1988; Hubeny \& Lanz 1992), and its spectrum was synthesized using SYNSPEC (Hubeny et al. 1994).

\subsection{Multiparameter Optimization Method}

The optimization method used to constrain the parameters for each system is based on the generation of a grid of models in a three-dimensional space $\left(\dot{M}, M_{1}\right.$, and $\left.i\right)$. The mass and inclination are first constrained by the most probable values found in the literature (Table 1). Thus, the $M_{1}$ and $i$ intervals sweep a wide and suitable range for each parameter. These intervals are different for each system and depend on the parameter uncertainties. In order to cover a suitable volume in the parameter space, an $M_{1}$ minimum value of $0.4 M_{\odot}$ was set. In the same sense, an inclination minimum value of $20^{\circ}$ was used. For an initial guess of $\dot{M}$, the flux level of the observed spectrum is fitted by a simple blackbody accretion disk model (e.g., Wade 1984). The value calculated in this simple way is taken as a first guess for the disk atmosphere models. The $\dot{M}$ search interval ranges from 2 dex below that value to 2 dex above. In the case of the distance we are currently forced to fix values because of the degeneracy between the distance and disk model parameters. For each disk model a synthetic spectrum is calculated and compared with the observed one through the value of $\chi_{\text {red }}^{2}$, calculated as follows:

$$
\chi_{\mathrm{red}}^{2}=\frac{1}{l} \sum_{i=1}^{n} \frac{\left[y_{i}-y\left(\lambda_{i}\right)\right]^{2}}{\sigma_{i}^{2}},
$$

where $l$ is the number of degrees of freedom, $n$ is the number of the spectral elements, $y_{i}$ is the value of the flux of the observed spectrum in the spectral element $\lambda_{i}, y\left(\lambda_{i}\right)$ is the flux value of the synthetic spectrum in the same spectral element, and $\sigma_{i}$ is the observed spectrum's rms, estimated using a polynomial fit to the "line-free" continuum. All $\chi_{\text {red }}^{2}$ values in the three-dimensional space of the parameters were fitted by a smooth surface, and the 


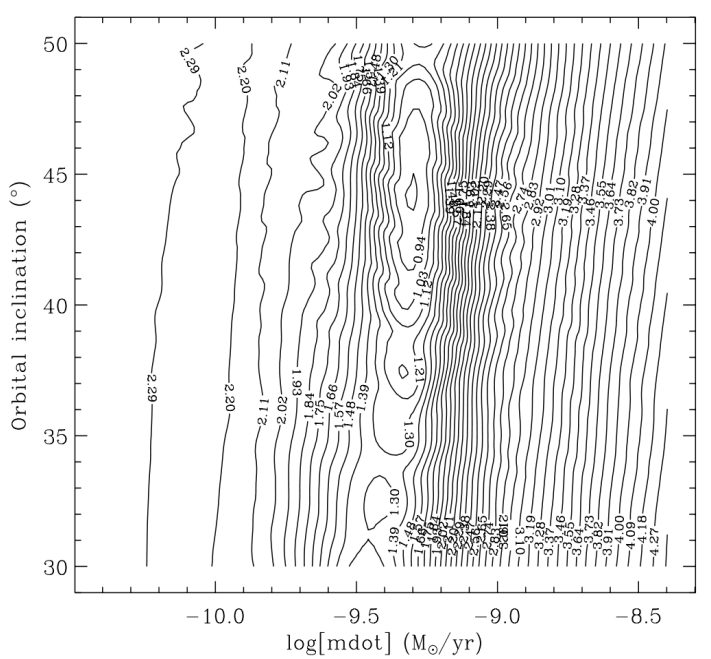

Fig. 1.-Sample of a $\log \chi_{\text {red }}^{2}$ surface for disk spectrum fitting. This sample corresponds to the fitting of the UV spectrum of KR Aur using $30^{\circ}<i<50^{\circ}$, $-10.4<\log \dot{M}<-8.4$, and $0.4 M_{\odot}<M_{1}<0.8 M_{\odot}$. A cut at $M_{1}=0.6 M_{\odot}$ is shown

minimum $\chi_{\text {red }}^{2}$ region was searched. The most probable $\dot{M}$ values for each system were those in the minimum $\chi_{\text {red }}^{2}$ region, within the most probable values for the other parameters obtained from the literature. Figure 1 shows an example of one such surface, indicating the most probable parameter region.

A four-dimensional space was also used, including the distance as a free parameter. However, when distance was let free, in most cases the model did not converge to a bounded minimum $\chi_{\text {red }}^{2}$ region, and it was impossible to fit the observed spectra within a reasonable four-dimensional parameter space $\left(\dot{M}, M_{1}, i\right.$, and $\left.d\right)$. These fitting problems have already been found in earlier works (Wade 1988). In the present work these problems suggest that improvements are needed in the calculation of model spectra. This point is discussed in more detail in $\S 4$.

The WD emission was not included as an additional free parameter; instead, the eventual contribution from a hot $(40,000 \mathrm{~K})$ WD was estimated for each object. We define disk-dominated CVs as those for which $\xi=f_{\mathrm{WD}} / f_{\text {disk }}<0.1$, where $f_{\mathrm{WD}}$ and $f_{\text {disk }}$ are the integrated spectral flux from 1500 to $3250 \AA$ for the WD and disk model, respectively.

\section{RESULTS}

\subsection{Model Behavior and Parameter Constraints}

\subsubsection{Analysis with Fixed Distance}

Using the method described in $\S \S 3.1$ and 3.2, the $\chi_{\text {red }}^{2}$ surfaces were analyzed at constant $M_{1}$ or $i$. Following this procedure, peculiar features, common behavior, and model families were identified in our sample of disks. Table 2 shows the search intervals used for each parameter for each system. When possible, the parameter region was bounded within the errors found in the literature (Table 1). Table 2 also shows the calculated values for $\dot{M}$ in $M_{\odot} \mathrm{yr}^{-1}$, and its dex error. The observed equivalent widths of the $\mathrm{C}$ IV $(\lambda 1550)$ and He II $(\lambda 1640)$ emission lines were also measured.

A characteristic shape is seen in all $\chi_{\text {red }}^{2}$ surfaces. They show a deep depression with the form of a narrow band (Fig. 1). This band basically corresponds to disk models that are able to reproduce the observed flux level (with that fixed distance). The quality of the model fit to the observed continuum shape is described by the de- tails within the band (see Fig. 1). It was also found that the band topology depends on the orbital inclination when we cut the threedimensional space at a fixed $M_{1}$. For systems with low inclination, the band is almost a straight vertical valley, with a small tilt toward higher accretion rate values. This is caused mainly by effect of the aspect factor $\cos i$ on the flux value. A decrement of this factor is roughly compensated for by a corresponding increment in the accretion rate. For systems with high orbital inclination we find that the band shape changes to a bent one, with a slope decreasing toward higher accretion rates and higher orbital inclinations. This effect is caused by the combined action of the steep cos $i$ factor change and limb darkening. In most systems with low inclination, the $\chi_{\text {red }}^{2}$ valley depth is almost constant, but for systems with high inclination, the bottom tends to sink for larger values of the inclination or to form a small local minimum around some particular inclination point. The minimum band at a fixed inclination value is not absolute; i.e., for different values of $M_{1}$, such a minimum migrates. As expected, for larger $M_{1}$ values the band moves toward lower values of $\dot{M}$, and an eventual minimum moves to higher orbital inclinations. This happens due to the combined action of the three parameters to maintain the flux level and color. It is found that the $\chi_{\text {red. }}^{2}$ value decreases for cooler disks (i.e., lower values for $M_{1}$ and $\dot{M}$ [eq. (1)]) but does not always achieve an absolute minimum value in the three-dimensional space $\left(M_{1}, \dot{M}\right.$, and $\left.i\right)$. This behavior indicates that the disk models used here, in most cases, generate spectra that are too blue in comparison with the observed data. This problem, which has already been found using classical atmosphere models, may suggest that extra sources of continuum light are possibly being neglected and/or that the radial temperature law is not correct. This is the reason why it is not possible to adjust these three parameters $\left(M_{1}, \dot{M}\right.$, and $\left.i\right)$ simultaneously without constraints. As an example, values of $i$ and $M_{1}$ were limited in order to constrain the $\dot{M}$ values.

After performing the analysis, we have convinced ourselves that the absolute $\chi_{\text {red }}^{2}$ values lack statistical meaning in this context. Therefore, $\chi_{\text {red }}^{2}$ was used to compare models only. Their numerical values are high because of at least two effects: (1) The uncertainty per resolution element is estimated from the residuals of a low-order fit to selected line-free continuum regions. Unfortunately, these regions also contain lines which do not behave like noise. An average residual (rms) is used as $\sigma(\lambda)$ in the $\chi_{\text {red }}^{2}$ calculation. The rms is in fact different from the pure noise $\sigma(\lambda)$ value at each wavelength. (2) As pointed out in the discussion, the model spectra are not capable of describing the line profiles and intensities. On the other hand, in many cases the model spectra contain lines that do not appear in the observations, thus increasing $\chi_{\text {red. }}^{2}$. The description of the upper disk atmosphere was found to be oversimplified or inaccurate, but there are also expected differences in the actual chemical abundances and effective gravities.

Using the calculated $\dot{M}$ values for the target sample, we have performed a search for its correlation with other system parameters. Figure 2 shows the accretion rate as a function of the orbital period. In contrast with the well-defined correlation derived by Patterson (1984), a higher dispersion in the $\dot{M}-P_{\text {orb }}$ diagram is found. The values are also systematically higher than those calculated by Patterson and more in agreement with those calculated by Rutten et al. (1992). The weak correlation between $\dot{M}$ and $P_{\text {orb }}$ found in this work is expressed by equation (6). This relation is less steep than the classical Patterson relation. These features are mostly due to the special sample chosen for the present work, which is limited to high accretion rate systems with bright disks. Another correlation revisited was that between the absolute magnitude $M_{V}$ and the accretion rate. The absolute magnitudes corrected for inclination effects and limb darkening were calculated 
TABLE 2

Accretion Mass Rates Calculated for 33 CVs Using the Atmosphere Disk Model and a Fixed Distance

\begin{tabular}{|c|c|c|c|c|c|c|c|c|}
\hline Object & $\begin{array}{c}P_{\text {orb }} \\
\text { (days) }\end{array}$ & $\begin{array}{c}M_{1} \text { Range } \\
\left(M_{\odot}\right)\end{array}$ & $\begin{array}{c}i \text { Range } \\
(\mathrm{deg})\end{array}$ & $\begin{array}{l}\text { Distance } \\
\quad(\mathrm{pc})\end{array}$ & $\begin{array}{c}\dot{M}(\mathrm{BB}) \\
\left(M_{\odot} \mathrm{yr}^{-1}\right)\end{array}$ & $\begin{array}{c}\log \dot{M} \\
\left(M_{\odot} \mathrm{yr}^{-1}\right)\end{array}$ & $\xi$ & $\eta$ \\
\hline CP Pup ................................. & 0.06 & $0.5-0.9$ & $20-40$ & 700 & $2.29 \times 10^{-9}$ & $-8.74(23)$ & 0.02 & 0.79 \\
\hline 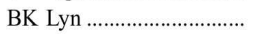 & 0.07 & $0.25-0.7$ & $20-45$ & 150 & $3.29 \times 10^{-10}$ & $-9.75(18)$ & 4.86 & 0.54 \\
\hline 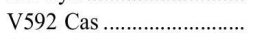 & 0.12 & $0.9-1.3$ & $15-40$ & 330 & $7.35 \times 10^{-9}$ & $-8.20(20)$ & 0.02 & 0.86 \\
\hline 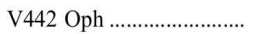 & 0.12 & $0.3-0.7$ & $50-80$ & 130 & $3.13 \times 10^{-9}$ & $-8.51(55)$ & 0.21 & 0.99 \\
\hline 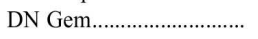 & 0.13 & $0.8-1.2$ & $30-60$ & 1600 & $4.11 \times 10^{-9}$ & $-8.72(39)$ & 0.02 & 0.46 \\
\hline 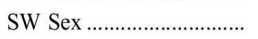 & 0.13 & $0.4-0.8$ & $62-82$ & 450 & $4.23 \times 10^{-9}$ & $-8.75(25)$ & 0.10 & 0.42 \\
\hline 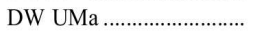 & 0.14 & $0.5-1.0$ & $65-85$ & 930 & $1.40 \times 10^{-8}$ & $-8.14(18)$ & 0.05 & 0.52 \\
\hline 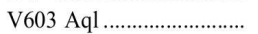 & 0.14 & $1.0-1.4$ & $5-25$ & 235 & $2.10 \times 10^{-9}$ & $-8.85(16)$ & 0.02 & 0.67 \\
\hline 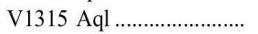 & 0.14 & $0.5-0.9$ & $75-85$ & 300 & $1.24 \times 10^{-9}$ & $-8.90(62)$ & 0.42 & 1.02 \\
\hline RR Pic ............................... & 0.15 & $0.75-1.15$ & $55-75$ & 250 & $6.68 \times 10^{-9}$ & $-8.27(40)$ & 0.02 & 0.80 \\
\hline 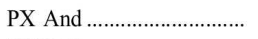 & 0.15 & $0.5-0.9$ & $64-84$ & 200 & $2.56 \times 10^{-10}$ & $-9.52(20)$ & 0.98 & 1.18 \\
\hline 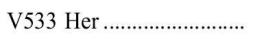 & 0.15 & $0.75-1.15$ & $55-75$ & 1200 & $1.25 \times 10^{-8}$ & $-8.05(15)$ & 0.01 & 0.71 \\
\hline 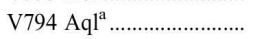 & 0.15 & $0.8-1.2$ & $25-55$ & 200 & $8.84 \times 10^{-11}$ & $-10.29(38)$ & 1.39 & 0.58 \\
\hline 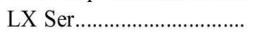 & 0.16 & $0.3-0.7$ & $70-85$ & 340 & $1.37 \times 10^{-9}$ & $-8.70(30)$ & 0.44 & 1.46 \\
\hline 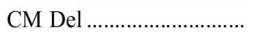 & 0.16 & $0.3-0.7$ & $60-85$ & 280 & $9.42 \times 10^{-9}$ & $-8.38(43)$ & 0.10 & 0.44 \\
\hline 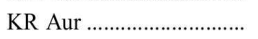 & 0.16 & $0.4-0.8$ & $30-50$ & 180 & $4.83 \times 10^{-10}$ & $-9.35(29)$ & 0.20 & 0.92 \\
\hline 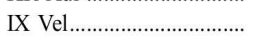 & 0.19 & $0.7-1.0$ & $45-70$ & 95 & $1.00 \times 10^{-8}$ & $-8.16(20)$ & 0.02 & 0.69 \\
\hline UX UMa & 0.2 & $0.4-0.8$ & $60-80$ & 340 & $1.69 \times 10^{-8}$ & $-7.85(15)$ & 0.02 & 0.84 \\
\hline 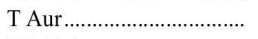 & 0.2 & $0.5-0.9$ & $50-70$ & 960 & $3.10 \times 10^{-8}$ & $-7.64(25)$ & 0.01 & 0.74 \\
\hline HR Del.................................. & 0.21 & $0.5-0.9$ & $30-50$ & 285 & $1.46 \times 10^{-8}$ & $-7.99(25)$ & 0.01 & 0.70 \\
\hline 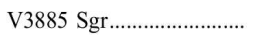 & 0.22 & $0.6-1.0$ & $30-50$ & 195 & $1.31 \times 10^{-8}$ & $-8.03(39)$ & 0.01 & 0.71 \\
\hline 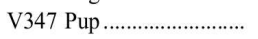 & 0.23 & $0.5-0.8$ & $65-85$ & 510 & $1.05 \times 10^{-8}$ & $-8.22(26)$ & 0.06 & 0.57 \\
\hline 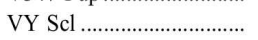 & 0.23 & $1.0-1.4$ & $20-40$ & 500 & $6.19 \times 10^{-9}$ & $-8.28(31)$ & 0.01 & 0.85 \\
\hline RW Tri ................................... & 0.23 & $0.4-0.8$ & $60-80$ & 345 & $6.17 \times 10^{-9}$ & $-8.33(25)$ & 0.05 & 0.76 \\
\hline 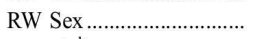 & 0.25 & $0.7-1.1$ & $25-45$ & 290 & $1.25 \times 10^{-8}$ & $-8.00(20)$ & 0.01 & 0.80 \\
\hline 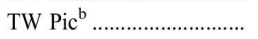 & 0.27 & $0.5-0.9$ & $25-26$ & 720 & $3.08 \times 10^{-9}$ & $-8.65(32)$ & 0.02 & 0.73 \\
\hline $\mathrm{AC} \mathrm{Cnc}$ & 0.3 & $0.5-1.0$ & $60-80$ & 550 & $1.17 \times 10^{-9}$ & $-9.02(29)$ & 0.16 & 0.82 \\
\hline 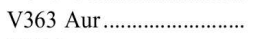 & 0.32 & $0.7-1.1$ & $60-80$ & 650 & $5.72 \times 10^{-9}$ & $-8.34(17)$ & 0.03 & 0.80 \\
\hline 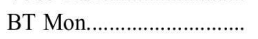 & 0.33 & $0.8-1.2$ & $65-84$ & 1700 & $4.24 \times 10^{-8}$ & $-7.71(33)$ & 0.02 & 0.46 \\
\hline 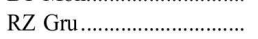 & 0.36 & $0.8-1.2$ & $10-35$ & 440 & $2.42 \times 10^{-9}$ & $-8.71(26)$ & 0.02 & 0.81 \\
\hline 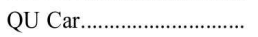 & 0.45 & $0.8-1.2$ & $35-65$ & 500 & $1.19 \times 10^{-7}$ & $-7.26(32)$ & 0.00 & 0.46 \\
\hline 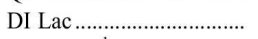 & 0.54 & $0.5-1.0$ & $5-30$ & 1318 & $8.01 \times 10^{-8}$ & $-7.22(12)$ & 0.00 & 0.75 \\
\hline 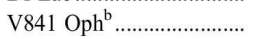 & 0.6 & $1.0-1.4$ & $30-70$ & 255 & $1.21 \times 10^{-9}$ & $-9.03(45)$ & 0.02 & 0.77 \\
\hline
\end{tabular}

NOTES.-The blackbody disk $\dot{M}$ value and the ranges in $M_{1}$ and $i$ used in the fitting are shown, as well as the adopted distance. Also shown is the ratio between a $40,000 \mathrm{~K}$ WD flux and a disk flux in the UV $(\xi)$ (see text) and the ratio between the $\dot{M}$ values calculated with the atmosphere disk model and the BB $\operatorname{approach}(\eta)$.

Values calculated using the HST STIS spectrum in the high state.

${ }^{b}$ Lower limit for $\dot{M}$ due to an upper limit on $M_{1}$.

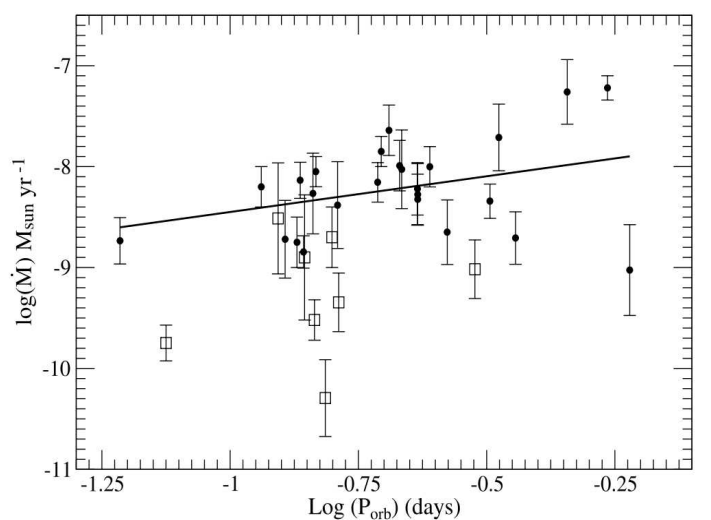

FIG. 2.-Dependence of the mass accretion rate $\dot{M}$ (calculated using fixed distances) on orbital period for quiescent nova and nova-like CVs. The best linear fit is shown and is expressed by eq. (6). The circles show disk-dominated CVs, while the squares represent objects with an eventual contribution from the WD. The latter were not considered in the linear fit. using the Warner (1986) approximation. As expected, the $M_{V}$ values show a strong correlation with $\dot{M}$ (Fig. 3). A simple linear fit leads to equation (7):

$$
\begin{gathered}
\dot{M}=1.82_{-0.86}^{+1.64} \times 10^{-8} P_{\mathrm{orb}}^{0.7 \pm 0.40} M_{\odot} \mathrm{yr}^{-1}, \\
\dot{M}=1.69_{-0.71}^{+1.26} \times 10^{(-0.34 \pm 0.05) M_{V}-7} M_{\odot} \mathrm{yr}^{-1} .
\end{gathered}
$$

Both equations (6) and (7) were derived using the disk-dominated subsample, and their correlation coefficients are 0.37 and 0.78 , respectively.

For completeness and comparison, the values calculated with blackbody standard disk models were also included in Table 2 . The computed blackbody fluxes were corrected for limb darkening in first order using the Eddington approximation (e.g., Paczyński \& Schwarzenberg-Czerny 1980). The ratio $\eta$ between these values and the atmosphere disk results was also calculated. On average, the disk atmosphere models reveal slightly lower mass transfer rates when compared to limb-darkened blackbody disks $(\sim 75 \%)$. However, individual disk models can be very different, depending on the particular observed continuum shape. Due to limb darkening the continuum is formed in higher and cooler regions in the disk 


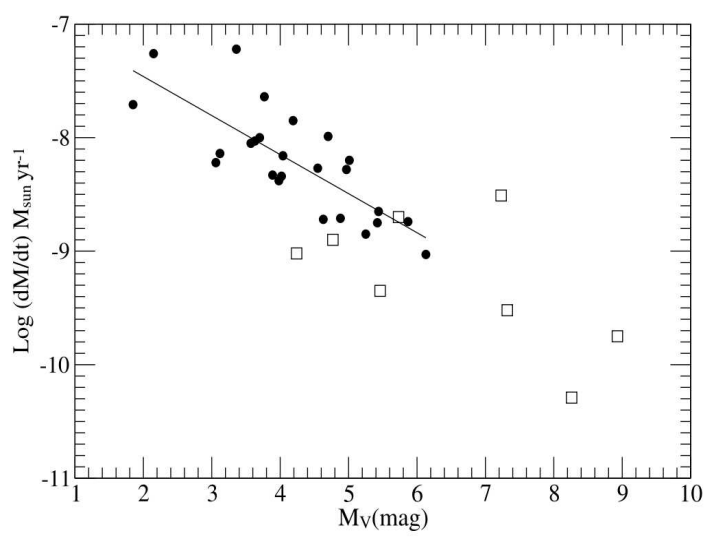

FIG. 3.-Dependence of accretion mass rate $\dot{M}$ (calculated using fixed distances) on the absolute magnitude of the disk $M_{V}$ (disk) corrected for inclination effects. The best linear fit is shown and is given by eq. (7). The circles show disk-dominated CVs, while the squares represent objects that may show an eventual contribution from the WD. The squares were not considered in the linear fit.

atmosphere, and thus produces a less intense and redder observed spectrum, which can also be interpreted as a lower $\dot{M}$ if the limb darkening is not taken into account.

\subsubsection{Analysis with Variable Distance}

The distance was scaled as a free parameter for each model in the grid to values that allowed the matching of the observed flux level. The calculated $\chi_{\text {red }}^{2}$ values were then analyzed in a fourdimensional space $\left(M_{1}, M, i\right.$, and $\left.d\right)$ in order to search for an absolute minimum. For most cases this search was not successful. The common behavior of the $\chi_{\text {red }}^{2}$ slices leads to a simple conclusion: there is not a unique set of parameters capable of fitting the UV spectra within the parameter frame using this disk model. The synthetic spectra are too blue, and the models improve toward cooler or more inclined disks without achieving a minimum. Nevertheless, we found a few systems where there is a reasonably well defined $\chi_{\text {red }}^{2}$ minimum region. In some cases the minimum $\chi_{\text {red }}^{2}$ parameters are far from those found in the literature. In particular, inconsistent values for the distance are inferred. In addition, the

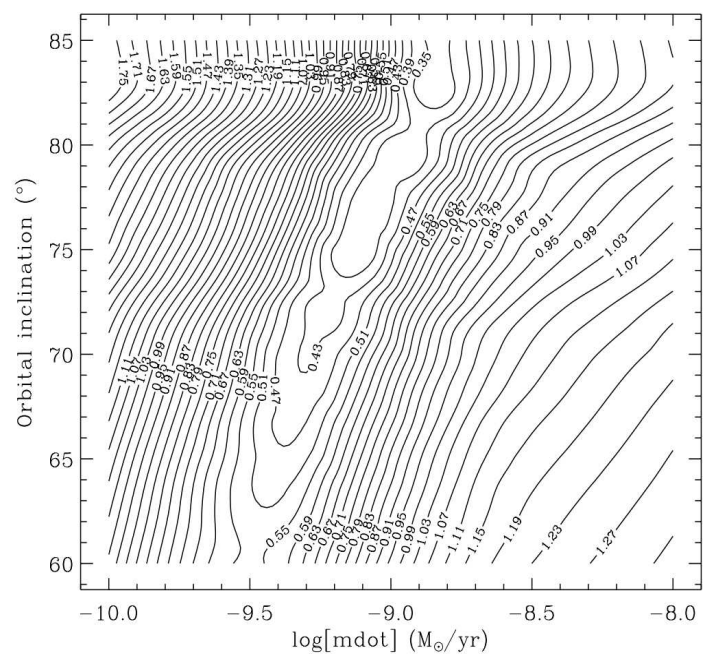

TABLE 3

Best Solutions Found Using Free Scaling of Distance

\begin{tabular}{clllll}
\hline \hline Object & \multicolumn{1}{c}{$\begin{array}{c}\dot{M} \\
\left(M_{\odot} \mathrm{yr}^{-1}\right)\end{array}$} & $\begin{array}{c}M_{1} \\
\left(M_{\odot}\right)\end{array}$ & $\begin{array}{c}i \\
(\mathrm{deg})\end{array}$ & $\begin{array}{c}d \\
(\mathrm{pc})\end{array}$ & $\begin{array}{c}d_{\text {lit }}{ }^{\mathrm{a}} \\
(\mathrm{pc})\end{array}$ \\
\hline V592 Cas ............ & $7.08 \times 10^{-10}$ & 0.95 & 40 & 130 & 330 \\
V442 Oph .......... & $6.00 \times 10^{-9}$ & 0.4 & 67 & 130 & 130 \\
CM Del ............... & $2.00 \times 10^{-9}$ & 0.65 & 82 & 147 & 215 \\
\hline
\end{tabular}

${ }^{\text {a }}$ Mean distance from the literature for comparison.

$\chi_{\text {red }}^{2}$ minimum regions are actually open regions, similar to the bands found in the fixed-distance case (Fig. 4). In fact, as already seen in the previous section, this feature is caused by the degeneracy between parameters that arises when one tries to describe only the continuum shape.

Due to the noise in the observed spectra, and the inability of the current model to describe the emission lines, many significant spectral features cannot be used to constrain the models. This leads to the strong degeneracy among the parameters within this disk model. Figure 4 shows two examples of $\chi_{\text {red }}^{2}$ surfaces with free distance scaling for $\mathrm{CM}$ Del. This figure shows that the region of minimum $\chi_{\text {red }}^{2}$ values is very close to the high-inclination limit, $\sim 85^{\circ}$, with $\log \dot{M}$ between -9 and -8.7 and $M_{1} \sim 0.6-0.7 M_{\odot}$. For this particular fit, the spectrum had to be scaled to a distance of only $147 \mathrm{pc}$. That distance is still reasonable when compared to the values found in the literature. But in most cases the distance for which the spectrum has to be scaled is too low in comparison with the literature values. On the other hand, the $M_{1}$ values are systematically smaller than the values from other studies. Only for three cases was a reasonable set of parameters obtained using the freedistance method: the nova-like systems V442 Oph, CM Del, and V592 Cas. Table 3 shows the best-fit parameter values, including the distance. For most of the systems it was impossible to find a reduced parameter space when the distance was left as an unconstrained parameter.

\subsubsection{The WD Contribution}

For every system the ratio $\xi=f_{\mathrm{WD}} / f_{\text {disk }}$ was calculated using the WD model described in $\S 3$.2. The results are shown in the last

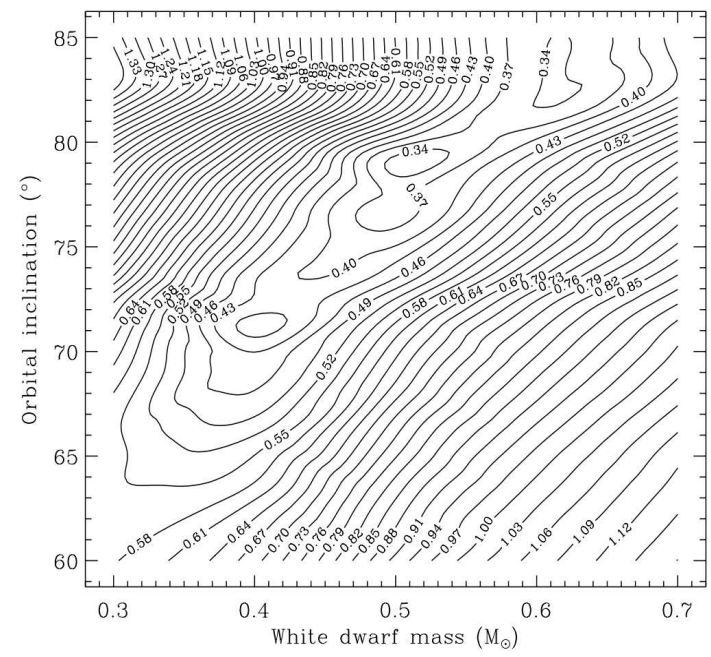

FIG. 4.- $\log \chi_{\text {red }}^{2}$ surfaces for the spectral fit of CM Del. A free scaling of distance was employed. Left, Cut of the three-dimensional parameter space at $M_{1}=$ $0.7 M_{\odot} ;$ right, cut at $\log \dot{M}=-8.66 M_{\odot} \mathrm{yr}^{-1}$. 
column in Table 2. It is easy to see that in most cases even a hot $(40,000 \mathrm{~K}) \mathrm{WD}$ does not contribute considerably in the UV in such a high- $\dot{M}$ sample. But there are cases (10 nova-like systems) for which an eventual contribution of a hot WD should not be ignored. Systems with an eventual contribution of the WD belong to the SW and VY nova-like subclasses (V442 Oph, V1315 Aql, PX And, LX Ser, KR Aur, V794 Aql, and AC Cnc). The latter subtype of CV presents variability and sporadic low states. This could be caused by a spontaneous decrease in the accretion rate in the disk, which could unveil the white dwarf (e.g., Knigge et al. $2000,2004)$. Interestingly, BK Lyn is a UX-type nova-like system (Ritter \& Kolb 2003), ${ }^{2}$ and its $\xi$-value was found to be 0.16 .

\subsection{Discussion \\ 4.2.1. Disk Stability}

Systems with no record of dwarf nova activity, like the systems in our sample, should maintain a relatively high mass transfer rate, above the critical mass transfer rate for disk instability outbursts. In that sense the mass transfer rates derived using the disk atmosphere models are consistent with the absence of dwarf nova-type outbursts in recent broadband photometry of our targets. The disk instability model predicts that the critical local mass transfer rate is a function of radius and $M_{1}$, with a weak dependence on the $\alpha$ viscosity parameter (e.g., Lasota 2001). If the disk is stable at the outer parts, it should be stable as a whole. Figure 5 shows that virtually all analyzed disks are above the stability curve.

It is important to take into account the influence of the parameter errors on that conclusion. Any change in the parameters that would modify the flux level or color would produce a change in $\dot{M}$ that could put the system in the instability zone. For example, the distance is one of the most inexact parameters; a lower value of distance would produce a lower value of $\dot{M}$, and some systems could fall into the instability zone. The adopted disk radius definition would also influence the present instability analysis. If the disk is larger, then the minimum $\dot{M}$ for stability increases and could eventually reach our $\dot{M}$ values. In this case we also should consider that the relation used to calculate the instability curves in Figure 5 does not take into account the influence of the hot spot and irradiation on the critical $\dot{M}$. Both effects lower that value, which tends to assure the stability of most of the disks in the sample. Considering the errors in $\dot{M}$, some systems may be close to the instability limit (e.g., V794 Aql, DN Gem, V442 Oph, and V1315 Aql). At least two of these systems are known to have VY Scl-type low states. During the mass transfer decrease toward their low states they would certainly be found below the critical mass transfer curve, according to our simulations. Hameury \& Lasota (2002) have proposed an explanation for the absence of disk instabilities during such reduced mass transfer events on the basis of the presence of magnetic white dwarfs in these systems, with magnetic moments comparable to those found in intermediate polars.

\subsubsection{Comments on Peculiar Systems}

We have found some intriguing peculiarities in a few objects of our sample. For example, the BT Mon spectra could not be even roughly modeled by any set of parameters. All models are far too blue. The models for TW Pic are also too blue. This system shows strong emission lines and has a low orbital inclination; this behavior may suggest an error in the inclination determination or an optically thin disk. Opposing that, for T Aur every model generated within parameter range is too red, unlike what happened

\footnotetext{
${ }^{2}$ For an updated version see RKcat7.6.
}

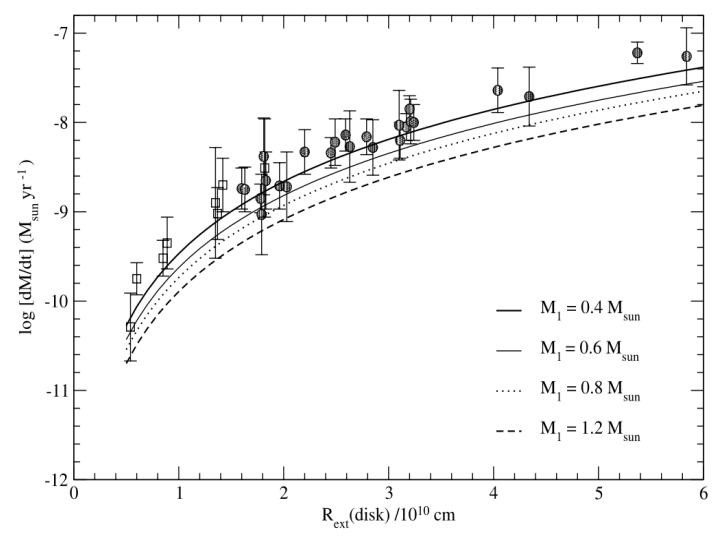

FIG. 5.- Mass transfer rate as a function of disk radius for all disks in the sample. The curved lines correspond to the critical $\dot{M}$ for stable mass transfer, considering white dwarf masses ranging from 0.4 to $1.2 M_{\odot}$. The circles correspond to disk-dominated CVs, while there may be some contribution from the white dwarf to the UV emission in the systems plotted with squares (see text).

with most of the disks in the sample. It may suggest an error in the $E(B-V)$ estimation.

There is no way to fit the observed spectra of BK Lyn with this accretion disk model; every model computed has a weak flux level or a too-red continuum. Considering the $M_{1}$ value, the flux level, the strong emission lines, and the low orbital inclination, it is possible that this system has an optically thin disk with a very low accretion rate.

V794 Aql presents strong emission lines in both spectra collected for this work: the low state (IUE) and also the high state (STIS). Other spectra taken with IUE in 1994 show V794 Aql in an even higher state and show emission lines weaker than previous spectra. Apparently this is a noneclipsing system, which would discard the explanation of a flat continuum and emission lines caused by high inclination. Its variability and the spectrum appearance suggest an unstable and optically thin disk (Honeycutt et al. 1994). In addition, the $\dot{M}$ calculated here seems too low for a system above the period gap.

We could not find any estimates of $M_{1}$ and $i$ for RZ Gru, but because of the deep P Cygni profiles we suspect that this system has a low orbital inclination. The WD mass assumed for this work is $1 M_{\odot}$. Due to these unconstrained values, the calculated $\dot{M}$ values have a considerable uncertainty.

The distance used for DI Lac is $1300 \mathrm{pc}$; this value was calculated using the $M_{V}$ value from Warner (1987). Moyer et al. (2003), using the HST STIS spectrum, fitted the same atmosphere disk model, but their best model leads to a distance of $\sim 2000-2500 \mathrm{pc}$. Nevertheless, by using the same spectrum and disk model, we found that such estimates for the distance seem incompatible with their values for the accretion rate.

\subsubsection{Comments on the Disk Model Spectra}

The simulations presented in this work indicate that the current generation of accretion disk models cannot yet reproduce completely the spectrum shape of CVs in the UV. It was shown that in this disk model we still find a flux/color dichotomy. This effect has been found already by Wade (1988), who used concentric rings of classical stellar atmospheres. He concluded that the models that could match the continuum shape appear to be $\dot{M} \sim 2$ dex below the models that could match the flux level.

In our study we left $\dot{M}, M_{1}$, and $i$ free within suitable intervals and constrained $d$ to a fixed value. In this case we still found that 


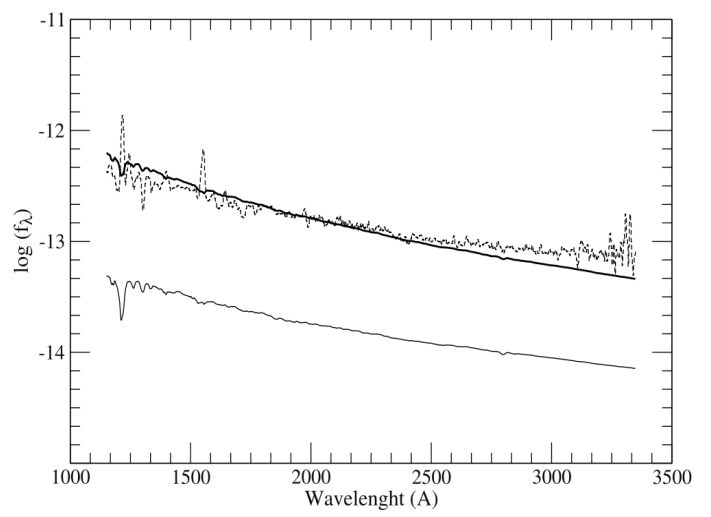

FIG. 6.-IUE UV spectrum of UX UMa (dotted line), the atmosphere disk model spectrum that best fit the flux level (thick solid line), and the atmosphere disk model that best fit the continuum shape (thin solid line). The former model was calculated with $M_{1}=0.8 M_{\odot}, \dot{M}=1.51 \times 10^{-8} M_{\odot} \mathrm{yr}^{-1}$, and $i=78^{\circ}$, while the latter was calculated with $M_{1}=0.4 M_{\odot}, \dot{M}=5.49 \times 10^{-9} M_{\odot} \mathrm{yr}^{-1}$, and $i=80^{\circ}$.

the best models are too blue. Figure 6 shows the IUE spectrum of UX UMa together with the model that matches the flux level and the model that matches the color. The former is bluer than the observed spectrum by a factor of $\sim 2$, and the second is $\sim 10$ times dimmer in flux level. On the other hand, there are systems (a few of them) for which the dichotomy is small, for instance, in the fit of the V442 Oph spectra. In order to evaluate quantitatively that dichotomy in our sample, the model that reproduces the flux level was matched to the observed spectrum at $1480 \AA$, and the flux ratio at $3000 \AA$ was measured for each system. The histogram in Figure 7 shows how that ratio, calculated as $\log \left(f_{\text {obs }}^{3000} / f_{\text {model }}^{3000}\right)$, is distributed in the sample. There is a high dispersion of values peaking close to the average at $\sim 0.3$ dex. These values are not much different from those found by Wade (1988). This can be explained if we realize that the disk atmosphere structure still resembles a stellar atmosphere because the dissipation of viscous energy occurs at high optical depths. Even for small $\zeta$-values the outer layers in the atmosphere only transport the energy generated at the inner region. A similar situation happens in a stellar atmosphere. A viscosity law with a very small $\zeta$-value will produce energy at more superficial layers. This leads to increased viscosity and dissipation in lowdensity regions, which in its turn, without a consistent model of dissipation in those conditions, will bring convergence and instability problems within a local thermodynamic equilibrium framework (Shaviv \& Wehrse 1986; Hubeny 1990a, 1990b).

One possible path to improving the fits to the data in the context of the disk models would be to adjust the place in the atmosphere where the dissipation of viscous energy occurs, increasing the amount of dissipation in the upper atmosphere. This, however, is beyond the scope of the present work.

An important factor affecting the spectrum shape is the adopted radial temperature law (eq. [1]). A good alternative to repair the flux/color problem could be the use of a nonstandard law. Different temperature laws have been studied (Orosz \& Wade 2003), and it has been shown that a less steep law better reproduces the observed spectra. But the physical mechanism responsible for flattening the temperature profile is not yet well known It is possible that a different temperature law is caused by mass loss in a wind (e.g., Knigge 1999) or disk irradiation by the BL. However, there are observational constraints available for guiding experiments with new radial temperature distributions. Eclipse-mapping results suggest that the radial temperature profiles are not too dif-

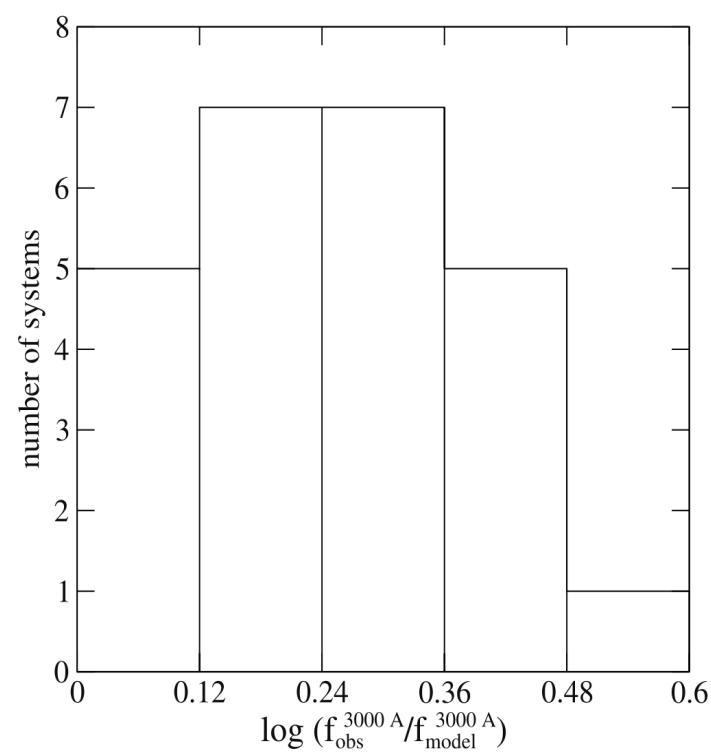

FIG. 7.-Distribution of the color/flux dichotomy in the disk-dominated subsample. The dichotomy is evaluated as $\log \left[f_{\text {obs }}(3000 \AA) / f_{\text {model }}(3000 \AA)\right]$, with the model and the observed fluxes matched at $1480 \AA$.

ferent from the standard $T \propto R^{-3 / 4}$ law (e.g., Rutten et al. 1992; Linnell et al. 2007). The importance of including an extended optically thin component in the accretion disk model is evident from the strong emission lines and the P Cygni profiles observed in the UV spectra. The P Cygni profiles, especially for $\mathrm{C}$ IV and $\mathrm{N} \mathrm{v}$, present a deep absorption component with minimum flux at relatively low velocities when compared to OB stars (e.g., Córdova \& Howarth 1987). The correlation between the equivalent width of the emission lines and the orbital inclination was confirmed, and, in addition, it was found that systems with low $\dot{M}$ do not show strong emission lines. This underlines the close relation between the disk model and the emission-line flux, which shows the need to include an extended optically thin region in the next generation of models.

As already mentioned, the degeneracy present in the solutions is due to a strong correlation among the variables within the model. Also, there are too many parameters to be fit $\left(M_{1}, \dot{M}, i\right.$, and eventually $d$ ), considering that mostly the continuum shape and level are analyzed. Furthermore, the other unknown parameters, $E(B-V)$, $\zeta$, and Re, were kept fixed. Unlike $E(B-V)$, however, it can be shown that the variation of those last two quantities does not strongly affect the spectrum appearance. It is important to remember that, due to the degeneracies between the parameters, the values calculated here strongly depend on each other. In other words, in order to calculate $\dot{M}$ we were forced to limit the values of the rest of parameters $\left(M_{1}\right.$ and $\left.i\right)$ within the literature values.

Two degrees of correlation exist among the parameters. A stronger correlation exists between $M_{1}$ and $\dot{M}$, and a weaker correlation between these quantities and the orbital inclination. These correlations come from the disk model itself, as much as from the atmosphere structure and spectral synthesis. These correlations are linked to the standard effective temperature distribution (eq. [1]) used as boundary condition for the atmosphere structure. Because of the dependence of the radial profile on $M_{1}$ and $\dot{M}$ (taking into account the mass-radius relation for the WD), it is difficult to uncouple these parameters, since the reddening caused by a smaller $M_{1}$ can be compensated for by a higher accretion rate. A weaker 
correlation between $M_{1}$ and $i$ or between $\dot{M}$ and $i$ is evident from Figure 4, unlike what happens in the $\left(M_{1}, \dot{M}\right)$-plane, where the depth of the valley is almost constant. Limb darkening could be the main cause of such weak uncoupling between those parameters, since it strongly depends on the orbital inclination. However, since the changes of concavity in the continuum shape are too small and the observed spectral noise is high, it is difficult to disentangle those parameters completely. If the accretion disk model included the necessary physics to describe the emissionline profiles and the optically thin emission in the continuum, we could eventually break down those degeneracies.

In a different analysis, the distance $d$ was left completely free, being scaled in order to match the spectrum level. A search for a complete set of parameters that could fit the spectra was performed for the whole sample. However, this search was successful for only a few systems, and within this subset, in only three cases were the parameters derived comparable to those found in previous works. These differences appear in a different degree for every system.

\section{SUMMARY AND CONCLUSIONS}

A sample of $33 \mathrm{CVs}$ with stable disks (nova-like systems and old classical novae) was selected in order to test the current generation of accretion disk models. In addition, using this model, the accretion rate for each system in the sample was estimated. A graphical multiparametric optimization method was used to verify how model spectra reproduce the observed spectra in the UV. A grid of disk models was calculated for each system, sweeping a three-dimensional space of parameters $\left(M_{1}, \dot{M}\right.$, and $\left.i\right)$ and maintaining a fixed or free distance. The minimum $\chi_{\text {red }}^{2}$ regions within that space selected the model properties and constrained the possible values of $\dot{M}$.

Almost all models are too blue when compared with the observed spectra. The models calculated using a free scaling distance can also be accommodated toward the reddest possible continua and faint disks. Strong degeneracies among system parameters were found in the solutions for each system. The current generation of accretion model spectra cannot reproduce in detail the observed absorption-line profiles, which would be helpful for breaking those degeneracies and achieving a description of UV spectra with a unique set of parameters. In fact, the emission-line fluxes appear strongly coupled to other disk properties, due to their correlation with the orbital inclination and accretion rate. We also found that the disk atmosphere model used here, even considering that it is more sophisticated, presents some problems already noted in previous works, like the flux/color dichotomy.

These findings point toward the need to improve the disk model by incorporating a component from an extended optically thin region, which can be contributed by a wind and/or a chromosphere. In that case, it will not be possible to use the local thermodynamic equilibrium approach. Disk irradiation by the boundary layer or by the central star, and nonstandard temperature profiles, would help to improve the model behavior. An additional possibility here is to consider a truncation or evaporation of the inner disk (as also suggested by Long et al. [1994] on observational grounds and by Liu et al. [1997] on theoretical grounds). Another possibility is to modify the viscosity law (eq. [2]) with some additional physical insight, for instance by using constraints on the viscosity following from numerical simulations of the magneto-rotational instability (Balbus \& Hawley 1991).

Excluding those systems for which a hot white dwarf may influence the UV continuum, the average of $\dot{M}$ for the whole sample of disk-dominated CVs is $\sim 1.1 \times 10^{-8} M . \mathrm{yr}^{-1}$, while for nova-like systems ( 15 systems) it is $\sim 9.3 \times 10^{-9} M_{\odot} \mathrm{yr}^{-1}$, and for quiescent novae $\sim 1.3 \times 10^{-8} M_{\odot} \mathrm{yr}^{-1}$. According to our $\dot{M}$ values, all disks were found in a stable mass transfer regime. The atmosphere disk model structure has a crucial role in estimating $\dot{M}$, and limb darkening is significant in high-inclination systems. It is important to continue the search for improvements on disk spectral synthesis, aiming at a better understanding of the physics of viscosity and emission-line-production mechanisms in accretion disks.

We thank the financial support from CAPES, CNPq (process 143070/2005-3), and FAPESP (process 2005/04128-5). M. P. D. acknowledges the support from CNPq under grant 301029. We are thankful to Jorge Horvath for carefully reading this manuscript. We also thank the anonymous referee for his valuable comments.
Araujo-Betancor, S., et al. 2003, ApJ, 583, 437

Balbus, S. A., \& Hawley, J. F. 1991, ApJ, 376, 214

Baptista, R., Steiner, J. E., \& Horne, K. 1996, MNRAS, 282, 99 Barret, P. 1996, PASP, 108, 412

Berriman, G., Szkody, P., \& Capps, R. W. 1985, MNRAS, 217, 327 Bruch, A., \& Engel, A. 1994, A\&AS, 104, 79 Buckley, D. A. H., \& Tuohy, I. R. 1990, ApJ, 349, 296

Cardelli, J. A., Clayton, G. C., \& Mathis, J. S. 1989, ApJ, 345, 245

Córdova, F. A., \& Howarth, I. D. 1987, in Scientific Accomplishments of the

IUE, ed. Y. Kondo (Dordrecht: Reidel), 467

Diaz, M. P., \& Bruch, A. 1997, A\&A, 322, 807

Diaz, M. P., \& Hubeny, I. 1999, ApJ, 523, 786

Diaz, M. P., \& Ribeiro, F. 2003, AJ, 125, 3359

Diaz, M. P., Wade, R., \& Hubeny, I. 1996, ApJ, 459, 236

Dobrzycka, D., \& Howell, S. 1992, ApJ, 388, 614

Downes, R., \& Duerbeck, H. 2000, AJ, 120, 2007

Duerbeck, H. W. 1999, Inf. Bull. Variable Stars, 4731, 1

Engle, S. G., \& Sion, E. M. 2005, PASP, 117, 1230

Eracleous, M., Halpern, J., \& Patterson, J. 1991, ApJ, 382, 290

Froming, C. Long, K. S., \& Baptista, R. 2003, AJ, 126, 964

Godon, P., Seward, L., Sion, E. M., \& Szkody, P. 2006, AJ, 131, 2634

Greenstein, J. L., \& Oke, J. B. 1982, ApJ, 258, 209

Greiner, J. 1998, A\&A, 336, 626

Hamada, T., \& Salpeter, E. 1961, ApJ, 134, 683

Hameury, J. M., \& Lasota, J. P. 2002, A\&A, 394, 231

Hamilton, R. T., \& Sion, R. M. 2004, PASP, 116, 926

Hoard, D. W., \& Szkody, P. 1996, ApJ, 470, 1052
REFERENCES

Hoard, D. W., \& Szkody, P. 1997, ApJ, 481, 433

Honeycutt, R. K., Cannizzo, J. K., \& Robertson, J. W. 1994, ApJ, 425, 835

Howell, S. B., Lorne, N. A., \& Rappaport, S. 2001, ApJ, 550, 897

Hubeny, I. 1988, Comput. Phys. Commun., 52, 103

1989, in Theory of Accretion Disks, ed. F. Meyer et al. (Dordrecht: Kluwer), 445

1990a, ApJ, 351, 632

1990b, in IAU Colloq. 129, Structure and Emission Properties of

Accretion Disks, ed. E. Bertout et al. (Gif-sur-Yvette: Editions Frontières), 227

Hubeny, I., \& Lanz, T. 1992, A\&A, 262, 501

1995, ApJ, 439, 875

Hubeny, I., Lanz, T., \& Jeffery, C. S. 1994, St. Andrew Univ. Newsl. Anal. Astron. Spectra, 20, 30

Huber, M. E., Howell, S. B., Ciardi, D. R., \& Fried, R. 1998, PASP, 110, 784

Hunger, K., Heber, U., \& Koester, D. 1985, A\&A, 149, L4

King, A. 1996, Ap\&SS, 237, 169

Knigge, C. 1999, MNRAS, 309, 409

Knigge, C., Araujo-Betancor, S., Gänsicke, B. T., Long, K. S., Szkody, P., Hynes, R. I., Hoard, D. W., \& Dhillon, V. S. 2004, ApJ, 615, L129

Knigge, C., Long, S., Hoard, D. W., Szkody, P., \& Dhillon, V. S. 2000, ApJ, 539, L49

Ko, Y., Lee, Y. P., Schlegel, E. M., \& Kallman, T. R. 1996, ApJ, 457, 363

Kriz, S., \& Hubeny, I. 1986, Bull. Astron. Inst. Czechoslovakia, 37, 129

Kurucz, R. L. 1979, ApJS, 40, 1

La Dous, C. 1989, A\&A, 211, 131

Lasota, J. P. 2001, NewA Rev., 45, 449 
Linnell, A. P., Godon, P., Hubeny, I., Sion, E. M., \& Szkody, P. 2007, ApJ, 662,

1204
Liu, B. F., Meyer, F., \& Meyer-Hofmeister, E. 1997, A\&A, 328, 247
Long, K. S., Wade, R. A., Blair, W. P., Davidsen, A. F. \& Hubeny,

Long, K. S., Wade, R. A., Blair, W. P., Davidsen, A. F., \& Hubeny, I. 1994, ApJ, 426, 704

Lynden-Bell, D. 1969, Nature, 223, 690

Lynden-Bell, D., \& Pringle, J. E. 1974, MNRAS, 168, 603

McArthur, B. E., et al. 1999, ApJ, 520, L59

Meliani, M. T., de Araujo, J. C. N., \& Aguiar, O. D. 2000, A\&A, 358, 417

Mouchet, M., Bonnet-Bidaud, J. M., Buckley, D. A., \& Tuohy, I. R. 1991, A\&A, 250, 99

Moyer, E., Sion, E. M., Szkody, P., Gänsicke, B., Howell, S., \& Starrfield, S. 2003, AJ, 125, 288

Nadalin, I., \& Sion, E. M. 2001, PASP, 113, 829

Orosz, J. A., \& Wade, R. 2003, ApJ, 593, 1032

Osaki, Y., Hirose, M., \& Ichikawa, S. 1993, in Accretion Disks in Compact Stellar Systems, ed. J. C. Wheeler (Singapore: World Sci.), 272

Paczyński, B., \& Schwarzenberg-Czerny, A. 1980, Acta Astron., 30, 127

Patterson, J. 1984, ApJS, 54, 443

Patterson, J., \& Raymond, J. C. 1985, ApJ, 292, 550

Pringle, J. E. 1981, ARA\&A, 19, 137

Prinja, R. K., Long, K. S., Froning, C. S., Knigge, C., Witherick, D. K., Clark,

J. S., \& Ringwald, F. A. 2003, MNRAS, 340, 551

Rappaport, S., Verbunt, F., \& Joss, P. C. 1983, ApJ, 275, 713

Retter, A., Leibowitz, E. M., \& Naylor, T. 1999, MNRAS, 308, 140

Retter, A., \& Naylor, T. 2000, MNRAS, 319, 510

Ritter, H., \& Kolb, U. 2003, A\&A, 404, 301

Rodríguez-Gil, P., Casares, J., Dhillon, V. S., \& Martínez-Pais, I. G. 2000

A\&A, 355, 181

Rodríguez-Gil, P., \& Martínez-Pais, I. G. 2002, MNRAS, 337, 209
Rutten, R. G. M., van Paradijs, J., \& Tinbergen, J. 1992, A\&A, 260, 213

Selvelli, P., \& Friedjung, M. 2003, A\&A, 401, 297

Shakura, N. I., \& Sunyaev, R. A. 1973, A\&A, 24, 337

Shaviv, G., \& Wehrse, R. 1986, A\&A, 159, L5

Smith, D. A., Dhillon, V. S., \& Marsh, T. R. 1998, MNRAS, 296, 465

Stickland, D. J., Kelly, B., Cooke, J. A., Coulson, I., Engelbrecht, C., Kilkenny, D., \& Spencer-Jones, J. 1984, MNRAS, 206, 819

Szkody, P., Garnavich, P., Holberg, J., Silber, A., \& Pastwick, L. 1997, AJ, 113, 2276

Taylor, C. J., Thorstensen, J. R., \& Patterson, J. 1999, PASP, 111, 184 Taylor, C., et al. 1998, PASP, 110, 1148

Thoroughgood, T. D., Dhillon, V. S., Watson, C. A., Buckley, D. A., Steeghs, D., \& Stevenson, M. J. 2004, MNRAS, 353, 1135

Tylenda, R. 1977, Acta Astron., 27, 235

1981, Acta Astron., 31, 127

Vande, P., Smith, R., Hawkins, N. A., \& Martin, J. S. 2003, MNRAS, 342, 151 Verbunt, F. 1997, MNRAS, 290, L55

Verbunt, F., Bunk, W. H., Ritter, H., \& Pfeffermann, E. 1997, A\&A, 327, 602 Verbunt, F., \& Wade, R. A. 1984, A\&AS, 57, 193

Wade, R. A. 1984, MNRAS, 208, 381 1988, ApJ, 335, 394

Wade, R., \& Hubeny, I. 1998, ApJ, 509, 350

Warner, B. 1986, MNRAS, 222, 11

1987, MNRAS, 227,23

Weight, A., Evans, A., Naylor, T., Wood, J. H., \& Bode, M. F. 1994, MNRAS, 266, 761

Williams, G. A., \& Shipman, H. L. 1988, ApJ, 326, 738

Williams, R. E. 1980, ApJ, 235, 939

Williams, R. E., \& Ferguson, D. H. 1982, ApJ, 257, 672 